\title{
Micrometeorological measurements and numerical simulations of turbulence and evapotranspiration over agroforestry
}

\author{
Dissertation \\ to attain the doctoral degree (Dr. rer. nat.) \\ of the Faculty of Forest Sciences and Forest Ecology \\ Georg-August-Universität Göttingen \\ Submitted by \\ Christian Markwitz \\ born on the $11^{\text {th }}$ September 1989 in Neubrandenburg
}

Göttingen, March 2021 
1. Examiner: Prof. Dr. Alexander Knohl

2. Examiner: Prof. Dr. Eckart Priesack

3. Oral examiner: Dr. Lukas Siebicke

4. Oral examiner: Prof. Dr. Dirk Hölscher

Date of oral examination: 25.02.2021 


\section{Abstract: Micrometeorological measurements and numerical simulations of turbulence and evapotranspiration over agroforestry}

Modern arable agriculture faces major challenges. The increasing occurrence of heat waves and long-lasting droughts leads to excessive loss of soil water, to increased risk for wind and water erosion of soils, and subsequent yield losses. Agricultural practices therefore have to be rethought. Agroforestry (AF), a combination of perennial trees and grassland or annual rotating crops, have been shown to increase the soil fertility and the sequestration of carbon dioxide in standing biomass and soil, reduce nutrient leaching into the ground water, and most important, alter the microclimate. Recent studies found a reduction in evaporation and transpiration (evapotranspiration, ET) in between tree strips, whereas studies on ecosystem scale water-use over agroforestry are scarce. Concerns have been raised about increased water losses to the atmosphere via evapotranspiration over agroforestry, due to the deeper rooting depth of trees and increased leaf area. Therefore, the aims of this thesis were to understand (1) whether and how agroforestry systems affect evapotranspiration on a ecosystem scale compared to monoculture (MC) systems without trees, and (2) how the agroforestry design affect wind velocity and evapotranspiration. In order to achieve the goals, both measurements and model simulations were carried out.

Measurements of evapotranspiration and meteorological parameter were performed over five agroforestry and five monoculture systems without trees across northern Germany in 2016 and 2017. Evapotranspiration was continuously measured with a newly developed lowcost eddy covariance setup (EC-LC) and a eddy covariance energy balance setup (ECEB). For the purpose of method validation one conventional eddy covariance setup for measuring campaigns of maximum four weeks duration was installed at all sites. Measurements were accompanied by large eddy simulations of the spatially varying wind velocity field over a model agroforestry system. From simulated wind velocity and meteorological measurements at the tower we derived a spatially varying evapotranspiration.

The analyses from the first and second study of this thesis showed high agreement between evapotranspiration rates from the low-cost EC setup and the conventional EC setup. Slopes of a linear regression analysis between $\mathrm{ET}_{E C-L C}$ and $\mathrm{ET}_{E C}$, were between 0.86 and 1.3 (coefficient of determination, $\mathrm{R}^{2}$, between 0.7 and 0.94 ). In contrast, $\mathrm{ET}_{E C E B}$ was consistently higher than $\mathrm{ET}_{E C}$, due to not accounting for the non-closure of the energy balance. In conclusion, these analyses indicated that low-cost EC setups can be an alternative to conventional EC setups, when the spatial variability of fluxes of the ecosystem of interest is larger than differences between fluxes from different methods.

In the second study, we analysed annual sums of evapotranspiration from the two methods over agroforestry and monoculture agriculture during two years. The analyses showed only small differences between annual sums of evapotranspiration over agroforestry and monoculture across sites and methods. Differences in evapotranspiration indices $\left(\sum\right.$ evapotranspiration/ $\sum$ precipitation) between the two land-uses (AF vs. MC) were smaller than differences between the two methods (ECEB vs. EC-LC) and even smaller than differences between the two years of contrasting precipitation regimes (2016 with low precipitation and 2017 with high precipitation). The small differences between evapotranspiration from the two land-uses can be interpreted as either an effect of the small fraction of the area 
covered by trees, or as the compensation of lower evapotranspiration next to the tree strips and higher evapotranspiration in the centre between tree strips. In conclusion, this study showed that agroforestry has not resulted in increased water losses to the atmosphere via evapotranspiration.

In the third study of this thesis model simulations of turbulence over one model agroforestry system were analysed. The analyses indicated the strongest wind velocity reduction for (i) tree strips orientated perpendicular to the main wind direction, (ii) shorter distances between the tree strips of about $50 \mathrm{~m}$, and (iii) tree heights of around $5 \mathrm{~m}$. The wind velocity reduction for the different agroforestry configurations led to a reduction in evapotranspiration on a ecosystem scale compared to a monoculture system without trees. From model simulations we showed that the reduction in wind velocity over agroforestry led to reduced evapotranspiration compared to monoculture agriculture without trees. But, for profound analyses of simulated evapotranspiration over agroforestry other spatially varying parameter such as incident radiation, soil moisture, air temperature and humidity should be considered in the model simulations.

The main conclusion of this thesis is that the agroforestry systems from this study have not resulted in higher evapotranspiration compared to monoculture systems without trees. This indicates that agroforestry in Germany can be a land-use alternative to monoculture agriculture. However, we suggest that further research should focus on effects of agroforestry on ecosystem scale evapotranspiration on the individual site level.

\section{Key words:}

Agroforestry, evapotranspiration, turbulence, eddy covariance technique, low-cost eddy covariance technique, large eddy simulation 


\section{Zusammenfassung: Mikrometeorologische Messungen und numerische Simulationen von Turbulenz und Evapotranspiration über Agroforst}

Der moderne Ackerbau steht vor großen Herausforderungen. Das zunehmende Auftreten von Hitzewellen und lang anhaltenden Dürreperioden führt zu einem übermäßigen Verlust von Bodenwasser, zu einem erhöhten Risiko für Wind- und Wassererosion der Böden und damit zu Ertragseinbußen. Heutige landwirtschaftliche Praktiken müssen daher überdacht werden. Die Agroforstwirtschaft (AF), welche eine Kombination aus mehrjährigen Bäumen und Grasland oder einjährigen Ackerkulturen ist, erhöht nachweislich die Bodenfruchtbarkeit und die Bindung von Kohlendioxid in der Biomasse und im Boden, verringert die Nährstoffauswaschung ins Grundwasser und beeinflusst das Mikroklima. Neuere Studien zeigten eine Verringerung der Verdunstung und Transpiration (Evapotranspiration, ET) zwischen den Baumstreifen eines Agroforstsystems, während Studien zum Wasserverbrauch von Agroforstsystemen im Ökosystemmaßstab selten sind. Es wurden Bedenken über erhöhte Wasserverluste durch Evapotranspiration über Agroforstsystemen geäußert, die auf die tiefere Wurzeltiefe der Bäume und die größere Blattfläche zurückzuführen seien. Ziel dieser Arbeit war es daher, (1) zu verstehen, ob und wie Agroforstsysteme Evapotranspiration im Ökosystemmaßstab im Vergleich zu Monokultursystemen (MC) ohne Bäume beeinflussen, und (2) wie die Anordnung der Baumstreifen in einem Agroforstsystem die Windgeschwindigkeit und die Evapotranspiration beeinflusst. Zum Erreichen der Ziele wurden Messungen und Modellsimulationen durchgeführt.

Evapotranspiration sowie weitere meteorologische Parameter wurden über fünf Agroforstund fünf Monokultursystemen ohne Bäume in Norddeutschland in den Jahren 2016 und 2017 gemessen. Evapotranspiration wurde mittels einem neu entwickelten kostengünstigen Eddy Kovarianz Aufbau (EC-LC) und einem Eddy Kovarianz Energiebilanzaufbau (ECEB) kontinuierlich gemessen. Zusätzlich wurde ein herkömmlicher Eddy Kovarianz Aufbau zur Validierung der beiden alternativen Messaufbauten für eine Dauer von maximal vier Wochen installiert. Neben Messungen wurden Large Eddy Simulationen des räumlich variierenden Windgeschwindigkeitsfeldes über einem Agroforstsystem durchgeführt. Aus der simulierten Windgeschwindigkeit und den meteorologischen Messungen wurde eine räumlich variierende Evapotranspiration abgeleitet.

Die Ergebnisse der durchgeführten Analysen in der ersten sowie zweiten Studie zeigten eine hohe Übereinstimmung zwischen halbstündiger Evapotranspiration vom kostengünstigen EC Aufbau und dem herkömmlichen EC Aufbau. Die Steigung einer linearen Regressionsanalyse zwischen $\mathrm{ET}_{E C-L C}$ und $\mathrm{ET}_{E C}$ lagen zwischen 0.86 und 1.3, mit einem Bestimmtheitsmaß, $\mathrm{R}^{2}$, zwischen 0.7 und 0.94. Im Gegensatz dazu war $\mathrm{ET}_{E C E B}$ durchgehend höher als $\mathrm{ET}_{E C}$, da die Nichtschließung der Energiebilanz nicht berücksichtigt wurde. Zusammenfassend zeigte sich, dass kostengünstige EC Aufbauten eine Alternative zu konventionellen EC Aufbauten sein können, wenn die räumliche Variabilität der Flüsse des jeweiligen Ökosystems größer ist als die Unterschiede zwischen den Flüssen verschiedener Methoden.

In der zweiten Studie wurden Jahressummen der Evapotranspiration von den beiden Messaufbauten für die Agroforst- und Monokultursysteme für eine Dauer von zwei Jahren ausgewertet. Die Analysen resultierten in geringen Unterschieden zwischen den Jahressum- 
men der Evapotranspiration über den Agroforst- und Monokultursystemen. Unterschiede in den Evapotranspirationsindizes ( $\sum$ Evapotranspiration/ $\sum$ Niederschlag) zwischen den beiden Landnutzungen (AF vs. MC) waren geringer als die Unterschiede zwischen den beiden Methoden (ECEB vs. EC-LC) und geringer als die Unterschiede zwischen zwei Jahren mit unterschiedlichem Niederschlag (2016 mit geringem Niederschlag und 2017 mit hohem Niederschlag). Die geringen Unterschiede in den Jahressummen der Evapotranspiration zwischen den beiden Landnutzungen können einerseits als Effekt des geringen Anteils der von Bäumen bedeckten Fläche interpretiert werden oder als Kompensationseffekt der niedrigeren Evapotranspiration an den Baumstreifen und der höheren Evapotranspiration zwischen den Baumstreifen. Diese Analyse zeigte, dass die in dieser Studie untersuchten Agroforstsysteme nicht zu erhöhten Wasserverlusten geführt haben.

In der dritten Studie dieser Arbeit wurden Modellsimulationen des Windfeldes über einem exemplarischen Agroforstsystem hinsichtlich der stärksten Windgeschwindigkeitsreduktion ausgewertet. Die Untersuchungen ergaben die stärkste Reduktion der Windgeschwindigkeit für (i) entgegengesetzt zur Hauptwindrichtung orientierte Baumstreifen, (ii) kürzere Abstände zwischen den Baumstreifen von $50 \mathrm{~m}$ und (iii) Baumhöhen von $5 \mathrm{~m}$. Die Reduktion der Windgeschwindigkeit für die verschiedenen Agroforstanordnungen führte zu einer Reduktion der Evapotranspiration im Ökosystemmaßstab, verglichen mit einem Monokultursystem ohne Bäume. Aus den Modellsimulationen kann demzufolge geschlossen werden, dass die Windreduktion im Agroforstsystem zu einer reduzierten Evapotranspiration führt. Für eine tiefgreifende Analyse der simulierten Evapotranspiration über Agroforstsystemen sollten jedoch andere räumlich variable Parameter wie die einfallende solare Strahlung, die Bodenfeuchte, die Lufttemperatur und die Luftfeuchtigkeit in den Modellsimulationen berücksichtigt werden.

Zusammenfassend zeigte sich, dass die Agroforstsysteme aus dieser Studie zu keiner erhöhten Evapotranspiration geführt haben verglichen mit Monokultursystemen ohne Bäume. Dies deutet darauf hin, dass Agroforstsysteme in Deutschland eine Landnutzungsalternative zu Monokultursystemen sein können. Dennoch sollten in Zukunft die Auswirkungen von Agroforstsystemen auf die Evapotranspiration für die individuellen Standorte analysiert werden.

Schlagwörter: Agroforstwirtschaft, Evapotranspiration, Turbulenz, Eddy Kovarianz Technik, kostengünstige Eddy Kovarianz Technik, Large Eddy Simulationen 


\section{Declaration}

I hereby declare that I wrote this PhD thesis under the supervision of Prof. Alexander Knohl and Dr. Lukas Siebicke. Any sources of information and used literature have been acknowledged.

Göttingen, March 2021

Christian Markwitz 



\section{Contents}

1 Introduction 1

1.1 Agroforestry and effects on microclimate, turbulence and evapotranspiration 2

1.2 Measurement techniques of evapotranspiration . . . . . . . . . . . . . . 4

1.2.1 Eddy covariance (EC) . . . . . . . . . . . . . . . . 4

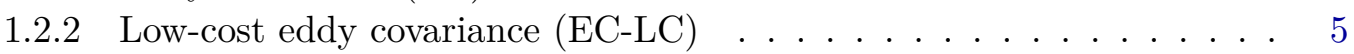

1.2.3 Eddy covariance energy balance (ECEB) $\ldots \ldots \ldots 6$

1.3 Large eddy simulation of turbulence over agroforestry . . . . . . . . . . 7

1.4 BonaRes-SIGNAL: experimental design . . . . . . . . . . . . . . 8

1.5 Objectives of this thesis . . . . . . . . . . . . . . . 12

1.6 Structure of this thesis . . . . . . . . . . . . . . . . . . 12

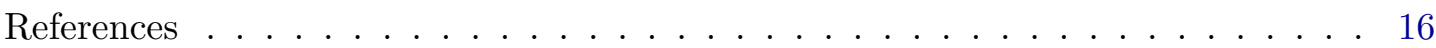

2 Low-cost eddy covariance: a case study of evapotranspiration over agroforestry in Germany 21

2.1 Introduction . . . . . . . . . . . . . . . . . . . . 22

2.2 Material and methods . . . . . . . . . . . . . . . . . 23

2.2 .1 Site description . . . . . . . . . . . . . . . . 23

2.2 .2 Instrumental set-up . . . . . . . . . . . . . . . . . 24

2.2 .3 Flux computation . . . . . . . . . . . . . . . 28

2.2.4 Spectral analysis . . . . . . . . . . . . . . . . . 31

2.3 Results and discussion . . . . . . . . . . . . . . . . . . 33

2.3.1 Meteorological conditions . . . . . . . . . . . . . . 33

2.3.2 Evapotranspiration rates from conventional and low-cost eddy covariance 34

2.3.3 Effect of spectral and WPL corrections on evapotranspiration rates

from low-cost eddy covariance . . . . . . . . . . . . . . . 34

2.3.4 Sensor cut-off frequency and time constant . . . . . . . . . . . . 38

2.3.5 Spectral analysis . . . . . . . . . . . . . . . . . 38

2.3.6 Water vapour molar densities from the thermohygrometer and the

LI-7200 gas analyser . . . . . . . . . . . . . . . . . . . 42

2.3.7 Linear regressions of latent heat fluxes from conventional and low-cost eddy covariance . . . . . . . . . . . . . . . 43

2.3.8 Dependency of the latent heat flux random uncertainty on relative humidity . . . . . . . . . . . . . . 4 46

2.3.9 Distribution of differences between evapotranspiration estimates . . . 48

2.3.10 Cumulative evapotranspiration rates . . . . . . . . . . . . . . . . . 49 
2.3.11 Annual cumulative ET rates for the agroforestry and the monocultural

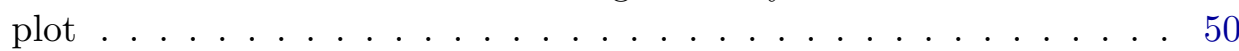

2.4 Conclusions ........................... 51

2.5 Data availability ........................ 52

2.6 Appendix ............................. 52

2.7 Author contribution ........................ 53

2.8 Competing interests . . . . . . . . . . . . . . . . . . . 53

2.9 Acknowledgements . . . . . . . . . . . . . . . . . . 53

2.10 Financial support . . . . . . . . . . . . . . . . . . 53

2.11 Review statement . . . . . . . . . . . . . . . . . . 54

References ......................... 55

3 Evapotranspiration over agroforestry sites in Germany 59

3.1 Introduction . . . . . . . . . . . . . . . . . . . . . . 60

3.2 Materials and methods ...................... . . 62

3.2.1 Site description . . . . . . . . . . . . . . . . . . . 62

3.2.2 Measurements ........................ 63

3.2.3 Gap-filling and energy balance closure adjustment . . . . . . . . . . . 67

3.2.4 Energy balance closure estimation . . . . . . . . . . . . . . 68

3.2.5 Flux footprint analysis . . . . . . . . . . . . . . . . 69

3.2.6 Canopy resistance ..................... 69

3.3 Results and discussion . . . . . . . . . . . . . . . . 70

3.3.1 Meteorological conditions during the campaigns . . . . . . . . . 70

3.3.2 Flux footprint climatology ................. . 71

3.3.3 Diel evapotranspiration .................... 72

3.3.4 Energy balance closure $(\mathrm{EBC})$. . . . . . . . . . . . . . . . . 74

3.3.5 Evapotranspiration over agroforestry . . . . . . . . . . . . . . 79

3.3.6 Uncertainty and limitations of ET measurements over AF . . . . . . . 86

3.4 Conclusions . . . . . . . . . . . . . . . . . 87

3.5 Appendix ....................... . . 88

3.5.1 Derivations ..................... . . 88

3.5.2 Tables........................ . . . 92

3.5.3 Figures ........................ 93

3.6 Data Availability . . . . . . . . . . . . . . . . 98

3.7 Author contribution . . . . . . . . . . . . . . . . 98

3.8 Competing Interests . . . . . . . . . . . . . . . . . . . . . . . . . . 98

3.9 Acknowledgements . . . . . . . . . . . . . . . . . . . . . 98

3.10 Financial support . . . . . . . . . . . . . . . . . . . . 98

3.11 Review statement . . . . . . . . . . . . . . . . . . . 98

References .......................... 99

4 Large eddy simulation of the wind field over agroforestry in Germany and wind effects on evapotranspiration 103

4.1 Introduction . . . . . . . . . . . . . . . . . . . . . 104 
4.2 Materials and methods . . . . . . . . . . . . . . . . . . . 105

4.2.1 Site description and measurements . . . . . . . . . . . . . 105

4.2.2 Estimation of evapotranspiration . . . . . . . . . . . . . . 107

4.2 .3 LES set-up . . . . . . . . . . . . . . . . . . . . . 108

4.2.4 Cases for the wind velocity simulation . . . . . . . . . . . 111

4.2 .5 Statistics . . . . . . . . . . . . . . . . . 111

4.3 Results and discussion . . . . . . . . . . . . . . . . 111

4.3.1 Wind simulations over agroforestry . . . . . . . . . . . 111

4.3.2 Wind effects on evapotranspiration . . . . . . . . . . . . 119

4.4 Conclusions and future work . . . . . . . . . . . . . . 125

4.5 Author contribution . . . . . . . . . . . . . . . . 125

4.6 Competing interests . . . . . . . . . . . . . . . . . . 125

4.7 Acknowledgements . . . . . . . . . . . . . . . . . . 125

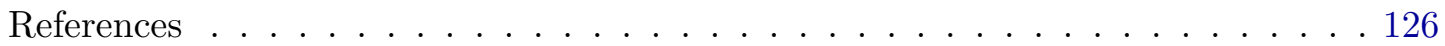

5 Synopsis $\quad \mathbf{1 2 9}$

5.1 Evapotranspiration measurements over agroforestry - method validation . . . 131

5.2 Impact of agroforestry on evapotranspiration . . . . . . . . . . . . . . . 132

5.3 Wind field simulations over agroforestry and effects on evapotranspiration . 134

5.4 The broader context of this thesis . . . . . . . . . . . . . . . 136

5.5 Future work . . . . . . . . . . . . . . . . . 137

References . . . . . . . . . . . . . . . . . . . 140

$\begin{array}{ll}\text { Acknowledgments } & 143\end{array}$ 

CHAPTER 1

Introduction 


\subsection{Agroforestry and effects on microclimate, turbulence and evapotranspiration}

Modern arable agriculture faces major challenges. Whilst future demand for both food and bioenergy crops is projected to rise the poor state and unsustainable use of many agricultural soils has become an important topic. In addition to the traditional focus on maximising biomass production recent scientific research has highlighted the role of soils in the provision of vital services such as storage and filtration of water and nutrients, as habitat for organisms or the sequestration of carbon (BLUM, 2005; VOGEL et al., 2018). To achieve long-term sustainability modern agriculture will therefore have to protect the proper functioning of soils whilst also adapting to the effects of climate change.

One land-use practice of high multifunctionality and sustainability is agroforestry (AF). Agroforestry is the cultivation of perennial woody components and either crops and/or animals on the same piece of land (NAIR, 1993). Traditional agroforestry types in Europe are silvoarable- and silvopastoral systems, orchard intercropping, forest farming, riparian buffer strips and windbreaks (NERLICH et al., 2013). Modern agroforestry systems initially follow the same concept, but their design is adapted to the requirements of modern agricultural machinery. Short rotation alley cropping is one modern agroforestry type, which describes the alternating cultivation of tree strips and strips of annual crops or perennial grasslands on the same piece of land (WoLz et al., 2017). The trees are often fast growing tree species, such as poplar, willow or robinia and are harvested every three to five years. In Figure 1.1 a typical alley cropping system together with the effects of the tree component on the various environmental factors is shown. From now on agroforestry refers to short rotation alley cropping systems.

Agroforestry aims to achieve two goals, firstly, the provision of sustainable biofuel and food, and secondly, the amelioration of the local microclimate. Here, microclimate refers to the climate within or in between tree strips, which is expected to be altered by the presence of the tree strips. Commonly, the tree strips are aligned perpendicular to the local main wind direction. This provides a wind shelter effect for adjoining crops (BöHM et al., 2014 ) and a reduction of incident radiation. The zone prone to the strongest wind velocity reduction in the lee of the tree strip is known as the quiet zone (Figure 1.1), followed by a region with increased turbulence, referred to the wake zone (DAVIS et al., 1988; JUDD et al., 1996; MCNaughton, 1988). As air passes through the tree strip, the initially parallel streamlined flow breaks down into smaller sized turbulent eddies, causing a reduction of the turbulent kinetic energy (TKE) (Figure 1.1). Thereafter, larger sized eddies penetrate the space between tree strips until the vertical profile of horizontal wind velocity recovers to the initial profile before the next tree strip downwind. The recovery of the vertical profile of horizontal wind velocity depends on tree strip properties such as the density, the width, the height and the distance between tree strips. For instance, larger distances between tree strips $(>50 \mathrm{~m})$ might lead to the recovery of the profile and subsequently higher wind velocities before the next tree strip downwind. For shorter distances $(<50$ $\mathrm{m}$ ) the vertical profile might not recover and lead to an overall wind velocity reduction relative to an open field (BöHM et al., 2014).

The variation of meteorological parameter in space and time across a agroforestry system strongly affect turbulent fluxes, in particular the vertical exchange of water vapour due 


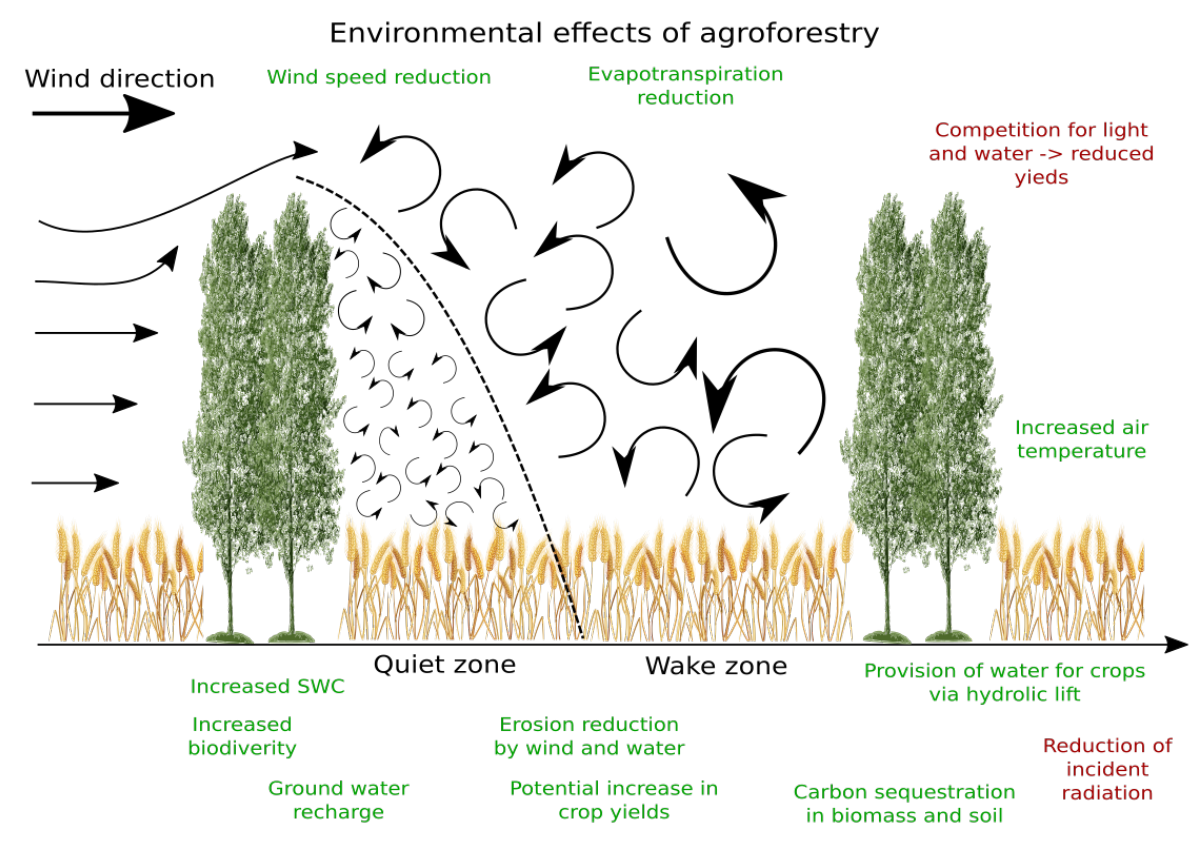

Figure 1.1: Effects of agroforestry on environmental factors. Green coloured text correspond to expected positive effects and red coloured text correspond to expected negative effects.

to the processes of evaporation from soil and intercepted water and leaf transpiration, which yields together evapotranspiration (ET) (KATUL et al., 2012). Evapotranspiration is regulated by incident radiation, air temperature, vapour pressure deficit, wind velocity and available soil water (MonTEITH, 1965). For agroforestry systems it is expected that the wind velocity reduction in the quiet zone also reduce evapotranspiration (CLEUGH, 1998). Studies on evapotranspiration over crops in agroforestry generally found lower evapotranspiration close to the tree strips and increased evapotranspiration in the centre between tree strips (Figure 1.2; (Cleugh, 1998; DAvis et al., 1988; KAnZler et al., 2018; Quinkenstein et al., 2009; VESTE et al., 2020)). The potential reduction in evapotranspiration in the quiet zone can be referred to the process of (1) the prevention of adjoining crops from dry air advection, which reduces the vapour pressure deficit, hence, lowering evapotranspiration (McNaughton, 1988), and (2) a reduction in incident radiation, leading to reduced photosynthesis and soil temperature. A reduced evapotranspiration in the quiet zone conserves soil moisture, which then is provided for adjoining crops.

However, so far it remains unclear how an expected reduction in evapotranspiration in the quiet zone and an increase in evapotranspiration in the wake zone is reflected in system scale evapotranspiration. In this thesis we report on system scale evapotranspiration measurements over agroforestry. Detailed analysis of measurements of half-hourly evapotranspiration rates over agroforestry is given in Chapter 3, whereas system scale effects of wind velocity on evapotranspiration are handled in depth in Chapter 4. 


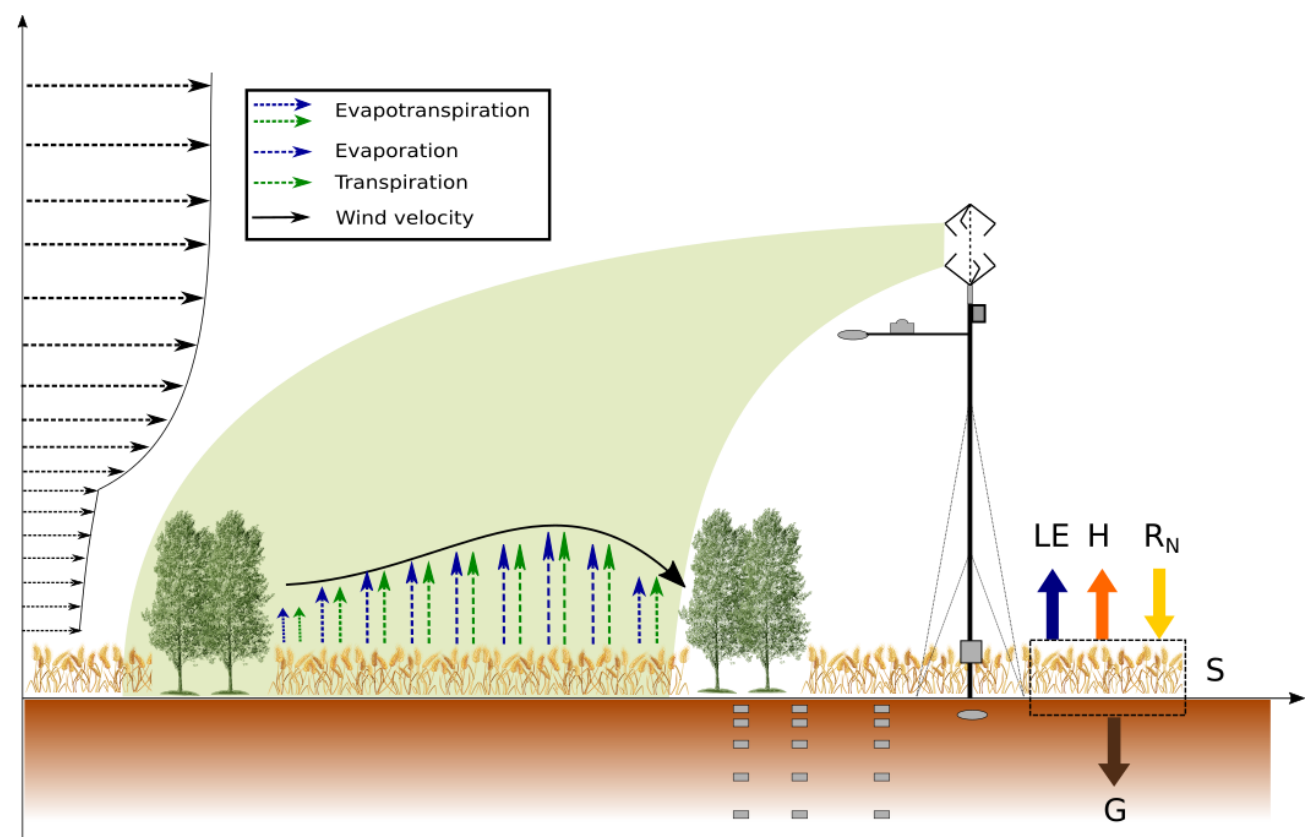

Figure 1.2: Conceptual figure of effects of agroforestry on wind velocity and evapotranspiration and the measuring setup. The green hatched area corresponds to the towers flux footprint. The components of the surface energy balance are included.

\subsection{Measurement techniques of evapotranspiration}

Replicated measurements of turbulent fluxes at one or multiple ecosystems are commonly limited by the number of available sampling units and costs of traditional methods. Hence, the single-tower approach is most common at many flux sites across the globe. The area represented of the turbulent fluxes is then only restricted to the flux footprint, which is interpreted as the source area of the measured turbulent fluxes (SCHMID, 2002). Depending on the methods assumptions and restrictions, and the heterogeneity of the landscape, the representativity of the measured fluxes can vary substantially.

We wanted to perform replicated measurements of evapotranspiration over five heterogeneous agroforestry and five homogeneous monoculture systems without trees. Therefore, we applied the eddy covariance energy balance method to each site and developed a low-cost eddy covariance setup. For validation, we performed measurement campaigns of maximum four weeks duration of direct ET measurements using EC. In the following sections we describe the principle concepts of the respective methods and discuss implications for ET measurements over heterogeneous agroforestry systems.

\subsubsection{Eddy covariance (EC)}

Eddy covariance (EC) has evolved as the most common technique for measurements of the vertical exchange of energy, momentum and trace gases between the biosphere and the atmosphere (BALDOCCHI, 2003; BALDOCCHI, 2014; FARAHANI et al., 2007). A turbulent flux is commonly expressed in units of a mass flux density, hence, the number of molecules 
or energy per unit surface area and time transported between the biosphere and the atmosphere. The mass flux density is calculated as the covariance between a scalar, C, and the vertical wind velocity component, w, applying Reynold's averaging, such as

$$
\begin{aligned}
F & =\overline{\rho_{a}} \overline{w^{\prime} C^{\prime}} \\
& =\overline{\rho_{a}} \overline{(w-\bar{w})(C-\bar{C})},
\end{aligned}
$$

with $\rho_{a}$ representing dry air density. Bars denote time averages (typically half an hour to one hour) and primes denote deviations from the mean. In equation 1.1 the vertical wind velocity and the scalar need to be measured sufficiently fast at a rate of approximately 10 to $20 \mathrm{~Hz}$. By convention, a flux towards the atmosphere is defined as a positive number, such as the number of molecules of a gas per unit volume are increased, whereas a flux towards the surface is defined as a negative number, which corresponds to a decrease of the number of molecules of a gas per unit of volume.

The underlying assumptions of the eddy covariance technique are horizontal homogeneity of the source area (PAw U et al., 2000), steady state ambient conditions (GU et al., 2012) and a zero mean vertical velocity component (Foken et al., 2012). The assumptions of the eddy covariance technique are explicitly violated, e.g., for measurements over heterogeneous surfaces or when the measured flux is affected by horizontal advection. Surface heterogeneities can develop continuous turbulent structures, which might lead to increased vertical wind components and increased turbulent fluxes. Therefore, the measurement height should be selected such that the measurement unit is outside of the roughness sub-layer (ROTACH, 1999). Whilst measurement height is critical to ensure that measured fluxes are representative of the underlying processes, the correct placement of the tower relative to the ecosystem of interest is vital to ensure that only fluxes from the ecosystem itself are detected. The right location for a tower can be estimated following the concept of the flux footprint (SCHMID, 2002), which is a function of the atmospheric stability, the measurement height and the wind direction.

\subsubsection{Low-cost eddy covariance (EC-LC)}

A sufficient number of sampling units for representative flux measurements over ecosystems is often limited by high costs of traditional EC setups, which are composed of a fast response sonic anemometer and a fast response gas analyser. The concept of eddy covariance is then applied to the vertical wind velocity component and the mole fraction of the gas of interest (Section 1.2.1). Using the fast response sonic anemometer, but replacing the gas analyser of fast response with cheap but slow response and less accurate sensors, requires the compensation of energy losses in the high-frequency range of the turbulent spectrum for frequencies faster than the instruments response time (IBROM et al., 2007; MoNCRIEFF et al., 1997). High-frequency losses for the slow response sensors can be larger the closer the measuring setup is placed to the surface, due to a shift of the turbulent signal towards high frequencies with decreasing measurement height (AUBINET et al., 2012).

For some applications low-cost systems for flux measurements can be a viable alternative to conventional EC systems. HiLl et al., 2017 presented low-cost EC measurements of $\mathrm{CO}_{2}$ and $\mathrm{H}_{2} \mathrm{O}_{v}$ fluxes over grassland using a slow response $\mathrm{CO}_{2}$ analyser and a relative humidity 
sensor in an enclosed-path setup, combined with a fast response sonic anemometer. The low response time of the instruments led to the loss of frequencies faster than the instruments response time. HiLl et al., 2017 accounted for the energy loss in the inertial sub-range by appropriate spectral corrections.

As part of this thesis a low-cost eddy covariance system suitable for evapotranspiration measurements (MARKWITZ et al., 2019) was developed and tested over agroforestry and monoculture systems without trees. The setup consisted of a traditional fast response sonic anemometer and a combined single board relative humidity, air temperature and pressure sensor typically used by industry and hobbyists. From the relative humidity, air temperature and pressure readings a water vapour mole fraction (number of water vapour molecules per number of molecules of air) was derived. The concept of eddy covariance was applied to the water vapour mole fraction and the vertical velocity component.

The spectral response characteristics, the time response, and the performance of the low-cost eddy covariance setup relative to a direct eddy covariance system for reference are presented in Chapter 2. One application of the low-cost EC system of long-term evapotranspiration measurements over agroforestry and monoculture systems is presented in Chapter 3.

\subsubsection{Eddy covariance energy balance (ECEB)}

The exchange of energy and matter between the biosphere and the atmosphere is driven by incident solar radiation. The incident radiation is the driver for and transformed into sensible and latent heat. The energy balance at the surface is then given as

$$
R_{N}-G=H+L E+S
$$

with $\mathrm{R}_{N}, \mathrm{G}, \mathrm{H}, \mathrm{LE}$ and $\mathrm{S}$ denoting net radiation, ground heat flux, sensible heat flux, latent heat flux and the integral energy storage term, respectively. The latter includes the soil heat storage, the photosynthesis flux, the crop enthalpy change, the air enthalpy change, the canopy dew water enthalpy change and the atmospheric moisture change (JACOBS et al., 2008). LE is composed of the latent heat of vaporization, L, and the evaporation flux, E. All energy components are expressed in units of energy per area and time, $\mathrm{J} \mathrm{m}^{-2} \mathrm{~s}^{-1}=$ $\mathrm{W} \mathrm{m}^{-2}$. After rearranging equation 1.2 the latent heat flux following the eddy covariance energy balance method (AMIRO, 2009) is

$$
L E_{E C E B}=R_{N}-G-H-S .
$$

In theory, the energy balance presented in equation 1.2 should be fulfilled. Hence, the sum of the turbulent fluxes $(\mathrm{H}+\mathrm{LE})$ should equal the available energy $\left(\mathrm{R}_{N}-\mathrm{G}-\mathrm{S}\right)$. Many studies (e.g. FoKen, 2006; FOKEn, 2008; FOKEn et al., 2010; WiLSON, 2002) commonly found an energy imbalance of 10 to $30 \%$. This phenomenon is known as the energy balance closure problem. Although the causes are not fully understood, a number of hypotheses have been put forward, including (i) the influence of measuring errors from the energy balance components, (ii) discounting of energy storage terms, (iii) a too low averaging time causing a loss of high energetic long-wave eddies, and (iv) measurements over heterogeneous terrain, which generate eddies on much longer time scales than the commonly applied 
averaging period of 30 minutes (FoKEn, 2008; LEUNiNG et al., 2012).

However, especially the first two hypotheses are of significant importance for measurements over heterogeneous agroforestry systems. The different footprints of the four energy balance components may lead to substantial energy losses, depending on the tower location and the number of instruments. Increasing the number of instruments might be a solution. Accounting for various storage terms in agroforestry is challenging again due to the heterogeneity of the systems and the different plant phenological stages of trees and crops during the year. For evapotranspiration obtained by ECEB AMIRO, 2009 argued that the effect of unaccounted storage terms is less critical on daily than on half-hourly time scale. Often the energy storage terms are smaller than zero in the morning and larger than zero in the afternoon with similar magnitude. This indicates a lack of energy in the morning and a surplus of energy in the afternoon. For daily sums of evapotranspiration this mismatch potentially compensates and results in a net zero effect. The fourth hypotheses is less critical for our agroforestry systems, due to the small system size. The size of the eddies correspond to the area of the landscape heterogeneity. Our agroforestry systems have a maximum size of 51 ha and the expected time scale of the eddies would be smaller than the commonly applied averaging period of 30 minutes.

In this thesis we estimated and accounted for the energy balance non-closure for both direct eddy covariance measurements, using a conventional enclosed-path gas analyser and a thermohygrometer of low cost. This served two purposes, firstly, the estimated energy balance closure is an indicator for the quality of the measurements. And secondly, to correct the measured evapotranspiration for the energy balance non-closure by partitioning the missing energy equally towards the latent and sensible heat flux. We suspect that $\mathrm{LE}_{E C E B}$ represents the reality better after correcting for the energy balance non-closure than not correcting for it. Results on the energy balance closure for the low-cost and conventional eddy covariance setups and the evapotranspiration rates corrected for the energy balance non-closure are presented in Chapter 3 of this thesis.

\subsection{Large eddy simulation of turbulence over agroforestry}

Methodologically sound eddy-covariance measurements of turbulent fluxes over structurally diverse agroforestry systems are difficult to achieve due to the heterogeneity of the system and the assumptions underlying this method. Discussions on methodological problems with regards to measurements of evapotranspiration over agroforestry can be found in section 1.2. Nevertheless, these kind of measurements are the only source available to understand biosphere-atmosphere exchange processes at this scale. Measurements over ecosystems usually assume homogeneity of the underlying surface, which is not the case for the majority of sites. The measured flux of a variable constitutes the mean value of the different sinks and sources in space and time. Locating sinks and sources after sampling is rather complicated and uncertain. In the case of agroforestry the tree-crop interactions are expected to have a significant impact on the microclimate, whereas system-scale fluxes show only small differences compared to a monoculture system with only crops. Numerical solutions could provide an ideal tool to better understand tree-crop interactions and associated large scale mechanisms.

Models need to capture a wide range of processes in an agroforestry system, e.g., light 
and wind shadowing, both tree and crop growth, water and nutrient transport processes between the soil-plant-atmosphere interface, harvest and fertilizer events, and carbon allocation (Luedeling et al., 2016). So far a number of models exist (e.g., Hi-sAFe (Dupraz et al., 2019); Yield-SAFE (SESERMAn et al., 2018); Expert-N (PrIESACK et al., 2006)) for the study of tree-crop interactions. But, the majority of models are on a 2D basis, whereas 3D models are scarce, e.g. Hi-sAFe (DupRAz et al., 2019). However, even 3-dimensional models often do not incorporate effects such as shadows or wind speed reductions. They are usually fed with in-situ single-point wind velocity measurements and assume an equal wind velocity behaviour across the whole agroforestry system. Especially for the purpose of wind speed or flow simulations around obstacles or in complex terrain, Large Eddy Simulations (LES) might provide a suitable tool. The complexity of the flow is associated with turbulent eddies of different scales, which can explicitly be simulated with LES according to the chosen grid size. Eddies of a size similar to the grid size can be resolved explicitly, whereas eddies smaller than the grid size (sub-grid scale eddies) need to be parametrized (GERMANO et al., 1991). Hence, for an accurate representation of the flow field within agroforestry systems, a fine grid resolution increases the accuracy of the simulated scalars (PATTON et al., 2011), but also increases the computation time. The air flow over agroforestry is mainly affected by tree strip properties, such as tree height, width and length, distance between tree strips, orientation and tree density. The tree strip properties determine the magnitude of the drag force acting on the mean flow (DUPRAz et al., 2019).

In this thesis the All Scale Atmospheric Model (ASAM, JÄHN et al., 2015; JÄHN et al., 2016) developed at the Leibniz Institute for Tropospheric Research (TROPOS), Leipzig, was used to simulate the turbulence over one model agroforestry system for different agroforestry setups. The aim was to quantify the general flow field properties and to identify the agroforestry design with the most efficient wind velocity reductions. To understand the effect of wind velocity on evapotranspiration, a potential evapotranspiration $\mathrm{ET}_{P}$ estimate was derived using the Penman-Monteith equation in accordance with the standard of the Food and Agriculture Organisation of the United Nations (FAO) (Allen et al., 1998). The estimate was calculated from a mix of both model simulations and measurement data, such as the spatially variable wind velocities and in-situ measurements of net radiation, ground heat flux, air temperature and relative humidity. The mix of both model simulations (spatially variable) and measurement data (point measurements) allowed us to separate the effect of wind velocity on evapotranspiration from the effect of limited incident radiation at the tree-crop interface. The simulated $\mathrm{ET}_{P}$ was compared with $\mathrm{ET}_{P}$ derived from measurements of wind velocity, air temperature and relative humidity in a horizontal transect between two tree strips at the same site (KANZLER et al., 2018). Related methods, results and discussions are presented in Chapter 4.

\subsection{BonaRes-SIGNAL: experimental design}

This research was carried out as part of the 'Sustainable intensification of agriculture through agroforestry' project (SIGNAL, http://www.signal. uni-goettingen.de/, last access: 20.02.2020), which is part of the funding initiative 'Soil as a sustainable resource for the bioeconomy' (BonaRes, https://www.bonares.de/, last access: 20.02.2020) of the 
German Federal Ministry for Education and Research (BMBF). The aim of the SIGNAL project is "to evaluate whether and under which site conditions agroforestry in Germany can be a land use alternative that is ecologically, economically and socially more sustainable than conventional agriculture" (VELDKAMP et al., 2020). Our project part was responsible for the atmospheric component in the soil-biosphere-atmosphere interface, with regards to evaporation and transpiration over agroforestry systems.

However, the effect of agroforestry on system-scale evapotranspiration is site-specific and depends on the local climate, the soil type, the soil water availability and the agroforestry design. Therefore, repeated measurements at different sites are essential for studies on the effects of agroforestry on evapotranspiration. Here, we performed replicated measurements of evapotranspiration at three cropland sites and two grassland sites in North-Eastern Germany (Figure 1.3 left). Each site consisted of a agroforestry system (alternating tree strips and crops or grasses) and a monoculture system (only crops or grasses) as reference (Figure 1.3 right for images and aerial photographs of the sites). Soil cultivation, harvesting and the crop or grass species at both agroforestry and monoculture systems was the same (Table 1.1 summarises site informations).

Table 1.1: Site information and agroforestry geometry.

\begin{tabular}{|c|c|c|c|c|c|c|}
\hline Site & $\begin{array}{l}\text { No. of } \\
\text { tree strips }\end{array}$ & $\begin{array}{c}\text { Distance between } \\
\text { tree strips }(\mathrm{m})\end{array}$ & $\begin{array}{l}\text { Orientation of } \\
\text { tree strips }\end{array}$ & $\begin{array}{l}\text { Agroforestry } \\
\text { type }\end{array}$ & $\begin{array}{c}\text { Agroforestry system } \\
\text { size (ha) }\end{array}$ & $\begin{array}{c}\text { Relative tree } \\
\text { cover }(\%)\end{array}$ \\
\hline Dornburg & 7 & $48,96,125$ & NW-SE & $\begin{array}{l}\text { Poplar- } \\
\text { cropland }\end{array}$ & 51 & 8 \\
\hline Forst & 7 & $24,48,96$ & $\mathrm{~N}-\mathrm{S}$ & $\begin{array}{l}\text { Poplar- } \\
\text { cropland }\end{array}$ & 39.1 & 12 \\
\hline Mariensee & 3 & 48 & N-S & $\begin{array}{l}\text { Willow- } \\
\text { grassland }\end{array}$ & 7 & 6 \\
\hline Reiffenhausen & 3 & 9 & NW-SE & $\begin{array}{l}\text { Willow- } \\
\text { grassland }\end{array}$ & 1.9 & 72 \\
\hline Wendhausen & 6 & $24,48,96$ & N-S & $\begin{array}{l}\text { Poplar- } \\
\text { cropland }\end{array}$ & 18 & 11.52 \\
\hline
\end{tabular}

Ten eddy covariance flux towers were deployed for continuous evapotranspiration and meteorological measurements at five different field sites. At each site one tower with a height of $10 \mathrm{~m}$ was installed at the agroforestry systems and a second, $3.5 \mathrm{~m}$ high tower, was installed at the monoculture systems. An overview of the measurement instruments deployed at these towers is given in Table 1.2. Ultrasonic anemometers, net radiometers and ground heat flux plates, were deployed to measure sensible heat fluxes, net radiation and ground heat flux for the eddy covariance energy balance method (Section 1.2.3) whilst a suite of three soil temperature profiles were deployed to determine the soil storage term. For evapotranspiration measurements by low-cost eddy covariance (Section 1.2.2) the instrumental setup was complemented with low-cost thermohygrometer (BME280, BOSCH, Germany) to measure relative humidity, air temperature and pressure. 

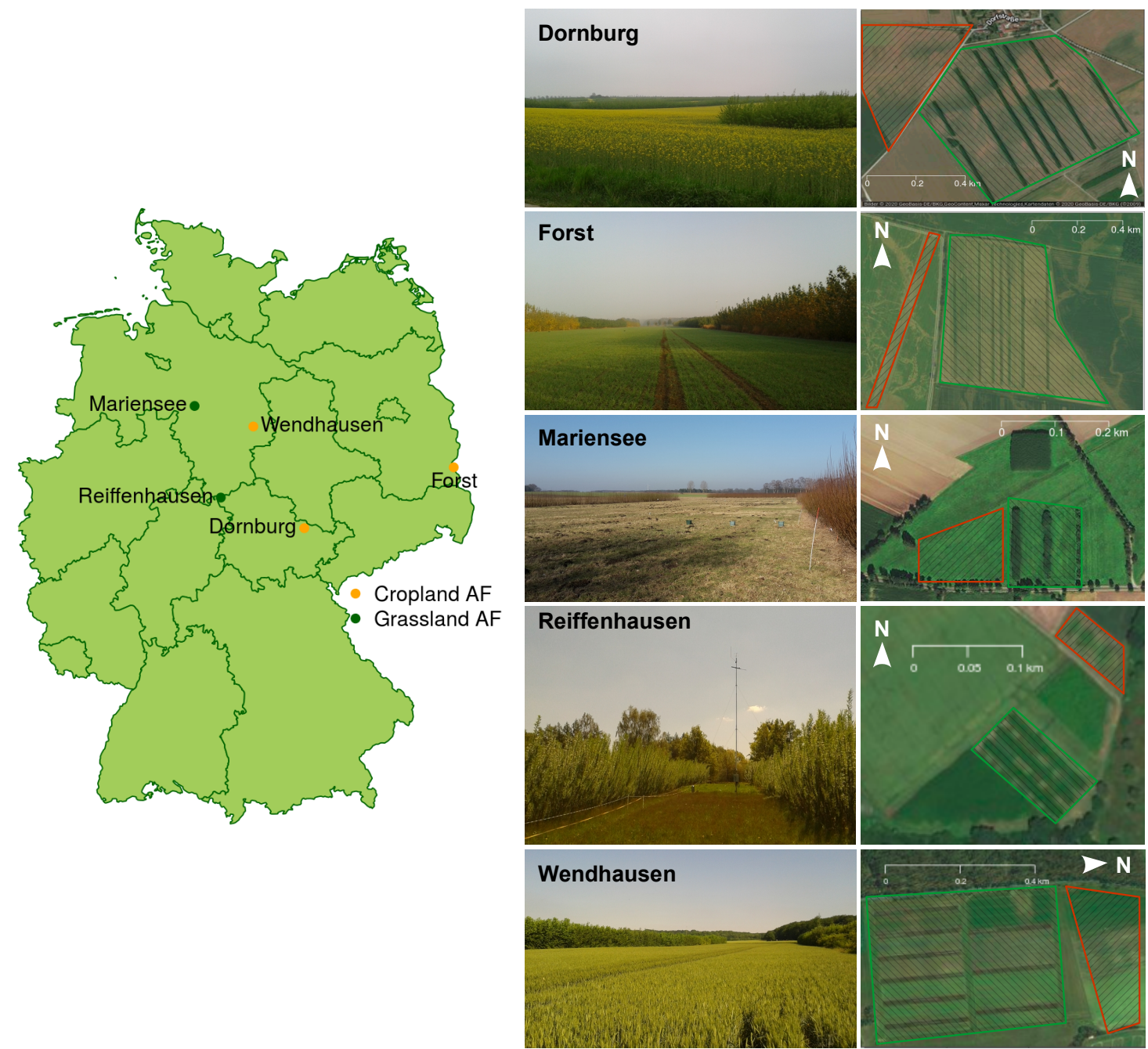

Figure 1.3: Left: map of the SIGNAL sites; right: images and aerial photographs of the agroforestry systems. Green hatched areas in the aerial photographs correspond to the agroforestry system and red hatched areas correspond to the monoculture system. 
Table 1.2: Instrumentation for flux and meteorological measurements used at all five agroforestry and monoculture systems. Set-up corresponds to eddy covariance (EC), low-cost eddy covariance (EC-LC), and eddy covariance energy balance (ECEB).

\begin{tabular}{|c|c|c|c|c|}
\hline Variable & Height $(\mathrm{m})$ & Instrument & Company & Set-up \\
\hline $\begin{array}{l}\text { The 3D wind components, } u, v, w\left(\mathrm{~ms}^{-1}\right) \text {, } \\
\text { ultrasonic temperature, } T_{\mathrm{s}}\left({ }^{\circ} \mathrm{C}\right) \text {, wind speed }\left(\mathrm{m} \mathrm{s}^{-1}\right) \text {, } \\
\text { and direction }\left({ }^{\circ}\right)\end{array}$ & $3.5,10$ & uSONIC-3 Omni & $\begin{array}{l}\text { METEK GmbH } \\
\text { Elmshorn, Germany }\end{array}$ & $\begin{array}{l}\text { EC, ECEB, } \\
\text { EC-LC }\end{array}$ \\
\hline Net radiation, $R_{\mathrm{N}}\left(\mathrm{W} \mathrm{m}^{-2}\right)$ & $3,9.5$ & NR Lite2 Net radiometer & $\begin{array}{l}\text { Kipp \& Zonen } \\
\text { Delft, the Netherlands }\end{array}$ & ECEB \\
\hline Global radiation, $R_{\mathrm{G}}\left(\mathrm{W} \mathrm{m}^{-2}\right)$ & $3,9.5$ & CMP3 pyranometer & $\begin{array}{l}\text { Kipp \& Zonen } \\
\text { Delft, the Netherlands }\end{array}$ & \\
\hline Relative humidity, $\mathrm{RH}(\%)$, air temperature, $T\left({ }^{\circ} \mathrm{C}\right)$ & 2 & $\begin{array}{l}\text { Hygro-thermo } \\
\text { transmitter compact } \\
\text { (model } 1.1005 .54 .160)\end{array}$ & $\begin{array}{l}\text { Thies Clima } \\
\text { Göttingen, Germany }\end{array}$ & EC, ECEB \\
\hline $\mathrm{RH}, T$, atmospheric pressure, $P_{\mathrm{A}}(\mathrm{Pa})$ & $0.5,3 / 9.5$ & BME280 & Bosch, Germany & EC-LC \\
\hline Precipitation, $P(\mathrm{~mm})$ & 1 & $\begin{array}{l}\text { Precipitation transmitter } \\
\text { (model 5.4032.35.007) }\end{array}$ & $\begin{array}{l}\text { Thies Clima } \\
\text { Göttingen, Germany }\end{array}$ & \\
\hline$P_{\mathrm{A}}$ & $0.5,1.5$ & $\begin{array}{l}\text { Baro transmitter } \\
\text { (model 3.1157.10.000) }\end{array}$ & $\begin{array}{l}\text { Thies Clima } \\
\text { Göttingen, Germany }\end{array}$ & $\begin{array}{l}\text { EC, ECEB, } \\
\text { EC-LC }\end{array}$ \\
\hline Ground heat flux, $G\left(\mathrm{~W} \mathrm{~m}^{-2}\right)$ & -0.05 & HFP01 & $\begin{array}{l}\text { Hukseflux } \\
\text { Delft, the Netherlands }\end{array}$ & ECEB \\
\hline Soil temperature, $T_{\text {Soil }}\left({ }^{\circ} \mathrm{C}\right)$ & $\begin{array}{r}-0.02,-0.05 \\
-0.10,-0.25,-0.5\end{array}$ & DS18B20 & & $\begin{array}{l}\text { ECEB, } \\
\text { EC-LC }\end{array}$ \\
\hline Water vapour mole fraction, $C_{H_{2} O_{\mathrm{v}}}\left(\mathrm{mmol} \mathrm{mol}^{-1}\right)$ & $3.5,10$ & LI-7200 & $\begin{array}{l}\text { LI-COR, Inc. } \\
\text { Lincoln, Nebraska (USA) }\end{array}$ & EC \\
\hline Carbon dioxide mole fraction, $C_{\mathrm{CO}_{2}}\left(\mu \mathrm{mol} \mathrm{mol}{ }^{-1}\right)$ & $3.5,10$ & LI-7200 & $\begin{array}{l}\text { LI-COR, Inc. } \\
\text { Lincoln, Nebraska (USA) }\end{array}$ & EC \\
\hline
\end{tabular}




\subsection{Objectives of this thesis}

The overall hypothesis of this thesis is that short-rotation alley cropping agroforestry systems have higher water losses to the atmosphere via evapotranspiration, compared to monoculture systems without trees.

In order to proof the main hypothesis, the objectives of this thesis were to

- evaluate the performance of the eddy covariance energy balance method and a lowcost eddy covariance setup for actual evapotranspiration measurements against direct eddy covariance measurements.

- assess actual evapotranspiration rates over agroforestry systems on ecosystem scale in Germany and compare those to monoculture systems without trees as a reference.

- assess the wind field over one model agroforestry system and investigate the impact of the wind velocity on evapotranspiration for idealised agroforestry configurations.

\subsection{Structure of this thesis}

The $\mathrm{PhD}$ thesis 'Micrometeorological measurements and numerical simulations of turbulence and evapotranspiration over agroforestry' presents evapotranspiration measurements over five agroforestry systems and five monoculture systems, and numerical simulations of turbulence for one model agroforestry site. Chapter 1 introduces the concept of agroforestry and effects of agroforestry on microclimate, turbulence and evapotranspiration (Section 1.1). The methods used, the underlying assumptions and shortcomings are presented in section 1.2. The need for model simulations of turbulence over agroforestry is highlighted in section 1.3. A brief presentation of the experimental design is given in section 1.4. This chapter is closed with the objectives of this thesis in section 1.5.

The introduction is followed by the three main chapters of this thesis, which correspond each to a scientific publication.

- Chapter 2: Low-cost eddy covariance: a case study of evapotranspiration over agroforestry in Germany,

Christian Markwitz and Lukas Siebicke,

Paper published in 'Atmospheric Measurement Techniques', (MARkwitz et al., 2019)

The aim of this study was to test the performance of a compact low-cost pressure, temperature and relative humidity sensor for the application of evapotranspiration measurements by eddy covariance over agroforestry and monoculture systems in Germany. We performed continuous low-cost eddy covariance measurements over agroforestry and monoculture systems for reference, at five sites across Northern Germany over a period of two years from 2016 to 2017. We conducted side-by-side measurements using a roving enclosed-path eddy covariance setup to assess the performance of the low-cost eddy covariance setup. In this paper we present the 
spectral response characteristics and the time response of the low-cost setup relative to direct EC for the campaigns. We give an error estimate of the random error uncertainty and evaluate the dependency of the random error uncertainty on ambient relative humidity. We close this paper with discussions on the application of the low-cost setup for long-term evapotranspiration measurements over agroforestry and monoculture systems.

- Chapter 3: Evapotranspiration over agroforestry sites in Germany, Christian Markwitz, Alexander Knohl and Lukas Siebicke, Paper published in 'Biogeosciences', (MARKwITZ et al., 2020a)

The aim of this study was to measure actual evapotranspiration of five agroforestry systems in Germany and compare those to five monoculture systems in close vicinity to the agroforestry systems with two setups (ECEB and EC-LC) during two growing seasons (2016 and 2017). In this study we briefly present the performance of both setups (ECEB and EC-LC) relative to direct EC measurements for time periods of approximately four weeks duration. Thereafter, we give an estimate of the energy balance closure for EC and EC-LC and discuss the diel course of the energy balance ratio and the residual energy. Finally, we present sums of evapotranspiration for the campaigns from all three setups, and weekly and annual sums of evapotranspiration for the two years, 2016 and 2017, respectively. Given the potential errors of each method, we further discuss the uncertainties and limitations of the methods for evapotranspiration measurements over heterogeneous agroforestry systems.

- Chapter 4: Large eddy simulation of the wind field over agroforestry in Germany and wind effects on evapotranspiration,

Christian Markwitz, Lukas Siebicke, Michael Kanzler, Alexander Knohl and Oswald Knoth,

Manuscript to be submitted to 'Atmospheric Chemistry and Physics', (Markwitz et al., 2020b)

The aim of this study was to investigate, firstly, the three-dimensional wind field over one model agroforestry system and, secondly, the wind effect on evapotranspiration. We used the All Scale Atmospheric Model (ASAM) to simulate the three-dimensional wind field over one model agroforestry system. The agroforestry system consisted of seven tree strips of $10 \mathrm{~m}$ width, $400 \mathrm{~m}$ length and tree strip distances of 24,48 and 96 $\mathrm{m}$. We ran simulations for three tree heights $(2,5,8 \mathrm{~m})$, three wind directions (north, north-west, west) and a reference case without trees. Simulated wind velocities were validated with wind velocity measurements at a $48 \mathrm{~m}$ horizontal transect between two tree strips. We studied the effect of wind velocity on evapotranspiration as per the FAO potential evapotranspiration, which we corrected by the crop coefficient. The FAO potential evapotranspiration was calculated from simulated spatially varying wind velocities and meteorological data from a flux tower at the site. In the first part of this study, we present the vertical structure of turbulence between tree strips within the model agroforestry system and the horizontal dynamics of the wind field across the agroforestry system. In the second part of this manuscript we investigate 
the effect of wind velocity on evapotranspiration and evaluate the results of annual sums of evapotranspiration over agroforestry presented in Chapter 3.

Chapter 5 presents discussions of the main conclusions of this thesis, with regards to uncertainties and limitations of evapotranspiration measurements over agroforestry (Section 5.1), the impact of agroforestry on evapotranspiration (Section 5.2), and wind field simulations over agroforestry systems and effects on evapotranspiration (Section 5.3). Thereafter, we present the wider impact of this thesis (Section 5.4) and discuss future perspectives of agroforestry with an outlook on future work (Section 5.5).

During my PhD I became co-author in the publication 'Eddy covariance measurements of the dual-isotope composition of evapotranspiration' by Jelka Braden-Behrens, Christian Markwitz and Alexander Knohl published in 'Agricultural and Forest Meteorology' (BRADEN-Behrens et al., 2019). I contributed to the data processing and interpretation of eddy covariance measurements performed by the closed-path LI-6262 (LI-COR Inc., Lincoln, Nebraska (USA)) gas analyser, contributed to manuscript writing on the description of the standard eddy covariance and meteorological measurements at the field site, and read and made editorial comments on the manuscript. 


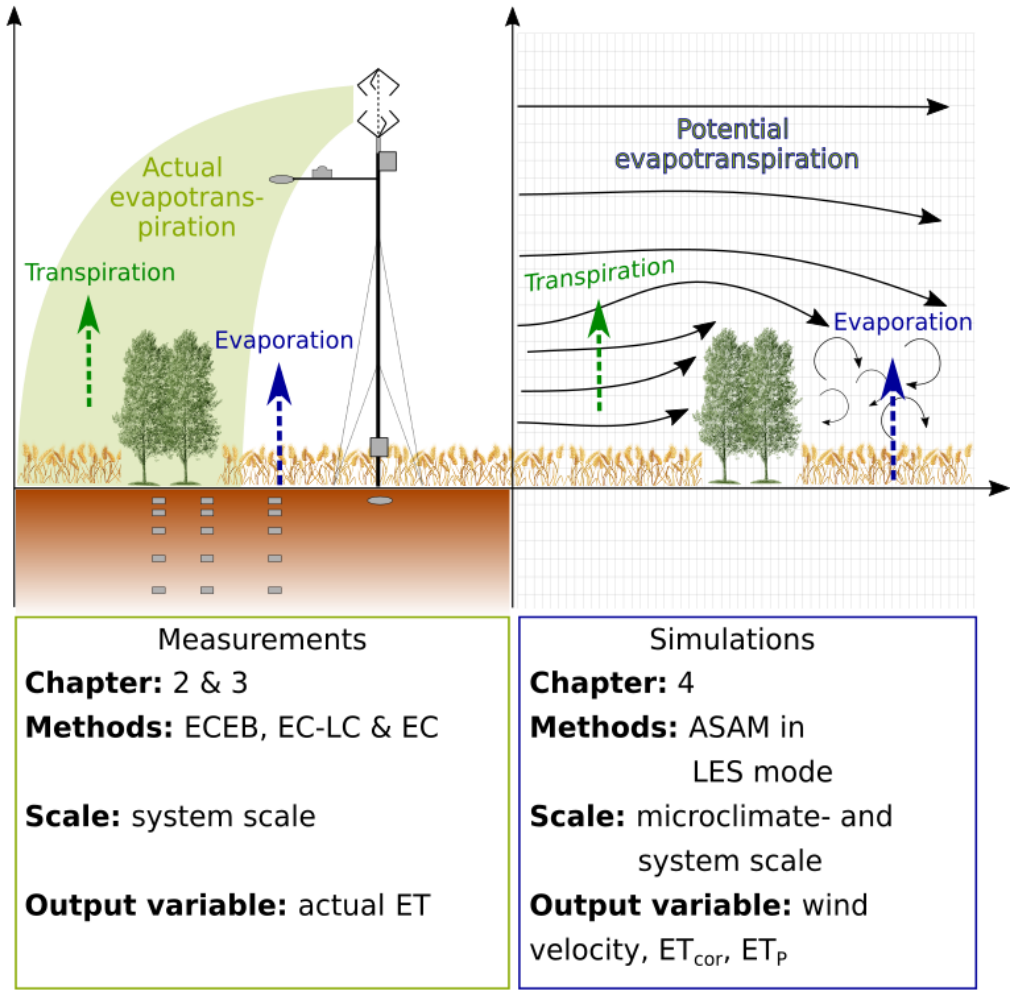

Figure 1.4: Summary of related methods; the chapter in which the methods are used; the spatial scale, the measurements are representative for; and the expected output variable, separated into measurements and simulations. 


\section{References}

Allen, R. G., L. S. Pereira, D. Raes, K. U. Leuven, and M. Smith (1998): 'Crop evapotranspiration - Guidelines for computing crop water requirements'. FAO Irrig. Drain. Pap. 56, vol. 56: pp. 1-15 (cit. on p. 8).

Amiro, B. (2009): 'Measuring boreal forest evapotranspiration using the energy balance residual'. J. Hydrol., vol. 366(1-4): pp. 112-118 (cit. on pp. 6, 7).

Aubinet, M., T. Vesala, and D. Papale, eds. (2012): Eddy Covariance: A Practical Guide to Measurement and Data Analysis. Springer Dordrecht, Heidelberg, London, New York: pp. 1-438 (cit. on p. 5).

BALDOCCHI, D. D. (2003): 'Assessing the eddy covariance technique for evaluating carbon dioxide exchange rates of ecosystems: past, present and future'. Glob. Chang. Biol., vol. 9(4): pp. 479-492 (cit. on p. 4).

BALDOCCHI, D. (2014): 'Measuring fluxes of trace gases and energy between ecosystems and the atmosphere - the state and future of the eddy covariance method'. Glob. Chang. Biol., vol. 20(12): pp. 3600-3609 (cit. on p. 4).

Blum, W. E. (2005): 'Functions of soil for society and the environment'. Rev. Environ. Sci. Biotechnol., vol. 4(3): pp. 75-79 (cit. on p. 2).

BöHm, C., M. KAnzler, and D. Freese (2014): 'Wind speed reductions as influenced by woody hedgerows grown for biomass in short rotation alley cropping systems in Germany'. Agrofor. Syst., vol. 88(4): pp. 579-591 (cit. on p. 2).

Braden-Behrens, J., C. Markwitz, and A. Knohl (2019): 'Eddy covariance measurements of the dual-isotope composition of evapotranspiration'. Agric. For. Meteorol., vol. 269-270(January): pp. 203-219 (cit. on p. 14).

Cleugh, H. A. (1998): 'Effects of windbreaks on airflow, microclimates and crop yields'. Agrofor. Syst., vol. 41(1): pp. 55-84 (cit. on p. 3).

Davis, J. E. and J. M. Norman (1988): '22. Effects of shelter on plant water use'. Agric. Ecosyst. Environ., vol. 22-23(C): pp. 393-402 (cit. on pp. 2, 3).

Dupraz, C. et al. (2019): 'Hi-sAFe : A 3D Agroforestry Model for Integrating Dynamic Tree-Crop Interactions'. Sustain., vol. 11(2293): pp. 1-25 (cit. on p. 8).

Farahani, H. J., T. A. Howell, W. J. Shuttleworth, and W. C. Bausch (2007): 'Evapotranspiration: Progress in Measurement and Modeling in Agriculture'. Am. Soc. Agric. Biol. Eng., vol. 50(5): pp. 1627-1638 (cit. on p. 4).

Foken, T. (2006): '50 Years of the Monin-Obukhov Similarity Theory'. Boundary-Layer Meteorol., vol. 119(3): pp. 431-447 (cit. on p. 6).

- (2008): 'The Energy Balance Closure Problem: an Overview'. Ecol. Appl., vol. 18(6): pp. 1351-1367 (cit. on pp. 6, 7).

Foken, T., M. Aubinet, and R. Leuning (2012): 'The Eddy Covariance Method'. Eddy Covariance A Pract. Guid. to Meas. Data Anal. Ed. by Aubinet, M., T. Vesala, and D. PAPale. Dordrecht: Springer Netherlands: pp. 1-19 (cit. on p. 5).

Foken, T., M. Mauder, C. Liebethal, F. Wimmer, F. Beyrich, J. P. Leps, S. Raasch, H. A. R. DeBruin, W. M. L. Meijninger, and J. Bange (2010): 'Energy balance closure for the LITFASS-2003 experiment'. Theor. Appl. Climatol., vol. 101(1): pp. 149-160 (cit. on p. 6). 
Germano, M., U. Piomelli, P. Moin, and W. H. Cabot (1991): 'A dynamic subgridscale eddy viscosity model'. Phys. Fluids A, vol. 3(7): pp. 1760-1765 (cit. on p. 8).

Gu, L., W. J. Massman, R. Leuning, S. G. Pallardy, T. Meyers, P. J. Hanson, J. S. Riggs, K. P. Hosman, and B. Yang (2012): 'The fundamental equation of eddy covariance and its application in flux measurements'. Agric. For. Meteorol., vol. 152(1): pp. $135-148$ (cit. on p. 5).

Hill, T., M. Chocholek, and R. Clement (2017): 'The case for increasing the statistical power of eddy covariance ecosystem studies: why, where and how?' Glob. Chang. Biol., vol. 23(6): pp. 2154-2165 (cit. on pp. 5, 6).

Ibrom, A., E. Dellwik, H. Flyvbjerg, N. O. Jensen, and K. Pilegaard (2007): 'Strong low-pass filtering effects on water vapour flux measurements with closed-path eddy correlation systems'. Agric. For. Meteorol., vol. 147(3-4): pp. 140-156 (cit. on p. 5).

Jacobs, A. F. G., B. G. Heusinkveld, and A. A. M. Holtslag (2008): 'Towards Closing the Surface Energy Budget of a Mid-latitude Grassland'. Bound.-Layer Meteor., vol. 126: pp. 125-136 (cit. on p. 6).

JÄhn, M, O KNoth, M KöNig, and U Vogelsberg (2015): 'ASAM v2.7: a compressible atmospheric model with a Cartesian cut cell approach'. Geosci. Model Dev., vol. 8: pp. 317-340 (cit. on p. 8).

Jähn, M., D. Muñoz-Esparza, F. Chouza, and O. Reitebuch (2016): 'Investigations of boundary layer structure, cloud characteristics and vertical mixing of aerosols at Barbados with large eddy simulations'. Atmos. Chem. Phys. Discuss., vol. 15(16): pp. 22637-22699 (cit. on p. 8).

Judd, M. J., M. R. Raupach, and J. J. Finnigan (1996): 'A wind tunnel study of turbulent flow around single and multiple windbreaks, part I: Velocity fields'. BoundaryLayer Meteorol., vol. 80(1-2): pp. 127-165 (cit. on p. 2).

Kanzler, M., C. Böhm, J. Mirck, D. Schmitt, and M. Veste (2018): 'Microclimate effects on evaporation and winter wheat (Triticum aestivum L.) yield within a temperate agroforestry system'. Agrofor. Syst., vol. 4 (cit. on pp. 3, 8).

Katul, G. G., R. Oren, S. Manzoni, C. Higgins, and M. B. Parlange (2012): 'Evapotranspiration: a process driving mass transport and energy exchnge in the soilplant-atmosphere-climate system'. Rev. Geophys., vol. 50(RG3002): pp. 1-25 (cit. on p. 3).

Leuning, R., E. van Gorsel, W. J. Massman, and P. R. IsaAc (2012): 'Reflections on the surface energy imbalance problem'. Agric. For. Meteorol., vol. 156: pp. 65-74 (cit. on p. 7).

Luedeling, E., P. J. Smethurst, F. Baudron, J. Bayala, N. I. Huth, M. van Noordwijk, C. K. Ong, R. Mulia, B. Lusiana, C. Muthuri, and F. L. Sinclair (2016): 'Field-scale modeling of tree-crop interactions: Challenges and development needs'. Agric. Syst., vol. 142: pp. 51-69 (cit. on p. 8).

Markwitz, C., A. Knohl, and L. SiebiCKe (2020a): 'Evapotranspiration over agroforestry sites in Germany'. Biogeosciences, vol. 17: pp. 5183-5208 (cit. on p. 13).

Markwitz, C. and L. Siebicke (2019): 'Low-cost eddy covariance: a case study of evapotranspiration over agroforestry in Germany'. Atmos. Meas. Tech., vol. 12: pp. 46774696 (cit. on pp. 6, 12). 
Markwitz, C., L. Siebicke, M. Kanzler, A. Knohl, and O. Knoth (2020b): 'Large eddy simulation of the wind field over agroforestry in Germany and wind effects on evapotranspiration'. to be Submitt. to Atmos. Chem. Phys., vol. in prep. (Cit. on p. 13).

McNaughton, K. G. (1988): '1. Effects of windbreaks on turbulent transport and microclimate'. Agric. Ecosyst. Environ., vol. 22-23(C): pp. 17-39 (cit. on pp. 2, 3).

Moncrieff, J., J. Massheder, H. de Bruin, J. Elbers, T. Friborg, B. Heusinkveld, P. Kabat, S. Scott, H. Soegaard, and A. Verhoef (1997): 'A system to measure surface fluxes of momentum, sensible heat, water vapour and carbon dioxide'. J. Hydrol., vol. 188-189: pp. 589-611 (cit. on p. 5).

Monteith, J. L. (1965): 'Evaporation and environment'. Symp. Soc. Exp. Biol., vol. 19: pp. 205-234 (cit. on p. 3).

NAIR, P. K. R. (1993): An Introduction to Agroforestry. Kluwer Acadamic Publishers Dordrecht/ Boston/ London: pp. 1-489 (cit. on p. 2).

Nerlich, K., S. Graeff-Hönninger, and W. Claupein (2013): 'Erratum to: Agroforestry in Europe: A review of the disappearance of traditional systems and development of modern agroforestry practices, with emphasis on experiences in Germany (Agroforest Syst, (2013), 87, (475-492), 10.1007/s10457-012-9560-2)'. Agrofor. Syst., vol. 87(5): p. 1211 (cit. on p. 2).

Patton, E. G. et al. (2011): 'The canopy horizontal array turbulence study'. Bull. Am. Meteorol. Soc., vol. 92(5): pp. 593-611 (cit. on p. 8).

Paw U, K, D. D. Baldocchi, T Meyers, and K Wilson (2000): 'Correction Of EddyCovariance Measurements Incorporating Both Advective Effects And Density Fluxes'. Boundary-Layer Meteorol., vol.: pp. 487-511 (cit. on p. 5).

Priesack, E., S. Gayler, and H. P. Hartmann (2006): 'The impact of crop growth sub-model choice on simulated water and nitrogen balances'. Nutr. Cycl. Agroecosystems, vol. 75(1-3): pp. 1-13 (cit. on p. 8).

Quinkenstein, A., J. Wöllecke, C. Böhm, H. Grünewald, D. Freese, B. U. SchneiDER, and R. F. HÜTTL (2009): 'Ecological benefits of the alley cropping agroforestry system in sensitive regions of Europe'. Environ. Sci. Policy, vol. 12(8): pp. 1112-1121 (cit. on p. 3).

Rotach, M. W. (1999): 'On the influence of the urban roughness sublayer on turbulence and dispersion'. Atmos. Environ., vol. 33(24-25): pp. 4001-4008 (cit. on p. 5).

Schmid, H. P. (2002): 'Footprint modeling for vegetation atmosphere exchange studies: A review and perspective'. Agric. For. Meteorol., vol. 113(1-4): pp. 159-183 (cit. on pp. 4, $5)$.

Seserman, D. M., I. Pohle, M. Veste, and D. Freese (2018): 'Simulating climate change impacts on hybrid-poplar and black locust short rotation coppices'. Forests, vol. 9(7): pp. 1-25 (cit. on p. 8).

Veldkamp, E., N. Lamersdorf, and M. Bredemeier (2020): SiGNAL homepage (cit. on p. 9).

Veste, M., T. Littmann, A. Kunneke, B. du Toit, and T. Seifert (2020): 'Windbreaks as part of climate-smart landscapes reduce evapotranspiration in vineyards, Western Cape Province, South Africa'. Plant, Soil Environ., vol. 66(No. 3): pp. 119-127 (cit. on p. 3). 
Vogel, H. J., S. Bartke, K. Daedlow, K. Helming, I. Kögel-Knabner, B. Lang, E. Rabot, D. Russell, B. Stössel, U. Weller, M. Wiesmeier, and U. Wollschläger (2018): 'A systemic approach for modeling soil functions'. Soil, vol. 4(1): pp. 83-92 (cit. on p. 2).

WiLson, K (2002): 'Energy balance closure at FLUXNET sites'. Agric. For. Meteorol., vol. 113(1-4): pp. 223-243 (cit. on p. 6).

Wolz, K. J., S. T. Lovell, B. E. Branham, W. C. Eddy, K. Keeley, R. S. Revord, M. M. Wander, W. H. Yang, and E. H. DeLucia (2017): 'Frontiers in alley cropping: Transformative solutions for temperate agriculture'. Glob. Chang. Biol., vol. 24(3): pp. 883-894 (cit. on p. 2). 



\section{CHAPTER 2}

Low-cost eddy covariance: a case study of evapotranspiration over agroforestry in Germany

Paper published in 'Atmospheric Measurement Techniques' (MARKwiTz et al., 2019) 


\section{Abstract}

Heterogeneous land surfaces require multiple measurement units for spatially adequate sampling and representative fluxes. The complexity and cost of traditional eddy covariance (EC) set-ups typically limits the feasible number of sampling units. Therefore, new low-cost eddy covariance systems provide ideal opportunities for spatially replicated sampling.

The aim of this study was to test the performance of a compact, low-cost pressure, temperature and relative humidity sensor for the application of evapotranspiration measurements by eddy covariance over agroforestry and conventional agriculture in Germany. We performed continuous low-cost eddy covariance measurements over agroforestry and conventional agriculture for reference at five sites across northern Germany over a period of 2 years from 2016 to 2017 . We conducted side-by-side measurements using a roving enclosed-path eddy covariance set-up to assess the performance of the low-cost eddy covariance set-up.

Evapotranspiration measured with low-cost eddy covariance compared well with fluxes from conventional eddy covariance. The slopes of linear regressions for evapotranspiration comparing low-cost and conventional eddy covariance set-ups ranged from 0.86 to 1.08 for 5 out of 10 sites, indicating a $14 \%$ flux underestimation and a $8 \%$ flux overestimation relative to the conventional eddy covariance set-up, respectively. Corresponding coefficients of determination, $R^{2}$, ranged from 0.71 to 0.94 across sites. The root-mean-square error for differences between latent heat fluxes obtained by both set-ups were small compared to the overall flux magnitude, with a mean and standard deviation of $34.23 \pm 3.2 \mathrm{~W} \mathrm{~m}^{-2}$, respectively, across sites.

The spectral response characteristics of the low-cost eddy covariance set-up were inferior to the eddy covariance set-up in the inertial sub-range of the turbulent spectrum. The water vapour flux co-spectrum of the low-cost eddy covariance set-up underestimated the theoretical slope of $-4 / 3$, stronger than the conventional eddy covariance set-up. This underestimation was mainly caused by the limited response time of the low-cost thermohygrometer being longer than $1 \mathrm{~s}$.

We conclude that low-cost eddy covariance sensors are an alternative to conventional eddy covariance sensors when, first, replicates are required and, second, the spatial variability of fluxes of the ecosystems of interest is larger than above-reported set-up-specific differences in fluxes.

\subsection{Introduction}

Eddy covariance (EC) is often the method of choice for measurements of the ecosystematmosphere exchange of water vapour, sensible heat, momentum and trace gases (BALDOCCHI, 2003; BALDOCCHI, 2014; FARAHANI et al., 2007) over a variety of ecosystems. In ecosystems with a spatial variability of surface cover, the representativity of the measured fluxes is limited by the flux footprint extent (SCHMID, 2002). Either the spatial variability of fluxes remains undetected (for small footprints) or can not be resolved explicitly (for large footprints). Such heterogeneous ecosystems require multiple towers for spatially representative flux sampling.

While the single-tower approach is still most common for ecosystem studies, a few studies 
have performed replicated EC measurements. DAVIS et al. (2010) studied carbon fluxes over an arable site in southeastern Ireland. HolLinger et al. (2005) used a set of two flux towers separated by a distance of $775 \mathrm{~m}$ for uncertainty estimation of EC flux measurements. Replication of sampling points was traditionally limited by high costs and the complexity of conventional EC set-ups. Therefore, there is increasing interest in the development of low-cost sensors for different applications in the biogeosciences.

DiAs et al. (2007) proposed a cost-efficient direct attenuated EC set-up to measure latent heat fluxes, combining a sonic anemometer and a hygrometer of fast response. They applied a correction factor to the time-domain covariance between the vertical velocity and relative humidity measurements. HiLl et al. (2017) presented a low-cost measuring set-up to measure both $\mathrm{CO}_{2}$ and water vapour fluxes and discussed the value of increasing the number of measuring complexes for the statistical power of EC measurements in a variety of landscapes. HILL et al. (2017) concluded that at least four flux towers per site are required to confirm with a statistical confidence of $95 \%$ that the flux over 1 year is not 0 and therefore to accept with a statistical confidence of $5 \%$ that the annual flux is 0 . This is of major importance for an ecosystem that is heterogeneous at a scale larger than the flux footprint of a single tower.

Besides the replication of measurement units within one ecosystem, the ecosystem-toecosystem replication of sampling points is of importance to, e.g. assess the potential of forests for climate change mitigation and as a $\mathrm{CO}_{2}$ sink (De StEFAno et al., 2018). The outcome of synthesis studies, e.g. on the water use of terrestrial ecosystems at global scale (TANG et al., 2014), could be strengthened by an increased number of flux-measuring units across ecosystems. Low-cost instrumentation can foster replicated EC measurements across the globe, especially in ecoregions that are currently only sparsely sampled, such as Africa, Oceania (except Australia) and South America (HILl et al., 2017 and Table 1 therein). With replicated measurements using low-cost equipment, effects of land-use changes or different agriculture management practices on turbulent fluxes can be assessed. A prominent example are flux measurements over heterogeneously shaped short-rotation alley-cropping systems (ACS) as one type of agroforestry (AF) in comparison to monocultural agriculture systems. Flux measurements over AF require replicated measurements to capture the spatial variability of the turbulent fluxes both at a single AF system and across multiple AF systems.

Our objectives are (i) to test the performance of a new EC measuring complex under field conditions for measuring half-hourly evapotranspiration over alley-cropping agroforestry systems and monocultural agriculture systems and (ii) to evaluate the low-cost measuring complex relative to conventional EC instrumentation.

\subsection{Material and methods}

\subsubsection{Site description}

The study is part of the SIGNAL (Sustainable intensification of Agriculture through agroforestry) project (http://www.signal.uni-goettingen.de/, last access: 21 August 2019), which aims to evaluate the sustainability of agroforestry in Germany. It is based on data collected at five sites in northern Germany (Fig. 2.1a). Each site consists of an 
agroforestry (AF) plot and a monocultural control (MC) plot. The agroforestry plots are alley-cropping systems, consisting of fast growing trees, such as willow (Salix), poplar (Populus) and black locust (Robinia), interleaved by either annually rotating crops or perennial grassland. The control plots consist of the same crop or grass type as planted between the tree strips and are managed as monocultural agriculture. Three sites undergo annual crop rotation (Dornburg, Forst and Wendhausen), while two systems are of a perennial grassland type (Mariensee and Reiffenhausen). The project design includes a fixed tree alley width of $10 \mathrm{~m}$, while alley length and number are variable across sites. Tree alley distances vary between 10, 24, 48 and $96 \mathrm{~m}$. The area covered by trees in relation to the whole agroforestry plot area varies between $6 \%$ and $72 \%$. Table 2.4 provides an overview of site locations, agroforestry geometry and stand characteristics.

We performed flux footprint climatology analyses with the flux footprint prediction online tool (http://footprint.kljun.net/, last access: 21 August 2019, KLJUN et al., 2015). The flux footprint climatology is valid for the respective campaign and only for daytime data according to a global radiation of $R_{\mathrm{G}}>20 \mathrm{~W} \mathrm{~m}^{-2}$. We found a $90 \%$ flux magnitude contribution of the agroforestry plot in Forst and the monoculture plot in Dornburg and a $80 \%$ flux magnitude contribution of the agroforestry plots in Dornburg and Wendhausen. The smallest agroforestry system, Reiffenhausen, contributed the least to the measured turbulent flux, with $60 \%$. Outside the agroforestry plot, fluxes were affected by nearby crop fields within about $400 \mathrm{~m}$ of the flux tower in the northerly direction and by the forest within about $200 \mathrm{~m}$ of the flux tower in the southerly direction.

\subsubsection{Instrumental set-up}

\subsubsection{Standard meteorological measurements}

Continuous measurements of micrometeorological and standard meteorological variables have been performed since March 2016. At each agroforestry plot, one eddy covariance mast with a height of $10 \mathrm{~m}$ (Fig. 2.1b) was installed, and at each monocultural plot one eddy covariance mast with a height of $3.5 \mathrm{~m}$ (Fig. 2.1c) was installed. Each mast in the agroforestry and the monocultural plots was equipped with an identical instrumental set-up. An overview of all installed instruments is given in Table 2.1. The data were logged and stored on a CR6 data logger (Campbell Scientific, Inc., Logan, UT, USA). The meteorological data were regularly sent to a database via mobile phone network.

\subsubsection{Conventional eddy covariance installation}

Fluxes of sensible heat and momentum were continuously measured with a uSONIC-3 Omni (METEK GmbH, Elmshorn, Germany) ultrasonic anemometer. $\mathrm{CO}_{2}$ and water vapour fluxes were measured in campaigns during the vegetation periods of 2016 and 2017. During the 2016 campaign, fluxes were measured separately during two consecutive periods of 4 weeks at the agroforestry and monocultural plots, whilst in 2017 both plots were sampled simultaneously over a time period of approximately 4 weeks (see Table 2.5 for exact dates). During the campaigns, the instrumentation specified in Table 2.1 was complemented by a LI-7200 (LI-COR Inc., Lincoln, NE, USA) enclosed-path infrared gas analyser (BURBA et al., 2012). The data were measured together with the three-dimensional wind velocity and the sonic temperature and stored on the same data logger (CR6, Campbell Scientific, 

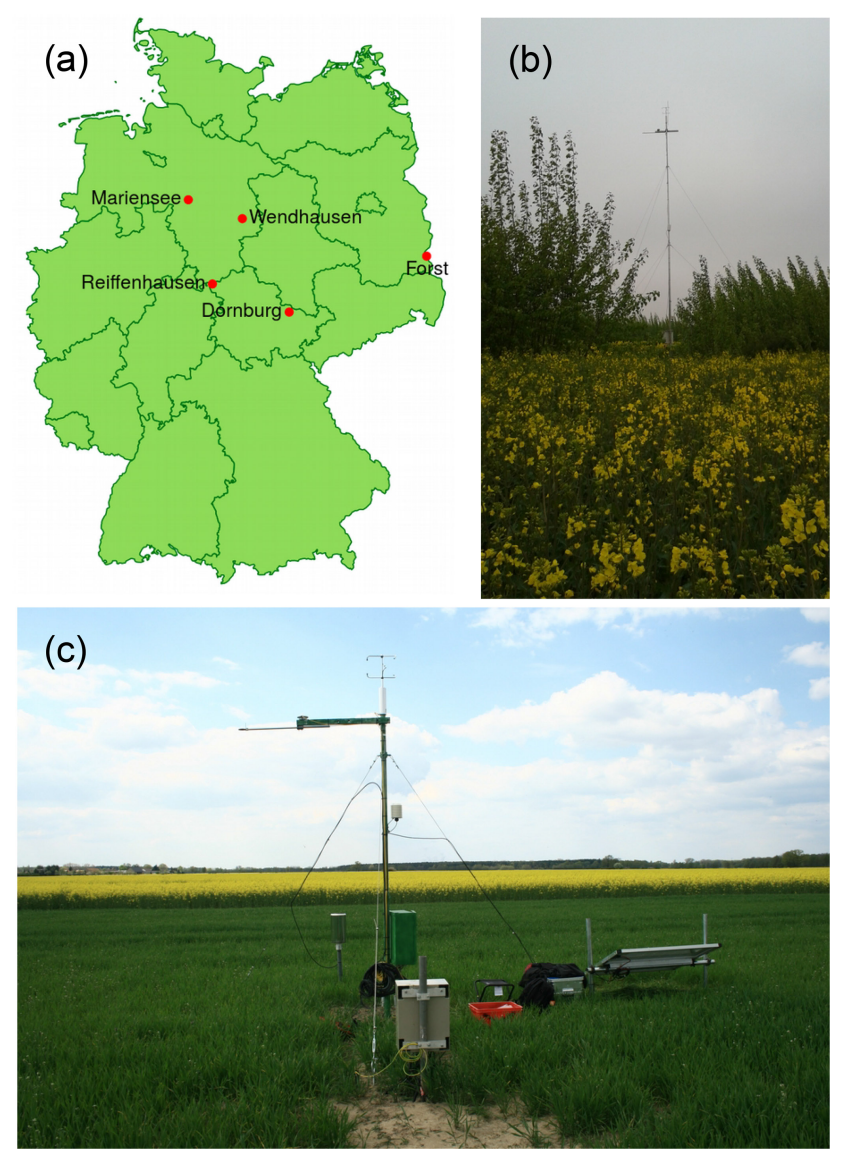

Figure 2.1: (a) SIGNAL sites (map source: BUNDESAMT FÜR KARTOGRAPHIE UND GEODÄsIE, 2011), (b) the agroforestry plot in Dornburg with eddy covariance mast and (c) the monocultural agriculture plot in Forst (Lower Lusatia) with eddy covariance mast.

Inc., Logan, UT, USA) as used for the meteorological variables. The water vapour and $\mathrm{CO}_{2}$ mole fractions were sampled with a sampling frequency of $20 \mathrm{~Hz}$. The intake tube was of $1 \mathrm{~m}$ length and had an inner tube diameter of $5.3 \mathrm{~mm}$ (2016) and $8.2 \mathrm{~mm}$ (2017). The separation of the gas analysers intake tube relative to the centre of the sonic anemometer was different for each plot and is summarized in Table 2.6. The flow rate was kept constant at $15 \mathrm{slpm}$.

\subsubsection{Low-cost eddy covariance (EC-LC) installation}

The low-cost eddy covariance set-up shared the same ultrasonic anemometer (uSONIC-3 Omni) as used for the conventional EC set-up. The water vapour mole fraction was derived from the combined digital pressure, relative humidity and air temperature sensor BME280 manufactured by Robert Bosch GmbH, Stuttgart, Germany (hereafter named thermohygrometer). Figure 2.2 depicts the low-cost set-up. The measuring principles of the air pressure sensor and the relative humidity sensor are resistive and capacitive, respectively. The temperature sensor readings are based on diode voltage measurements. 
Table 2.1: Instrumentation for flux and meteorological measurements used at all five agroforestry and five monocultural agriculture plots.

\begin{tabular}{|c|c|c|c|}
\hline Variable & Height $[\mathrm{m}]$ & Instrument & Company \\
\hline \multicolumn{4}{|l|}{ Standard meteorological measurements } \\
\hline $\begin{array}{l}3 \text {-D wind components, } u, v, w \text {, } \\
\text { sonic temperature, } T_{\mathrm{s}} \text {, } \\
\text { wind speed and -direction }\end{array}$ & $3.5,10$ & uSONIC-3 Omni & METEK GmbH, Elmshorn, Germany \\
\hline Net radiation, $R_{\mathrm{N}}$ & $3,9.5$ & NR-Lite2 net radiometer & Kipp \& Zonen, Delft, The Netherlands \\
\hline Global radiation, $R_{\mathrm{G}}$ & $3,9.5$ & CMP3 pyranometer & Kipp \& Zonen, Delft, The Netherlands \\
\hline $\begin{array}{l}\text { Relative humidity, } \mathrm{RH} \text {, } \\
\text { air temperature, } T\end{array}$ & 2 & $\begin{array}{l}\text { Hygro-thermo transmitter-compact } \\
\text { (Model } 1.1005 .54 .160 \text { ) }\end{array}$ & Thies Clima, Göttingen, Germany \\
\hline Precipitation & 1 & $\begin{array}{l}\text { Precipitation transmitter } \\
\text { (Model 5.4032.35.007) }\end{array}$ & Thies Clima, Göttingen, Germany \\
\hline Atmospheric pressure, ppp & 0.5 & $\begin{array}{l}\text { Baro transmitter } \\
\text { (Model } 3.1157 .10 .000)\end{array}$ & Thies Clima, Göttingen, Germany \\
\hline Ground heat flux, $G$ & -0.05 & Hukseflux HFP01 & Hukseflux, Delft, The Netherlands \\
\hline Soil temperature, $T_{\text {Soil }}$ & $\begin{array}{r}-0.02,-0.05 \\
-0.10,-0.25,-0.5\end{array}$ & DS18B20 & \\
\hline \multicolumn{4}{|c|}{ Conventional eddy covariance measurements } \\
\hline$u, v, w, T_{\mathrm{s}}$ & $3.5,10$ & uSONIC-3 Omni & METEK GmbH, Elmshorn, Germany \\
\hline Water vapour mole fraction, $C_{\mathrm{H}_{2} \mathrm{O}_{v}}$ & $3.5,10$ & LI-7200 & LI-COR Inc., Lincoln, NE, USA \\
\hline Carbon dioxide mole fraction, $\mathrm{C}_{\mathrm{CO}_{2}}$ & $3.5,10$ & LI-7200 & LI-COR Inc., Lincoln, NE, USA \\
\hline \multicolumn{4}{|l|}{ Low-cost eddy covariance measurements } \\
\hline$u, v, w, T_{\mathrm{s}}$ & $3.5,10$ & uSONIC-3 Omni & METEK GmbH, Elmshorn, Germany \\
\hline $\mathrm{RH}, T, \mathrm{ppp}$ & $3,9.5$ & BME280 & Robert Bosch GmbH, Stuttgart, Germany \\
\hline
\end{tabular}

The ultrasonic anemometer measured the three-dimensional wind speed and the ultrasonic temperature at a frequency of $20 \mathrm{~Hz}$, whereas the thermohygrometer measured the air temperature, relative humidity and air pressure at a sampling frequency of $8 \mathrm{~Hz}$. The specified response time of the thermohygrometer for relative humidity measurements is $1 \mathrm{~s}$, in order to overcome $63 \%$ of the step change from $90 \%$ to $0 \%$ or $0 \%$ to $90 \%$ relative humidity at a $25^{\circ} \mathrm{C}$ air temperature.

The response time of the temperature sensor of the thermohygrometer was not explicitly stated. Therefore, we estimated the response time in a lab experiment. We exposed the temperature sensor to a rapid temperature change about $10^{\circ} \mathrm{C}$ warmer than ambient air temperature. The time constant $\tau$ was then directly proportional to the slope of the linear regression fit:

$$
t=\tau \ln \left(\frac{\vartheta(t=1)-\vartheta_{\text {Ambient }}}{\vartheta\left(t=t_{\mathrm{var}}\right)-\vartheta_{\text {Ambient }}}\right),
$$

with the measurement time, $t$, the air temperature at the first time step, $\vartheta(t=1)$, the ambient air temperature, $\vartheta_{\text {Ambient }}$, and air temperature at variable time step, $\vartheta\left(t=t_{\mathrm{var}}\right)$. The time constant achieved for the temperature sensor was $23.3 \pm 0.9 \mathrm{~s}$ as a mean of four replications. During the lab experiment the thermohygrometer was placed inside the same housing as deployed in the field.

The thermohygrometer was placed $0.5 \mathrm{~m}$ below the centre of the sonic anemometer in a polyvinyl chloride (PVC) housing to protect the thermohygrometer from precipitation. The PVC housing consisted of an outer and an inner cylinder. The inner cylinder was perforated on the top to provide a continuous air flow of $15 \mathrm{~L} \mathrm{~min}^{-1}$, which was generated by a ventilator (HA30101V3-0000-A99, Sunonwealth Electric Machine Industry Co. Ltd., 
Fresnes Cedex, France). The ventilator was placed below the thermohygrometer inside the inner cylinder. The volume of the inner cylinder was $98.1 \mathrm{~cm}^{3}$.

The absolute accuracy tolerance of the relative humidity sensor was specified as $\pm 3 \%$ for $20 \%$ to $80 \%$ relative humidity at $25^{\circ} \mathrm{C}$ air temperature. For the temperature sensor an absolute accuracy tolerance of $\pm 0.5^{\circ} \mathrm{C}$ at $25^{\circ} \mathrm{C}$ air temperature was given and for a temperature range of 0 to $65^{\circ} \mathrm{C}$ an absolute accuracy tolerance of $\pm 1^{\circ} \mathrm{C}$ was specified. The pressure sensor has an absolute accuracy tolerance of $\pm 1 \mathrm{hPa}$ for a pressure range from 300 to $1100 \mathrm{hPa}$ at air temperature between 0 and $65^{\circ} \mathrm{C}$ (Bosch Sensortec GmbH, 2016).

Digital data from the thermohygrometer were recorded via the i2c protocol and stored on a Raspberry Pi model B+ (Raspberry Pi Foundation, Cambridge, UK). The thermohygrometer has very low power consumption of approximately $3.6 \mu \mathrm{A}$ at a sampling frequency of $1 \mathrm{~Hz}$. The power draw of the thermohygrometer is $9.4 \mathrm{e}-5 \mathrm{~W}$ at a measuring frequency of $8 \mathrm{~Hz}$, when powered with $3.3 \mathrm{~V}$ and if all three variables are measured at the same time. The Raspberry Pi has a maximum power consumption of about $1.1 \mathrm{~W}$.

The key potential of the low-cost EC set-up is for replicated measurements of evapotranspiration across different ecosystems. The relative cost of the low-cost set-up (featuring a sonic anemometer, a Raspberry Pi and the thermohygrometer of low cost) is often less then $10 \%$ of a typical conventional EC set-up. Besides a precipitation protection and a stable power supply, the thermohygrometer is also low maintenance. The mean time before failure of the sensor in our study was approximately 2 years. 


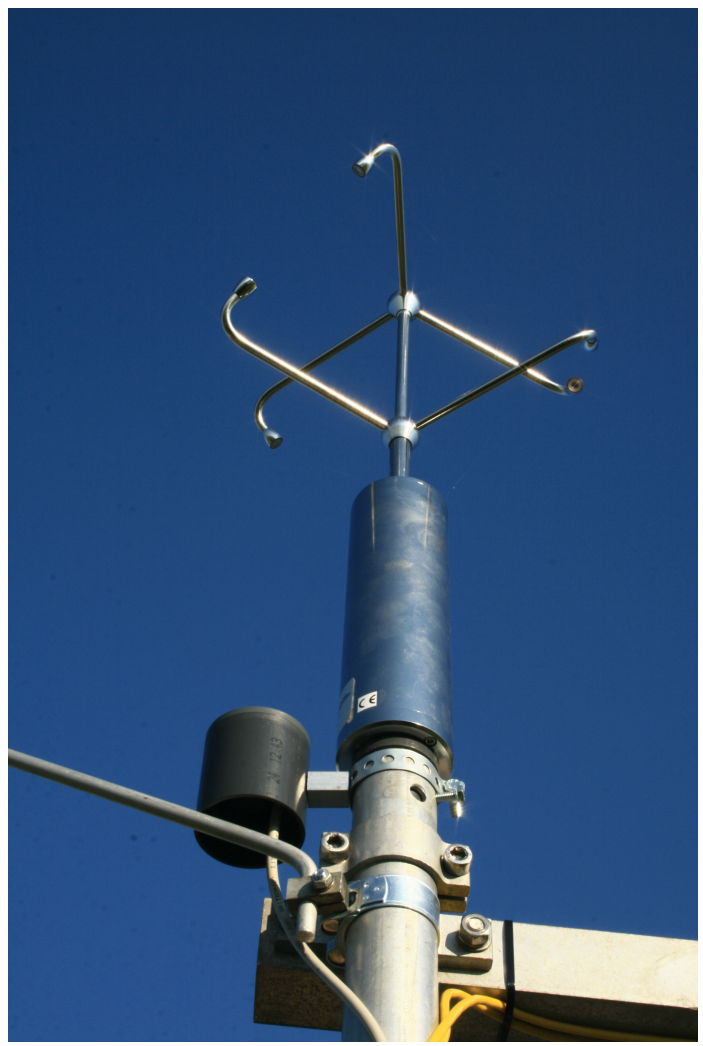

Figure 2.2: Low-cost eddy covariance instrumentation, featuring a uSONIC-3 Omni sonic anemometer and a BME280 thermohygrometer. The thermohygrometer is placed in a ventilated PVC housing below the sonic anemometer.

\subsubsection{Flux computation}

\subsubsection{Conventional eddy covariance set-up}

Latent heat fluxes and sensible heat fluxes were calculated with the open source EddyPro ${ }^{\circledR}$ eddy covariance software (LI-COR, Inc., Lincoln, NE, USA, version 6.2.0).

The fluxes were computed as follows:

$$
H=\rho_{\mathrm{a}} c_{\mathrm{p}} \overline{w^{\prime} T_{\mathrm{s}}^{\prime}}, \quad \lambda E_{\mathrm{EC}}=\lambda M_{\mathrm{H}_{2} \mathrm{O}_{v}} \overline{w^{\prime} d_{\mathrm{H}_{2} \mathrm{O}_{v}}^{\prime}},
$$

with the density of dry air, $\rho_{\mathrm{a}}$, the specific heat capacity at constant pressure, $c_{\mathrm{p}}$, the vertical velocity component, $w$, the ultrasonic temperature, $T_{\mathrm{s}}$, the latent heat of evaporation, $\lambda$, the molar mass of water vapour, $M_{\mathrm{H}_{2} \mathrm{O}_{v}}$, and the molar density of water vapour, $d_{\mathrm{H}_{2} \mathrm{O}_{v}}$. Primes denote deviations from the mean and overlines denote time averages.

Fluxes were calculated over a block averaging period of $30 \mathrm{~min}$. The horizontal wind component was rotated into the mean wind direction via double rotation (KAIMAL et al., 1994). Time lags between the ultrasonic anemometer and the intake tube of the LI-7200 gas analyser were calculated and corrected as a function of relative humidity (LI-COR, 2015). The effect of density fluctuations on the turbulent fluxes was corrected for by the Webb, 
Pearman and Leuning (WPL) correction (WEBB et al., 1980) and the ultrasonic temperature was corrected for humidity effects (Schotanus et al., 1983). Fluxes of sensible and latent heat as well as momentum were filtered by removing all flux values corresponding to a flag of 2, following the two-stage quality control procedure of MAUDER et al. (2011). Latent heat fluxes below $-50 \mathrm{~W} \mathrm{~m}^{-2}$ and above $500 \mathrm{~W} \mathrm{~m}^{-2}$ were discarded. We further discarded latent heat fluxes according to the $97.5 \%$ percentile of the $\mathrm{H}_{2} \mathrm{O}$ variance, and spikes were removed following VICKERS et al. (1997). Through a quality check $9.6 \pm 3.2 \%$ of half-hourly latent heat fluxes obtained by the EC set-up were discarded and $10.4 \pm 3.8 \%$ of half-hourly latent heat fluxes obtained by the EC-LC set-up were discarded, as a mean over all five plots. Low-frequency and high-frequency losses were corrected by the procedures of MonCRIEFF et al. (2004) and IBROM et al. (2007), respectively. Random uncertainties of fluxes were calculated following MANN et al. (1994).

\subsubsection{Low-cost eddy covariance set-up}

The latent heat flux from the low-cost eddy covariance set-ups was calculated as the covariance between the vertical velocity and the water vapour mole fraction, again with the EddyPro ${ }^{\circledR}$ eddy covariance software (LI-COR, Inc., Lincoln, NE, USA, version 6.2.0). The water vapour mole fraction, $C_{\mathrm{H}_{2} \mathrm{O}_{v}}$, was derived from relative humidity, temperature and pressure measured with the thermohygrometer from the definition of the specific humidity, $q$, as the quantity of water vapour per quantity of moist air. The latter two quantities were expressed as the density of water vapour, $\rho_{\mathrm{H}_{2} \mathrm{O}_{v}}$, and moist air, $\rho_{\mathrm{m}}$, respectively. The density of moist air is defined as the sum of the density of dry air, $\rho_{\mathrm{d}}$, and the density of water vapour.

$$
\begin{aligned}
q & =\frac{\rho_{H_{2} O_{v}}}{\rho_{\mathrm{m}}} \\
& =\frac{\rho_{H_{2} O_{v}}}{\rho_{\mathrm{d}}+\rho_{H_{2} O_{v}}}
\end{aligned}
$$

We then replaced the density of water vapour and the density of dry air in Eq. (2.2) as per Eqs. (2.3) and (2.4), respectively,

$$
\begin{array}{r}
\rho_{H_{2} O_{v}}=\frac{C_{H_{2} O_{v}} \cdot M_{H_{2} O_{v}}}{V_{\mathrm{m}}}, \\
\rho_{\mathrm{d}}=\frac{p-e}{R_{\mathrm{d}} \cdot T_{\mathrm{A}}},
\end{array}
$$

with the molar mass of water vapour, $M_{\mathrm{H}_{2} \mathrm{O}_{v}}=18.02 \mathrm{~g} \mathrm{~mol}^{-1}$, the molar volume of air

$$
V_{\mathrm{m}}=\frac{\mathfrak{R} \cdot T_{\mathrm{A}}}{p}\left(\mathrm{~m}^{3} \mathrm{~mol}^{-1}\right),
$$

the universal gas constant, $\mathfrak{R}=8.314 \mathrm{~J} \mathrm{~mol}^{-1} \mathrm{~K}^{-1}$, and the specific gas constant of dry air, $R_{\mathrm{d}}=287.058 \mathrm{~J} \mathrm{~kg}^{-1} \mathrm{~K}^{-1}$. 
Solving Eq. (2.2) for $C_{H_{2} O_{v}}$ leads to the following water vapour mole fraction:

$$
C_{\mathrm{H}_{2} \mathrm{O}_{v}}=\frac{q \Re(p-e)}{p M_{\mathrm{H}_{2} \mathrm{O}} R_{\mathrm{d}}(1-q)} .
$$

The specific humidity in Eq. (2.6) was calculated as a function of relative humidity, temperature and air pressure measurements from the thermohygrometer:

$$
q=0.622 \cdot \frac{e}{p} .
$$

The saturation vapour pressure, $E_{\text {Sat }}$, and vapour pressure, $e$, in Eq. (2.7) were calculated using Eqs. (2.10) and (2.11), respectively.

The water vapour mole fraction is expressed as the wet mole fraction, thus the mass of water vapour molecules per total mass of air. Therefore, latent heat fluxes derived from the water vapour mole fraction need to be corrected for density effects (WPL correction, WEBB et al., 1980) caused by temperature and water vapour fluctuations. The WPL correction requires true ambient air temperature measurements. Our fast measurements of the true air temperature obtained by the thermohygrometer were attenuated by the slow response time of the thermohygrometer temperature measurements. Additionally, the air temperature obtained by the thermohygrometer overestimated the ultrasonic temperature used as a reference, caused by a radiation effect from the grey PVC housing. Therefore, we derived a true air temperature for the WPL correction from the definition of the ultrasonic temperature, $T_{\mathrm{s}}$, and its dependency on air humidity:

$$
T_{\mathrm{s}}=T\left(1+0.32 \frac{e}{p}\right),
$$

with the atmospheric pressure, $p$, to calculate a moisture-corrected temperature, which we used as an estimate of true air temperature, $T$ :

$$
T=\frac{T_{\mathrm{S}}}{\left(1+0.32 \frac{e}{p}\right)} .
$$

An initial value for the vapour pressure in Eq. (2.9) was calculated from an approximation of the saturation vapour pressure, $E_{\text {Sat }}$ (based on $T_{\mathrm{S}}$ ) (STULL, 1989) and from relative humidity $(\mathrm{RH})$ :

$$
\begin{aligned}
E_{\text {Sat }} & =0.6112 \exp \frac{17.6294 \cdot\left(T_{\mathrm{S}}-273.16\right)}{T_{\mathrm{S}}-35.86 \mathrm{~K}}, \\
e & =\frac{\mathrm{RH} \cdot E_{\mathrm{Sat}}}{100} .
\end{aligned}
$$

The derivation of the vapour pressure was iterated using Eqs. (2.8), (2.9) and (2.10).

We matched the water vapour mole fraction calculated from the thermohygrometer data and the velocity components measured with the ultrasonic anemometer according to the 
nearest-neighbour date values to address the two different sampling frequencies of 8 and $20 \mathrm{~Hz}$, respectively. The two data acquisition systems (the CR6 logger and the Raspberry $\mathrm{Pi}$, respectively) were regularly manually synchronized. In detail, the Raspberry Pi was synchronized with an online NTP server, whereas the CR6 logger was synchronized during regular maintenance visits.

A time lag between the anemometer and the thermohygrometer was corrected for in a preprocessing routine. The cross-correlation function (CCF) from the R-package tseries (TRAPLETTI et al., 2017) was used to detect the time lag between the vertical velocity component and the water vapour mole fraction. The respective time lag was extracted according to the maximum cross-correlation coefficient. The estimated lag time was used to merge the velocity components, $u, v$, and $w$, and the ultrasonic temperature with the nearest-neighbour water vapour mole fraction.

We applied the same flux corrections and quality checks to fluxes obtained by the EC-LC set-up as for the conventional EC set-up (see Sect. 2.2.3.1). The only difference was the correction of high-frequency losses, where we applied the correction following MoncRIEFF et al. (1997). The correction procedure was explicitly recommended by MoNCRIEFF et al. (1997) for either open-path sensors or closed-path systems of very short and heated sampling lines.

The method is fully analytic and for each half-hour period the flux co-spectra are estimated from analytical formulations following MoNCRIEFF et al. (1997) (Eqs. 12-18 therein). Those equations are a modified version of the formulas in KAIMAL et al. (1972). The co-spectra are expressed as a function of the normalized frequency, which is a function of the natural frequency, measurement height, zero displacement height, wind speed and atmospheric stability.

We studied the impact of the different corrections on the raw turbulent evapotranspiration rates obtained by the EC-LC set-up. We applied the single corrections separately on a test dataset from the agroforestry plot in Dornburg from 14 July to 12 August 2016. We assessed the impact of the following corrections on the raw evapotranspiration rates: (1) the fully analytic high-frequency co-spectral correction following MONCRIEFF et al. (1997), (2) the low-frequency co-spectral correction following MoNCRIEFF et al. (2004) and (3) the WPL correction following WEBB et al. (1980). The corresponding results are presented in Sect. 2.3.3.

Linear regression analyses were performed between evapotranspiration obtained by the EC set-up and the EC-LC set-up. We used the major axis linear regression method from the lmodel2 function as part of the lmodel2 R-package (LEGEndRE et al., 2018). The major axis linear regression method assumes equally distributed errors in both time series.

\subsubsection{Spectral analysis}

Commonly, high-frequency trace gas measurements (e.g. the water vapour mole fraction or $\mathrm{CO}_{2}$ mole fraction) taken by closed- or enclosed-path gas analysers are attenuated in the high-frequency range of the energy spectrum (LENSCHOW et al., 1991). Attenuation is mainly caused by exchange processes (adsorption or desorption) of gas molecules with tubing walls (IBRom et al., 2007; LEuning et al., 1990). This effect is most severe for sticky gases, such as water vapour. In contrast, the temperature spectrum and co-spectrum 
are assumed to be not attenuated by the molecular exchange processes with tubing walls, as the measurements are taken with a sonic anemometer, which is open path. Attenuation of the ultrasonic temperature and the wind velocity components is mainly caused by the path-averaging effect, especially at low wind speeds and at very high wavenumbers (KRISTEnSEn et al., 1984), which is outside the inertial sub-range. Therefore, we quantified the frequency response characteristics of the EC and EC-LC set-ups by ensemble-averaged spectra and co-spectra of water vapour fluxes and compared them with temperature spectra and co-spectra.

Additionally, we followed the Kolmogorov law (Kolmogorov, 1991), which describes a theoretical energy decrease with increasing frequency in the inertial sub-range of $-5 / 3$. The same theory formulates an energy decrease of $-2 / 3$ for scalars and $-4 / 3$ for covariances in the inertial sub-range (FOKEN et al., 2004) if multiplied by the frequency. The inertial sub-range is the region of the spectrum where neither dissipation nor the generation of turbulent kinetic energy is important for the respective eddy. The eddies in the inertial sub-range receive energy from larger eddies and pass it on to smaller eddies (STULL, 1989). The corresponding results are presented in Sect. 2.3.5.

The spectral response characteristics of the LI-7200 gas analyser and the low-cost thermohygrometer were further investigated in terms of the cut-off frequency, $f_{\mathrm{c}}$, derived from true water vapour spectra. We estimated the cut-off frequency as the frequency of the intercept between the maximum water vapour spectral energy and the linear fit of the energy spectrum in the inertial sub-range (between 0.1 and $1 \mathrm{~Hz}$ ) on a double logarithmic scale (see Fig. 2.3 for clarification). From the cut-off frequency we estimated the sensors time constant, $\tau_{\mathrm{c}}$, with the following relationship:

$$
\tau_{\mathrm{c}}=1 /\left(2 \pi f_{\mathrm{c}}\right) .
$$

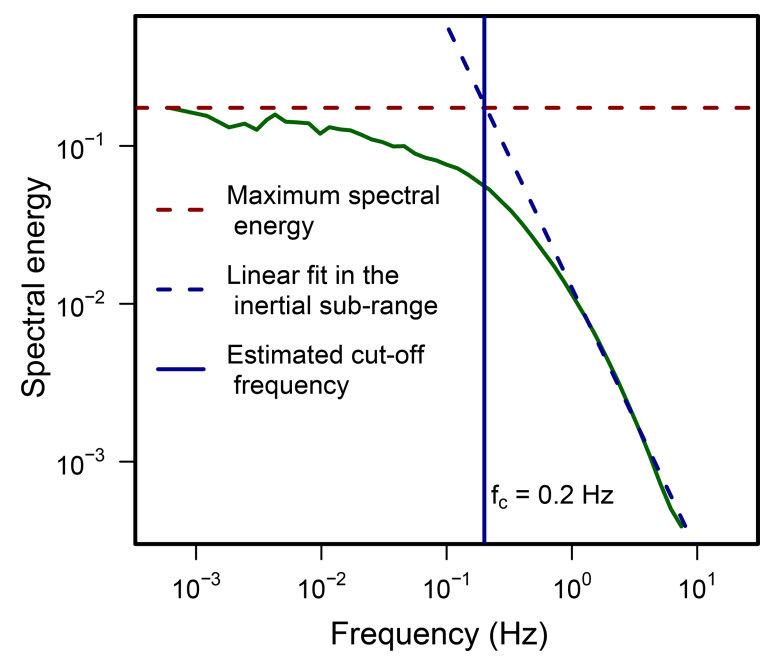

Figure 2.3: Sketch of the cut-off frequency estimation procedure with an exemplary true water vapour spectrum shown against frequency. 


\subsection{Results and discussion}

\subsubsection{Meteorological conditions}

The measuring period at the monocultural agriculture plot in Dornburg (16 June to 14 July 2016) was characterized by high air temperature with a maximum daily mean of $25^{\circ} \mathrm{C}$ and an average over the whole period of $18^{\circ} \mathrm{C}$ (Fig. 2.4a and Table 2.7). Cumulative precipitation over the period was low at only $2 \mathrm{~mm}$ (Fig. 2.4a). The low amount of rainfall caused a rapid ripening of the crops, which had a significant impact on the turbulent fluxes: evapotranspiration decreased and the sensible heat fluxes increased during the measuring period of 4 weeks.

In contrast, the measuring period (14 July to 12 August 2016) at the agroforestry plot in Dornburg (Fig. 2.4b), about $500 \mathrm{~m}$ away from the monocultural plot, was characterized by warm (mean air temperature of $19^{\circ} \mathrm{C}$ ) and humid ambient conditions with a cumulative precipitation of about $50 \mathrm{~mm}$ and a mean vapour pressure deficit (VPD) of $6.41 \mathrm{hPa}$. At the time of installation of the EC set-up, the crops were already mature, whilst the trees were at the seasonal maximum of their productivity.

The weather conditions during the measuring period at the agroforestry plot in Reiffenhausen (12 August to 14 September 2016, Fig. 2.4c) were warm, with mean daily air temperatures above $15^{\circ} \mathrm{C}$ and a total mean temperature of $19.31^{\circ} \mathrm{C}$. The period was characterized by a few intense precipitation events with a cumulative sum of $26.3 \mathrm{~mm}$ (Table 2.7) and a mean VPD of $8.02 \mathrm{hPa}$.

The following measuring campaign in Wendhausen (3 May to 2 June 2017) was characterized by low mean VPD values of $5.4 \mathrm{hPa}$ at the agroforestry plot and $5.2 \mathrm{hPa}$ at the monocultural plot. At the beginning of the campaign, mean air temperature was at its lowest between 10 and $15^{\circ} \mathrm{C}$, whilst at the end air temperature was between 15 and $20^{\circ} \mathrm{C}$. The mean air temperature was $16.6^{\circ} \mathrm{C}$ at the agroforestry plot and $15.5^{\circ} \mathrm{C}$ at the monocultural plot (Fig. 2.4d and Table 2.7). Plants were very productive in terms of transpiration both at the agroforestry (trees and crops) and the monocultural (only crops) plots.

In contrast, the campaign period in Forst (8 June to 8 July 2017) was very warm, with a mean air temperature of $21.4{ }^{\circ} \mathrm{C}$ at the agroforestry plot and $21.2^{\circ} \mathrm{C}$ at the monocultural plot. High VPD values of around $12 \mathrm{hPa}$ indicate dry ambient conditions. 


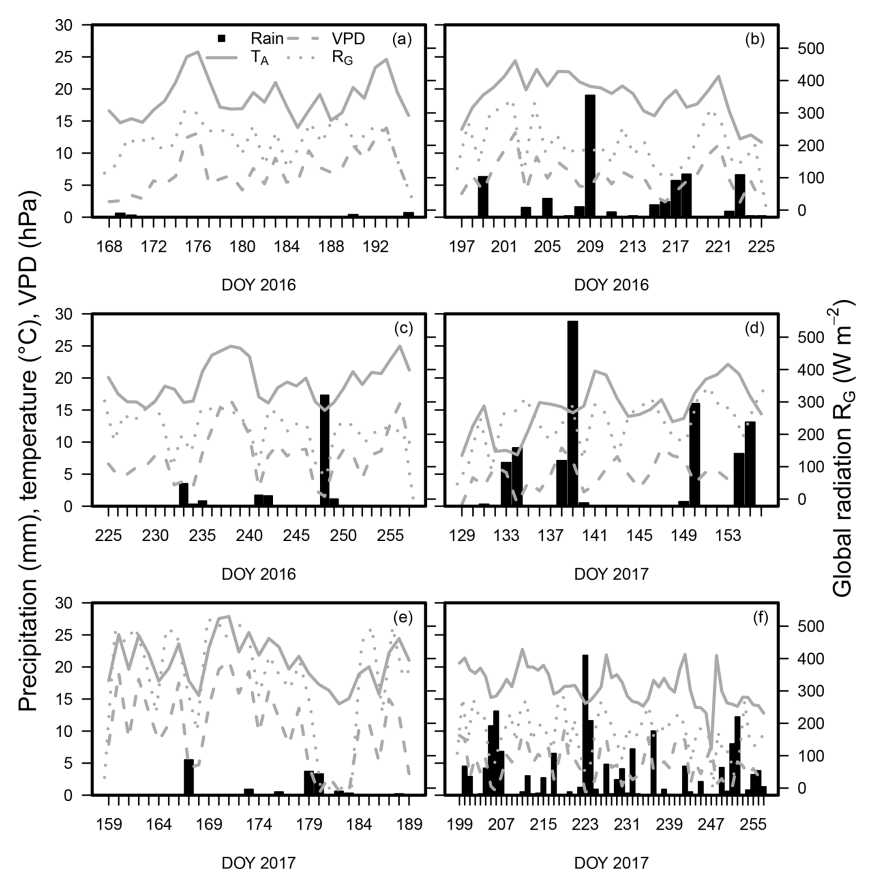

Figure 2.4: Daily averaged air temperature, vapour pressure deficit (VPD), daily summed precipitation and averaged global radiation, $R_{\mathrm{G}}$, for the following plots in each panel: Dornburg monoculture (a), Dornburg agroforestry (b), Reiffenhausen agroforestry (c), Wendhausen (d), Forst (e) and Mariensee (f). For Wendhausen, Forst and Mariensee, we took the average between the agroforestry and monocultural plot to provide a general overview of the meteorological conditions during the campaign. The averaging was done because both plots at the three sites were sampled simultaneously and the distance between both plots was $600 \mathrm{~m}$ maximum. We assumed similar weather conditions.

\subsubsection{Evapotranspiration rates from conventional and low-cost eddy covariance}

Diel cycles of evapotranspiration were well represented by the EC-LC set-up compared to the EC set-up on a 30 min timescale (Fig. 2.5) at all sites. On a longer timescale (over a period of 4 weeks) the EC-LC set-up showed changes in daily summed evapotranspiration rates from higher sums $\left(\approx 6 \mathrm{~mm} \mathrm{~d}^{-1}\right)$ at the beginning and lower sums $\left(\approx 3 \mathrm{mmd}^{-1}\right)$ at the end of the measuring period (from 16 June to 14 July 2016) at the monocultural agriculture plot in Dornburg, in the same way as the EC set-up did (Fig. 2.5f). We interpret this as a result of the ripening process of the crops. The ripening process was intensified by an exceptionally low cumulative precipitation of about $2 \mathrm{~mm}$ over the entire campaign period (Fig. 2.4a) and a resulting low soil water content (not shown).

\subsubsection{Effect of spectral and WPL corrections on evapotranspiration rates from low-cost eddy covariance}

A linear regression analysis between the uncorrected and the fully corrected evapotranspiration rates yielded a slope of $0.74\left(R^{2}=99 \%\right)$ (Fig. 2.6). The applied corrections accounted for an increase of $26 \%$ of the overall flux magnitude.

The low-frequency co-spectral correction, following MoNCRIEFF et al. (2004), accounted 

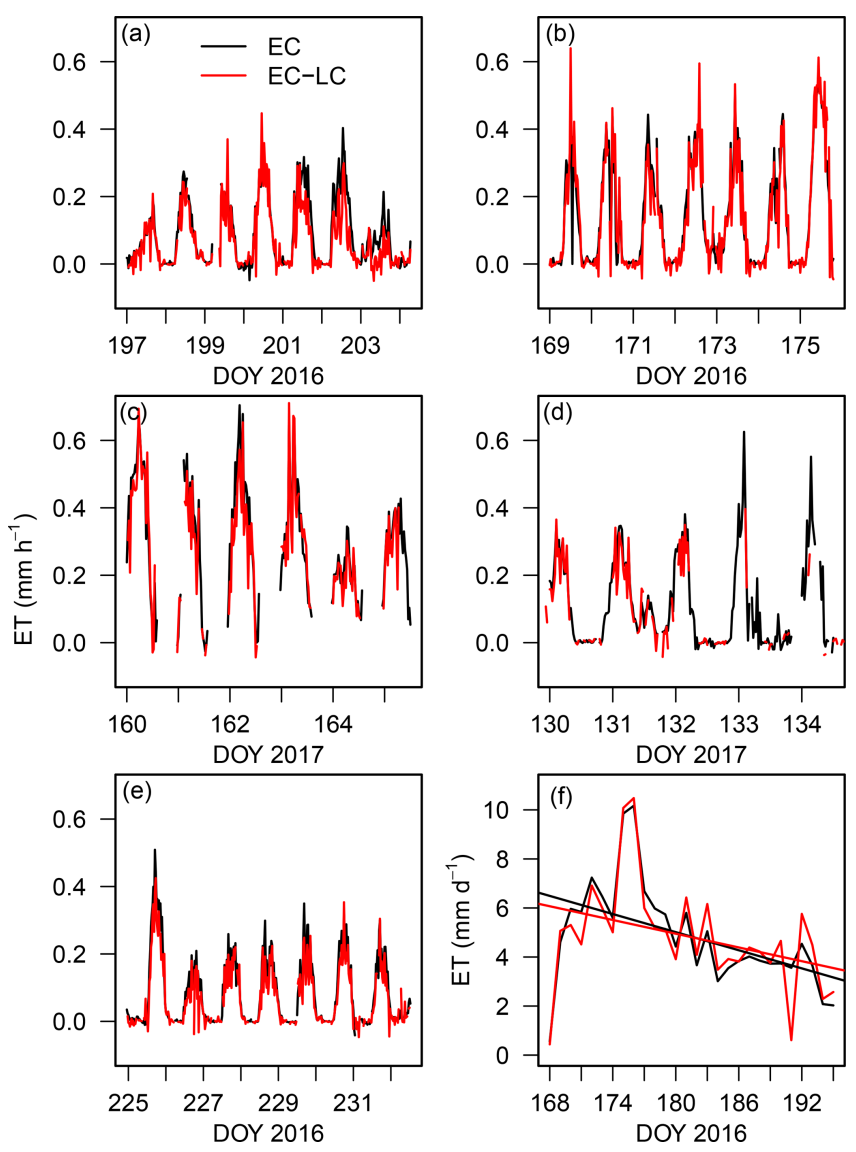

Figure 2.5: Half-hourly evapotranspiration rates of 1 exemplary week, measured with the conventional EC (black) and the EC-LC set-up (red) for Dornburg agroforestry (a), Dornburg monoculture (b), Forst agroforestry (c), Wendhausen agroforestry (d), and Reiffenhausen agroforestry (e). Panel (f) shows time series of daily summed evapotranspiration for the EC and EC-LC set-ups for Dornburg monoculture over the whole campaign period (from 16 June to 14 July 2016). We included the linear trend lines with a slope of $-0.1232 \mathrm{~mm} \mathrm{~d}^{-1}$ and a $p$ value of 0.009595 (black line) for the EC set-up and a slope of $-0.09337 \mathrm{~mm} \mathrm{~d}^{-1}$ with a $p$ value of 0.06549 (red line) for the EC-LC set-up.

for $1 \%$ of the fully corrected flux, which was the smallest contribution of all corrections to a flux magnitude increase.

The WPL correction yielded an increase in the flux magnitude of about $2 \%$. Other studies found an increase in the mean latent heat flux of $5.6 \%$ (MAUDER et al., 2006) when the WPL correction was applied. In the study of MAUDER et al. (2006), the WPL-corrected latent heat flux measured with a LI-7500 open-path EC system was compared with an uncorrected flux from the same EC complex.

The high-frequency correction, following MoncriefF et al. (1997), accounted for $23 \%$ of the fully corrected flux, which was the largest contribution of all corrections to a flux magnitude increase. We interpret the high contribution of the correction from MoNCRIEFF et al. (1997) as a result of the low response time of the thermohygrometer. In IBRom et al. 


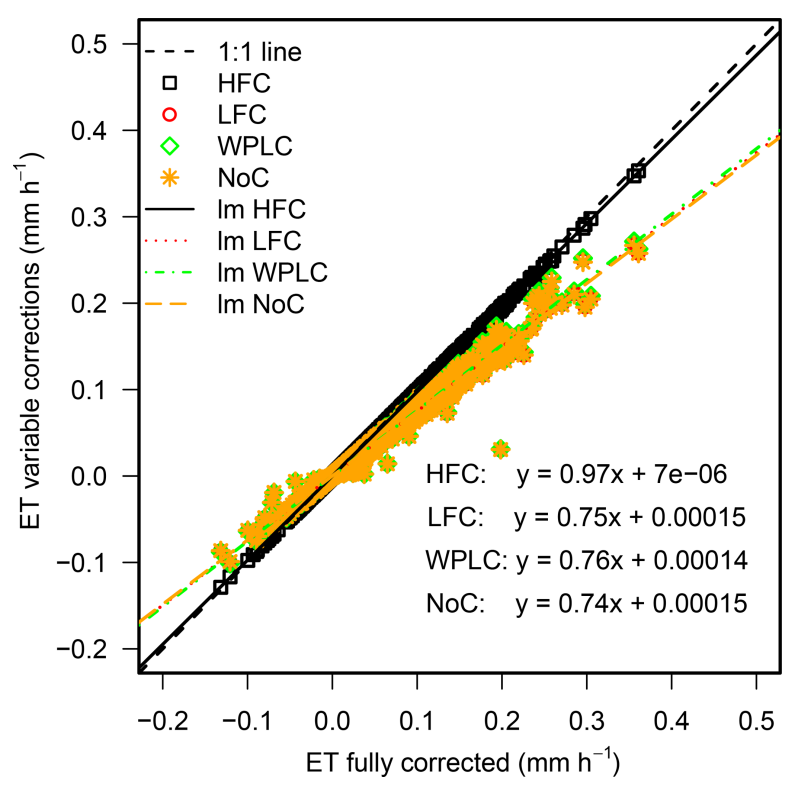

Figure 2.6: Evapotranspiration rates with the following corrections applied separately: (1) the high-frequency co-spectral correction following MONCRIEFF et al. (1997) (HFC, black squares), (2) the low-frequency co-spectral correction following MONCRIEFF et al. (2004) (LFC, red circles), (3) WPL correction following WEBB et al. (1980) (WPLC, green diamonds) and (4) no correction (NoC, yellow stars) vs. the fully corrected evapotranspiration rates of the EC-LC dataset from Dornburg agroforestry. The best fit line with the same colours as the corresponding data points and the linear regression results for the respective corrections are also shown. The linear regression is based on 1381 data points gathered during the campaign from the 14 July to 12 August 2016.

(2007) the low-pass filtering properties of the closed-path system led to an underestimation of the measured latent heat flux and resulted in a necessary correction of $42 \%$.

The overall impact of spectral corrections on a change of the turbulent latent heat fluxes was stronger for the EC-LC set-up compared to the EC set-up. Here, we quantify the overall impact of spectral corrections on latent heat fluxes in terms of the spectral correction factor (SCF) calculated for each 30 min period. The 30 min SCF was multiplied with the respective uncorrected flux. A SCF larger than 1 indicates a flux magnitude increase, whereas a SCF lower than 1 indicates a flux magnitude decrease. Box and whisker plots of $30 \mathrm{~min}$ SCFs for each site and each set-up are shown in Fig. 2.7a. We found a mean SCF of $1.96 \pm 0.64$ for the EC-LC set-up and $1.14 \pm 0.05$ for the EC set-up across all sites, indicating a mean flux magnitude increase of $96 \%$ for the EC-LC set-up and a mean flux magnitude increase of $14 \%$ for the EC set-up. The mean SCF presented here integrates both night and daytime periods. Thus, a high SCF during night-time with commonly low latent heat fluxes leads to a smaller change of the flux magnitude than during daytime, when fluxes are commonly high. Therefore, we also present the sum of 30 min evapotranspiration (ET) rates corrected for spectral losses and the sum of the total ET attributed to the spectral corrections in Fig. 2.7b. The part of the total corrected ET attributed to the spectral corrections was higher for the EC-LC set-up compared to the 
EC set-up and amounted on average to $42.7 \pm 14.1 \%$ of total ET for the EC-LC set-up and $9.3 \pm 3.3 \%$ of total ET for the EC set-up.

Across sites, we found the highest median spectral correction factor of 3.01 and the highest part of the total corrected ET attributed to the spectral corrections of $60.9 \%$ for the EC-LC set-up at the monocultural agriculture plot in Dornburg. We interpret this as a measurement height dependency of the spectral corrections. The measurement height at the agroforestry plots was $10 \mathrm{~m}$ and at the monocultural agriculture plots the measurement height was $3.5 \mathrm{~m}$. We assume that high-frequency eddies are more likely close to the surface. Therefore, a detected turbulent signal at the lower measurement height would be shifted towards high frequencies compared to the detected turbulent signal at the higher measurement height (AUBINET et al., 2012). If a sensor is not capable of detecting the turbulent signal in the high-frequency range of the spectrum, the signal is attenuated and needs to be corrected.

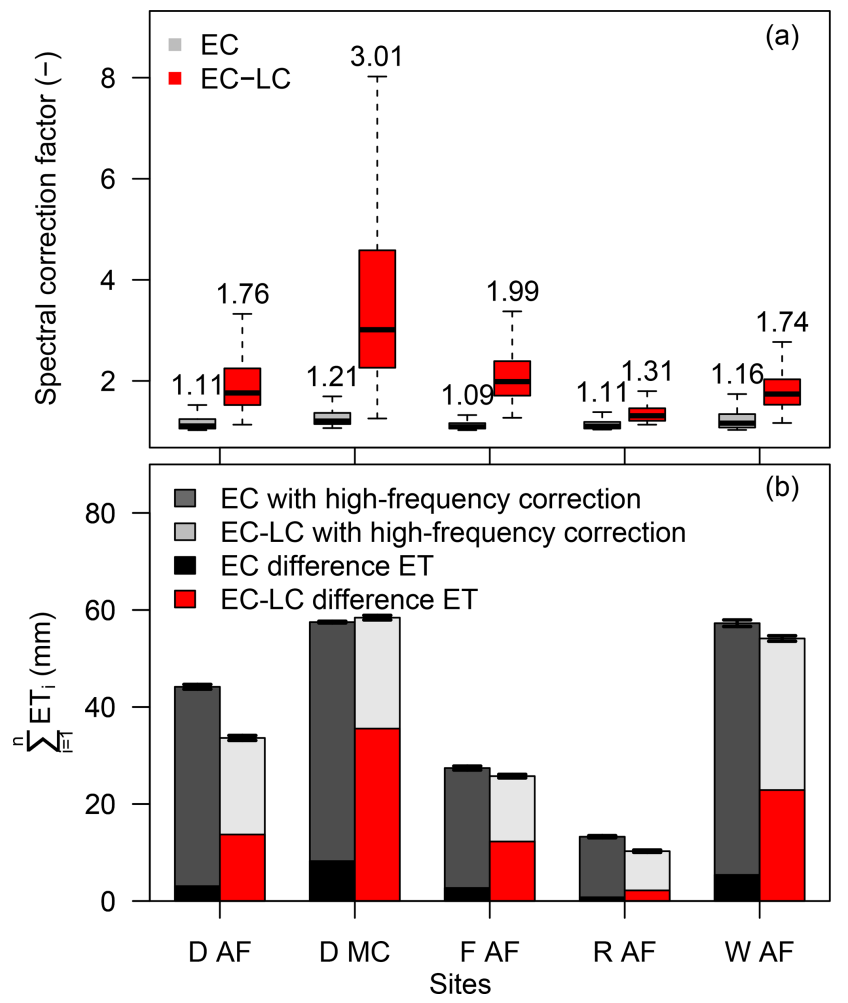

Figure 2.7: (a) Box and whisker plot of spectral correction factors for the EC (grey) and the EC-LC (red) set-up for all sites. Values above the bars correspond to the median spectral correction factor and (b) cumulative evapotranspiration rates for the EC and EC-LC set-ups for all sites: Dornburg agroforestry (D AF), Dornburg monoculture (D MC), Forst agroforestry (F AF), Wendhausen agroforestry (W AF) and Reiffenhausen agroforestry (R AF) over the respective campaign periods (Table 2.5). The error bars in (b) correspond to the summed random uncertainties. The black and red bars correspond to that part of the total ET attributed to the high-frequency correction for the EC and EC-LC set-up, respectively. Incomplete records with either EC or EC-LC missing were omitted. 


\subsubsection{Sensor cut-off frequency and time constant}

The nominal time response of the relative humidity sensor as part of the thermohygrometer yields a theoretical sensor cut-off frequency of $0.16 \mathrm{~Hz}(6.3 \mathrm{~s})$ calculated from Eq. (2.12).

Under field conditions we observed a mean cut-off frequency of $0.063 \pm 0.02 \mathrm{~Hz}$ for the low-cost thermohygrometer and $0.3 \pm 0.2 \mathrm{~Hz}$ for the LI-7200 gas analyser across five plots and all humidity classes (from $30 \%$ to $90 \%$ relative humidity bins). The respective mean time constant was $2.8 \pm 1 \mathrm{~s}$ for the low-cost thermohygrometer and $0.6 \pm 0.3 \mathrm{~s}$ for the LI-7200 gas analyser (see Fig. 2.8). For both sensors we found an exponential increase in the time constant with relative humidity (see Fig. 2.8).

Under field conditions, the cut-off frequency and the respective time constant of the thermohygrometer were inferior to the one given in the specifications. We interpret this as caused by the design of the enclosure. The thermohygrometer is placed at the end of a cylinder with the ventilator directly below, so that the flow velocity is decelerated. Subsequently, the decelerated flow velocity leads to a limited signal response. One suggestion for improvement of the frequency response would be to place the thermohygrometer inside a longer tube with a freely moving air stream. This ensures a faster air exchange inside the measurement cell of the thermohygrometer and hence a faster response time.

\subsubsection{Spectral analysis}

\subsubsection{Ensemble-averaged spectra of the water vapour mole fraction and sonic temperature and their dependency on relative humidity}

The match of the water vapour mole fraction spectra with the theoretical $-2 / 3$ slope was found to be dependent on relative humidity. We observed the least deviation of the water vapour spectra obtained by the EC and EC-LC set-ups from the theoretical $-2 / 3$ slope for low relative humidity (Fig. 2.9). The relative humidity dependency of the water vapour spectra is a known feature for closed- and enclosed-path gas analysers. FRATINI et al. (2012) reported the same behaviour for both short $(4 \mathrm{~m})$ and very short $(1 \mathrm{~m})$ sampling lines. The so-called "amplitude attenuation effect" (FrATinI et al., 2012) was explained by IBROM et al. (2007) as a result of absorption and desorption of water vapour molecules by hygroscopic particles inside the tube. Absorption and desorption processes are more pronounced at higher relative humidity and follow an exponential dependency on increasing relative humidity (Fratini et al., 2012; IBrom et al., 2007).

The spectral response characteristics of the EC set-up were superior to the ones from the EC-LC set-up. The water vapour spectra from the EC-LC set-up deviated more from the theoretical $-2 / 3$ slope than the EC set-up in the inertial sub-range (between 0.1 and $1 \mathrm{~Hz}$ ) (Fig. 2.9). The ultrasonic temperature spectra followed a slope of $-2 / 3$ in the particular range of the energy spectrum, as the measurements are open path.

For frequencies higher than $1 \mathrm{~Hz}$, an increase in the spectral energy of water vapour for two out of five plots and both set-ups (i.e. Forst and Wendhausen agroforestry, Fig. 2.9c and d) was observed, whereas the water vapour spectral energy increase for the agroforestry and monocultural plots in Dornburg and Reiffenhausen agroforestry was only found for the EC-LC set-up. We interpret the spectral energy increase in water vapour in the particular frequency range as sensor noise, as indicated by the $f^{1}$ slope for white noise (EuGSTER 


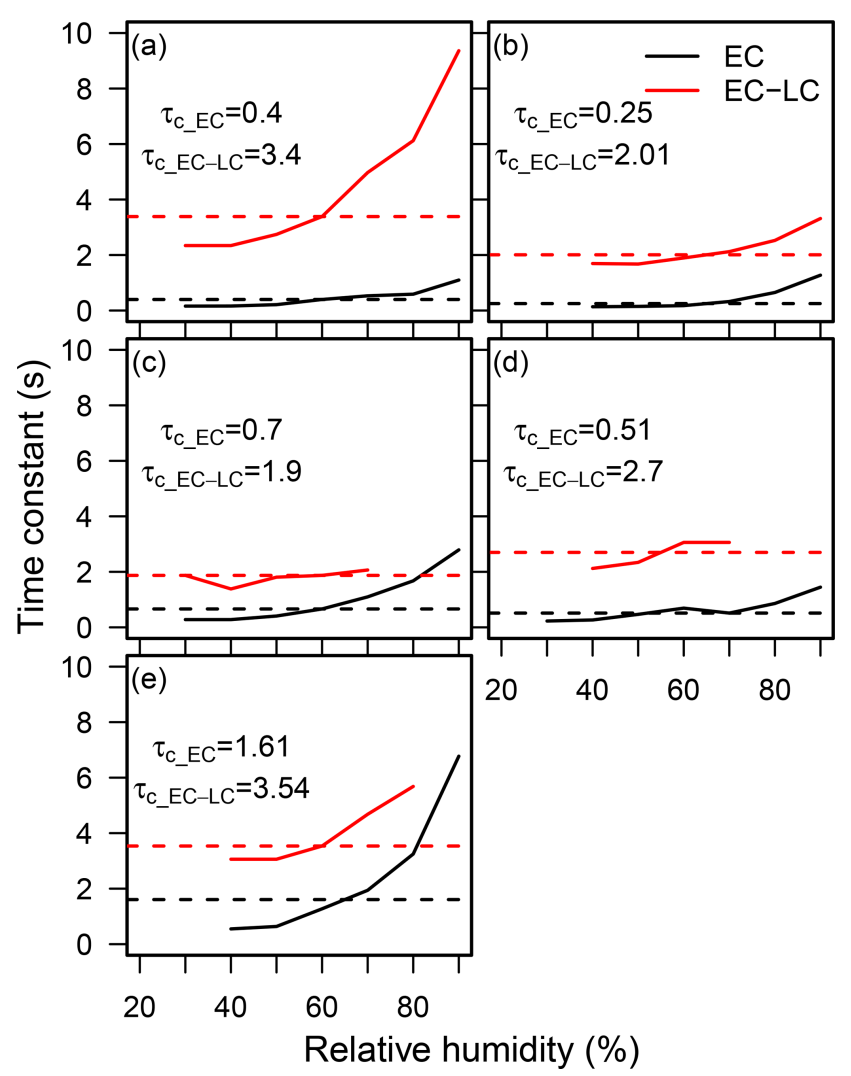

Figure 2.8: Time constant against relative humidity for the LI-7200 (black solid lines) and the thermohygrometer (red solid lines). The dashed lines have the same colour coding as the data shown, and the values written correspond to the mean time constant for the respective sensors across all relative humidity classes. Sites correspond to Dornburg agroforestry (a), Dornburg monoculture (b), Forst agroforestry (c), Reiffenhausen agroforestry (d) and Wendhausen agroforestry (e).

et al., 2010) in Fig. 2.9. The ultrasonic temperature spectra showed a slight spectral energy increase from frequencies higher than 4 to $5 \mathrm{~Hz}$, which we interpret as an attenuation effect caused by the path-averaging (KRISTENSEN et al., 1984).

The observed noise of the water vapour spectra obtained by the EC set-up at the agroforestry plots of Forst and Wendhausen (Fig. 2.9c and d) might be caused by the different tube diameters used in 2016 and 2017. In 2017 a thicker tube, with an inner diameter of $8.2 \mathrm{~mm}$, was used compared to 2016 (inner tube diameter of $5.3 \mathrm{~mm}$ ). In both years, a flow rate of $15 \mathrm{slpm}$ was applied. The change in the inner tube diameter led to more turbulent conditions within the thinner tube than within the thicker tube. The thinner tube had a Reynolds number of 3950.6 (towards turbulent flow) and the thicker tube had a Reynolds number of 2551.71 (towards laminar flow). 


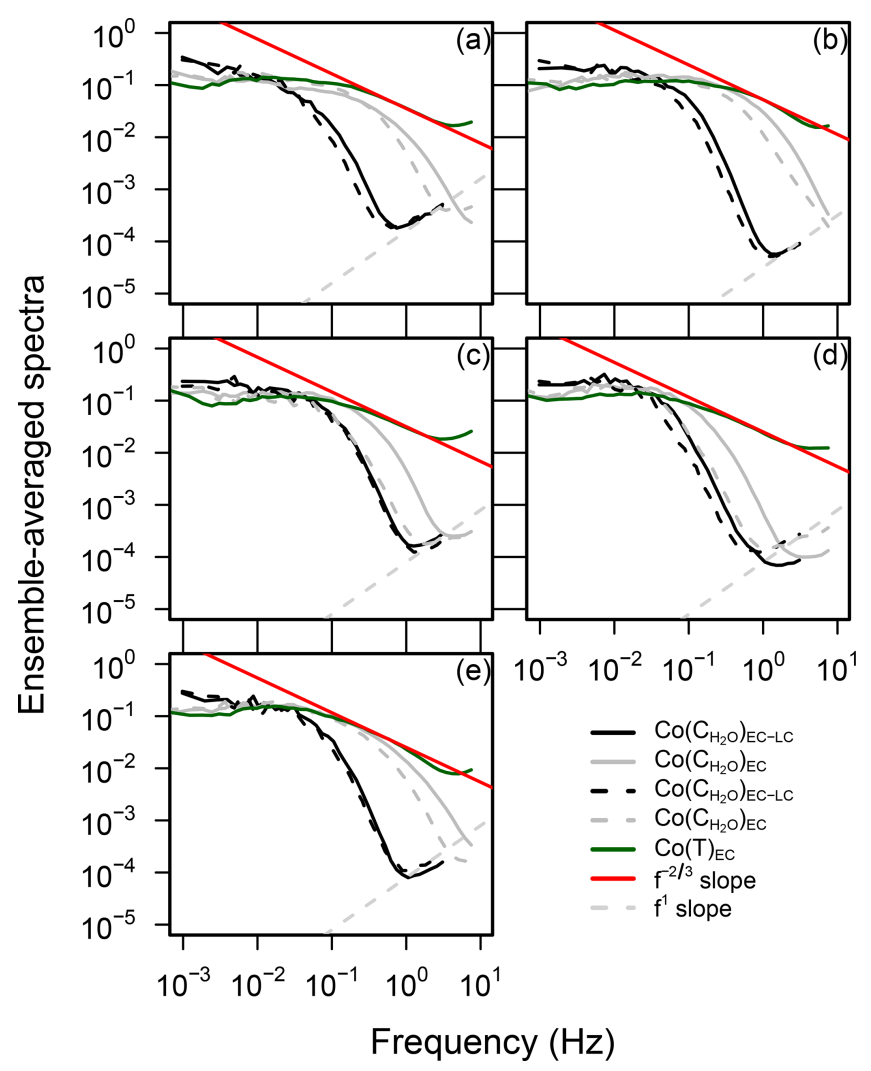

Figure 2.9: Ensemble-averaged normalized water vapour and temperature spectra for relative humidity thresholds of $60 \%$ (solid lines) and $80 \%$ (dashed lines) vs. the natural frequency. Spectra of the EC set-up (grey) and the EC-LC set-up (black) are shown. Panels correspond to plots: Dornburg agroforestry (a), Dornburg monoculture (b), Forst agroforestry (c), Wendhausen agroforestry (d) and Reiffenhausen agroforestry (e). Spectra were filtered for low-quality data, corresponding to a flag of 2, following the procedure of MAUDER et al. (2011) and according to spike removal methods described in VICKERs et al. (1997). Relative humidity classes correspond to ancillary relative humidity measurements.

\subsubsection{Ensemble-averaged co-spectra of the water vapour flux and sensible heat flux}

The water vapour flux co-spectra deviated negatively from the theoretical $-4 / 3$ slope for the EC and EC-LC set-ups between a normalized frequency of 0.1 and 8 (the inertial sub-range) for all sites (Fig. 2.10). The deviation from the $-4 / 3$ slope in this particular frequency range was strongest for the EC-LC set-up, which is a result of the limited spectral response characteristics of the thermohygrometer. As discussed in Sect. 2.3.4, the response time of the thermohygrometer was lower than given in the specifications.

The water vapour flux co-spectra of the conventional EC set-up at the agroforestry plots of Forst and Wendhausen (Fig. 2.10c and d) showed a stronger attenuation in the inertial sub-range, compared to the agroforestry plot and the monocultural agriculture plot in Dornburg and the agroforestry plot in Reiffenhausen (Fig. 2.10a, b and e). That was likely caused by the different tube diameter at the respective plots and the effect on the 


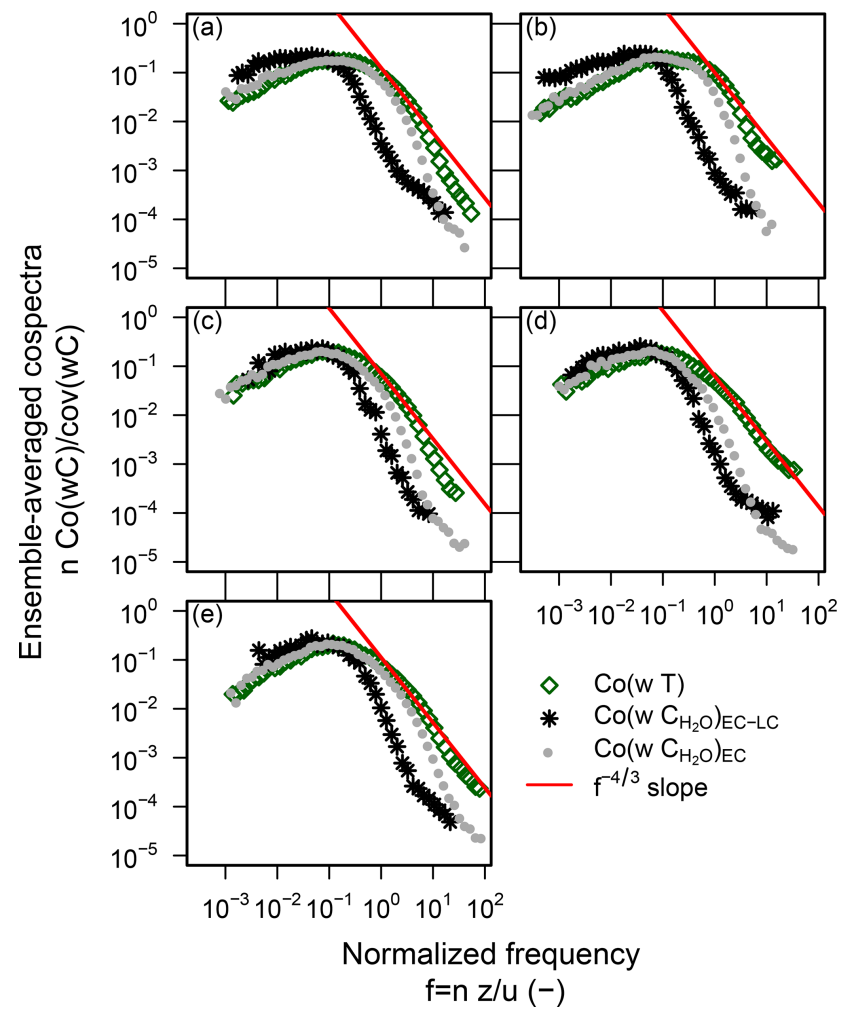

Figure 2.10: Ensemble-averaged co-spectra of the water vapour flux for the EC and the EC-LC set-ups (grey and black dots, respectively) and the co-spectrum of the sensible heat flux (green dots) vs. the normalized frequency over the entire campaign period for Dornburg agroforestry (a), Dornburg monoculture (b), Forst agroforestry (c), Wendhausen agroforestry (d) and Reiffenhausen agroforestry (e). Co-spectra shown correspond to an unstable stratified atmosphere, according to a Monin-Obukhov length between $-650<L<0$. Co-spectra were filtered for low-quality data, corresponding to a flag of 2, following the procedure of MAUDER et al. (2011) and according to spike removal methods described in VICKERS et al. (1997).

turbulence characteristics inside the tubes, as discussed in Sect. 2.3.5.1.

At normalized frequencies higher than 8, we found a slope decrease in the water vapour flux co-spectra obtained by the EC-LC set-up at all sites, which we interpret as an effect of sensor noise. Assuming that the vertical wind velocity measurements are unaffected by sensor noise, only the thermohygrometer measurements contribute to the slope decrease in the water vapour flux co-spectra found in Fig. 2.10 for the EC-LC set-up.

In the low-frequency range (for a normalized frequency $<0.1$ ) of the turbulent spectrum, the normalized water vapour co-spectrum obtained by the EC-LC set-up was higher than the temperature co-spectrum (Fig. 2.10). We interpret this finding as an effect of aliasing, which is an increased spectral energy in the low-frequency range due to an incorrect representation of the high frequencies (FoKEn, 2008). This implies a too high sampling frequency relative to the sensor response time. The effect of aliasing was also observed for the EC co-spectrum but was much lower compared to the EC-LC set-up. 


\subsubsection{Water vapour molar densities from the thermohygrometer and the LI-7200 gas analyser}

The water vapour molar density calculated from the thermohygrometer output was shown to be a smoothed version of the water vapour molar density directly measured by the LI-7200 gas analyser, as shown for a time period of $1 \mathrm{~h}$ for the agroforestry plot in Dornburg in Fig. 2.11. The low-frequency fluctuations were captured, whereas the high-frequency fluctuations were attenuated. A linear regression analysis between both water vapour molar densities yielded a $R^{2}$ value of 0.85 (based on 29419 data points). We interpret the smoothed water vapour molar density calculated by the thermohygrometer set-up as an effect of the longer response time of the thermohygrometer and the limited sampling frequency of $8 \mathrm{~Hz}$. Spectral analysis of the water vapour mole fraction (Sect. 2.3.5.1 and Fig. 2.9) derived from the thermohygrometer confirmed the attenuation of high frequencies by the thermohygrometer. The water vapour spectra from the thermohygrometer showed a strong deviation from the theoretical $-2 / 3$ slope and from the temperature spectrum at frequencies higher than $0.1 \mathrm{~Hz}$. For frequencies lower than $0.1 \mathrm{~Hz}$ the water vapour spectra compared well with the temperature spectrum.

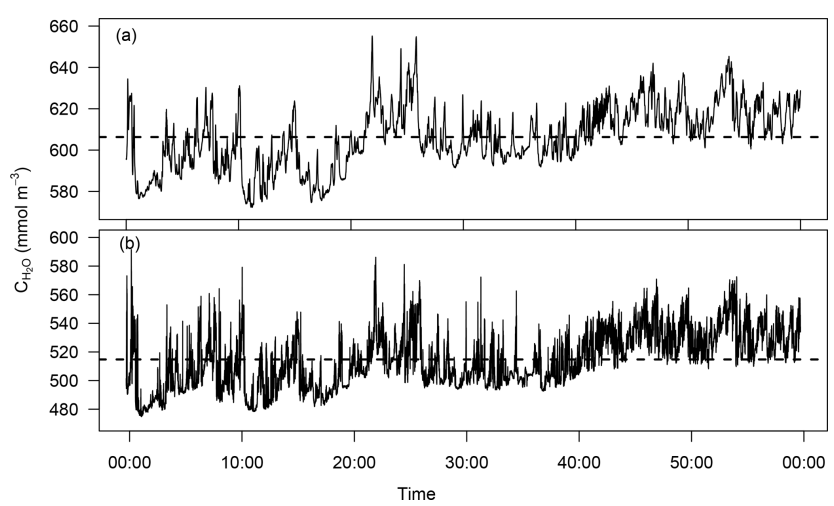

Figure 2.11: Water vapour molar density time series (solid line) and mean (dashed line) for the thermohygrometer (a) and the LI-7200 gas analyser (b) at the Dornburg agroforestry plot. The time series represent a $1 \mathrm{~h}$ period from 14:00 to 15:00 LT on 19 July 2016.

The molar density derived from the thermohygrometer was on average about $100 \mathrm{mmol} \mathrm{m}^{-3}$ higher than the molar density measured by the LI-7200 gas analyser during the $1 \mathrm{~h}$ period. A mean value of $606.32 \mathrm{mmol} \mathrm{m}^{-3}$ was found for the thermohygrometer and $514.8 \mathrm{mmol} \mathrm{m}^{-3}$ for the LI-7200 gas analyser. We interpret the higher water vapour density derived from temperature, relative humidity and air pressure measurements from the thermohygrometer as an effect of the temperature measurements from the thermohygrometer. We found a $5{ }^{\circ} \mathrm{C}$ higher air temperature from the thermohygrometer compared to the sonic temperature under clear sky conditions. The temperature difference is caused by a radiation effect originating from the PVC housing.

In addition, the temperature measurements from the thermohygrometer were attenuated compared to the sonic temperature. We interpret this as an inertia effect of the thermohygrometer. So, if the thermohygrometer complex has a higher thermal mass than the ambient air, the temperature measurements taken by the thermohygrometer are attenuated in the high-frequency range. As the attenuation effect was not found in the relative humidity 
measurements, we assume that the relative humidity measurements were independent of temperature measurements, and therefore relative humidity was not attenuated in the same way as air temperature. Subsequently, relative humidity fluctuations were conserved and could be used for the calculations of the water vapour mole fraction. In general, the deviation from the mean is of higher interest than the mean itself for the EC method (BALDOCCHI, 2014). As long as the relative humidity fluctuations are conserved in the calculations of the water vapour mole fraction, a plausible covariance between the water vapour mole fraction and the vertical velocity can be calculated.

\subsubsection{Linear regressions of latent heat fluxes from conventional and low-cost eddy covariance}

Results of a linear regression analysis between evapotranspiration rates obtained by the EC and EC-LC set-ups revealed a dependency of the evapotranspiration rates on the high-frequency co-spectral correction method used. Evapotranspiration rates obtained by the EC-LC set-up using the IBROM et al. (2007) high-frequency co-spectral correction underestimated evapotranspiration rates obtained by EC using the high-frequency correction following IBRom et al. (2007) (always used for the EC set-up) at all sites (Table 2.2). The largest underestimation was $32 \%$ (Forst agroforestry) and the smallest underestimation was $13 \%$ (Dornburg agroforestry), with a median underestimation of $22 \%$ across all five plots.

Table 2.2: Major axis linear regression of evapotranspiration from EC-LC vs. EC, using two high-frequency correction methods (IBrom et al., 2007; MoncriefF et al., 1997). The slopes include the $\pm 2.5 \%$ confidence interval. The root-mean-square error (RMSE) and the coefficient of determination $\left(R^{2}\right)$ are given.

\begin{tabular}{|c|c|c|c|c|c|c|}
\hline \multirow[t]{3}{*}{ Site } & \multicolumn{6}{|c|}{ Correction method } \\
\hline & \multicolumn{3}{|c|}{ IBROM et al. (2007) } & \multicolumn{3}{|c|}{ MONCRIEFF et al. (1997) } \\
\hline & Slope/intercept & $R^{2}$ & $\begin{array}{r}\text { RMSE } \\
\left(\mathrm{W} \mathrm{m}^{-2}\right)\end{array}$ & Slope/intercept & $R^{2}$ & $\begin{array}{r}\text { RMSE } \\
\left(\mathrm{W} \mathrm{m}^{-2}\right)\end{array}$ \\
\hline Dornbi & $0.87 \pm 0.034 /-9.04$ & 0.71 & 36.0 & $0.94 \pm 0.036 /-10.87$ & 0.71 & 35.13 \\
\hline Dornburg MC & $0.78 \pm 0.030 /-4.3$ & 0.71 & 50.8 & $1.08 \pm 0.027 /-5.12$ & 0.86 & 34.31 \\
\hline Forst AF & $0.68 \pm 0.026 /-0.45$ & 0.93 & 74.9 & $0.95 \pm 0.045 /-2.9$ & 0.90 & 38.5 \\
\hline Wendhausen AF & $0.78 \pm 0.016 /-5.8$ & 0.93 & 53.71 & $0.99 \pm 0.021 /-6.63$ & 0.94 & 33.5 \\
\hline Reiffenhausen AF & $0.85 \pm 0.034 /-4.1$ & 0.90 & 28.13 & $0.86 \pm 0.032 /-4.86$ & 0.90 & 29.7 \\
\hline
\end{tabular}

In contrast, evapotranspiration estimates obtained by the EC-LC set-up using the MONCRIEFF et al. (1997) high-frequency co-spectral correction revealed an underestimation of evapotranspiration rates by the EC-LC set-up of $14 \%, 6 \%, 5 \%$ and $1 \%$ for the agroforestry plots of Reiffenhausen, Dornburg, Forst and Wendhausen, respectively, and an overestimation by the EC-LC set-up of $8 \%$ for the monocultural agriculture plot in Dornburg relative to the conventional EC set-up (Table 2.2 and Fig. 2.12).

The dependency of the evapotranspiration estimates on the chosen high-frequency cospectral correction method may be caused by the assumptions of each method. The IBrom et al. (2007) high-frequency correction method was initially developed for a closed-path eddy covariance system, with a tube length of about $50 \mathrm{~m}$. The method described in IBROM et al. (2007) takes into account the dependency of water vapour concentration measurements on relative humidity effects inside the tube. A low-pass cut-off frequency was estimated for each $30 \mathrm{~min}$ period as a function of ambient relative humidity. At least 


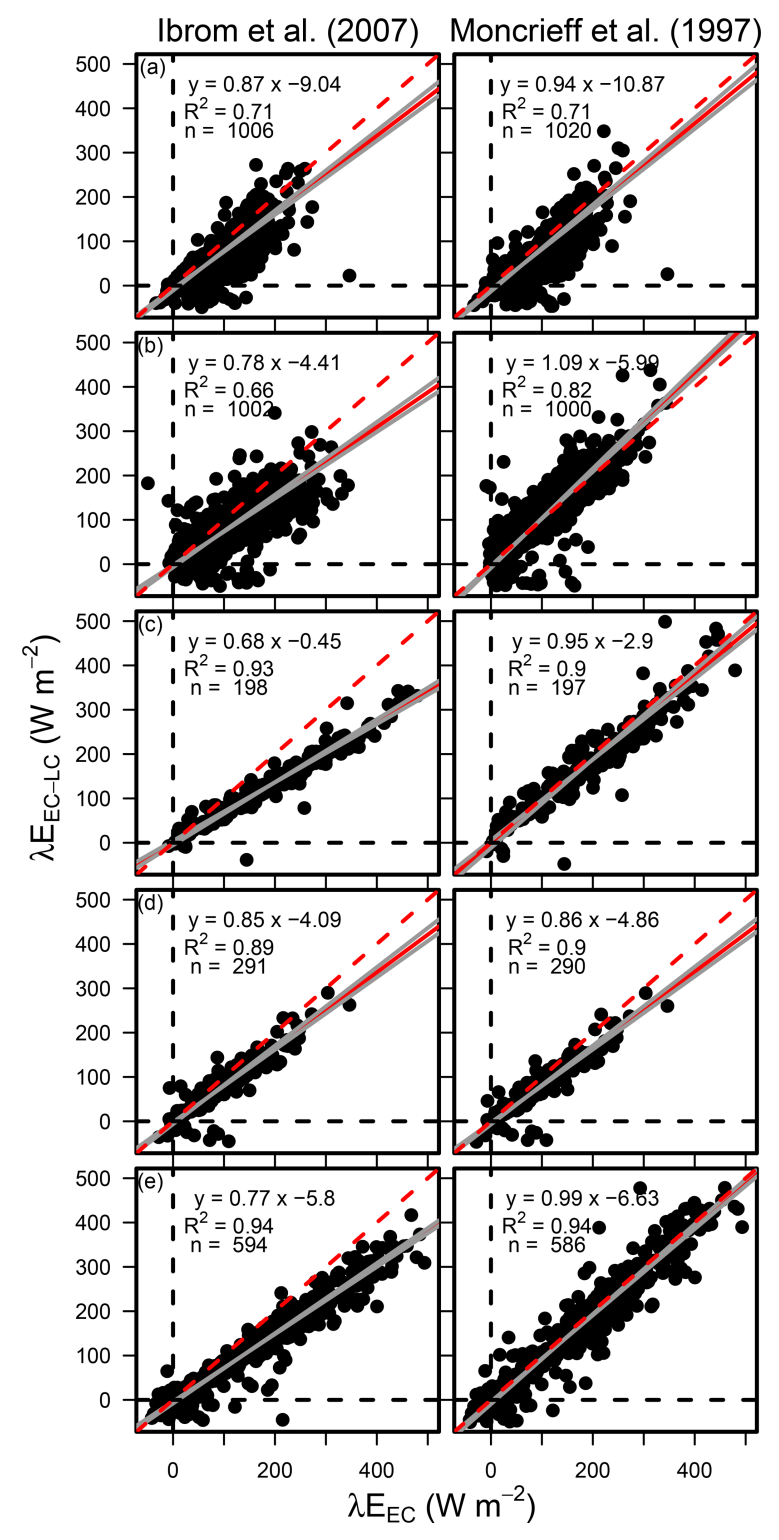

Figure 2.12: Scatter plots of latent heat fluxes obtained by the low-cost EC set-up vs. latent heat fluxes obtained by the conventional EC set-up for Dornburg agroforestry (a), Dornburg monoculture (b), Forst agroforestry (c), Reiffenhausen agroforestry (d) and Wendhausen agroforestry (e). Latent heat fluxes obtained by the conventional EC set-up were corrected for high-frequency losses via the high-frequency correction method of IBROM et al. (2007), whereas the latent heat fluxes obtained by the low-cost EC set-up were corrected first by the high-frequency correction method of IBrom et al. (2007) (left-hand column) and, second, the high-frequency correction method of MONCRIEFF et al. (1997) (right-hand column).

1 month of data are suggested to estimate the low-pass cut-off frequency (LI-COR, 2015). In contrast, the high-frequency correction method following MONCRIEFF et al. (1997) is purely analytical and applies a fit of the temperature co-spectra measured with the 
sonic anemometer on the water vapour co-spectra. This analytical method can be applied independent of meteorological measurements. Furthermore, the correction following MONCRIEFF et al. (1997) was recommended for either open-path EC systems or under conditions when the intake tube is short and heated (LI-COR, 2015). From an analysis of the high-frequency transfer function from MONCRIEFF et al. (1997) and the Lorentzian of the infinite impulse response filter from IBROM et al. (2007) it is evident that the correction of high-frequency losses is better represented by the high-frequency spectral correction of MonCRIEFF et al. (1997) (see Fig. 2.13). The transfer function of MonCRIEFF et al. (1997) is shifted towards higher frequencies and lower frequencies are conserved. According to the Lorentzian (IBROM et al., 2007) the filtering properties are more pronounced for IBROM et al. (2007) and low frequencies $\left(<10^{-2} \mathrm{~Hz}\right)$ are attenuated. Based on the assumptions and recommendations given in MONCRIEFF et al. (1997) and LI-COR (2015), we decided to apply the correction of MONCRIEFF et al. (1997) to our EC-LC set-up.

The authors of the only known related study, published by HiLl et al. (2017), present a low-cost EC set-up for measurements of $\mathrm{CO}_{2}$ and water vapour fluxes. The authors compared the low-cost EC set-up with a LI-7500 gas analyser sharing the same Campbell Scientific CSAT3 sonic anemometer. They reported a $6 \%$ flux magnitude overestimation of the latent heat flux obtained by the low-cost EC system relative to the reference EC set-up.

Flux magnitude differences observed for our low-cost set-up are comparable to flux magnitude differences between conventional EC set-ups observed in a recently published study by POLONIK et al. (2019). The authors found average differences between $4 \%$ and $14 \%$ between water vapour fluxes obtained by different EC set-ups consisting of three different sonic anemometers and five conventional gas analysers. 


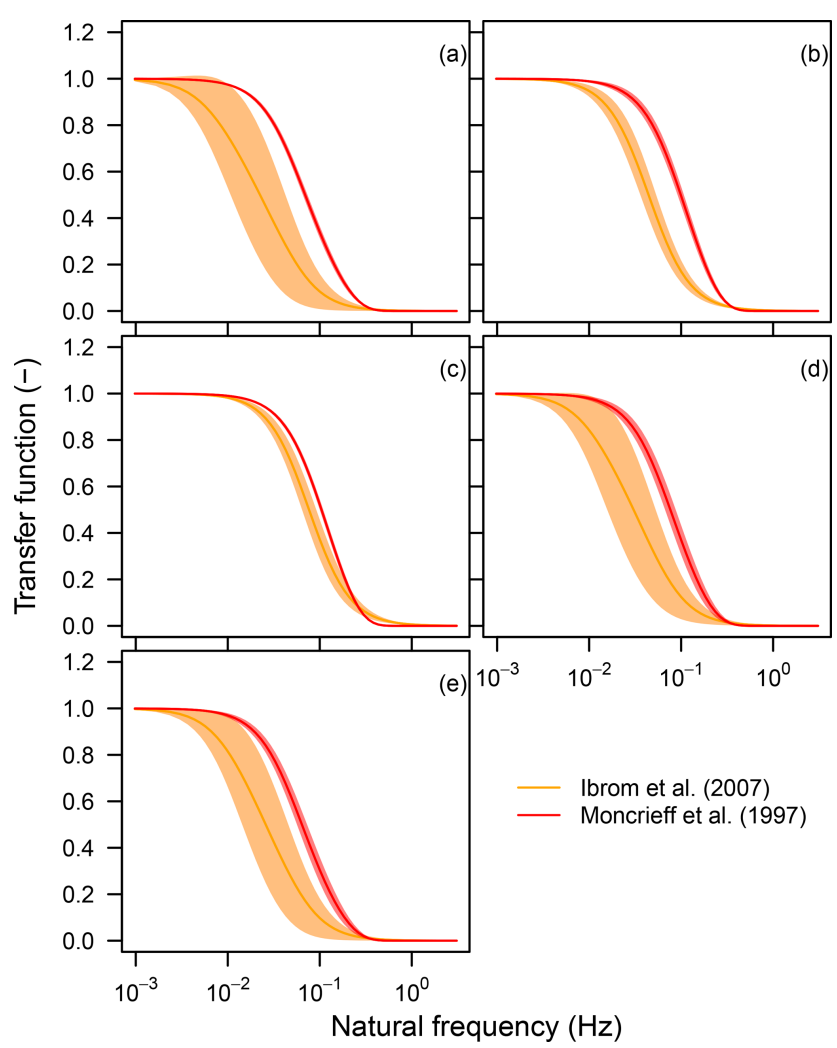

Figure 2.13: Mean and standard deviation of the spectral correction transfer functions vs. the natural frequency for the high-frequency spectral correction methods of IBROM et al. (2007) and MonCRIEFF et al. (1997), respectively, for the following sites: Dornburg agroforestry (a), Dornburg monoculture (b), Forst agroforestry (c), Reiffenhausen agroforestry (d) and Wendhausen agroforestry (e). The transfer function of IBROM et al. (2007) represents the mean over all infinite impulse response (IIR) filters, approximated by the Lorentzian $H_{\mathrm{IIR}}\left(f \mid f_{c}\right)=\frac{1}{1+\left(f / f_{c}\right)^{2}}$. $H_{\text {IIR }}\left(f \mid f_{c}\right)$ was estimated for each 30 min period as per the mean ambient relative humidity.

\subsubsection{Dependency of the latent heat flux random uncertainty on relative humidity}

Common to all sites and both set-ups was a decreasing absolute random uncertainty of the latent heat flux with increasing relative humidity (Fig. 2.14). At high relative humidity, turbulent latent heat fluxes were low, commonly during night-time and bad weather conditions. Whereas during daytime and good weather conditions (generally low relative humidity), the fluxes were high. Richardson et al. (2006) described a linear dependency of the absolute random uncertainty on the magnitude of the turbulent fluxes.

For three out of five plots (Dornburg agroforestry and monoculture and Reiffenhausen agroforestry, respectively, Fig. 2.14a, b and e), we found a lower median random uncertainty for the latent heat fluxes obtained by the conventional EC set-up at low relative humidity, compared to the EC-LC set-up. At high relative humidity $(\geq 70 \%)$ the median of both random uncertainties was equal.

For the other two plots (Fig. 2.14c and d) either a higher or nearly equal mean and 
standard deviation was found for the latent heat flux random uncertainty from the EC set-up compared to the EC-LC set-up. Furthermore, the standard deviation of the random uncertainty of the latent heat fluxes obtained by the EC and EC-LC set-ups was of the same order of magnitude as their respective mean (Table 2.3).

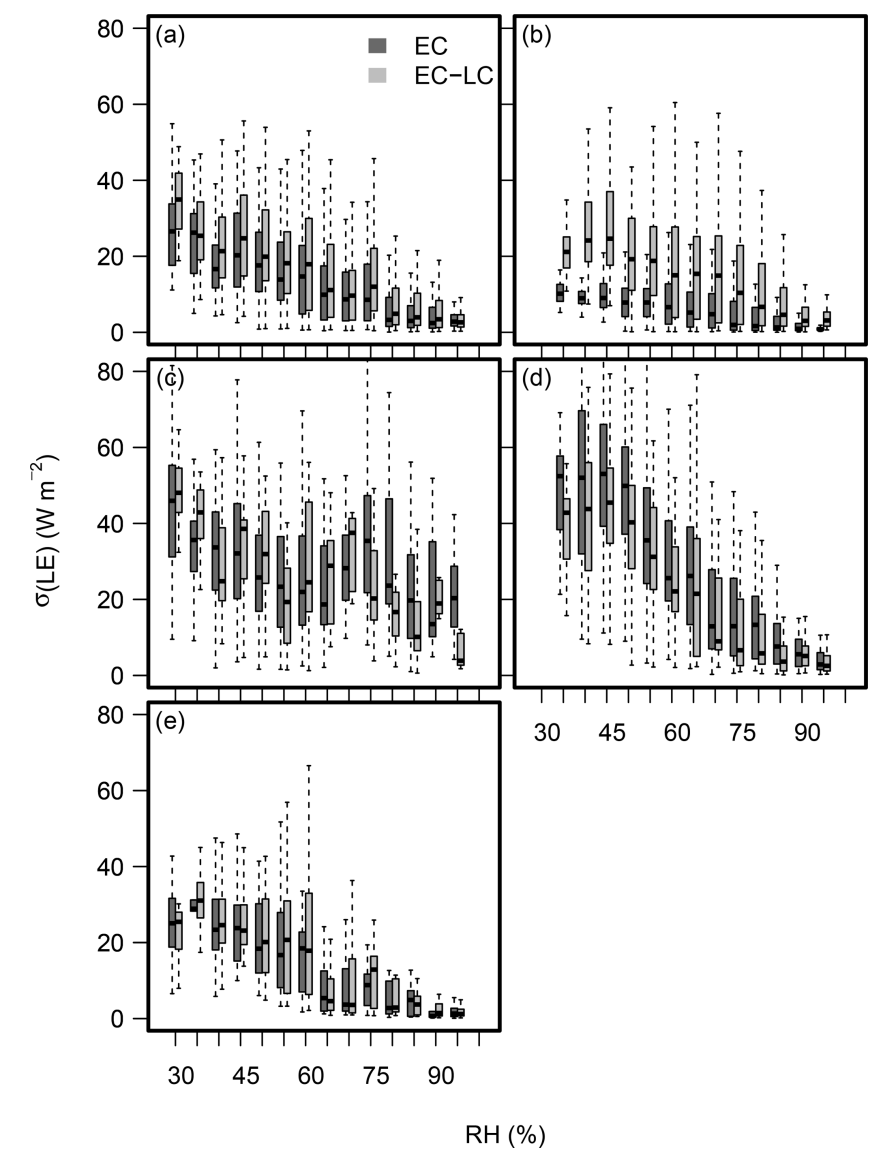

Figure 2.14: Box and whisker plots with random error uncertainty of the latent heat flux calculated by the EC and EC-LC set-up, respectively, vs. relative humidity bins of $5 \%$. Panels correspond to the following plots: Dornburg agroforestry (a), Dornburg monoculture (b), Forst agroforestry (c), Wendhausen agroforestry (d) and Reiffenhausen agroforestry (e).

Table 2.3: Mean random uncertainties and standard deviations of the latent heat fluxes obtained by the EC and EC-LC set-up.

\begin{tabular}{lrr}
\hline Site & $\overline{\sigma\left(\mathrm{LE}_{\mathrm{EC}}\right)}$ & $\overline{\sigma\left(\mathrm{LE}_{\mathrm{EC}-\mathrm{LC}}\right)}$ \\
\hline Dornburg AF & $12.94 \pm 15.82$ & $15.76 \pm 16.91$ \\
Dornburg MC & $6.27 \pm 6.01$ & $16.23 \pm 14.42$ \\
Forst AF & $30.87 \pm 18.84$ & $30.84 \pm 18.86$ \\
Wendhausen AF & $27.45 \pm 23.49$ & $23.70 \pm 20.93$ \\
Reiffenhausen AF & $13.2 \pm 14.3$ & $14.4 \pm 15.7$ \\
\hline
\end{tabular}




\subsubsection{Distribution of differences between evapotranspiration estimates}

The median of differences between evapotranspiration rates obtained by the EC and EC-LC set-up was negative for the agroforestry plots (Fig. 2.15a, c, d and e). This indicates an underestimation of ET rates obtained by the EC-LC set-up, compared to the EC set-up. The distribution of the differences between evapotranspiration rates followed a skewed distribution with a tail towards negative differences of up to $\sim-0.15 \mathrm{~mm} \mathrm{~h}^{-1}$. The tail towards positive values declined sharply after the maximum of the distribution.

At the monocultural agriculture plot at Dornburg (Fig. 2.15b) there was no significant difference in the median evapotranspiration rates of the two set-ups. The differences were equally distributed towards overestimated and underestimated ET rates until a zero density of $\pm 0.1 \mathrm{~mm} \mathrm{~h}^{-1}$.
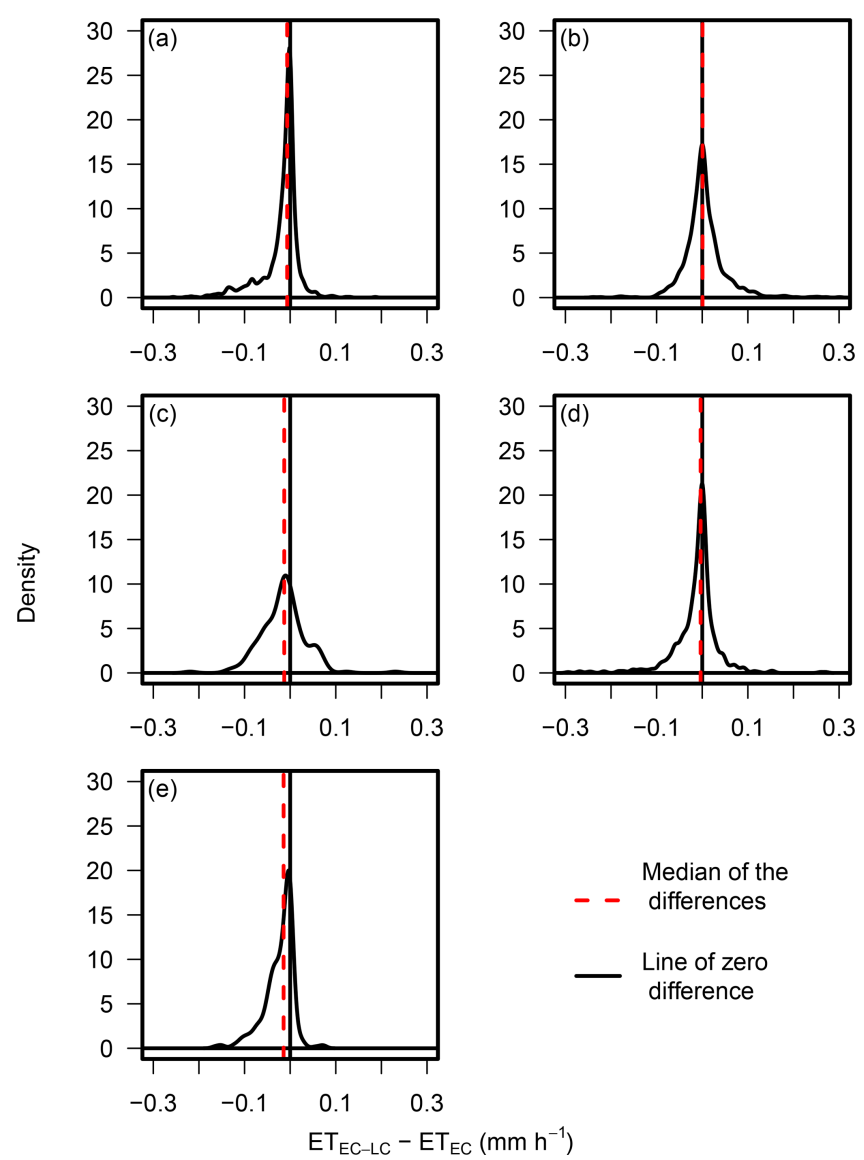

Figure 2.15: Density distribution of differences between evapotranspiration rates obtained by the EC and EC-LC set-up for Dornburg agroforestry (a), Dornburg monoculture (b), Forst agroforestry (c), Wendhausen agroforestry (d) and Reiffenhausen agroforestry (e). 


\subsubsection{Cumulative evapotranspiration rates}

We observed a lower cumulative evapotranspiration for the EC-LC set-up at all agroforestry plots, relative to the conventional EC set-up (Figs. 2.16 and 2.17). In contrast, a higher cumulative ET was found for the EC-LC set-up at the monocultural agriculture plot in Dornburg. The plot of cumulative ET lines in Fig. 2.17a I indicates a discrepancy between the cumulative ET lines at the agroforestry plot in Dornburg. This is caused by a period of poor performance of the low-cost set-up. After removing this period from the dataset, we still observed higher ET sums at the AF than at the MC plot but now differences were comparable to differences observed at the other plots, as indicated by the shaded bars in Fig. 2.16. In general, the observation of underestimated or overestimated (agroforestry vs. monocultural plots) ET rates obtained by the EC-LC set-up relative to the EC set-up is in agreement with the linear regression results presented in Sect. 2.3.7.

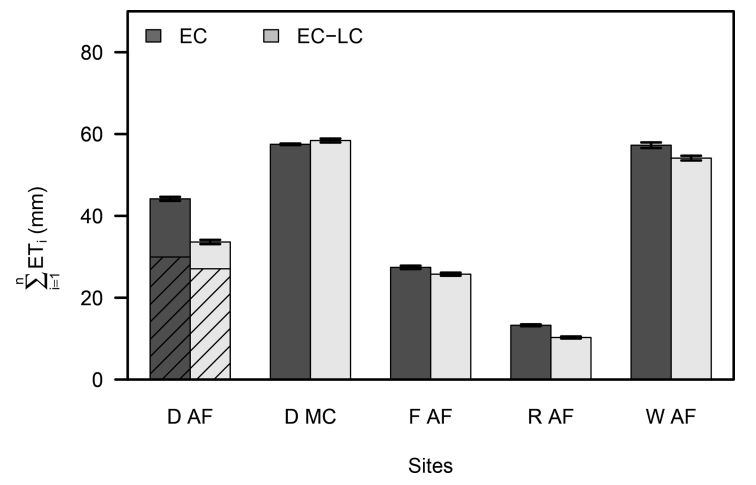

Figure 2.16: Cumulative evapotranspiration rates for the EC and EC-LC set-ups for Dornburg agroforestry (D AF), Dornburg monoculture (D MC), Forst agroforestry (F AF), Wendhausen agroforestry (W AF) and Reiffenhausen agroforestry (R AF) over the respective campaign periods (Table 2.5). The error bars correspond to the summed random uncertainties. The shaded area of the Dornburg agroforestry data corresponds to the cumulative sum of ET, filtered for the period of poor performance of the EC-LC set-up. Incomplete records with either EC or EC-LC missing were omitted. 

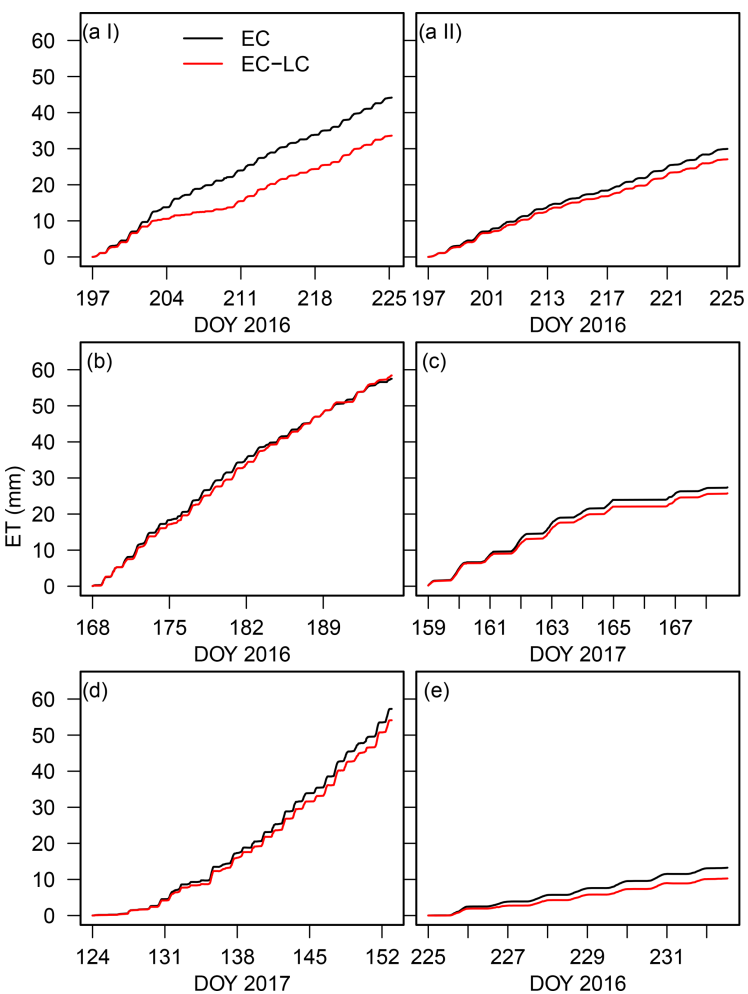

Figure 2.17: The 30 min cumulative evapotranspiration rates for the EC (solid black line) and EC-LC (solid red line) set-ups for Dornburg agroforestry with unfiltered data for the period of poor performance of the EC-LC set-up (a I), Dornburg agroforestry with filtered data for the period of poor performance of the EC-LC set-up (a II), Dornburg monoculture (b), Forst agroforestry (c), Wendhausen agroforestry (d) and Reiffenhausen agroforestry (e) over their respective campaign periods (Table 2.5). Incomplete records with either EC or EC-LC missing were omitted.

\subsubsection{Annual cumulative ET rates for the agroforestry and the monocultural plot}

We wanted to understand how evapotranspiration of agroforestry and monoculture differed. We deployed the EC-LC set-up as a convenient means to obtain continuous long-term evapotranspiration estimates at $30 \mathrm{~min}$ resolution. Here, we present annual cumulative sums of 30 min evapotranspiration rates for 2016 from all sites, independent of the measuring campaigns.

At the Dornburg site, annual cumulative evapotranspiration rates were higher at the monocultural agriculture plot compared to the agroforestry plot (Fig. 2.18), which might be caused by the wind-exposed location of the monocultural agriculture plot. The higher wind speed at the monocultural agriculture plot increases the boundary layer conductance, and therefore both soil evaporation and plant transpiration increase.

At the remaining four out of five sites the annual cumulative evapotranspiration rates were higher at the agroforestry plots than at the monocultural agriculture plots (Forst, Wendhausen, Mariensee and Reiffenhausen, Fig. 2.18). We interpret higher evapotranspiration rates at the agroforestry than at the monocultural plots as an effect of the increased 


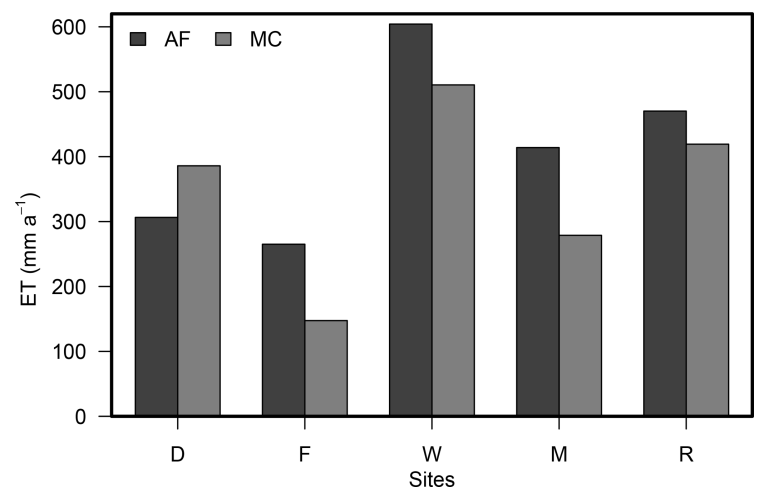

Figure 2.18: Cumulative evapotranspiration rates obtained by the EC-LC set-up at sites Dornburg (D), Forst (F), Wendhausen (W), Mariensee (M) and Reiffenhausen (R) for 2016. Incomplete records with either agroforestry or monoculture missing were omitted. Gap-filling was performed by multiplying the summed ET using the ratio of the number of maximum possible records to the number of missing records.

biomass at the agroforestry plot, originating both from the trees and the crops grown between the tree strips. Despite the presence of a leeward side with reduced evapotranspiration caused by the wind reduction and the increased shade, both crops and trees are affected by wind on the windward site. More turbulent conditions are present at the agroforestry plots, caused by the presence of the tree strips, which is indicated by a higher mean roughness length at the agroforestry plots compared to the conventional agriculture plots, as shown in Fig. 2.19 for all sites.

\subsection{Conclusions}

We presented a new low-cost eddy covariance set-up, which is comprised of a conventional ultrasonic anemometer and a low-cost thermohygrometer. We applied the eddy covariance method on the vertical velocity component and the water vapour mole fraction derived from the thermohygrometer. The advantages of the set-up are low material costs and low power consumption. The performance of the EC-LC set-up was comparable to the EC set-up with regards to mean evapotranspiration rates. The set-up-specific differences in mean evapotranspiration rates were insignificant compared to the variability between sites.

In detail, we were able to explain more than $80 \%$ of the variability in evapotranspiration obtained by the conventional eddy covariance set-up by the variability of the low-cost eddy covariance set-up. The low-cost eddy covariance set-up is a good alternative to the conventional EC set-up for both conventional agriculture systems and agroforestry ecosystems at a temporal resolution of $30 \mathrm{~min}$.

We showed that under conditions of high relative humidity and low air temperature the flux random error uncertainty of both set-ups was highest. ET rates obtained by the EC-LC set-up with limited frequency response had a lower relative difference with ET rates obtained by the EC set-up at the $10 \mathrm{~m}$ measurement height (AF) than at the $3.5 \mathrm{~m}$ height given a larger contribution of low-frequency eddies at the larger measurement height.

We anticipate potential applications of the EC-LC set-up in experiments comparing 
different treatments (management effects, different agriculture systems, water use) and chronosequences after fires or clear cuts. The set-up provides a tool for replicated ET measurements across different ecosystems. With low-cost instruments, flux measurements at existing flux networks such as FLUXNET, ICOS or NEON can be complemented and provided at remote and so-far under-represented sites.

\subsection{Data availability}

All data used for the figures presented here are provided at 10.5281/zenodo.3356837.

\subsection{Appendix}

Table 2.4: Site locations, agroforestry geometry and stand characteristics.

\begin{tabular}{lrrrrr}
\hline Site & Coordinates & $\begin{array}{r}\text { No. of } \\
\text { tree alleys }\end{array}$ & $\begin{array}{r}\text { System size } \\
{\left[\mathrm{m}^{2}\right]}\end{array}$ & $\begin{array}{r}\text { Relative } \\
\text { tree cover }\end{array}$ & Tree height $[\mathrm{m}]$ \\
\hline Reiffenhausen & $51^{\circ} 24^{\prime} \mathrm{N} 9^{\circ} 59^{\prime} \mathrm{E}$ & 3 & 18700 & $72 \%$ & $4.73 \pm 0.32(n=69)($ MALEC, 2017) \\
\hline Mariensee & $52^{\circ} 34^{\prime} \mathrm{N} 9^{\circ} 28^{\prime} \mathrm{E}$ & 3 & 69260 & $6 \%$ & $4.01 \pm 0.33(n=96)($ SWIETER et al., 2017) \\
\hline Wendhausen & $52^{\circ} 20^{\prime} \mathrm{N} 10^{\circ} 38^{\prime} \mathrm{E}$ & 6 & 179738 & $11.52 \%$ & $6.21 \pm 0.4(n=114)($ SWIETER et al., 2017) \\
\hline Forst & $51^{\circ} 47^{\prime} \mathrm{N} 14^{\circ} 38^{\prime} \mathrm{E}$ & 7 & 391300 & $12 \%$ & $6.5 \pm 1.8(n=161)($ SESERMAN, 2017) \\
\hline Dornburg & $51^{\circ} 47^{\prime} \mathrm{N} 11^{\circ} 39^{\prime} \mathrm{E}$ & 7 & 508723 & $8 \%$ & $6.4 \pm 0.64(n=160)(\mathrm{RUDOLF}, 2017)$ \\
\hline
\end{tabular}

Table 2.5: Temporal extent of the EC measurement campaigns.

\begin{tabular}{ll}
\hline Site & Campaign period \\
\hline Dornburg Conv & 16 June to 14 July 2016 \\
Dornburg AF & 14 July to 12 August 2016 \\
Reiffenhausen AF & 12 August to 14 September 2016 \\
Wendhausen & 3 May to 2 June 2017 \\
Forst & 8 June to 8 July 2017 \\
Mariensee & 21 July to 19 September 2017 \\
\hline
\end{tabular}

Table 2.6: Instrument separation of the gas analyser relative to the centre of the sonic anemometer in the northern, eastern and vertical direction.

\begin{tabular}{lrrrr}
\hline Site & $\begin{array}{r}\text { Northern } \\
{[\mathrm{cm}]}\end{array}$ & $\begin{array}{r}\text { Eastern } \\
{[\mathrm{cm}]}\end{array}$ & $\begin{array}{r}\text { Vertical } \\
{[\mathrm{cm}]}\end{array}$ & Year \\
\hline Dornburg MC & 6 & 14 & -21 & 2016 \\
Dornburg AF & -27 & 4 & -26 & 2016 \\
Reiffenhausen AF & 1 & 9 & -20 & 2016 \\
Wendhausen AF & -10 & 0 & -20 & 2017 \\
Forst AF & -12 & 0 & -22 & 2017 \\
\hline
\end{tabular}


Table 2.7: Mean air temperature, $T$, vapour pressure deficit, VPD, global radiation, $R_{\mathrm{G}}$ and the cumulative precipitation, Rain, for the respective site and measurement period.

\begin{tabular}{lrrcr}
\hline Site & $\begin{array}{r}T \\
\left({ }^{\circ} \mathrm{C}\right)\end{array}$ & $\begin{array}{r}\mathrm{VPD} \\
(\mathrm{hPa})\end{array}$ & $\begin{array}{c}R_{\mathrm{G}} \\
\left(\mathrm{W} \mathrm{m}^{-2}\right)\end{array}$ & $\begin{array}{r}\text { Rain } \\
(\mathrm{mm})\end{array}$ \\
\hline Dornburg MC & 18.6 & 7.35 & 212.6 & 2.1 \\
Dornburg AF & 19.0 & 6.41 & 200.7 & 57.1 \\
Reiffenhausen AF & 19.31 & 8.02 & 219.1 & 26.3 \\
Wendhausen AF & 16.6 & 5.4 & 235.0 & 48.6 \\
Forst AF & 21.4 & 12.02 & 358.8 & 18.9 \\
\hline
\end{tabular}

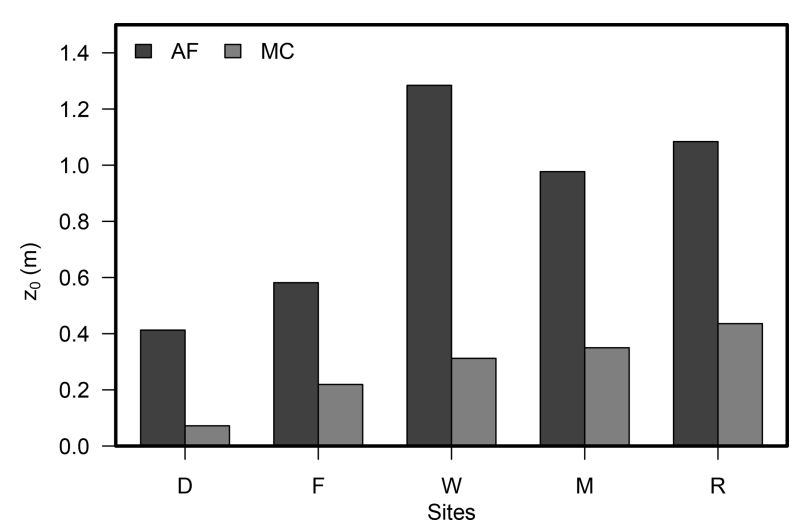

Figure 2.19: Mean roughness length at sites Dornburg (D), Forst (F), Wendhausen (W), Mariensee (M) and Reiffenhausen (R) for 2016.

\subsection{Author contribution}

CM designed and performed the field work, analysed the data, and wrote the manuscript. LS wrote the project's scientific proposal; acquired the funding as part of the BonaRes SIGNAL consortium; and contributed to field work, analysis, and manuscript writing.

\subsection{Competing interests}

The authors declare that they have no conflict of interest.

\subsection{Acknowledgements}

We wish to acknowledge contributions by Alexander Knohl and Mathias Herbst to the BonaRes SIGNAL proposal and project design, as well as the technical support in the field work received by Frank Tiedemann, Edgar Tunsch, Dietmar Fellert, Martin Lindenberg, Johann Peters (bioclimatology group) and Dirk Böttger (soil science group of tropical and subtropical ecosystems) from the University of Göttingen.

\subsection{Financial support}

This research has been supported by the German Federal Ministry of Education and Research (BMBF, project BonaRes, Module A, SIGNAL 031A562A) and by the Deutsche Forschungsgemeinschaft (INST 186/1118-1 FUGG).

This open-access publication was funded by the University of Göttingen. 


\subsection{Review statement}

This paper was edited by Christian Brümmer and reviewed by Timothy Hill and two anonymous referees. 


\section{References}

Aubinet, M., T. Vesala, and D. Papale, eds. (2012): Eddy Covariance: A Practical Guide to Measurement and Data Analysis. Springer Dordrecht, Heidelberg, London, New York: pp. 1-438 (cit. on p. 37).

BALDOCCHI, D. D. (2003): 'Assessing the eddy covariance technique for evaluating carbon dioxide exchange rates of ecosystems: past, present and future'. Glob. Chang. Biol., vol. 9(4): pp. 479-492 (cit. on p. 22).

BALDOCCHI, D. (2014): 'Measuring fluxes of trace gases and energy between ecosystems and the atmosphere - the state and future of the eddy covariance method'. Glob. Chang. Biol., vol. 20(12): pp. 3600-3609 (cit. on pp. 22, 43).

Bosch Sensortec GmbH (2016): BME280: Combined humidity and pressure sensor (cit. on p. 27).

Bundesamt Für Kartographie und GeodësIe (2011): Frankfurt am Main (cit. on p. 25).

Burba, G., A. Schmidt, R. L. Scott, T. Nakai, J. Kathilankal, G. Fratini, C. Hanson, B. Law, D. K. Mcdermitt, R. Eckles, M. Furtaw, and M. Velgersdyk (2012): 'Calculating $\mathrm{C} \$ \mathrm{O} \_2 \$$ and $\$ \mathrm{H} \_2 \$ \mathrm{O}$ eddy covariance fluxes from an enclosed gas analyzer using an instantaneous mixing ratio'. Glob. Chang. Biol., vol. 18(1): pp. 385-399 (cit. on p. 24).

Davis, P. A., J. C. Brown, M. Saunders, G. Lanigan, E. Wright, T. Fortune, J. Burke, J. Connolly, M. B. Jones, and B. Osborne (2010): 'Assessing the effects of agricultural management practices on carbon fluxes: Spatial variation and the need for replicated estimates of Net Ecosystem Exchange'. Agric. For. Meteorol., vol. 150(4): pp. 564-574 (cit. on p. 23).

De Stefano, A. and M. G. Jacobson (2018): 'Soil carbon sequestration in agroforestry systems: a meta-analysis'. Agrofor. Syst., vol. 92(2): pp. 285-299 (cit. on p. 23).

Dias, N. L., H. F. Duarte, and S. R. Maggiotto (2007): 'An attenuated eddy covariance method for latent heat flux measurements'. Water Resour. Res., vol. 43: pp. 1-9 (cit. on p. 23).

EugsteR, W. and P. PLüss (2010): 'A fault-tolerant eddy covariance system for measuring CH4fluxes'. Agric. For. Meteorol., vol. 150(6): pp. 841-851 (cit. on p. 38).

Farahani, H. J., T. A. Howell, W. J. Shuttleworth, and W. C. Bausch (2007): 'Evapotranspiration: Progress in Measurement and Modeling in Agriculture'. Am. Soc. Agric. Biol. Eng., vol. 50(5): pp. 1627-1638 (cit. on p. 22).

Foken, T. (2008): Micrometorology. Vol. 1. Bayreuth: Springer-Verlag Berlin Heidelberg (cit. on p. 41).

Foken, T, M Göckede, M Mauder, L Mahrt, B Amiro, and W Munger (2004): 'Post-field data quality control'. Handb. Micrometeorology, vol. 29(1988): pp. 181-208 (cit. on p. 32).

Fratini, G., A. Ibrom, N. Arriga, G. Burba, and D. Papale (2012): 'Relative humidity effects on water vapour fluxes measured with closed-path eddy-covariance systems with short sampling lines'. Agric. For. Meteorol., vol. 165: pp. 53-63 (cit. on p. 38). 
Hill, T., M. Chocholek, and R. Clement (2017): 'The case for increasing the statistical power of eddy covariance ecosystem studies: why, where and how?' Glob. Chang. Biol., vol. 23(6): pp. 2154-2165 (cit. on pp. 23, 45).

Hollinger, D. Y. and A. D. Richardson (2005): 'Uncertainty in eddy covariance measurements and its application to physiological models'. Tree Physiol., vol. 25(7): pp. 873-885 (cit. on p. 23).

Ibrom, A., E. Dellwik, H. Flyvbjerg, N. O. Jensen, and K. Pilegaard (2007): 'Strong low-pass filtering effects on water vapour flux measurements with closed-path eddy correlation systems'. Agric. For. Meteorol., vol. 147(3-4): pp. 140-156 (cit. on pp. 29, 31, 35, 38, 43-46).

Kaimal, J. C., J. C. Wyngaard, Y. Izumi, and O. R. Coté (1972): 'Spectral characteristics of surface layer turbulence'. Q. J. R. Meteorol. Soc., vol. 98(417): pp. 563-589 (cit. on p. 31).

Kaimal, J. and J. Finnigan (1994): Atmospheric boundary layer flows: Their structure and measurement. New York: Oxford University Press: pp. 1-289 (cit. on p. 28).

Kluun, N., P. Calanca, M. W. Rotach, and H. P. Schmid (2015): 'A simple twodimensional parameterisation for Flux Footprint Prediction (FFP)'. Geosci. Model Dev., vol. 8(11): pp. 3695-3713 (cit. on p. 24).

Kolmogorov, A. N. (1991): 'The local structure of turbulence in incompressible viscous fluid for very large Reynolds numbers'. Proc. R. Soc. London A Math. Phys. Eng. Sci., vol. 434(1890): pp. 9-13 (cit. on p. 32).

Kristensen, L. and D. R. Fritzjarrals (1984): 'The Effect of Line Averaging on Scalar Flux Measurements with a Sonic Anemomete near the Surface'. J. Atmos. Ocean. Technol., vol. 1: pp. 138-146 (cit. on pp. 32, 39).

Legendre, P. and J. Oksanen (2018): lmodel2: Model II Regression. Tech. rep. University of Helsinki: pp. 1-6 (cit. on p. 31).

Lenschow, D. H. and M. R. RAupaCh (1991): 'The attenuation of fluctuations in scalar concentrations through sampling tubes'. J. Geophys. Res., vol. 96(D8): p. 15259 (cit. on p. 31).

Leuning, R. and J. MoncRIEFF (1990): 'Eddy-covariance CO2 flux measurements using open- and closed-path $\mathrm{CO} 2$ analysers: Corrections for analyser water vapour sensitivity and damping of fluctuations in air sampling tubes'. Boundary-Layer Meteorol., vol. 53(1-2): pp. 63-76 (cit. on p. 31).

LI-COR, I. (2015): EddyPro 6 - Eddy Covariance Software Instruction Manual. Tech. rep.: pp. 1-311 (cit. on pp. $28,44,45$ ).

Malec, S. (2017): University of Kassel, Grassland Science and Renewable Plant Resources. Unpublished data. (Cit. on p. 52).

Mann, J. and D. H. LensChOW (1994): 'Errors in airborne flux measurements'. J. Geophys. Res., vol. 99(D7): p. 14519 (cit. on p. 29).

Markwitz, C. and L. Siebicke (2019): 'Low-cost eddy covariance: a case study of evapotranspiration over agroforestry in Germany'. Atmos. Meas. Tech., vol. 12: pp. 46774696 (cit. on p. 21). 
Mauder, M. and T. Foken (2011): Documentation and Instruction Manual of the Eddy-Covariance Software Package TK3. 46th ed. Universität Bayreuth, Abt. Mikrometeorologie (cit. on pp. 29, 40, 41).

- (2006): 'Impact of post-field data processing on eddy covariance flux estimates and energy balance closure'. Meteorol. Zeitschrift, vol. 15(6): pp. 597-609 (cit. on p. 35).

Moncrieff, J., J. Massheder, H. de Bruin, J. Elbers, T. Friborg, B. Heusinkveld, P. Kabat, S. Scott, H. Soegaard, and A. Verhoef (1997): 'A system to measure surface fluxes of momentum, sensible heat, water vapour and carbon dioxide'. J. Hydrol., vol. 188-189: pp. 589-611 (cit. on pp. 31, 35, 36, 43-46).

Moncrieff, J., R. Clement, J. Finnigan, and T. Meyers (2004): 'Averaging, Detrending, and Filtering of Eddy Covariance Time Series'. Handb. Micrometeorology, vol. 29: pp. 7-31 (cit. on pp. 29, 31, 34, 36).

Polonik, P., W. Chan, D. Billesbach, G. Burba, J. Li, A. Nottrott, I. Bogoev, B. Conrad, and S. Biraud (2019): 'Comparison of gas analyzers for eddy covariance: Effects of analyzer type and spectral corrections on fluxes'. Agric. For. Meteorol., vol. 272-273(December 2018): pp. 128-142 (cit. on p. 45).

Richardson, A. D., D. Y. Hollinger, G. G. Burba, K. J. Davis, L. B. Flanagan, G. G. Katul, J. William Munger, D. M. Ricciuto, P. C. Stoy, A. E. Suyker, S. B. Verma, and S. C. Wofsy (2006): 'A multi-site analysis of random error in tower-based measurements of carbon and energy fluxes'. Agric. For. Meteorol., vol. 136(1-2): pp. 1-18 (cit. on p. 46).

Rudolf, C. (2017): Thurengian state office of agriculture and rural areas. Unpublished data. (Cit. on p. 52).

Schmid, H. P. (2002): 'Footprint modeling for vegetation atmosphere exchange studies: A review and perspective'. Agric. For. Meteorol., vol. 113(1-4): pp. 159-183 (cit. on p. 22).

Schotanus, P., F. T. M. Nieuwstadt, and H. A. R. De Bruin (1983): 'Temperature measurement with a sonic anemometer and its application to heat and moisture fluxes'. Boundary-Layer Meteorol., vol. 26(1): pp. 81-93 (cit. on p. 29).

Seserman, D.-M. (2017): Brandenburg University of Technology, Cottbus-Senftenberg, Soil protection and recultivation. Unpublished data. (Cit. on p. 52).

Stull, R. B. (1989): An introduction to boundary layer meteorology. Kluwer Academic Publishers (cit. on pp. 30, 32).

Swieter, A. and M. LAnghof (2017): Julius Kühn-Institut, Institute for crop and soil science. Unpublished data (cit. on p. 52).

Tang, X., H. Li, A. R. Desai, Z. Nagy, J. Luo, T. E. Kolb, A. Olioso, X. Xu, L. Yao, W. Kutsch, K. Pilegaard, B. Köstner, and C. Ammann (2014): 'How is water-use efficiency of terrestrial ecosystems distributed and changing on Earth?' Sci. Rep., vol. 4(August 2016): p. 7483 (cit. on p. 23).

Trapletti, A. and K. HorniK (2017): tseries: Time Series Analysis and Computational Finance. Tech. rep. (cit. on p. 31).

Vickers, D. and L. MAHRT (1997): 'Quality control and flux sampling problems for tower and aircraft data'. J. Atmos. Ocean. Technol., vol. 14(3): pp. 512-526 (cit. on pp. 29, 40, 41). 
Webb, E. K., G. I. Pearman, and R. Leuning (1980): 'Correction of flux measurements for density effects due to heat and water vapour transfer'. Q. J. R. Meteorol. Soc., vol. 106(447): pp. 85-100 (cit. on pp. 29-31, 36). 


\section{CHAPTER 3}

Evapotranspiration over agroforestry sites in Germany

Paper published in 'Biogeosciences' (MARKwitz et al., 2020) 


\section{Abstract}

In the past few years, the interest in growing crops and trees for bioenergy production has increased. One agricultural practice is the mixed cultivation of fast-growing trees and annual crops or perennial grasslands on the same piece of land, which is referred to as one type of agroforestry (AF). The inclusion of tree strips into the agricultural landscape has been shown - on the one hand - to lead to reduced wind speeds and higher carbon sequestration above ground and in the soil. On the other hand, concerns have been raised about increased water losses to the atmosphere via evapotranspiration (ET). Therefore, we hypothesise that short rotation coppice agroforestry systems have higher water losses to the atmosphere via ET compared to monoculture (MC) agriculture without trees. In order to test the hypothesis, the main objective was to measure the actual evapotranspiration of five AF systems in Germany and compare those to five monoculture systems in the close vicinity of the $\mathrm{AF}$ systems.

We measured actual ET at five AF sites in direct comparison to five monoculture sites in northern Germany in 2016 and 2017. We used an eddy covariance energy balance (ECEB) set-up and a low-cost eddy covariance (EC-LC) set-up to measure actual ET over each AF and each MC system. We conducted direct eddy covariance (EC) measurement campaigns with approximately 4 weeks' duration for method validation.

Results from the short-term measurement campaigns showed a high agreement between $\mathrm{ET}_{\mathrm{EC}-\mathrm{LC}}$ and $\mathrm{ET}_{E C}$, indicated by slopes of a linear regression analysis between 0.86 and $1.3\left(R^{2}\right.$ between 0.7 and 0.94$)$ across sites. Root mean square errors of LE $\mathrm{EC}_{-\mathrm{LC}}$ vs. $\mathrm{LE}_{E C}$ (where $\mathrm{LE}$ is the latent heat flux) were half as small as $\mathrm{LE}_{E C E B}$ vs. $\mathrm{LE}_{E C}$, indicating a superior agreement of the EC-LC set-up with the EC set-up compared to the ECEB set-up.

With respect to the annual sums of ET over AF and MC, we observed small differences between the two land uses. We interpret this as being an effect of compensating the small-scale differences in ET next to and in between the tree strips for ET measurements on the system scale. Most likely, the differences in ET rates next to and in between the tree strips are of the same order of magnitude, but of the opposite sign, and compensate each other throughout the year. Differences between annual sums of ET from the two methods were of the same order of magnitude as differences between the two land uses. Compared to the effect of land use and different methods on ET, we found larger mean evapotranspiration indices $\left(\sum \mathrm{ET} / \sum P\right)$ across sites for a drier than normal year (2016) compared to a wet year (2017). This indicates that we were able to detect differences in ET due to different ambient conditions with the applied methods, rather than the potentially small effect of AF on ET.

We conclude that agroforestry has not resulted in an increased water loss to the atmosphere, indicating that agroforestry in Germany can be a land-use alternative to monoculture agriculture without trees.

\subsection{Introduction}

In the past few years, the interest in growing crops and trees for the production of bioenergy has increased, especially in the scope of climate change mitigation and carbon sequestration (FISCHER et al., 2013; ZENONE et al., 2015). One method of efficient biomass production 
is the cultivation of short rotation coppice (SRC), referred to as "any high-yielding woody species managed in a coppice system" (AYLOTT et al., 2008). Typically, fast-growing tree species, such as poplar or willow, are used for SRC plantations. The trees are commonly harvested after a 3 to 5 year rotation period and are used for energy and heat production (AYLOTT et al., 2008). SRC plantations are monoculture systems in which a single tree species is grown.

The cultivation of fast-growing trees with annual crops or perennial grasslands on the same piece of land is an example of agroforestry (AF) (MorHART et al., 2014; SMITH et al., 2013), and it has numerous environmental benefits relative to monoculture (MC) systems consisting only of crops or grasses without trees (QuinkENSTEIN et al., 2009). DE Stefano et al. (2018) found that the inclusion of fast-growing trees arranged into tree strips (short rotation alley cropping agroforestry) leads to a higher carbon sequestration above ground and in the soil relative to monoculture systems. The additional biomass input from litter, dead wood, and roots led to increased soil fertility (e.g. BEuscheL et al., 2018; Quinkenstein et al., 2009; Tsonkova et al., 2012). BöHm et al. (2014) and KANZLER et al. (2018) reported reduced wind velocity leewards of the tree strips when oriented perpendicular to the prevailing wind direction. In addition, CLEUGH (1998) and Quinkenstein et al. (2009) found that tree strips reduce incident solar radiation, leading to reduced air temperature (MCNAUGHTON, 1988). The effects of tree strips on the microclimate are mostly attributed to a region next to the tree strips, with the extent depending on tree strip properties such as the space between the tree strips, their orientation relative to the prevailing wind direction, their density, height, and width (QUINKENSTEIN et al., 2009).

Evapotranspiration (ET) in AF is strongly affected by the tree strip properties and is the combined process of (1) evaporation from the soil and open water from leaf surfaces and (2) leaf transpiration (KATUL et al., 2012). ET within AF is reduced on the downwind side of the tree strips due to a wind velocity reduction (CLEUGH, 1998; DAVIS et al., 1988; KAnZler et al., 2018; Quinkenstein et al., 2009; Tsonkova et al., 2012). DAvis et al. (1988) explained the reduction in ET by the protection of adjacent crops from dry air advection. The reduced dry air advection leads to a decreased vapour pressure deficit $(D)$, lowering ET (KANZLER et al., 2018). The potential reduction in ET in the vicinity of the tree strips leads to an increased soil water content downwind, with the potential for enhancing yield production (KANZLER et al., 2018; SwIETER et al., 2018).

Currently, little is known about the system-scale water use of heterogeneously shaped short rotation alley cropping agroforestry systems in Germany. The majority of the previous studies focused on the water use of short rotation coppices, but not on AF systems (Bloemen et al., 2016; Fischer et al., 2013; Fischer et al., 2018; Schmidt-Walter et al., 2014). Fischer et al. (2013) and ZENONE et al. (2015) observed a lower annual sum of evapotranspiration over a poplar SRC in the Czech Republic and in Belgium, compared to the annual sum of evapotranspiration over a reference grassland. This is contradictory to the assumption that SRC plantations are excessive water consumers. For AF systems, we formulated the same hypothesis, i.e. system-scale evapotranspiration over AF systems is higher compared to monoculture agriculture without trees.

However, the effect of AF on system-scale evapotranspiration is site specific and depends 
on the local climate, soil type, water availability, and AF design. Therefore, repeated measurements at different sites are essential for studies on the effects of AF on evapotranspiration. Nevertheless, this requires low maintenance methods with low power consumption and a moderate cost.

The most common approach for evapotranspiration measurements at ecosystem scale is the eddy covariance (EC) method (BALDOCCHI, 2003; BALDOCCHI, 2014). EC provides a tool for real-time flux measurements on a timescale of $30 \mathrm{~min}$. The complexity and cost of traditional EC systems, however, usually limits the required replication of measurement units (HILl et al., 2017). An alternative method with lower costs is the eddy covariance energy balance method (ECEB) (AmIro, 2009). The latent heat flux (LE) is calculated as the residual of the energy balance components, i.e. the net radiation, the ground heat flux, the sensible heat flux, and various storage terms. The ECEB method is limited by the accuracy of the energy balance components, typically leading to an overestimation of latent heat fluxes. Therefore, we need to assess to what extent the energy balance is closed at the given sites. Another alternative method for measurements of evapotranspiration is the use of slower but cheaper humidity sensors resulting in a low-cost eddy covariance set-up (EC-LC) (MARKWITZ et al., 2019). The measurement principle follows the concept of the eddy covariance method; however, the fast response gas analyser is replaced by a slow response thermohygrometer. The slow response time of the humidity sensor limits the sampling of turbulent eddies across the whole energy spectrum, which we address with appropriate high-frequency corrections during preprocessing. For latent heat fluxes obtained by EC-LC, the non-closure of the energy balance causes a flux underestimation as observed for traditional EC set-ups. Any potential non-closure is then addressed by direct measurements of the latent heat flux to estimate the energy balance non-closure and partition the residual energy to the sensible and latent heat flux.

The main hypothesis of the current work is that short rotation alley cropping AF systems have higher water losses to the atmosphere via ET, compared to monoculture agriculture without trees. In order to test the hypothesis, the main objectives of the study are (1) to evaluate the eddy covariance energy balance (ECEB) and low-cost eddy covariance (EC-LC) method against direct eddy covariance (EC) measurements and (2) to measure the actual evapotranspiration of five AF systems in Germany and compare those to five monoculture systems in the close vicinity of the AF systems using the two different approaches.

\subsection{Materials and methods}

\subsubsection{Site description}

This study was carried out as part of the sustainable intensification of agriculture through agroforestry (SIGNAL) project (http://signal . uni-goettingen.de/, last access: 19 January 2020), to investigate the sustainability of AF systems in Germany. We performed measurements at five sites across northern Germany (Fig. 3.1, left). Each site consisted of one AF system and one monoculture (MC) system (see Fig. 3.1 for an aerial photograph of the Dornburg, Forst, Mariensee, Reiffenhausen, and Wendhausen sites with AF and MC selected). The AF systems are of a short rotation alley cropping type, with fast-growing trees interleaved by either crops (see Fig. 3.1 for images of the cropland AF systems in 
Dornburg, Forst, and Wendhausen) or perennial grasslands (see Fig. 3.1 for images of the grassland AF systems in Mariensee and Reiffenhausen). The crops and grasses at the monoculture systems undergo the same tillage and fertilisation as the crops and grasses cultivated between the tree strips. The MC system serves as a reference to the AF system. Table 3.1 specifies the site locations and the AF geometry.

\subsubsection{Measurements}

Measurements of meteorological and micrometeorological variables have been performed since March 2016. At each AF system we installed an eddy covariance mast with a height of $10 \mathrm{~m}$, and at each MC system an eddy covariance mast with a height of $3.5 \mathrm{~m}$ was installed. Each mast was equipped with the same meteorological and micrometeorological instrumentation. The standard set-up consisted of instruments measuring wind speed, wind direction, sensible heat flux, net radiation, global radiation, air temperature, relative humidity, precipitation, and ground heat flux. An overview of the installed instruments and the respective variables used for the presented set-ups is given in Table 3.2.

Gaps in precipitation measurements at all sites were filled by precipitation data collected at nearby weather stations operated by the German weather service (DWD). We used the R package of rdwd (Boessenkool, 2019) for data downloads from the ftp server maintained by the DWD. We replaced gaps in precipitation measurements with DWD data if more than $25 \%$ of the precipitation data per day were missing. We used precipitation data from the weather stations at Erfurt-Weimar airport, Cottbus, Hannover-Herrenhausen, and Braunschweig to fill data gaps in precipitation at Dornburg, Forst, Mariensee, and Wendhausen, respectively. In Reiffenhausen we used the precipitation records of a station placed at the same site and operated by the soil hydrology group at the University of Göttingen. As the precipitation transmitter was placed inside or next to the tree strips at the majority of the AF systems, the measurements were affected by interception and were lower than at the MC system. Therefore, we used the precipitation measurements from the MC system to compute ratios of annually summed actual ET and net radiation to precipitation at both $\mathrm{AF}$ and $\mathrm{MC}$ systems. We assume that the annual sum of precipitation at the $\mathrm{AF}$ and the MC systems do not differ due to the relatively small size of the AF systems and no expected local effects of the AF systems on the precipitation formation.

In the following sections, we briefly describe the concepts of the used set-ups, eddy covariance (EC), eddy covariance energy balance (ECEB) and low-cost eddy covariance (EC-LC). Throughout the paper we used the respective abbreviations.

\subsubsection{Eddy covariance (EC)}

Sensible heat and momentum fluxes have been measured continuously with ultrasonic anemometers since 2016. The water vapour and $\mathrm{CO}_{2}$ mole fraction were measured during field campaigns during the vegetation periods of 2016 and 2017 (Table 3.7). During the field campaigns, the standard set-up was extended by an enclosed-path infrared gas analyser (LI-7200; LI-COR Inc., Lincoln, Nebraska, USA). In 2016, the campaigns were conducted separately at the AF and MC systems with one available gas analyser, whilst in 2017 both systems were sampled simultaneously with two available gas analysers. Data processing and the analysis procedure is described in more detail in MARKWITZ et al. (2019). 

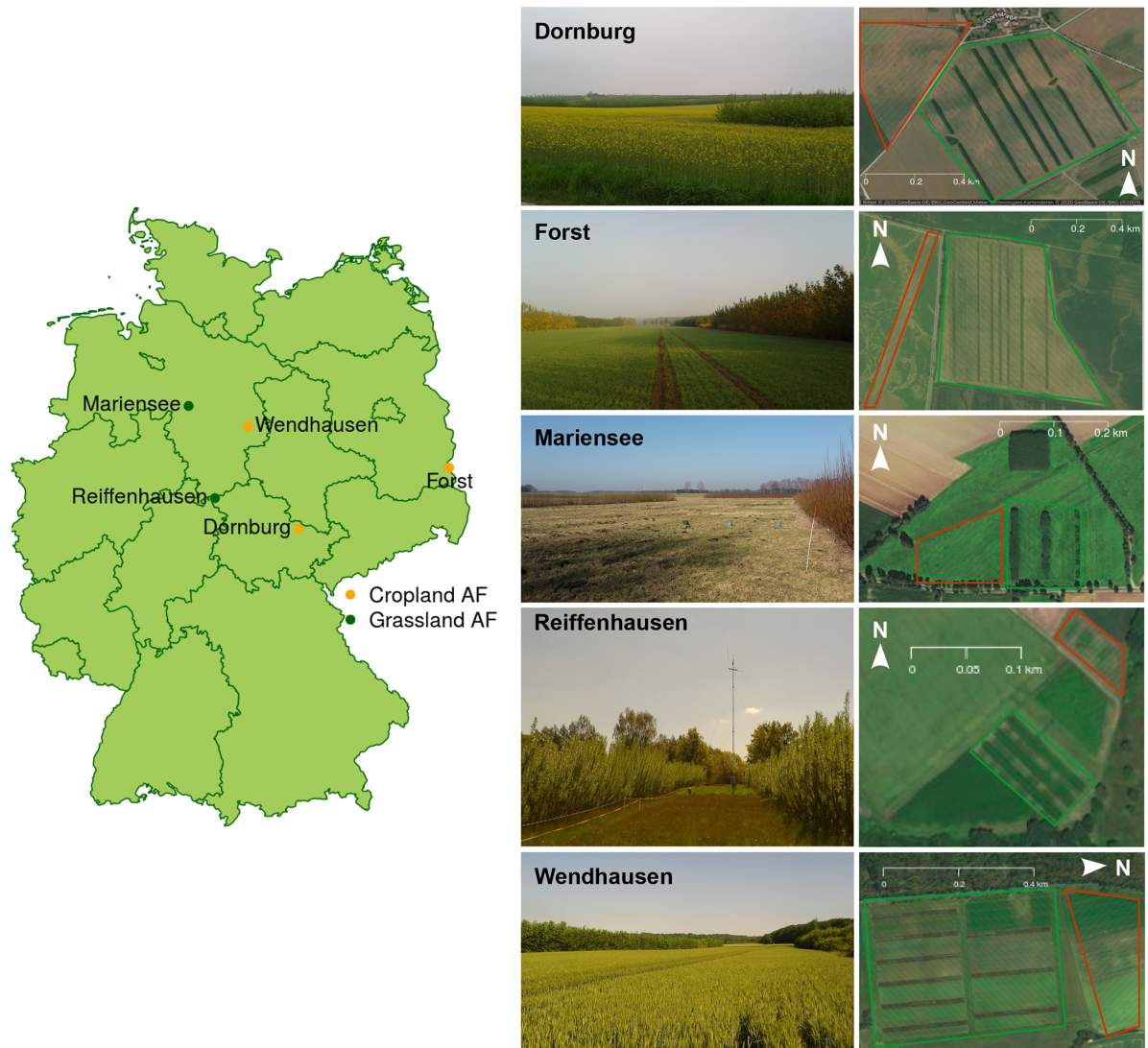

Figure 3.1: Map of the SIGNAL sites, with the respective agroforestry (AF) system type of either cropland or grassland AF, and an image and aerial photograph of the AF systems. Green hatched areas in the aerial photographs correspond to the area of the AF system, and red hatched areas correspond to the area of the MC system. Site images are our own photographs, and the aerial photographs originate from Google Maps and Google Earth. (c) Google 2020.

\subsubsection{Eddy covariance energy balance (ECEB)}

The energy balance at the surface is as follows:

$$
R_{\mathrm{N}}-G=H+\mathrm{LE}+S,
$$

with net radiation $\left(R_{\mathrm{N}} ; \mathrm{W} \mathrm{m}^{-2}\right)$, ground heat flux $\left(G ; \mathrm{W} \mathrm{m}^{-2}\right)$, sensible heat flux $(H$; $\mathrm{W} \mathrm{m}^{-2}$ ), latent heat flux (LE; $\left.\mathrm{W} \mathrm{m}^{-2}\right)$, and soil storage flux $\left(S ; \mathrm{W} \mathrm{m}^{-2}\right)$. By convention, a turbulent flux towards the atmosphere is defined as positive and a turbulent flux towards the surface is defined as negative. A positive net radiation corresponds to a surplus of radiative energy at the surface and a positive ground heat flux describes a heat transport into the soil.

LE from ECEB ( $\left.\mathrm{LE}_{E C E B}\right)$ was calculated as the residual of the net radiation, with the 
Table 3.1: Site locations and agroforestry (AF) system geometry.

\begin{tabular}{|c|c|c|c|c|c|c|c|c|}
\hline Site & Coordinates & $\begin{array}{r}\text { No. of } \\
\text { tree } \\
\text { strips }\end{array}$ & $\begin{array}{r}\text { Distance } \\
\text { between tree } \\
\text { strips }(\mathrm{m})\end{array}$ & $\begin{array}{l}\text { Orientation } \\
\text { of tree } \\
\text { strips }\end{array}$ & $\begin{array}{l}\text { Tree height } \\
(\mathrm{m})\end{array}$ & $\begin{array}{l}\text { Agroforestry } \\
\text { system } \\
\text { type }\end{array}$ & $\begin{array}{r}\text { Agroforestry } \\
\text { system } \\
\text { size (ha) }\end{array}$ & $\begin{array}{r}\text { Relative } \\
\text { tree cover } \\
(\%)\end{array}$ \\
\hline Reiffenhausen & $\begin{array}{l}51^{\circ} 24^{\prime} \mathrm{N} \\
9^{\circ} 59^{\prime} \mathrm{E}\end{array}$ & 3 & 9 & NW-SE & $\begin{array}{l}4.73 \pm 0.32(n=69) \\
\text { (Sarah Malec, Univer- } \\
\text { sity of Kassel, Grass- } \\
\text { land Science } \\
\text { and Renewable Plant } \\
\text { Resources, personal } \\
\text { communication, } \\
2017)\end{array}$ & $\begin{array}{l}\text { Willow } \\
\text { grassland }\end{array}$ & 1.9 & 72 \\
\hline Mariensee & $\begin{array}{l}52^{\circ} 34^{\prime} \mathrm{N} \\
9^{\circ} 28^{\prime} \mathrm{E}\end{array}$ & 3 & 48 & $\mathrm{~N}-\mathrm{S}$ & $\begin{array}{l}4.01 \pm 0.33(n=96) \\
\text { (Anita Swieter and } \\
\text { Maren Langhof, } \\
\text { Julius } \\
\text { Kühn-Institut, Insti- } \\
\text { tute for } \\
\text { crop and soil science, } \\
\text { personal communica- } \\
\text { tion, 2017) }\end{array}$ & $\begin{array}{l}\text { Willow } \\
\text { grassland }\end{array}$ & 7 & 6 \\
\hline Wendhausen & $\begin{array}{l}52^{\circ} 20^{\prime} \mathrm{N} \\
10^{\circ} 38^{\prime} \mathrm{E}\end{array}$ & 6 & $24,48,96$ & $\mathrm{~N}-\mathrm{S}$ & $\begin{array}{l}6.21 \pm 0.4(n=114) \\
\text { (Anita Swieter and } \\
\text { Maren Langhof, } \\
\text { Julius } \\
\text { Kühn-Institut, Insti- } \\
\text { tute for } \\
\text { crop and soil science, } \\
\text { personal communica- } \\
\text { tion, 2017) }\end{array}$ & $\begin{array}{l}\text { Poplar } \\
\text { cropland }\end{array}$ & 18 & 11.52 \\
\hline Forst & $\begin{array}{l}51^{\circ} 47^{\prime} \mathrm{N} \\
14^{\circ} 38^{\prime} \mathrm{E}\end{array}$ & 7 & $24,48,96$ & $\mathrm{~N}-\mathrm{S}$ & $\begin{array}{l}6.5 \pm 1.8(n=161) \\
\text { (Diana-M. Seserman, } \\
\text { Brandenburg Univer- } \\
\text { sity } \\
\text { of Technology, } \\
\text { Cottbus- } \\
\text { Senftenberg, Soil pro- } \\
\text { tection and recultiva- } \\
\text { tion, personal } \\
\text { communication, } \\
2017)\end{array}$ & $\begin{array}{l}\text { Poplar } \\
\text { cropland }\end{array}$ & 39.1 & 12 \\
\hline Dornburg & $\begin{array}{l}51^{\circ} 00^{\prime} \mathrm{N} \\
11^{\circ} 38^{\prime} \mathrm{E}\end{array}$ & 7 & $48,96,125$ & NW-SE & $\begin{array}{l}6.4 \pm 0.64(n=160) \\
\text { (Carolin Rudolf, } \\
\text { Thurengian } \\
\text { state office of agricul- } \\
\text { ture } \\
\text { and rural areas, per- } \\
\text { sonal } \\
\text { communication, } \\
2017)\end{array}$ & $\begin{array}{l}\text { Poplar } \\
\text { cropland }\end{array}$ & 51 & 8 \\
\hline
\end{tabular}

ground and sensible heat flux, and the soil storage flux according to Eq. (3.1) as follows:

$$
\mathrm{LE}_{\mathrm{ECEB}}=R_{\mathrm{N}}-G-H-S,
$$

assuming a fully closed surface energy balance. The conversion of LE into ET and the derivation of the soil storage flux are given in Sect. 3.5.1.1.

The energy balance residual (Res) per half-hour interval was calculated from Eq. (3.1) 
Table 3.2: Instrumentation for flux and meteorological measurements used at all five AF and MC systems. Set-up corresponds to eddy covariance (EC), low-cost eddy covariance (EC-LC), and eddy covariance energy balance (ECEB).

\begin{tabular}{|c|c|c|c|c|}
\hline Variable & Height $(\mathrm{m})$ & Instrument & Company & Set-up \\
\hline $\begin{array}{l}\text { The } 3 \mathrm{D} \text { wind components, } u, v, w\left(\mathrm{~ms} \mathrm{~s}^{-1}\right) \text {, } \\
\text { ultrasonic temperature, } T_{\mathrm{s}}\left({ }^{\circ} \mathrm{C}\right) \text {, wind speed }\left(\mathrm{m} \mathrm{s}^{-1}\right) \text {, } \\
\text { and direction }\left(^{\circ}\right)\end{array}$ & $3.5,10$ & uSONIC-3 Omni & $\begin{array}{l}\text { METEK GmbH } \\
\text { Elmshorn, Germany }\end{array}$ & $\begin{array}{l}\text { EC, ECEB, } \\
\text { EC-LC }\end{array}$ \\
\hline Net radiation, $R_{\mathrm{N}}\left(\mathrm{W} \mathrm{m}^{-2}\right)$ & $3,9.5$ & NR Lite2 Net radiometer & $\begin{array}{l}\text { Kipp \& Zonen } \\
\text { Delft, the Netherlands }\end{array}$ & ECEB \\
\hline Global radiation, $R_{\mathrm{G}}\left(\mathrm{W} \mathrm{m}^{-2}\right)$ & $3,9.5$ & CMP3 pyranometer & $\begin{array}{l}\text { Kipp \& Zonen } \\
\text { Delft, the Netherlands }\end{array}$ & \\
\hline Relative humidity, $\mathrm{RH}(\%)$, air temperature, $T\left({ }^{\circ} \mathrm{C}\right)$ & 2 & $\begin{array}{l}\text { Hygro-thermo } \\
\text { transmitter compact } \\
\text { (model 1.1005.54.160) }\end{array}$ & $\begin{array}{l}\text { Thies Clima } \\
\text { Göttingen, Germany }\end{array}$ & EC, ECEB \\
\hline $\mathrm{RH}, T$, atmospheric pressure, $P_{\mathrm{A}}(\mathrm{Pa})$ & $0.5,3 / 9.5$ & BME280 & Bosch, Germany & EC-LC \\
\hline Precipitation, $P(\mathrm{~mm})$ & 1 & $\begin{array}{l}\text { Precipitation transmitter } \\
\text { (model 5.4032.35.007) }\end{array}$ & $\begin{array}{l}\text { Thies Clima } \\
\text { Göttingen, Germany }\end{array}$ & \\
\hline$P_{\mathrm{A}}$ & $0.5,1.5$ & $\begin{array}{l}\text { Baro transmitter } \\
\text { (model 3.1157.10.000) }\end{array}$ & $\begin{array}{l}\text { Thies Clima } \\
\text { Göttingen, Germany }\end{array}$ & $\begin{array}{l}\text { EC, ECEB, } \\
\text { EC-LC }\end{array}$ \\
\hline Ground heat flux, $G\left(\mathrm{~W} \mathrm{~m}^{-2}\right)$ & -0.05 & HFP01 & $\begin{array}{l}\text { Hukseflux } \\
\text { Delft, the Netherlands }\end{array}$ & ECEB \\
\hline Soil temperature, $T_{\text {Soil }}\left({ }^{\circ} \mathrm{C}\right)$ & $\begin{array}{r}-0.02,-0.05, \\
-0.10,-0.25,-0.5\end{array}$ & DS18B20 & & $\begin{array}{l}\text { ECEB, } \\
\text { EC-LC }\end{array}$ \\
\hline Water vapour mole fraction, $C_{H_{2} O_{v}}\left(\mathrm{mmol} \mathrm{mol}^{-1}\right)$ & $3.5,10$ & LI-7200 & $\begin{array}{l}\text { LI-COR, Inc. } \\
\text { Lincoln, Nebraska (USA) }\end{array}$ & EC \\
\hline Carbon dioxide mole fraction, $C_{\mathrm{CO}_{2}}\left(\mu \mathrm{mol} \mathrm{mol}^{-1}\right)$ & $3.5,10$ & LI-7200 & $\begin{array}{l}\text { LI-COR, Inc. } \\
\text { Lincoln, Nebraska (USA) }\end{array}$ & EC \\
\hline
\end{tabular}

as follows:

$$
\text { Res }=R_{\mathrm{N}}-\mathrm{LE}-G-H-S,
$$

with LE from either EC or EC-LC ( $\mathrm{LE}_{E C}$ and $\mathrm{LE}_{\mathrm{EC}-\mathrm{LC}}$, respectively) and $H$ from EC.

\subsubsection{Low-cost eddy covariance (EC-LC)}

The EC-LC set-ups comprised the same ultrasonic anemometer uSONIC-3 Omni as used for the EC and ECEB set-ups plus a compact, low-cost relative humidity, air temperature, and pressure sensor (BME280; Bosch, Germany; see Table 3.2). Water vapour mole fraction was calculated using measurements of relative humidity, air temperature, and air pressure from the low-cost thermohygrometer. A derivation of the water vapour mole fraction from the low-cost thermohygrometer is given in Sect. 3.5.1.2. The turbulent water vapour fluxes were calculated as the covariance between the vertical wind velocity and the water vapour mole fraction from EC-LC, as per the principle of the eddy covariance method (BALDOCCHI, 2014). The cheaper but slower thermohygrometer had inferior spectral response characteristics compared to a gas analyser with a fast response. The mean spectral correction factor of the thermohygrometer was $42 \%$ larger than for the LI-7200 fast response gas analyser for reference, with a $78 \%$ larger mean time constant of the thermohygrometer compared to the LI-7200. The mean time constant of the thermohygrometer and the LI-7200 was $2.8 \pm 1$ and $0.6 \pm 0.3 \mathrm{~s}$, respectively (MARKWITZ et al., 2019). Spectral losses in the high-frequency range of the energy spectrum of the thermohygrometer were corrected by the fully analytical correction method of MONCRIEFF et al. (1997), which was explicitly recommended for either open-path sensors or closed-path sensors of heated and very short sampling lines. A detailed description and application 
of the EC-LC set-up for evapotranspiration measurements over AF and MC is given in MARKWITZ et al. (2019). Evapotranspiration from EC-LC was neither gap-filled for the methodological comparison nor for the analysis of the energy balance closure due to the risk of new errors and artefacts from the respective gap-filling method.

\subsubsection{Gap-filling and energy balance closure adjustment}

For the comparison of $\mathrm{ET}_{E C}, \mathrm{ET}_{E C E B}$, and $\mathrm{ET}_{\mathrm{EC}-\mathrm{LC}}$ and the estimation of the energy balance closure during the campaigns, we neither gap-filled the data nor corrected the data for the energy balance non-closure. For the calculation of annual sums of $\mathrm{ET}_{E C E B}$ and $\mathrm{ET}_{\mathrm{EC}-\mathrm{LC}}$, data gaps were filled and corrected for the energy balance non-closure by distributing the residual equally to $H$ and LE. The residual was estimated by machine learning for times when no data were available. In the following subsections, we describe the gap-filling and energy balance closure adjustment procedures for the ECEB and EC-LC set-ups in more detail.

\subsubsection{ECEB}

For the calculation of annual sums of $\mathrm{ET}_{E C E B}$, gaps were filled with the online eddy covariance gap-filling and flux-partitioning tool, REddyProc, developed at the Max Planck Institute for Biogeochemistry in Jena, Germany (https://www.bgc-jena.mpg.de/bgi/ index.php/Services/REddyProcWeb, last access: 19 January 2020). The methods used therein are based on FALGE et al. (2001) and REICHSTEIN et al. (2005). We corrected $\mathrm{ET}_{E C E B}$ for the average energy balance non-closure, which we estimated from direct LE measurements by EC during measurement campaigns of a minimum of 4 weeks in duration. In the current study we found that considering the energy balance residual reduces $\mathrm{ET}_{E C E B}$. We used machine learning to estimate the energy balance residuals (Eq. 3.3) during times when no campaigns took place. We used the machine learning technique of extreme gradient boosting (CHEN et al., 2016; CHEN et al., 2019) and predicted the residual energy for both years, 2016 and 2017, at all sites with the R package of XGBoost (ChEN et al., 2019).

The calculated residual was treated as the dependent variable, whereas the net radiation, the ground heat flux, and the sensible heat flux were treated as the independent variables. The model was tested with the data gathered during the campaigns and divided into a training period and a testing period. At a ratio of two-thirds of training to testing data, we achieved a Pearson correlation coefficient between the testing and predicted data of 0.66. The trained model was then applied to both years with the net radiation, the ground heat flux, and sensible heat flux as input parameters. As a last step, the predicted residual was subtracted from half-hourly ET. We assumed that the residual distributes equally to the LE and $H$, and thus we subtracted only half of the residual from ET. Commonly, the residual energy is partitioned according to the Bowen ratio (TwINE et al., 2000), which requires direct and continuous measurements of $H$ and LE by EC. We decided on an equal separation of the residual energy because direct LE measurements by EC were not continuously available at our sites. This assumption may cause an overestimation of LE during dry ambient conditions when the Bowen ratio is high. In contrast, LE is expected to be underestimated during moist ambient conditions when the Bowen ratio is small. As no campaign on the energy balance closure was conducted at the monoculture system 
of Reiffenhausen, we used the data gathered during the campaign at the AF system of Reiffenhausen to train the model and to predict the residual at the MC system.

\subsubsection{EC-LC}

Unlike for the methodological comparison and energy balance analysis, a gap-filling of ET $_{\text {EC-LC }}$ could not be avoided for the calculation of annual sums of ET. Therefore, for these analyses we gap-filled the half-hourly $\mathrm{ET}_{\mathrm{EC}-\mathrm{LC}}$ with half-hourly $\mathrm{ET}_{E C E B}$ and corrected both $\mathrm{ET}_{\mathrm{EC}-\mathrm{LC}}$ and $\mathrm{ET}_{E C E B}$ for the surface energy balance closure as follows:

1. The residual energy was estimated from all available data in 2016 and 2017, following Eq. (3.3).

2. We trained the same machine learning tool as used for the ECEB set-up to predict the residual energy with the residual treated as the dependent variable and net radiation, ground heat flux, and sensible heat flux the independent variables.

3. The residual was predicted by the trained model; data gaps in the residuals, originating mainly from missing LE caused by data quality checks, were filled with the predicted values.

4. Subsequently, we distributed the residual to $\mathrm{ET}_{\mathrm{EC}-\mathrm{LC}}\left(\mathrm{LE}_{\mathrm{EC}-\mathrm{LC}}^{c o r}\right)$ and to $\mathrm{ET}_{E C E B}$, used for gap-filling $\left(\mathrm{LE}_{E C E B}^{g f}\right)$ as follows:

$$
\begin{aligned}
& \alpha=0.5 \\
& \mathrm{LE}_{\mathrm{EC}-\mathrm{LC}}^{\mathrm{cor}}=\mathrm{LE}_{\mathrm{EC}-\mathrm{LC}}+\operatorname{Res} \cdot \alpha \\
& \mathrm{LE}_{\mathrm{ECEB}}^{\mathrm{gf}}=\mathrm{LE}_{\mathrm{ECEB}}^{\mathrm{gf}}-\operatorname{Res} \cdot \alpha .
\end{aligned}
$$

\subsubsection{Energy balance closure estimation}

The energy balance closure (EBC) was quantified in two ways:

1. First, as the linear regression between the sum of the turbulent flux components $(\mathrm{LE}+H)$ and the available energy $\left(R_{\mathrm{N}}-G-S\right)$. We applied the major axis linear regression (WEBSTER, 1997), which assumes equally distributed errors in both time series. We interpreted the slope between the sum of the turbulent fluxes and the available energy as the closure of the surface energy balance. A slope of one and an intercept of zero corresponds to perfect energy balance closure. In the present study, both the slope and the intercept were considered as variable.

2. Second, as the energy balance ratio (EBR), also called the "instantaneous energy balance closure" (STOY et al., 2013). Thus, the closure per half-hour is as follows:

$$
\mathrm{EBR}=\frac{\mathrm{LE}+H}{R_{\mathrm{N}}-G-S}
$$

with either $\mathrm{LE}_{E C}$ or $\mathrm{LE}_{\mathrm{EC}-\mathrm{LC}}$. 


\subsubsection{Flux footprint analysis}

The spatial coverage and the position of the source area of turbulent sensible and latent heat fluxes and momentum at a specific point in time is defined by the flux footprint (KLJUn et al., 2015; Schmid, 2002). In the present study, a flux footprint climatology was calculated with the flux footprint prediction online data-processing tool developed by KLJUN et al. (2015) (http://footprint.kljun.net/, last access: 19 January 2020). The analyses were performed separately for the respective campaign periods (see Table 3.7 in Appendix 3.5.2 for dates) and for both years at each site. We selected only daytime data, according to a global radiation $R_{\mathrm{G}}>20 \mathrm{~W} \mathrm{~m}^{-2}$.

\subsubsection{Canopy resistance}

The effects of structural differences between $\mathrm{AF}$ and MC on ET were studied in terms of the relationship between half-hourly ET and the aerodynamic and canopy resistances $\left(\mathrm{s} \mathrm{m}^{-1}\right)$. The canopy resistance was calculated from the rearranged Penman-Monteith equation (see Eq. 3.19 in Appendix 3.5.1.3) for evapotranspiration, which depends on the canopy resistance $\left(r_{\mathrm{c}}=1 / g_{\mathrm{c}} ; \mathrm{s} \mathrm{m}^{-1}\right)$ and the aerodynamic resistance for heat $\left(r_{\mathrm{ah}}=1 / g_{\mathrm{ah}}\right.$; $\mathrm{s} \mathrm{m}^{-1}$ ). The canopy resistance follows the big leaf assumption, which assumes that the whole canopy response to environmental changes equals the response of a single leaf. This assumption is valid for the monoculture system with a single crop type of similar height. For the AF systems, this assumption might be violated due to the heterogeneity of the AF systems with different plant species (trees and crops) of different heights. In the lee of the tree strips, the reduced wind speed and incident radiation might lead to reduced ET due to a different leaf stomata regulation of sunlit and shaded leaves. In the windward site of the tree strips, trees and crops are affected by increased wind velocities and varying incident radiation; thus, the opposite conditions, compared to the lee of the tree strips, are found. However, we assume that the meteorological data from the flux tower represent the mean state of the meteorological conditions within the AF system. Therefore, we are confident that the big leaf assumption also holds for AF systems.

We studied the relationship between ET and canopy resistance and aerodynamic resistance for idealised ambient conditions with global radiation $\left(R_{\mathrm{G}} \geq 400 \mathrm{~W} \mathrm{~m}^{-2}\right)$, horizontal wind speed $\left(u \geq 1 \mathrm{~m} \mathrm{~s}^{-1}\right)$, and vapour pressure deficit $(D=1 \pm 0.3 \mathrm{kPa}$; SCHMIDT-WaLter et al., 2014). A derivation of the canopy resistance is given in Sect. 3.5.1.3. 


\subsection{Results and discussion}

\subsubsection{Meteorological conditions during the campaigns}

For the meteorological conditions during the campaigns, we refer to the time series of the relevant meteorological parameter in Fig. 3.2 and mean values in Table 3.3.
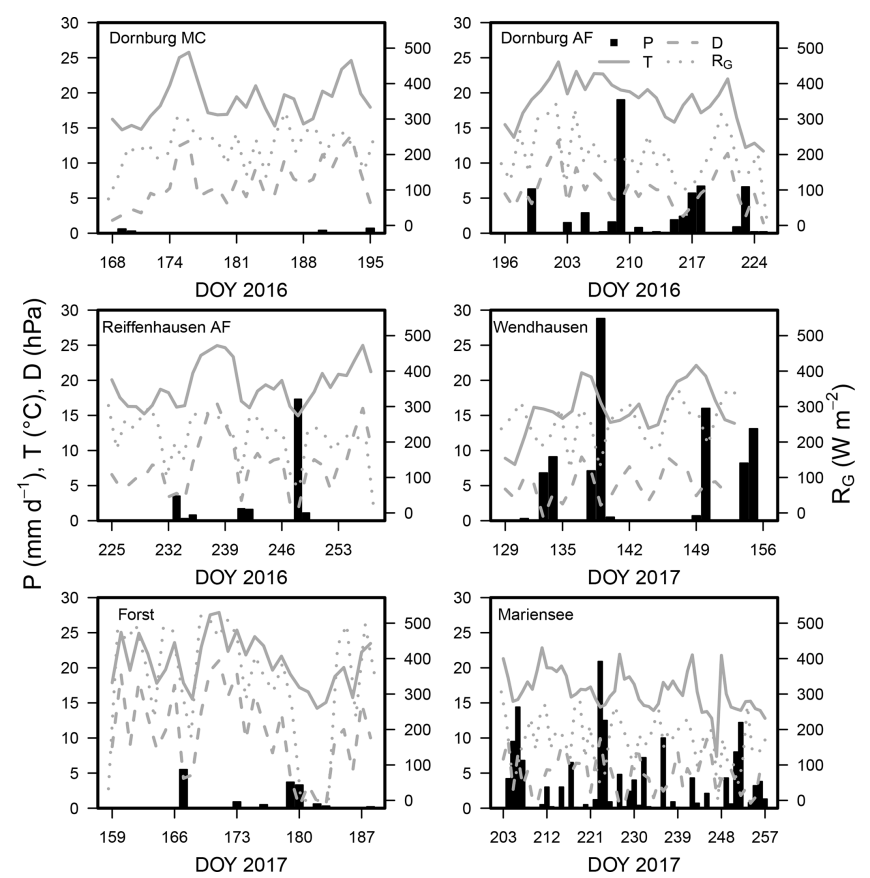

Figure 3.2: Time series of daily mean air temperature $\left(T ;{ }^{\circ} \mathrm{C}\right)$, vapour pressure deficit $(D$; $\mathrm{hPa})$, daily summed precipitation $\left(\mathrm{mm} \mathrm{d}^{-1}\right.$; left $y$ axis), and daily mean global radiation $\left(R_{\mathrm{G}}\right.$; $\mathrm{W} \mathrm{m}^{-2}$; right $y$ axis) for all sites. The data for $\mathrm{AF}$ and $\mathrm{MC}$ of the respective sites of Forst, Mariensee, and Wendhausen were averaged. The field campaigns at the AF and MC systems were conducted during the same time, and we assumed similar weather conditions due to the small distance between the $\mathrm{AF}$ and $\mathrm{MC}$ system. 
Table 3.3: Mean air temperature $\left(T ;{ }^{\circ} \mathrm{C}\right)$, vapour pressure deficit $(D ; \mathrm{hPa})$, global radiation $\left(R_{\mathrm{G}} ; \mathrm{Wm} \mathrm{m}^{-2}\right)$, and the cumulative precipitation $\left(P ; \mathrm{mm}^{-1}\right)$ for the respective site and campaign period. Data for Reiffenhausen $\mathrm{MC}$ are missing due to the unavailability of a campaign.

\begin{tabular}{lrrrr}
\hline Site & $\begin{array}{r}T \\
\left({ }^{\circ} \mathrm{C}\right)\end{array}$ & $\begin{array}{r}P \\
(\mathrm{~mm})\end{array}$ & $\begin{array}{r}D \\
(\mathrm{hPa})\end{array}$ & $\begin{array}{r}R_{\mathrm{G}} \\
\left(\mathrm{W} \mathrm{m}^{-2}\right)\end{array}$ \\
\hline Dornburg AF & 19.0 & 57.1 & 6.41 & 200.7 \\
Dornburg MC & 18.6 & 2.1 & 7.35 & 212.6 \\
Forst AF & 21.4 & 18.9 & 12.02 & 358.8 \\
Forst MC & 21.2 & 14.8 & 11.88 & 371.5 \\
Mariensee AF & 18.54 & 40.6 & 6.2 & 258.9 \\
Mariensee MC & 16.93 & 163.5 & 4.7 & 172.8 \\
Reiffenhausen AF & 19.31 & 26.3 & 8.02 & 219.1 \\
Wendhausen AF & 16.6 & 48.6 & 5.4 & 235.0 \\
Wendhausen MC & 15.5 & 90.7 & 5.2 & 239.9 \\
\hline
\end{tabular}

\subsubsection{Flux footprint climatology}

The flux footprint analyses showed that the measured turbulent fluxes were representative of the larger AF systems and their respective MC systems during the time of the experiments (e.g. Dornburg, Forst and Wendhausen, Fig. 3.3). At the AF and MC systems of Dornburg, $80 \%$ of the flux magnitude originated from the respective system. The $90 \%$ flux magnitude contribution line at the AF system overlapped with the $90 \%$ flux magnitude contribution line at the MC system to the west. The overlapping footprint was also found for the annual footprint analyses (see Fig. 3.15 in Appendix 3.5.3).

At the $\mathrm{AF}$ and the MC system of Wendhausen, we observed a $80 \%$ flux magnitude contribution from both land uses to the total turbulent flux (Fig. 3.3). A $10 \%$ flux magnitude contribution originated from the forest around $200 \mathrm{~m}$ east of the flux tower. Easterly winds are most likely during stable atmospheric stratification in winter or summer. During the time of the experiment, the wind mainly originated from a westerly direction (not shown).

A total of $70 \%$ of the area of the AF and MC grassland systems of Mariensee contributed to the measured fluxes, respectively (Fig. 3.3). The remaining $20 \%$ of the area contributing to the measured flux originated from surrounding crops and the AF and MC grassland systems. There was an overlap of the two footprints at the AF and the MC grassland system, which was expected as both flux towers are separated by a distance of about $200 \mathrm{~m}$.

The fluxes measured at the smallest AF system in Reiffenhausen were influenced by fluxes originating from the nearby forests and crop fields at about a $400 \mathrm{~m}$ distance from the flux tower in a northerly direction and about $200 \mathrm{~m}$ distance in a southerly direction (Fig. 3.3). Only $60 \%$ of the fluxes originated from the willow-grassland AF system and the short rotation willow plantation in the west. The terrain at the AF system of Reiffenhausen is sloped towards the northwest. The main wind direction at the site was north-northwest in the direction of the sloped terrain. 

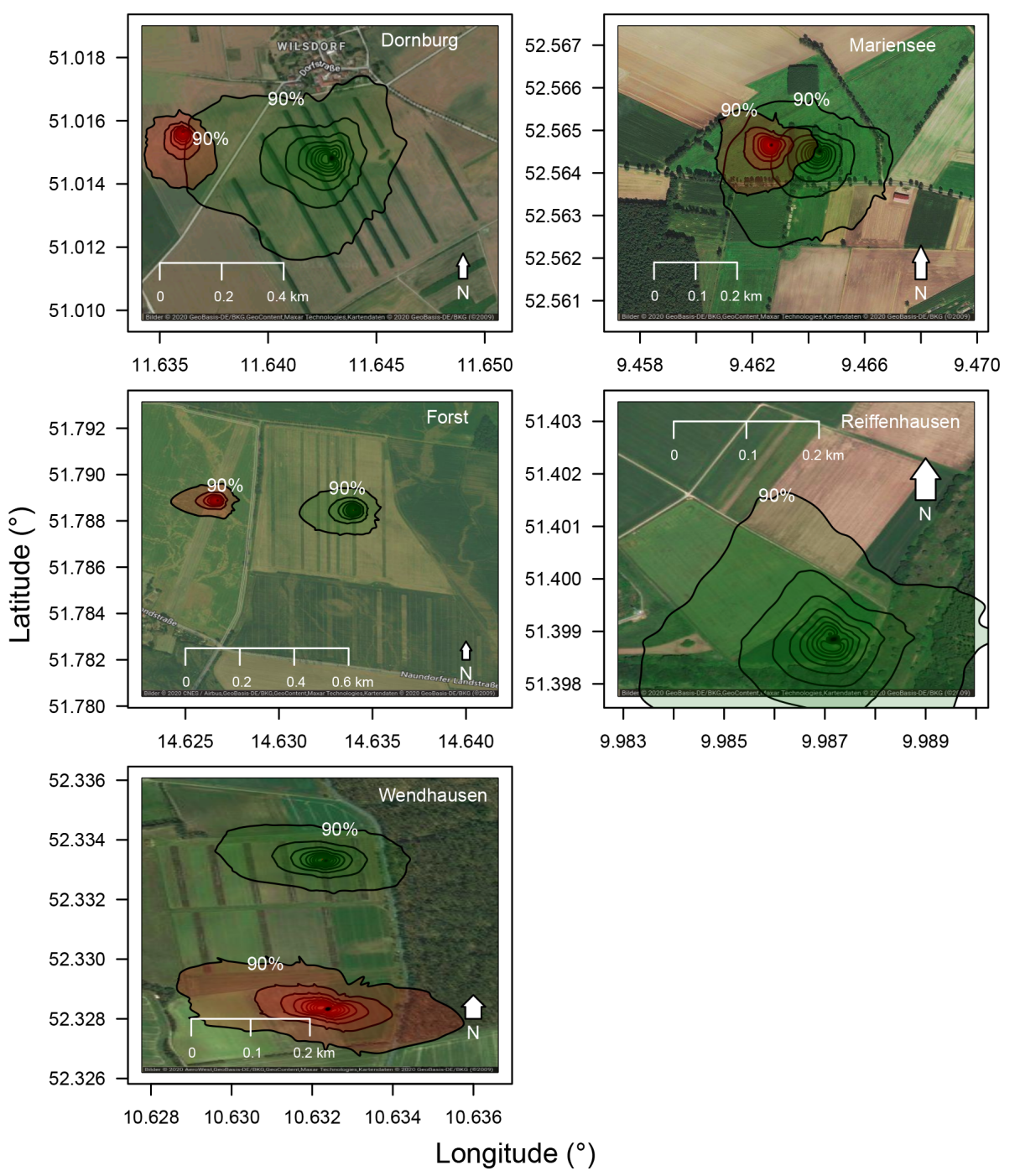

Figure 3.3: Flux footprint climatologies for all sites for the respective campaign period. Green shaded footprints correspond to the AF system, and red shaded footprints correspond to the MC system. For the analysis only daytime data were used $\left(R_{\mathrm{G}}>20 \mathrm{~W} \mathrm{~m}^{-2}\right)$. Isolines correspond to a $10 \%$ to $90 \%$ flux magnitude contribution in $10 \%$ steps, with the $90 \%$ isoline labelled in the system. The flux footprint climatology for Reiffenhausen MC is missing due to the unavailability of a campaign. Aerial photographs originate from Google Maps and Google Earth. (C) Google 2020.

\subsubsection{Diel evapotranspiration}

The diel variation of ET for all three set-ups at all sites is depicted in time series plots for an exemplary time period in Fig. 3.4.

The EC-LC set-up showed the best performance relative to direct EC measurements, with coefficients of determination between a minimum of $71 \%$ and a maximum of $94 \%$. The EC-LC set-up captured the temporal variability of ET and the flux response to changing 
ambient conditions as well as the direct EC measurements. The slopes from a linear regression analysis of $\mathrm{LE}_{\mathrm{EC}-\mathrm{LC}}$ vs. $\mathrm{LE}_{E C}$ showed an agreement between $86 \%$ and $99 \%$ across four AF systems and between $108 \%$ and $142 \%$ across four monoculture agriculture systems (see Table 3.4 and Fig. 3.14).

At the MC systems of Forst and Wendhausen (Fig. 3.4), we observed comparably high $\mathrm{ET}_{\mathrm{EC}-\mathrm{LC}}$ relative to direct $\mathrm{EC}$ measurements, while attaining high coefficients of determination. We suspect that the laser source of the LI-7200 gas analyser did not work as expected as indicated by the spectral analysis (data not shown). Only low-frequency fluctuations were sampled, whereas the high-frequency fluctuations were attenuated. The spectral response characteristics of the gas analyser and the thermohygrometer set-up were similar. Therefore, the correction of high-frequency losses is expected to be higher for the compromised gas analyser at the respective MC systems than for a fully functional gas analyser.

$\mathrm{ET}_{E C E B}$ also captured the diel cycle of ET and gave an indication of the ecosystem response to changing meteorological drivers (Fig. 3.4). $\mathrm{ET}_{E C E B}$ overestimated $\mathrm{ET}_{E C}$ across all sites. A minimum overestimation of $27 \%$ was observed at the AF system of Forst, and a maximum overestimation of $101 \%$ was observed at the MC system of Forst at a half-hourly timescale (see Table 3.4 and Fig. 3.13). Differences between $\mathrm{ET}_{E C E B}$ and $\mathrm{ET}_{E C}$ were attributed to the assumption of a fully closed energy balance at the surface (FOKEN et al., 2006). $\mathrm{ET}_{E C E B}$ was calculated as the residual of net radiation, sensible heat flux, ground heat flux, and soil storage. In this analysis, we did not account for the commonly observed non-closure of the energy balance and added the surface energy balance residual completely to LE. 


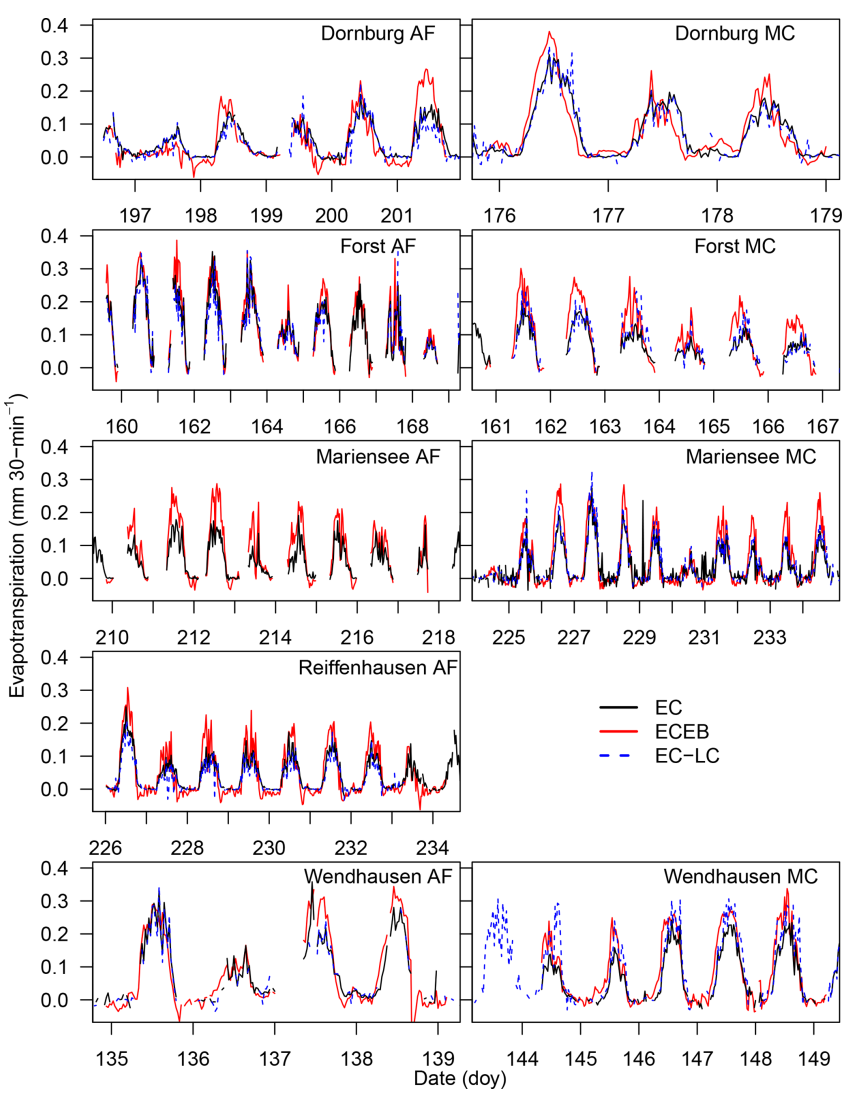

Figure 3.4: Time series of half-hourly evapotranspiration rates of an exemplary time period for ECEB, EC-LC, and EC as a reference for all sites. Time series of half-hourly ET rates for Reiffenhausen MC are missing due to the unavailability of a campaign, and $\mathrm{ET}_{\mathrm{EC}-\mathrm{LC}}$ at Mariensee AF are missing due to technical problems with the sensor during the campaign. The presented time series were not corrected for the energy balance non-closure. Gaps in nocturnal data are due to the limited power availability from the solar power supply.

\subsubsection{Energy balance closure (EBC)}

\subsubsection{EBC from EC and EC-LC}

The mean EBC was $79.4 \pm 8.5 \%$ and $79.25 \pm 6 \%$ across the five AF systems and four MC systems for $\mathrm{LE}_{E C}$ (see Fig. 3.5 and Table 3.5). The coefficient of determination, $R^{2}$, was a minimum of 0.77 and a maximum of 0.92 across sites (Table 3.5).

The $\mathrm{EBC}$ for $\mathrm{LE}_{E C}$ at the $\mathrm{AF}$ and the $\mathrm{MC}$ systems were comparable to agricultural systems as reported by STOY et al. (2013), who found a mean EBC of $84 \pm 20 \%$ across 173 FLUXNET sites, a mean EBC of $91 \%$ to $94 \%$ for evergreen broadleaf forests and savannas, and a mean EBC of $70 \%$ to $78 \%$ for crops, deciduous broadleaf forests, mixed forests, and wetlands. IMUKOva et al. (2016) found an EBC of $71 \%$ and $64 \%$ for two consecutive growing seasons over a winter wheat stand in Germany. Studying a belt and alley system in Australia, WARD et al. (2012) found an EBC between $67 \%$ and $80 \%$ over the time period of 6 months. FISCHER et al. (2018) reported on the water requirements of 
Table 3.4: Statistical analysis results for a linear regression of $\mathrm{LE}_{\mathrm{EC}-\mathrm{LC}} \mathrm{vs} . \mathrm{LE}_{E C}$ and $\mathrm{LE}_{E C E B}$ vs. $\mathrm{LE}_{E C}$. Shown here are the root mean square error (RMSE), the standard deviation of the differences between both set-ups (SD), the bias (Bias), the number of points used for the analysis $(n)$, the slope for a linear regression of $\mathrm{LE}_{\mathrm{EC}-\mathrm{LC}}$ vs. $\mathrm{LE}_{E C}$ and $\mathrm{LE}_{E C E B}$ vs. $\mathrm{LE}_{E C}$, and the coefficient of determination of the linear regression $\left(R^{2}\right)$. Data for $\mathrm{LE}_{\mathrm{EC}-\mathrm{LC}}$ at Mariensee AF are missing due to technical problems with the sensor during the campaign, and data for Reiffenhausen MC are missing due to the unavailability of a campaign.

\begin{tabular}{llrrrrrr}
\hline Sites & Method & RMSE $\left(\mathrm{W} \mathrm{m}^{-2}\right)$ & $\mathrm{SD}\left(\mathrm{W} \mathrm{m}^{-2}\right)$ & Bias $\left(\mathrm{W} \mathrm{m}^{-2}\right)$ & $n$ & Slope & $R^{2}$ \\
\hline Dornburg AF & ECEB/EC & 68.8 & 68.5 & -6.2 & 1200 & 1.97 & 0.45 \\
& EC-LC/EC & 35 & 31.9 & -11.2 & 1037 & 0.94 & 0.71 \\
\hline Dornburg MC & ECEB/EC & 73.8 & 73.8 & 2.1 & 1152 & 1.36 & 0.5 \\
& EC-LC/EC & 34.3 & 34.3 & 1.1 & 1030 & 1.08 & 0.86 \\
\hline Forst AF & ECEB/EC & 58.9 & 57 & 7.6 & 549 & 1.27 & 0.79 \\
& EC-LC/EC & 38.5 & 36.74 & -2.1 & 197 & 0.95 & 0.9 \\
\hline Forst MC & ECEB/EC & 74.7 & 61.9 & 18.5 & 612 & 2.01 & 0.7 \\
& EC-LC/EC & 37.9 & 34.5 & 5.3 & 461 & 1.42 & 0.8 \\
\hline Mariensee AF & ECEB/EC & 79.8 & 65.5 & 23.8 & 1503 & 2.0 & 0.78 \\
& EC-LC/EC & - & - & - & - & - & - \\
\hline Mariensee MC & ECEB/EC & 61.1 & 59.85 & 8.8 & 1852 & 1.42 & 0.75 \\
& EC-LC/EC & 44.6 & 43.9 & 4.6 & 1520 & 1.16 & 0.8 \\
\hline Reiffenhausen AF & ECEB/EC & 55.4 & 55.3 & 4.1 & 1395 & 1.65 & 0.74 \\
& EC-LC/EC & 27.8 & 23.6 & -2.7 & 279 & 0.86 & 0.9 \\
\hline Wendhausen AF & ECEB/EC & 67.9 & 67.5 & 4.9 & 954 & 1.3 & 0.8 \\
& EC-LC/EC & 33.5 & 32.7 & -3.1 & 586 & 0.99 & 0.94 \\
\hline \multirow{2}{*}{ Wendhausen MC } & ECEB/EC & 73.5 & 61.4 & 24.1 & 792 & 1.41 & 0.85 \\
& EC-LC/EC & 57.9 & 47 & 15.53 & 604 & 1.3 & 0.89 \\
\hline
\end{tabular}

three short rotation poplar stands and found a mean long-term energy balance closure of $82 \%$ at a site in Italy, an EBC of $91 \%$ or $95 \%$ at a site in the Czech Republic, and an $\mathrm{EBC}$ of $69 \%$ at a site in Belgium.

The $\mathrm{EBC}$ for $\mathrm{LE}_{\mathrm{EC}-\mathrm{LC}}$ was slightly lower at the $\mathrm{AF}$ systems with a mean $\mathrm{EBC}$ of $79 \pm 5.3 \%$ compared to the MC systems with a mean EBC of $82 \pm 11.8 \%$ for five sites. The differentiation into lower EBC at the $\mathrm{AF}$ and higher $\mathrm{EBC}$ at $\mathrm{MC}$ systems observed for the two different set-ups is in agreement with the linear regression results presented in Sect. 3.3.3. At the AF systems, $\mathrm{LE}_{\mathrm{EC}-\mathrm{LC}}$ was lower than $\mathrm{LE}_{E C}$. In the calculation of the energy balance closure only LE was changed, and the other energy balance components were held constant. Therefore, increased LE led to a decreased residual energy and, subsequently, to a better fit of the energy balance closure. 


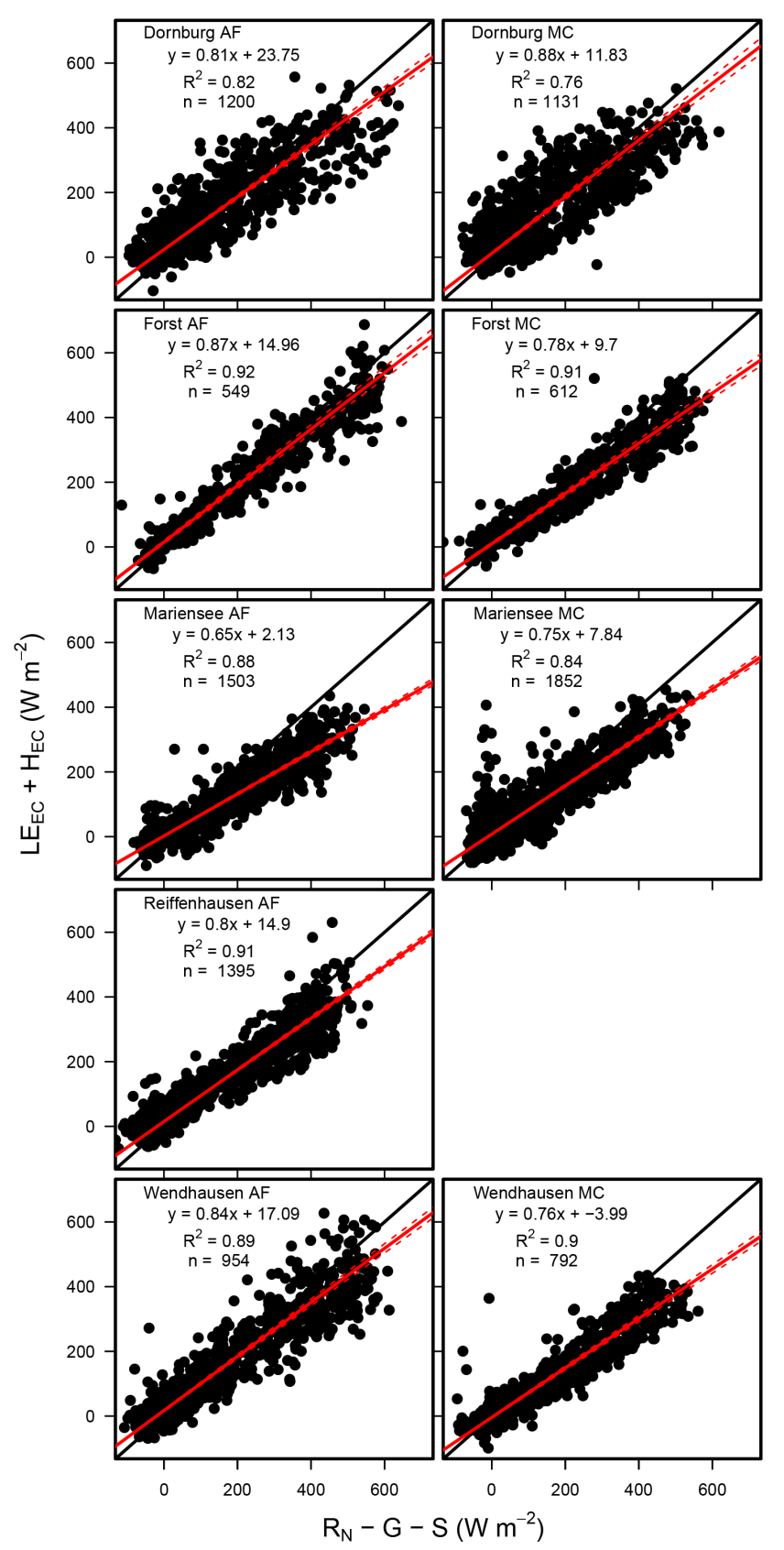

Figure 3.5: Scatterplot of the sum of the turbulent fluxes $\left(\mathrm{LE}_{E C}+\mathrm{H}_{\mathrm{EC}}\right)$ vs. the sum of the available energy $\left(\mathrm{R}_{\mathrm{N}}-G-S\right)$ for all sites. Each plot contains the linear regression equation, the coefficient of determination $\left(R^{2}\right)$, and the number of data points used for the analysis $(n)$. Data for Reiffenhausen MC are missing due to the unavailability of a campaign.

\subsubsection{Diel cycles of the energy balance ratio and the energy balance residual}

The diel cycle of the energy balance ratio from $\mathrm{LE}_{E C}$ at the sites can be classified into two different patterns. The diel cycle of the EBR for Dornburg (Fig 3.6) shows a strong 
Table 3.5: Statistical analysis results of the linear regression between the sum of the turbulent fluxes and the available energy, namely the sites, the set-up used, the slope $( \pm 5 \%$ confidence interval), the intercept, the coefficient of determination of the linear regression $\left(R^{2}\right)$, and the number of points used for the analysis $(n)$. The energy balance closure determined by EC-LC at Mariensee AF is based on data collected from 23 March to 20 November 2016, and at Reiffenhausen MC, the analyses are based on data collected from 7 April to 31 December 2016 due to the unavailability of data during the campaigns. The energy balance closure determined by EC for Reiffenhausen MC is missing due to the unavailability of a campaign.

\begin{tabular}{llrrrr}
\hline Sites & Set-up & Slope & Intercept $\left(\mathrm{W} \mathrm{m}^{-2}\right)$ & $R^{2}$ & $n$ \\
\hline Dornburg AF & EC & $0.81 \pm 0.02$ & $23.75 \pm 1.95$ & 0.82 & 1200 \\
& EC-LC & $0.75 \pm 0.03$ & $17.3 \pm 2.6$ & 0.72 & 1088 \\
\hline Dornburg MC & EC & $0.88 \pm 0.025$ & $11.83 \pm 3.1$ & 0.76 & 1131 \\
& EC-LC & $0.90 \pm 0.035$ & $12.03 \pm 4.2$ & 0.70 & 1046 \\
\hline Forst AF & EC & $0.87 \pm 0.02$ & $14.96 \pm 5.1$ & 0.92 & 549 \\
& EC-LC & $0.81 \pm 0.045$ & $17.2 \pm 11.1$ & 0.85 & 205 \\
\hline Forst MC & EC & $0.78 \pm 0.02$ & $9.7 \pm 4.4$ & 0.91 & 612 \\
& EC-LC & $0.85 \pm 0.03$ & $10.3 \pm 7.9$ & 0.85 & 486 \\
\hline Mariensee AF & EC & $0.65 \pm 0.01$ & $2.13 \pm 1.63$ & 0.88 & 1503 \\
& EC-LC & $0.85 \pm 0.009$ & $-1 \pm 0.6$ & 0.85 & 6525 \\
\hline Mariensee MC & EC & $0.75 \pm 0.015$ & $7.8 \pm 1.2$ & 0.84 & 1852 \\
& EC-LC & $0.82 \pm 0.015$ & $7.7 \pm 1.4$ & 0.88 & 1632 \\
\hline Reiffenhausen AF & EC & $0.80 \pm 0.01$ & $14.94 \pm 1.2$ & 0.91 & 1395 \\
& EC-LC & $0.72 \pm 0.03$ & $10.55 \pm 3.1$ & 0.91 & 306 \\
\hline Reiffenhausen MC & EC & & & - & - \\
& EC-LC & $0.62 \pm 0.005$ & $5.7 \pm 0.35$ & 0.84 & 9717 \\
\hline Wendhausen AF & EC & $0.84 \pm 0.02$ & $17.1 \pm 2.8$ & 0.89 & 954 \\
& EC-LC & $0.82 \pm 0.03$ & $13.8 \pm 4.4$ & 0.84 & 641 \\
\hline Wendhausen MC & EC & $0.76 \pm 0.02$ & $-3.9 \pm 2.6$ & 0.9 & 792 \\
& EC-LC & $0.91 \pm 0.025$ & $3.1 \pm 4.4$ & 0.85 & 710 \\
\hline
\end{tabular}

increase between 06:00 and 08:00 local time (LT), followed by a positive slope between 08:00 and 14:00, and a strong increase thereafter until 18:00. The EBR is a minimum of 0 at 06:00 and a maximum of 1.8 at 18:00. The diel cycle of the EBR at the remaining sites (Forst, Mariensee, Reiffenhausen, and Wendhausen; Fig. 3.6) is the lowest at 06:00 and 18:00 with an EBR of 0.5, whereas between 08:00 and 16:00 the EBR is fairly constant and at a similar range as the EBC estimated for all sites and the whole campaign (Table 3.5).

The Dornburg site might be affected by the horizontal advection of moisture and heat. ONCLEY et al. (2007) reported that the advection of moisture had the highest contribution to the unclosed energy balance compared to the other components. The maximum peak of the horizontal moisture advection term was in the afternoon, as energy was accumulated during the day and released in the afternoon. We suspect that this is also the case for the Dornburg site. The sensible heat flux follows the diurnal cycle of available energy, with the maximum peak at midday at the agroforestry and the monoculture system (Fig. 3.7). In 
contrast, the median of the latent heat flux had its maximum in the afternoon at around 14:00 and was positive even after the available energy changed its sign.

In addition to advective transport, the unclosed surface energy balance could be related to energy storage terms such as biomass, the air, or photosynthesis (J ACOBS et al., 2008), which have not been considered previously. The pattern seen at Dornburg may be attributed to a release of energy during the afternoon, which corresponds to a surplus of energy and a better closure of the energy balance. In the morning hours, the storage terms have an opposite sign, which corresponds to a lack of energy and a subsequent poorer energy balance closure. Considering the storage terms would lead to a reduction in the residual energy and a better closure of the energy balance.

Interestingly, the diel pattern of the EBR from $\mathrm{LE}_{E C}$ at both land uses at all sites are equal. Additionally, the differences between the median diel cycle EBRs (between 06:00 and 18:00) at the $\mathrm{AF}$ and the MC system were small, with differences of a minimum of -0.09 and a maximum of 0.13 across sites. As both flux towers located at the AF and the MC system at one site are separated by approximately 100 to $500 \mathrm{~m}$ and the diel patterns look similar, we suspect that the non-closed surface energy balance at one site is caused by local effects of a longer wavelength than the commonly applied averaging period of $30 \mathrm{~min}$ and is thus beyond the individual site level.

The diel cycles of the EBRs and the residuals were similar for both EC-LC and EC set-ups (Fig. 3.16). This is promising, as it indicates, first, a performance of EC-LC comparable to EC, and, second, the capability of the EC-LC set-up to capture site-specific effects. Nevertheless, the observed differences between EBRs and residuals at the AF and $\mathrm{MC}$ at one site were mostly attributed to differences in LE. Higher $\mathrm{LE}_{\mathrm{EC}-\mathrm{LC}}$ than $\mathrm{LE}_{E C}$ led to higher EBRs. 


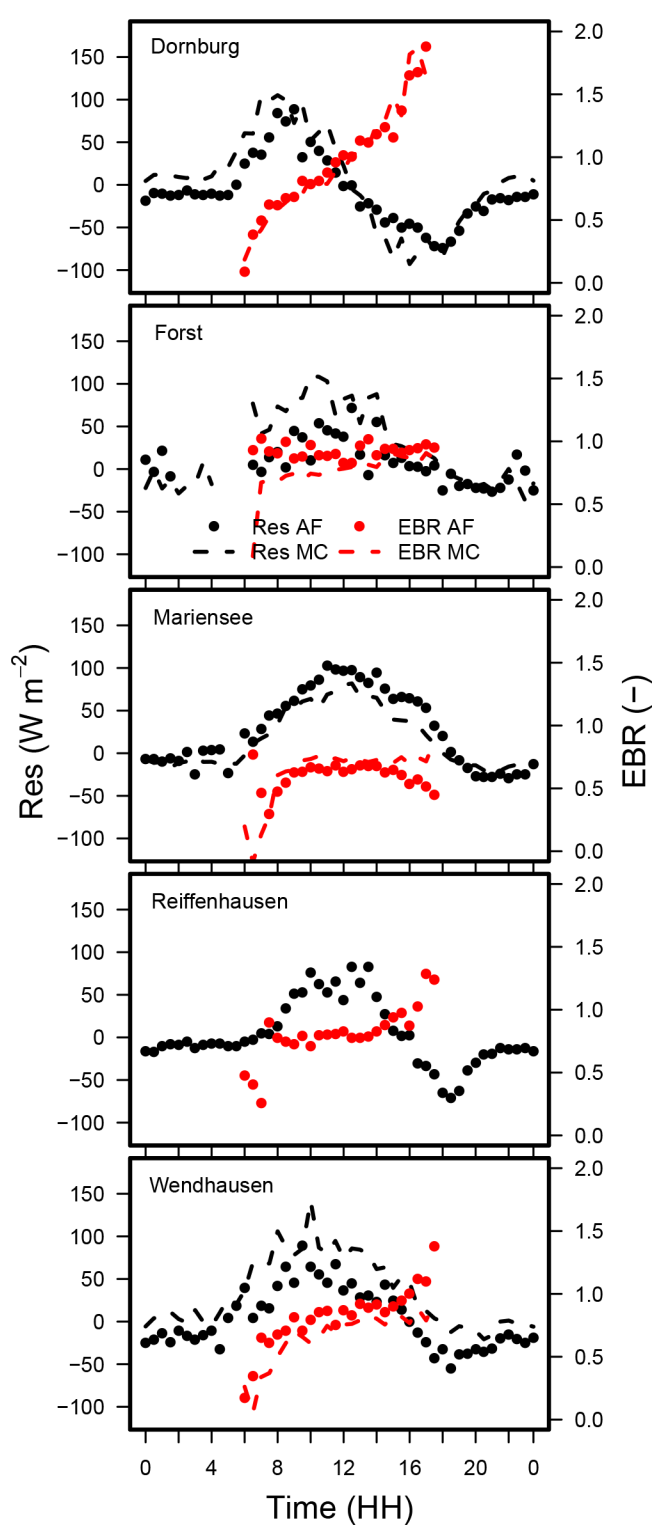

Figure 3.6: Median diel cycle of the energy balance ratio (EBR) and diurnal cycle of the residual energy for the $\mathrm{AF}$ and the MC systems at all sites. LE and $H$ were obtained by EC. Data from Reiffenhausen MC are missing due to the unavailability of a campaign.

\subsubsection{Evapotranspiration over agroforestry}

\subsubsection{Sums of evapotranspiration during the campaigns}

Sums of evapotranspiration for all three methods, all sites, and campaign periods indicate higher sums of $\mathrm{ET}_{E C E B}$ relative to $\mathrm{ET}_{E C}$, except for Dornburg AF (Fig. 3.8). The difference between sums of $\mathrm{ET}_{E C E B}$ and $\mathrm{ET}_{E C}$ reflects the unaccounted correction of $\mathrm{ET}_{E C}$ and $\mathrm{ET}_{E C E B}$ for the energy balance non-closure. The large difference between sums of $\mathrm{ET}_{E C E B}$ and $\mathrm{ET}_{E C}$ at Mariensee $\mathrm{AF}$ correspond to the low energy balance closure of 


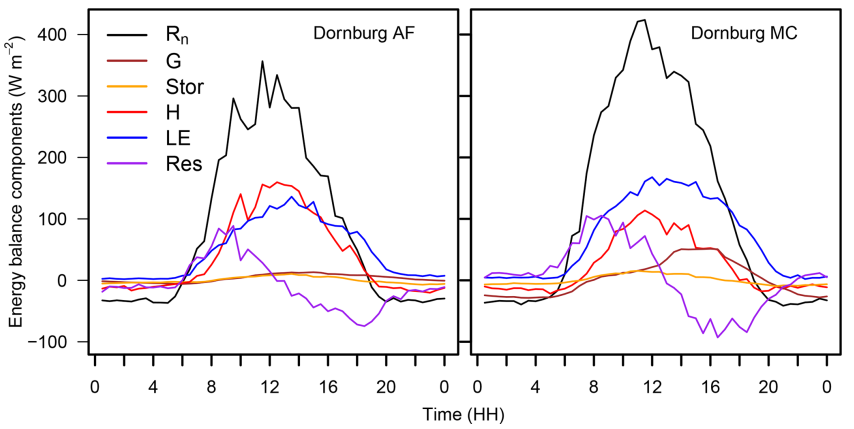

Figure 3.7: Median diurnal cycle of the energy balance components for Dornburg AF and MC for the campaign times (see Table 3.7).

$65 \%$ at the site. Differences between sums of $\mathrm{ET}_{\mathrm{EC}-\mathrm{LC}}$ and $\mathrm{ET}_{E C}$ correspond to lower $\mathrm{ET}_{\mathrm{EC}-\mathrm{LC}}$ than $\mathrm{ET}_{E C}$ over the $\mathrm{AF}$ systems and higher $\mathrm{ET}_{\mathrm{EC}-\mathrm{LC}}$ than $\mathrm{ET}_{E C}$ over the $\mathrm{MC}$ systems. This is indicated by slopes smaller and higher than one of a linear regression analysis between $\mathrm{ET}_{\mathrm{EC}-\mathrm{LC}}$ and $\mathrm{ET}_{E C}$ (Table 3.4).

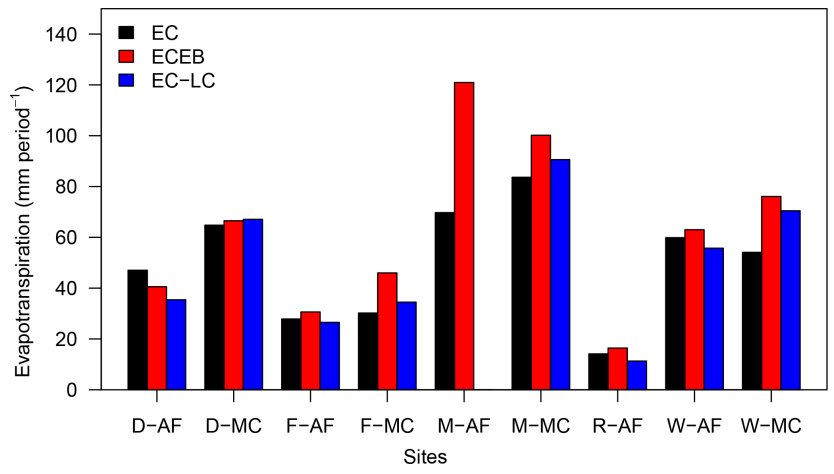

Figure 3.8: Sums of uncorrected and not gap-filled half-hourly evapotranspiration for all three methods and all sites during the campaign periods. Sites are abbreviated by their first letter and are identified as being either AF (agroforestry) or MC (monoculture). Incomplete records with $\mathrm{ET}_{E C}, \mathrm{ET}_{E C E B}$, or $\mathrm{ET}_{\mathrm{EC}-\mathrm{LC}}$ missing were omitted. Data for $\mathrm{ET}_{\mathrm{EC}-\mathrm{LC}}$ at Mariensee $\mathrm{AF}$ are missing due to technical problems with the sensor during the campaign, and all data for Reiffenhausen MC are missing due to the unavailability of a campaign.

\subsubsection{Weekly sums of evapotranspiration}

The annual cycle of evapotranspiration across all sites and for the years 2016 and 2017 depicts the typical seasonal cycle of the highest ET during summer and the lowest ET during winter (Fig. 3.9). We found small differences between the weekly sums of ET at the $\mathrm{AF}$ and the MC systems during the main growing period of the crops. After the ripening of the crops, we found higher weekly sums of ET at the AF systems compared to the MC systems at the cropland sites of Dornburg, Forst, and Wendhausen (Fig. 3.9). We assume that, after the ripening of the crops, evaporation contributed the most to the measured ET at the MC system, whereas at the AF system both evaporation from the crop fields between the tree strips and transpiration from the trees contributed to the measured flux. 
At the grassland sites of Mariensee and Reiffenhausen (Fig. 3.9), differences in the weekly sums of ET between both land uses were small, with a tendency towards higher ET rates at the MC system compared to the AF system.

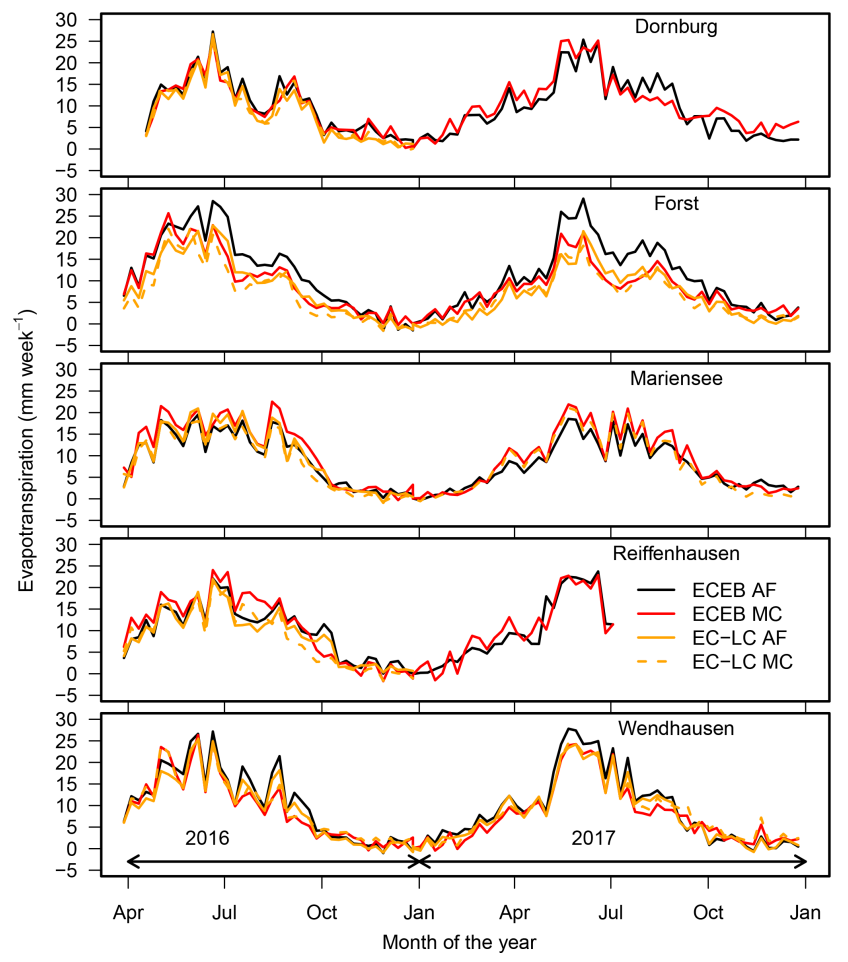

Figure 3.9: Weekly sum of half-hourly $\mathrm{ET}_{E C E B}$ (black and red solid lines for $\mathrm{AF}$ and $\mathrm{MC}$, respectively) and $\mathrm{ET}_{\mathrm{EC}-\mathrm{LC}}$ (orange solid and dashed lines for $\mathrm{AF}$ and $\mathrm{MC}$, respectively) for all sites. In 2017, data in Reiffenhausen AF and MC were only available until the end of July due to station failure.

\subsubsection{Annual sums of evapotranspiration}

Differences between the annual sums of ET for the two land uses, AF and MC, were in the range of a maximum of $+31 \%$ and a minimum of $-16 \%$ (see Fig. 3.10 and Table 3.6) across sites and methods. We wanted to understand where differences between annual sums of ET come from. Therefore, we investigated differences between ET according to (1) the effect of the different land uses, i.e. AF and MC, (2) the effect of different methods, i.e. EC-LC and ECEB, and (3) the effect of different years, i.e. 2016 and 2017, with different precipitation inputs. For this purpose, we used the relationship between the evapotranspiration index $\left(\sum \mathrm{ET} / \sum P\right)$ and the radiative dryness index $\left(R_{\mathrm{N}} / \lambda P\right)$ proposed by Budyko (BuDYKo, 1974). Figure 3.11a shows the ET index as a function of the radiative dryness index for all sites, both set-ups, and both years.

The figure indicates, first, that plots with an ET index larger than one were water limited, corresponding to an radiative dryness index $R_{\mathrm{N}} / \lambda P>1$. Second, the figure shows a separation between the sites with an energy limitation $\left(R_{\mathrm{N}} / \lambda P<1\right)$ and water limitation $\left(R_{\mathrm{N}} / \lambda P>1\right)$ for the years 2016 and 2017 , respectively. 


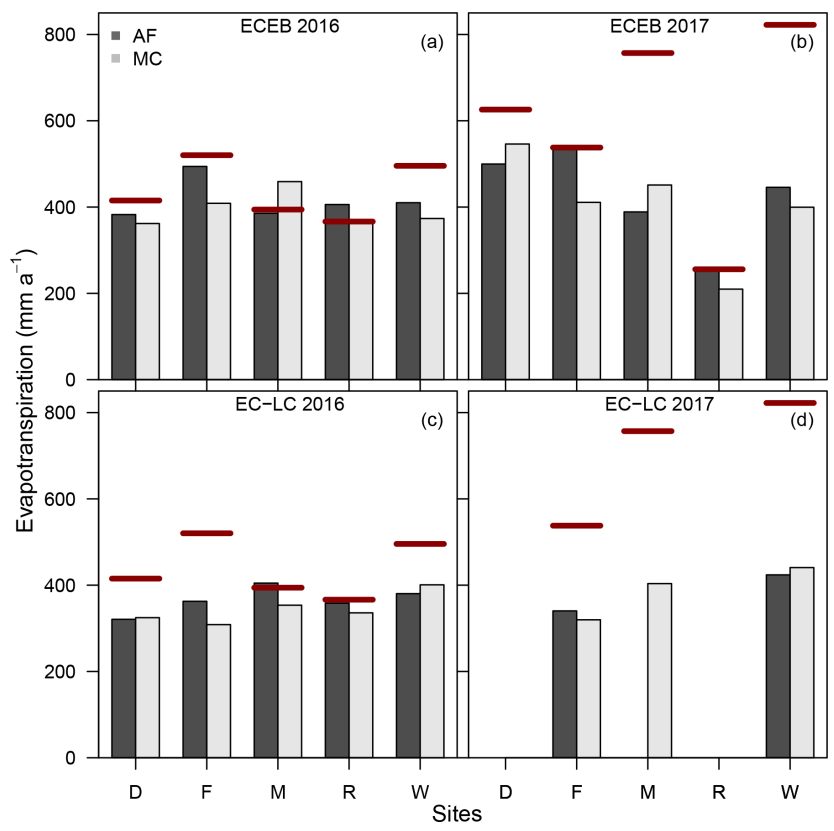

Figure 3.10: Annual sums of $\mathrm{ET}_{E C E B}$ in 2016 (a) and 2017 (b) and $\mathrm{ET}_{\mathrm{EC}-\mathrm{LC}}$ in 2016 (c) and 2017 (d) for Dornburg (D), Forst (F), Mariensee (M), Reiffenhausen (R), and Wendhausen (W). The red solid lines correspond to the annual sum of precipitation from the monoculture system of the respective site. The annual sums of evapotranspiration at Reiffenhausen AF and Reiffenhausen MC in 2017 contain only data from 1 January to 9 July 2017 due to station failure. Annual sums of $\mathrm{ET}_{\mathrm{EC}-\mathrm{LC}}$ for Dornburg AF and MC, Mariensee AF, and Reiffenhausen $\mathrm{AF}$ and $\mathrm{MC}$ in 2017 are missing due to instrument malfunctions.

With regards to the first finding, in 2016 the grassland site of Mariensee MC and Reiffenhausen AF and MC had an ET index larger than one. At those sites, the annual sum of ET was generally high relative to the annual sum of precipitation (Fig. 3.17a). This finding seems to be typical for grasslands. WiLLIAMs et al. (2012) reported that there was on average a $9 \%$ higher transformation of precipitation into evapotranspiration at grasslands compared to forests across 167 sites as part of FLUXNET, the global flux measurement network. They concluded, first, that higher ET of grasslands may have been caused by the less conservative water use compared to trees, and second, that it could indicate that grasses have an extensive, well-developed root system similar to trees. Nevertheless, considering the water balance equation with precipitation equalling the sum of evapotranspiration and water runoff, an ET index larger than one indicates water losses via ET and no runoff. An ET index larger than one is only to be expected under groundwater access, irrigation, or the impact of a nearby stream. At the grassland site of Mariensee it is likely that the trees and grasses had groundwater access, as the groundwater table was at about a $1.5-2 \mathrm{~m}$ depth.

The AF system in Reiffenhausen is located on a gentle slope with no groundwater access, which we expect should promote run-off, contrary to the high ET index observed. But the ET measurements are affected by a poplar and willow SRC in the south-southeast 
Table 3.6: Annual sums of energy balance closure corrected actual evapotranspiration, ET $\left(\mathrm{mma}^{-1}\right)$, and precipitation, $P\left(\mathrm{~mm} \mathrm{a}^{-1}\right)$ for all sites, both set-ups (ECEB and EC-LC), and both years (April to December 2016; January to December 2017). The annual sums of $\mathrm{ET}_{E C E B}$ and precipitation at Reiffenhausen $\mathrm{AF}$ and $\mathrm{MC}$ in 2017 contain data from 1 January to 1 July 2017 due to the destruction of the station. Annual sums of $\mathrm{ET}_{\mathrm{EC}-\mathrm{LC}}$ for Dornburg AF and MC, Mariensee AF, and Reiffenhausen AF and MC in 2017 are missing due to instrument malfunctions.

\begin{tabular}{|c|c|c|c|c|c|c|}
\hline \multirow{2}{*}{$\begin{array}{l}\text { Method } \\
\text { Sites }\end{array}$} & \multicolumn{2}{|c|}{ ECEB } & \multicolumn{2}{|c|}{ EC-LC } & \multirow[b]{2}{*}{ P 2016} & \multirow[b]{2}{*}{$P 2017$} \\
\hline & ET 2016 & ET 2017 & ET 2016 & ET 2017 & & \\
\hline Dornburg AF & 383 & 500 & 321 & - & 414 & 626 \\
\hline Dornburg MC & 362 & 546 & 325 & - & 414 & 626 \\
\hline Forst AF & 494 & 540 & 363 & 340 & 520 & 538 \\
\hline Forst MC & 409 & 411 & 309 & 320 & 520 & 538 \\
\hline Mariensee AF & 386 & 389 & 405 & - & 394 & 757 \\
\hline Mariensee MC & 459 & 451 & 354 & 404 & 394 & 757 \\
\hline Reiffenhausen AF & 406 & 252 & 358 & - & 366 & 256 \\
\hline Reiffenhausen MC & 368 & 210 & 336 & - & 366 & 256 \\
\hline Wendhausen AF & 410 & 446 & 380 & 424 & 496 & 822 \\
\hline Wendhausen MC & 373 & 400 & 401 & 440 & 496 & 822 \\
\hline
\end{tabular}

and north-northwest directly within the flux footprint (see Sect. 3.3.2 and Fig. 3.3). And with respect to the overall area of the AF system, the area covered by trees amounts to $72 \%$ and is much higher compared to the other sites (Table 3.1). In both cases, a radiative dryness index larger than one is also possible, despite this indicating a water limitation at the particular sites. Additionally this also indicates a surplus of radiative energy, which promotes photosynthesis and higher transpiration, assuming that soil water is not limited. In contrast, the Mariensee and Wendhausen sites had evapotranspiration and radiative dryness indices of approximately 0.5 and 0.6 in 2017. Those sites were affected by exceptionally high annual precipitation events, but annual sums of ET were comparable to 2016 (Table 3.6).

The second finding gives evidence of a dependency of ET on the local climate. The years 2016 and 2017 correspond to a dry and a wet year, respectively. In Fig. 3.11a and b, arrows indicate the difference between mean evapotranspiration indices and mean radiative dryness indices grouped by year, method, and land use. The length of the arrows corresponds to the overall difference. The ET index averaged over all annual sums of ET for the years 2016, and 2017 showed the largest difference, with a trend from a water-limited (2016) regime to an energy-limited (2017) regime. Higher available energy and lower precipitation than normal in 2016 led to a higher radiative dryness index, whereas lower available energy and higher precipitation led to a smaller radiative dryness index in 2017. Differences between mean ET indices from the two methods had the second largest impact on annual sums, with a trend of a higher mean ET index of $\mathrm{ET}_{E C E B}$ compared to $\mathrm{ET}_{\mathrm{EC}-\mathrm{LC}}$. The land use type had the least impact on differences between the ET indices, with a small trend of higher $\mathrm{ET} / P$ over $\mathrm{AF}$ than over $\mathrm{MC}$. 
However, our results indicate that the effect of agroforestry on ET is small compared to differences between methods and differences between years with different precipitation regimes. We therefore reject the initial hypothesis that short rotation alley cropping agroforestry systems lead to higher water losses to the atmosphere via ET, compared to monoculture agriculture without trees.
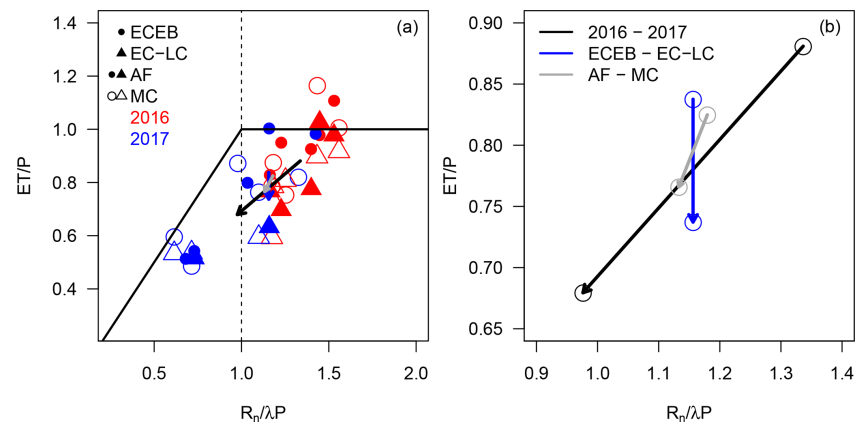

Figure 3.11: (a) Evapotranspiration index $(\mathrm{ET} / P)$ vs. the radiative dryness index $\left(R_{\mathrm{N}} / \lambda P\right)$ for both land uses (AF - filled triangles and dots; $\mathrm{MC}$ - empty triangles and dots), both set-ups (ECEB - dots; EC-LC - triangles), and both years (2016 - red; 2017 - blue). The bold black line describes the regions of an energy limitation $\left(R_{\mathrm{N}} / \lambda P<1\right)$ and a water limitation $\left(R_{\mathrm{N}} / \lambda P>1\right)$. The arrows indicate the mean trends of ET for the effect of different years (black arrow), different methods (blue arrow), and different land uses (grey arrow). (b) Trends of the mean evapotranspiration index $(\mathrm{ET} / P)$ vs. the mean radiative dryness index $\left(R_{\mathrm{N}} / \lambda P\right)$ for the effect of different years (black), different methods (blue), and different land uses (grey) extracted from (a).

\subsubsection{Effect of agroforestry on ET as explained by aerodynamic and canopy resistance}

We wanted to understand if the heterogeneity of the AF systems can explain the differences between half-hourly ET rates from AF relative to MC systems. We quantified the effect of surface heterogeneity on ET as per the relationship between half-hourly ET rates and aerodynamic and canopy resistances. Tree strips orientated perpendicularly to the prevailing wind direction significantly reduce the wind speed (BöHM et al., 2014) and the aerodynamic resistance (LINDROTH, 1993). The canopy resistance depends linearly on the aerodynamic resistance and is part of the first term of Eq. (3.21). If the first term on the right-hand side of Eq. (3.21) is high, the canopy resistance is high, and evapotranspiration is controlled by atmospheric processes. Whereas if the aerodynamic resistance is low, the second term on the right-hand side of Eq. (3.21) dominates, i.e. ET is mainly controlled by the plant's physiology.

Mean aerodynamic resistances $\left(r_{\mathrm{ah}}\right)$ were lower at the AF systems compared to the MC systems (Fig. 3.12). We interpret this as an effect of the higher roughness incurred by the higher tree alleys compared to the MC system. As an example, we derived an aerodynamic resistance for two different canopy heights of 1 and $5 \mathrm{~m}$. We assumed a constant wind speed $\left(u=2 \mathrm{~m} \mathrm{~s}^{-1}\right)$, universal constants for momentum $\left(\psi_{\mathrm{m}}=0.9\right)$ and heat $\left(\psi_{\mathrm{h}}=0.4\right)$, a measurement height $(z)$ of $10 \mathrm{~m}$, and a displacement height $(d)$ of 0.7 and $3.5 \mathrm{~m}$ for a canopy height of 1 and $5 \mathrm{~m}$, respectively. We derived a roughness length for momentum and heat of 0.1 and $0.01 \mathrm{~m}$ for a canopy height of $1 \mathrm{~m}$ and of 0.5 and $0.05 \mathrm{~m}$ for a canopy 
height of $5 \mathrm{~m}$. Subsequently, we arrived at an aerodynamic resistance of $41.5 \mathrm{~s} \mathrm{~m}^{-1}$ for a canopy height of $1 \mathrm{~m}$ and of $10.3 \mathrm{~s} \mathrm{~m}^{-1}$ for a canopy height of $5 \mathrm{~m}$. Thus, an increase in canopy height of $4 \mathrm{~m}$ led to a decrease in aerodynamic resistance of $75.2 \%$.

The relationship between half-hourly evapotranspiration rates and the canopy resistance at the sites followed an exponential function (Fig. 3.12). The differences between the mean canopy resistances at the $\mathrm{AF}$ and $\mathrm{MC}$ systems were much smaller than the differences in mean aerodynamic resistances at the $\mathrm{AF}$ and $\mathrm{MC}$ systems. This suggests that the $\mathrm{AF}$ and MC systems behave in a similar way, from a plant's physiological point of view, regarding the stomatal control of both the trees and crops.

In the current study, the differences between the annual sums of ET over AF and MC were small. Effects of AF on evapotranspiration rates are mostly attributed to a small region next to the tree strips (KANZLER et al., 2018), i.e. the quiet zone. There, the reduction in wind velocity and incident radiation is strongest, and this causes a reduction in evapotranspiration. The quiet zone extends to roughly 4 to 12 times the tree height (NuberG, 1998). The quiet zone changes to the wake zone, where the wind velocity increases and light is no longer limited; hence, evapotranspiration increases towards the centre between tree strips (KANZLER et al., 2018). As a result, lower ET in the quiet zone and higher ET in the wake zone might compensate each other on a system scale, leading to ET over AF comparable to ET over MC. A similar effect occurs when ET is measured over a whole AF system with, for example, the EC method (BALDOCCHI, 2003). EC measurements integrate over a larger area, and small-scale differences in between tree strips cannot be detected. 


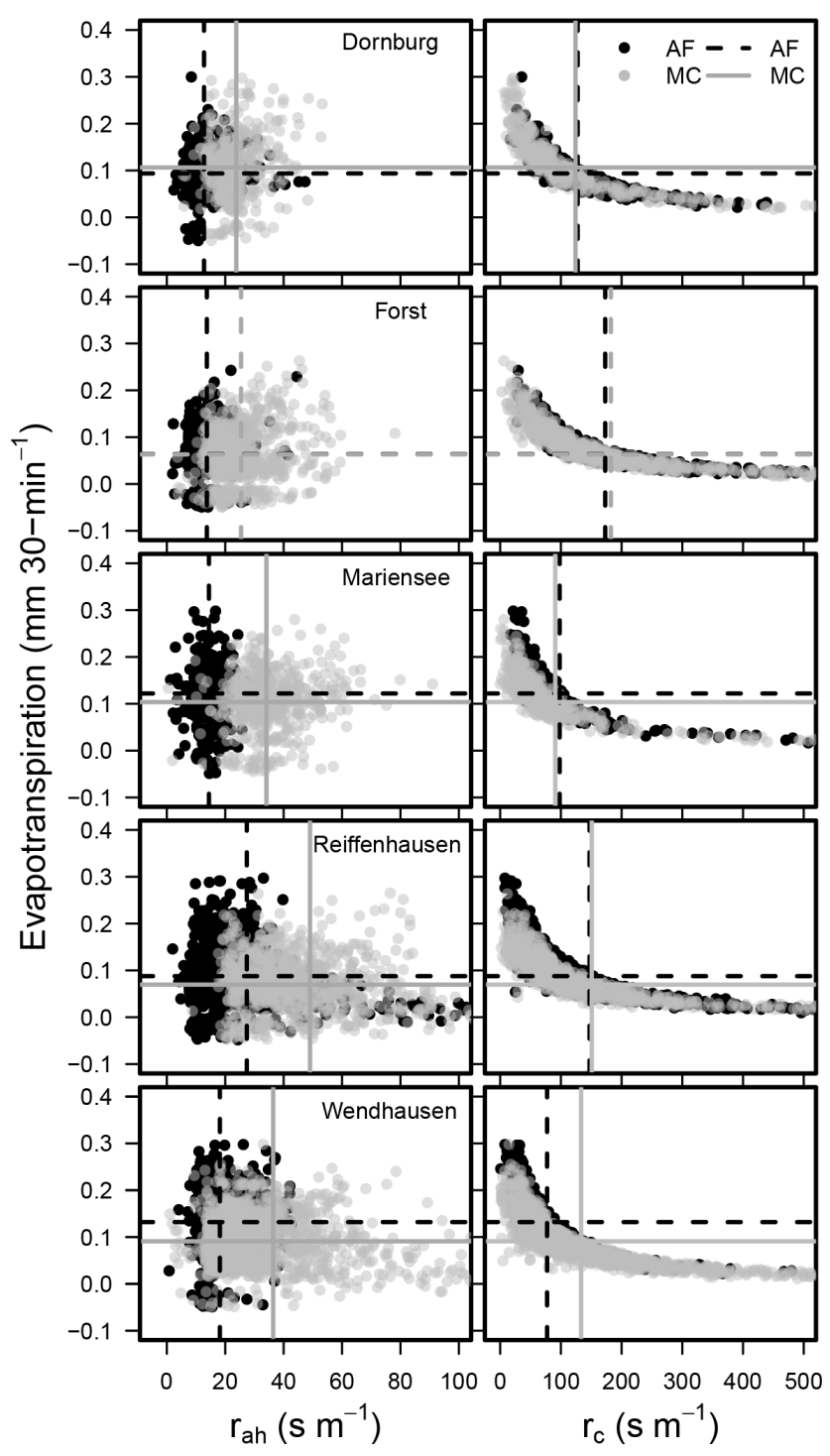

Figure 3.12: Half-hourly $\mathrm{ET}_{\mathrm{EC}-\mathrm{LC}}$ vs. aerodynamic resistance ( $r_{\mathrm{ah}}$; left) and canopy resistance $\left(r_{\mathrm{c}}\right.$; right) for all sites. The dashed grey line corresponds to the mean aerodynamic and canopy resistance and evapotranspiration at the AF system, and the dashed black line corresponds to the mean aerodynamic and canopy resistance and evapotranspiration at the MC system at the specific site. Only data corresponding to ideal ambient conditions are shown, e.g. global radiation $\left(R_{\mathrm{G}} \geq 400 \mathrm{~W} \mathrm{~m}^{-2}\right)$, wind speed $\left(u \geq 1 \mathrm{~ms}^{-1}\right)$, and vapour pressure deficit ( $D=1 \pm 0.3 \mathrm{kPa}$; SchmidT-WALter et al., 2014).

\subsubsection{Uncertainty and limitations of ET measurements over AF}

As outlined in the previous section, differences in annual sums of ET between the different land uses were small. Besides the discussed ecological reasons, we are aware of measurement errors due to the heterogeneous terrain (FOKEN, 2008a). The most critical assumptions of the eddy covariance method are horizontally homogeneous terrain and steady state ambient 
conditions (FOKEn, 2008a; FOKEn et al., 2006). It is assumed that the heterogeneities generate turbulent motions of a longer timescale than the commonly applied averaging period of half an hour. This is also strongly connected to horizontal advection, which is commonly not properly represented in eddy covariance flux measurements. FoKEN et al. (2006) noted that the eddy covariance method is the most accurate method, with errors between $5 \%$ and $10 \%$, depending on the turbulent conditions. The errors are higher during the nighttime due to limited turbulent conditions, causing a common flux underestimation (AuBinET et al., 2010). But during the night especially ET is small, and the effect of high errors is small compared to the daytime conditions when ET is high.

For the low-cost eddy covariance set-up we anticipate higher errors compared to direct EC due to the limited time response of the thermohygrometer and, subsequently, higher spectral correction factors (MARKWITZ et al., 2019). We found that the effect of heterogeneity on ET is less important for EC-LC than the effect of different measurement heights (MARKWITZ et al., 2019). For a measurement height of $3.5 \mathrm{~m}$, we found a latent heat flux underestimation compared to direct EC, and for a measurement height of $10 \mathrm{~m}$, we found a slight latent heat flux overestimation (Table 3.4). At a lower height the contribution of small and high-frequency fluctuations to the energy spectrum is higher. Due to the limited time response of the thermohygrometer between 1.9 and 3.5 s (MARKWITZ et al., 2019), the high-frequency eddies cannot be adequately detected, and the signal losses are higher.

In contrast, $\mathrm{ET}_{E C E B}$ might be affected by greater errors than $\mathrm{ET}_{\mathrm{EC}-\mathrm{LC}}$ due to multiple error sources inferred from each of the energy balance components, the assumption of a fully closed energy balance, and resulting inaccuracies from the energy balance residual partitioning. For the ECEB set-up the heterogeneity of the landscape has a larger impact than for the EC-LC set-up, such as net radiation and ground heat flux measurements are not representative for the whole landscape.

Although errors for ET measurements with the respective set-ups can be large on a half-hourly timescale, for annual sums of ET the errors often compensate each other and are small relative to the measured signal (Hollinger et al., 2005). As an example, we calculated the random error uncertainty after HolLINGER et al. (2005) for the latent heat fluxes $\left(\mathrm{LE}_{E C E B}\right)$ from Dornburg AF for 2016. The larger the integration time (hourly, daily, and monthly), the smaller the random error. The magnitude of the random error was about $2.3 \%$ (median over $n=9$ ) of the flux magnitude for monthly averages, $11.55 \%$ $(n=254)$ for daily averages, and $34.5 \%(n=12191)$ for hourly averages. Hence, the random error for annual sums would be even smaller.

\subsection{Conclusions}

The main objective of the current work was to investigate the effect of AF on evapotranspiration in comparison to monoculture agriculture without trees. We performed evapotranspiration measurements at multiple sites, for 2 consecutive years, with a low-cost eddy covariance set-up and an eddy covariance energy balance set-up.

In the first part of this paper, we investigated the performance of the measurement set-ups. In comparison with direct eddy covariance measurements, the low-cost eddy covariance set-up captured the temporal variability in half-hourly ET rates with high coefficients of determination during a comparison measuring campaign. The ECEB set-up 
also represented the diel cycle of ET but was characterised by more scatter. We therefore conclude that the EC-LC set-up is a viable alternative compared to conventional eddy covariance set-ups, as this set-up represents the ET of the underlying ecosystem more accurately than the ECEB set-up.

In the second part of the paper, we focused on the question of whether AF systems have higher water losses to the atmosphere via ET compared to monoculture systems. Our results showed that differences in ET between AF and MC were small. Instead, we found higher evapotranspiration indices during a drier than normal year compared to a wet year across sites and methods. This shows that the potentially small effect from the trees on ET was overlaid by the effect of local climatic conditions. In addition, we found a similar plant physiological response to the $\mathrm{AF}$ and the $\mathrm{MC}$ systems which is characterised by small differences between canopy resistances.

Overall, we conclude that the inclusion of tree strips into the agricultural landscape has not resulted in higher water losses to the atmosphere via ET, and agroforestry can be a land use alternative to monoculture agriculture without trees.

\subsection{Appendix}

\subsubsection{Derivations}

\subsubsection{Half-hourly ET rates and soil storage flux}

Half-hourly evapotranspiration rates in units of $\mathrm{mm} 30 \mathrm{~min}^{-1}$ were calculated from LE as follows:

$$
\begin{aligned}
\mathrm{ET} & =\frac{L E_{E C E B}\left(\mathrm{~J} \mathrm{~kg}^{-1} \mathrm{~s}^{-1}\right)}{L\left(\mathrm{~J} \mathrm{~kg}^{-1}\right)} \cdot 1800\left(\mathrm{~s} 30 \mathrm{~min}^{-1}\right) \\
& \cdot \frac{1}{\rho_{\mathrm{H}_{2} O}}\left(\mathrm{~m}^{3} \mathrm{~kg}^{-1}\right) \cdot 1000 \mathrm{~mm} \mathrm{~m}^{-1},
\end{aligned}
$$

with $L\left(\mathrm{~J} \mathrm{~kg}^{-1}\right)$, the latent heat of vaporisation (DAKE, 1972), depending on air temperature $T\left({ }^{\circ} \mathrm{C}\right)$, as follows:

$$
L=(2.501-0.00237 T) \times 10^{6},
$$

and $\rho_{\mathrm{H}_{2} \mathrm{O}}=1000 \mathrm{~kg} \mathrm{~m}^{-3}$ the density of liquid water.

The soil heat storage term has a major contribution to the unclosed energy balance (FoKEn, 2008b), and the magnitude of the soil heat storage is comparably larger than the other storage terms, i.e. the photosynthesis flux, the crop enthalpy change, the air enthalpy change, the canopy dew water enthalpy change, and the atmospheric moisture change (JACOBS et al., 2008). We used the ground heat flux $(G)$ from the ground heat flux measurements, $G_{\mathrm{HFP}}\left(\mathrm{W} \mathrm{m}^{-2}\right)$, at the sites and calculated the soil heat storage between the soil heat flux plate and the soil layer above, following LiEBETHAL et al. (2007) as follows:

$$
G=G_{\mathrm{HFP}}+\int_{z=-0.05 \mathrm{~m}}^{0 \mathrm{~m}} c_{\mathrm{V}} \frac{\partial T}{\partial t} \mathrm{~d} z .
$$


The soil heat storage (second term on the right-hand side of Eq. 3.10) consists of the vertical integral of the change in temperature over time at depth $z=0.02 \mathrm{~m} . \quad c_{\mathrm{V}}$ is the volumetric heat capacity of the soil, calculated from the soil components, i.e. organic, mineral, and water and their respective heat capacities. Soil texture and bulk densities are summarised in Table 3.8 and were provided by GöBEL et al. (2018) and Marcus Schmidt (personal communication, Georg August University of Göttingen, Buesgen Institute, Soil Science of Tropical and Subtropical Ecosystems, 2018). Gaps in soil storage data were filled according to a multiple linear regression with soil storage vs. net radiation and ground heat flux. The multiple linear regression fitting parameters were derived from records when the soil storage, the net radiation, and the ground heat flux were available at the same time.

\subsubsection{Water vapour mole fraction $C_{\mathrm{H}_{2} \mathrm{O}_{\mathrm{v}}}$ from the thermohygrometer}

The derivation of the water vapour mole fraction $\left(C_{H_{2} O_{\mathrm{v}}}\right)$ from relative humidity, air temperature, and air pressure from the low-cost thermohygrometer was also presented in MARKWITZ et al. (2019) and is given in this section.

The water vapour mole fraction was derived from the definition of the specific humidity $(q)$ as being the quantity of water vapour per quantity of moist air. The latter two quantities were expressed as the density of water vapour $\left(\rho_{\mathrm{H}_{2} \mathrm{O}_{\mathrm{v}}}\right)$ and moist air $\left(\rho_{\mathrm{m}}\right)$, respectively. The density of moist air is defined as the sum of the density of dry air $\left(\rho_{\mathrm{d}}\right)$ and the density of water vapour.

$$
\begin{aligned}
q & =\frac{\rho_{\mathrm{H}_{2} \mathrm{O}_{\mathrm{v}}}}{\rho_{\mathrm{m}}} \\
& =\frac{\rho_{\mathrm{H}_{2} O_{\mathrm{v}}}}{\rho_{\mathrm{d}}+\rho_{\mathrm{H}_{2} O_{\mathrm{v}}}} .
\end{aligned}
$$

We then replaced the density of water vapour and the density of dry air in Eq. (3.11) as per Eqs. (3.12) and (3.13), respectively, as follows:

$$
\begin{aligned}
& \rho_{H_{2} O_{\mathrm{v}}}=\frac{C_{H_{2} O_{\mathrm{v}}} \cdot M_{H_{2} O_{\mathrm{v}}}}{V_{\mathrm{m}}} \\
& \rho_{\mathrm{d}}=\frac{p-e_{\mathrm{a}}}{R_{\mathrm{d}} \cdot T},
\end{aligned}
$$

with the molar mass of water vapour, $M_{\mathrm{H}_{2} \mathrm{O}_{\mathrm{v}}}=18.02 \mathrm{~g} \mathrm{~mol}^{-1}$, and the molar volume of air, as follows:

$$
V_{\mathrm{m}}=\frac{\Re \cdot T}{p}\left(\mathrm{~m}^{3} \mathrm{~mol}^{-1}\right),
$$

the universal gas constant $\left(\mathfrak{R}=8.314 \mathrm{~J} \mathrm{~mol}^{-1} \mathrm{~K}^{-1}\right)$ and the specific gas constant of dry air $\left(R_{\mathrm{d}}=287.058 \mathrm{~J} \mathrm{~kg}^{-1} \mathrm{~K}^{-1}\right)$. 
Solving Eq. (3.11) for $C_{H_{2} O_{\mathrm{v}}}$ leads to the water vapour mole fraction as follows:

$$
C_{\mathrm{H}_{2} \mathrm{O}_{\mathrm{v}}}=\frac{q \mathfrak{R}\left(p-e_{\mathrm{a}}\right)}{p M_{\mathrm{H}_{2} \mathrm{O}_{\mathrm{v}}} R_{\mathrm{d}}(1-q)} .
$$

The specific humidity in Eq. (3.15) was calculated as a function of relative humidity, temperature, and air pressure measurements from the thermohygrometer as follows:

$$
q=0.622 \cdot \frac{e_{\mathrm{a}}}{p} .
$$

The actual vapour pressure $\left(e_{\mathrm{a}} ; \mathrm{kPa}\right)$ in Eq. (3.16) was calculated from an approximation of the saturation vapour pressure $\left(e_{*}(T)\right.$; STULL, 1989) and from relative humidity $(\mathrm{RH})$ as follows:

$$
\begin{aligned}
e & =\frac{\mathrm{RH} \cdot e_{*}(T)}{100} \\
e_{*}(T) & =0.6112 \exp \left(\frac{17.67 T}{(T+273.15)-29.66}\right) .
\end{aligned}
$$

\subsubsection{Canopy resistance}

The Penman-Monteith equation for the latent heat flux of a canopy (MonTeITH, 1965) is as follows:

$$
\mathrm{LE}=\frac{s\left(R_{\mathrm{N}}-G\right)+c_{\mathrm{p}} D g_{\mathrm{ah}}}{s+\gamma\left(1+g_{\mathrm{ah}} / g_{\mathrm{c}}\right)}
$$

with the vapour pressure deficit $\left(D=e_{*}(T)-e_{\mathrm{a}} ; \mathrm{hPa}\right)$, the heat capacity at constant pressure $\left(c_{\mathrm{p}}=1005 \mathrm{~J}(\mathrm{~kg} \mathrm{~K})^{-1}\right)$, and the psychrometer constant $\left(\gamma=\left(c_{\mathrm{p}} P_{\mathrm{A}}\right) /(L 0.622)\right)$.

The slope of the saturation vapour pressure curve $(s)$ is as follows:

$$
s=\frac{\epsilon L q_{\mathrm{sat}}}{R_{\mathrm{v}} T},
$$

with $\epsilon=0.622$ and the specific humidity at saturation $\left(q_{\mathrm{sat}}=\epsilon e_{*}(T) / P_{\mathrm{A}}\right)$ as a function of temperature.

Rearranging Eq. (3.19) yields the canopy resistance $\left(r_{\mathrm{c}} ; \mathrm{s} \mathrm{m}^{-1}\right)$ as follows:

$$
r_{\mathrm{c}}=\frac{1}{g_{\mathrm{c}}}=\frac{s / \gamma+1}{g_{\mathrm{ah}}}\left[\frac{s / \gamma\left(R_{\mathrm{N}}-G\right)}{(s / \gamma+1) \mathrm{LE}}-1\right]+\frac{c_{\mathrm{p}} D}{\gamma \mathrm{LE}} .
$$


The aerodynamic conductance for heat is as follows:

$$
\begin{aligned}
g_{\mathrm{ah}} & =\frac{1}{r_{\mathrm{ah}}} \\
& =\frac{\kappa^{2} u}{\left(\ln \left(\frac{z-d}{z_{0 \mathrm{~m}}}\right)-\psi_{\mathrm{m}}(\zeta)\right)\left(\ln \left(\frac{z-d}{z_{0 \mathrm{~h}}}\right)-\psi_{\mathrm{h}}(\zeta)\right)},
\end{aligned}
$$

with the von Kármán constant $(\kappa=0.4)$, the horizontal wind velocity $\left(u ; \mathrm{m} \mathrm{s}^{-1}\right)$, the measurement height $(z ; \mathrm{m})$ and the displacement height $(d ; \mathrm{m})$, estimated as $70 \%$ of the canopy height, and the roughness length for momentum transport $\left(z_{0 \mathrm{~m}}\right)$, estimated as $10 \%$ of the canopy height and the roughness length for heat transport $\left(z_{0 \mathrm{~h}}\right)$, estimated as $10 \%$ of $z_{0 \mathrm{~m}} \cdot \psi_{\mathrm{m}}(\zeta)$ is the universal function for momentum, and $\psi_{\mathrm{h}}(\zeta)$ is the universal function for heat. $\psi_{\mathrm{m}}(\zeta)$ and $\psi_{\mathrm{h}}(\zeta)$ depend on atmospheric stability with the stability parameter $\zeta=(z-d) / L$, including the Monin-Obukhov length $(L) . \psi_{\mathrm{m}}$ and $\psi_{\mathrm{h}}$ were calculated as follows:

$$
\begin{aligned}
& \psi_{\mathrm{m}}(\zeta)= \begin{cases}2 \ln [(1+x) / 2]+\ln \left[\left(1+x^{2}\right) / 2\right] & \text { for } \zeta<0 \\
-2 \arctan (x)+\pi / 2 & \text { for } \zeta \geq 0 \\
-5 \zeta & \text { for } \zeta<0\end{cases} \\
& \psi_{\mathrm{h}}(\zeta)= \begin{cases}2 \ln \left[\left(1+x^{2}\right) / 2\right] \\
-5 \zeta & \text { for } \zeta \geq 0,\end{cases}
\end{aligned}
$$

with $x=(1-16 \zeta)^{1 / 4}$ (BonAn, 2016; Businger et al., 1971; STUll, 1989). 


\subsubsection{Tables}

Table 3.7: Temporal extent of the EC measurement campaigns.

\begin{tabular}{ll}
\hline Site & Campaign period \\
\hline Dornburg MC & 16 June to 14 July 2016 \\
Donburg AF & 14 July to 12 August 2016 \\
Reiffenhausen AF & 12 August to 14 September 2016 \\
Wendhausen & 3 May to 2 June 2017 \\
Forst & 8 June to 8 July 2017 \\
Mariensee & 21 July to 19 September 2017 \\
\hline
\end{tabular}

Table 3.8: Site-specific soil characteristics, with the soil texture being representative for the top soil column of $0.3 \mathrm{~m}$. The bulk density is representative for the top soil column of $0.05 \mathrm{~m}$. Data provided by GöBEL et al. (2018) and Marcus Schmidt (personal communication, Georg August University of Göttingen, Buesgen Institute, Soil Science of Tropical and Subtropical Ecosystems, 2018).

\begin{tabular}{lrrr}
\hline Site & $\begin{array}{r}\text { Clay content } \\
(\%)\end{array}$ & $\begin{array}{r}\text { Sand content } \\
(\%)\end{array}$ & $\begin{array}{r}\text { Bulk density } \\
\left(\mathrm{kg} \mathrm{m}^{-3}\right)\end{array}$ \\
\hline Dornburg AF & 20.5 & 3.75 & 1.22 \\
Dornburg MC & 38 & 10.75 & 1.19 \\
Forst AF & 7 & 60.75 & 1.3 \\
Forst MC & 9.5 & 66.75 & 1.28 \\
Mariensee AF & 11.75 & 48 & - \\
Mariensee MC & 31.67 & 54.33 & 1.28 \\
Reiffenhausen AF & 23.75 & 31.5 & 1.28 \\
Reiffenhausen MC & 22.75 & 49.75 & 1.28 \\
Wendhausen AF & 35 & 18.25 & 1.085 \\
Wendhausen MC & 44.5 & 27 & 0.89 \\
\hline
\end{tabular}




\subsubsection{Figures}
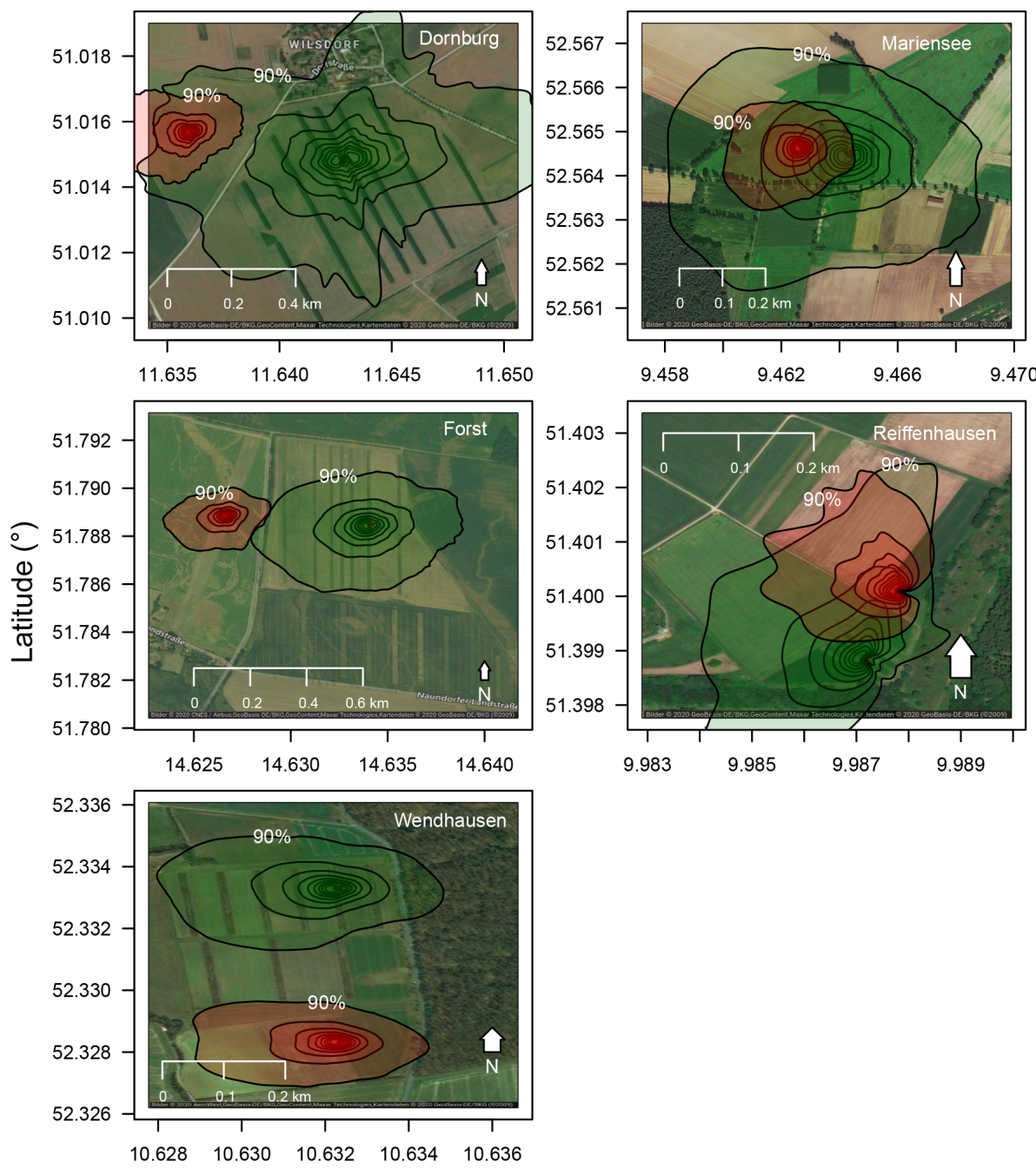

\section{Longitude $\left({ }^{\circ}\right)$}

Figure 3.13: Flux footprint climatology for all sites and all available data during the years 2016 and 2017. Green shaded footprints correspond to the agroforestry system, and red shaded footprints correspond to the monoculture system. For the analysis only daytime data were used $\left(R_{\mathrm{G}}>20 \mathrm{~W} \mathrm{~m}^{-2}\right)$. Aerial photographs originate from Google Maps and Google Earth.

(c) Google 2020. 


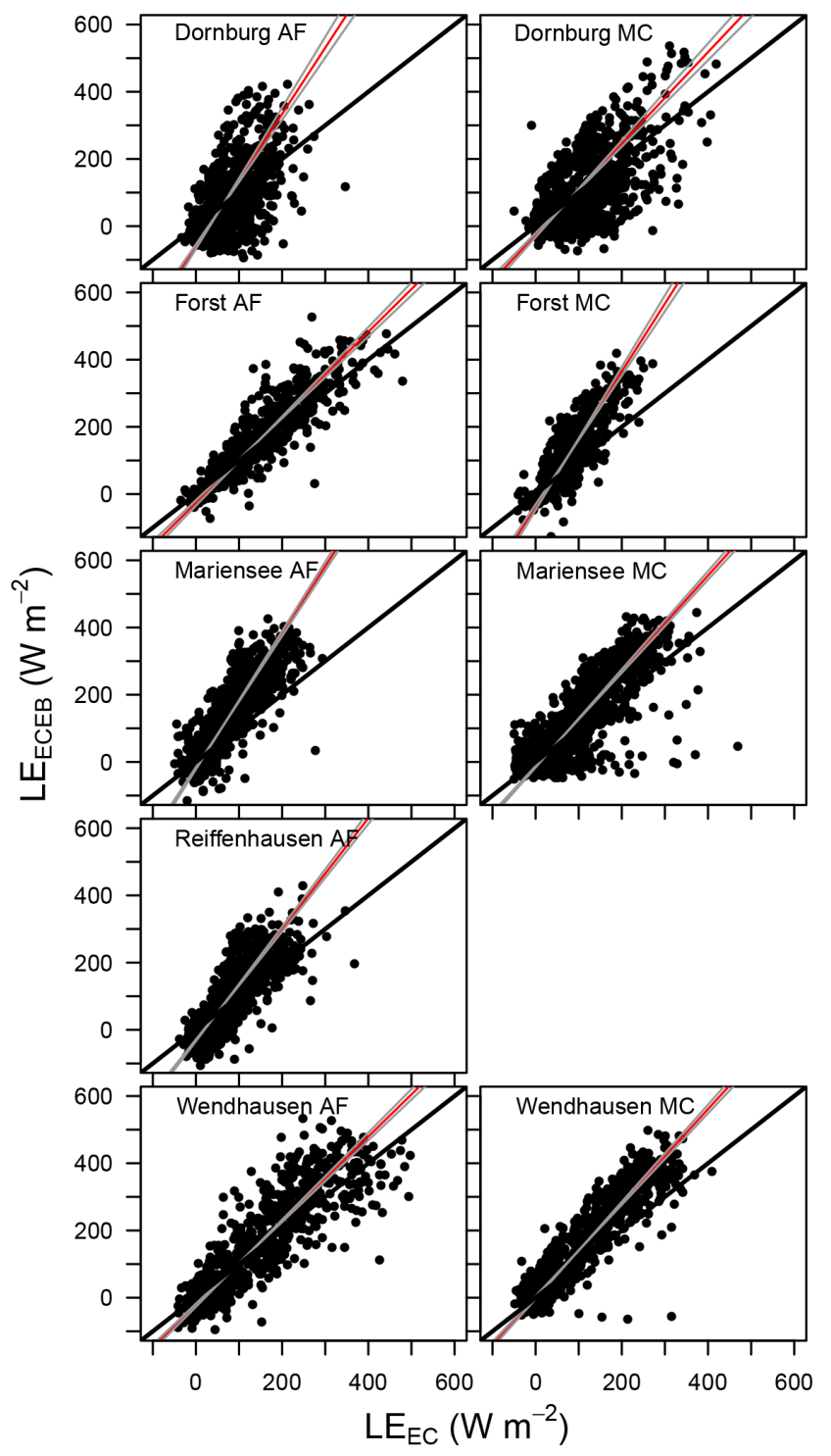

Figure 3.14: Scatter plot of $\mathrm{LE}_{E C E B}$ vs. $\mathrm{LE}_{E C}$ for all sites. The red line denotes the best fit line, with grey lines as the $\pm 2.5 \%$ confidence interval lines, and the solid black lines corresponding to the 1:1 line. Data from Reiffenhausen MC are missing due to the unavailability of a campaign. 


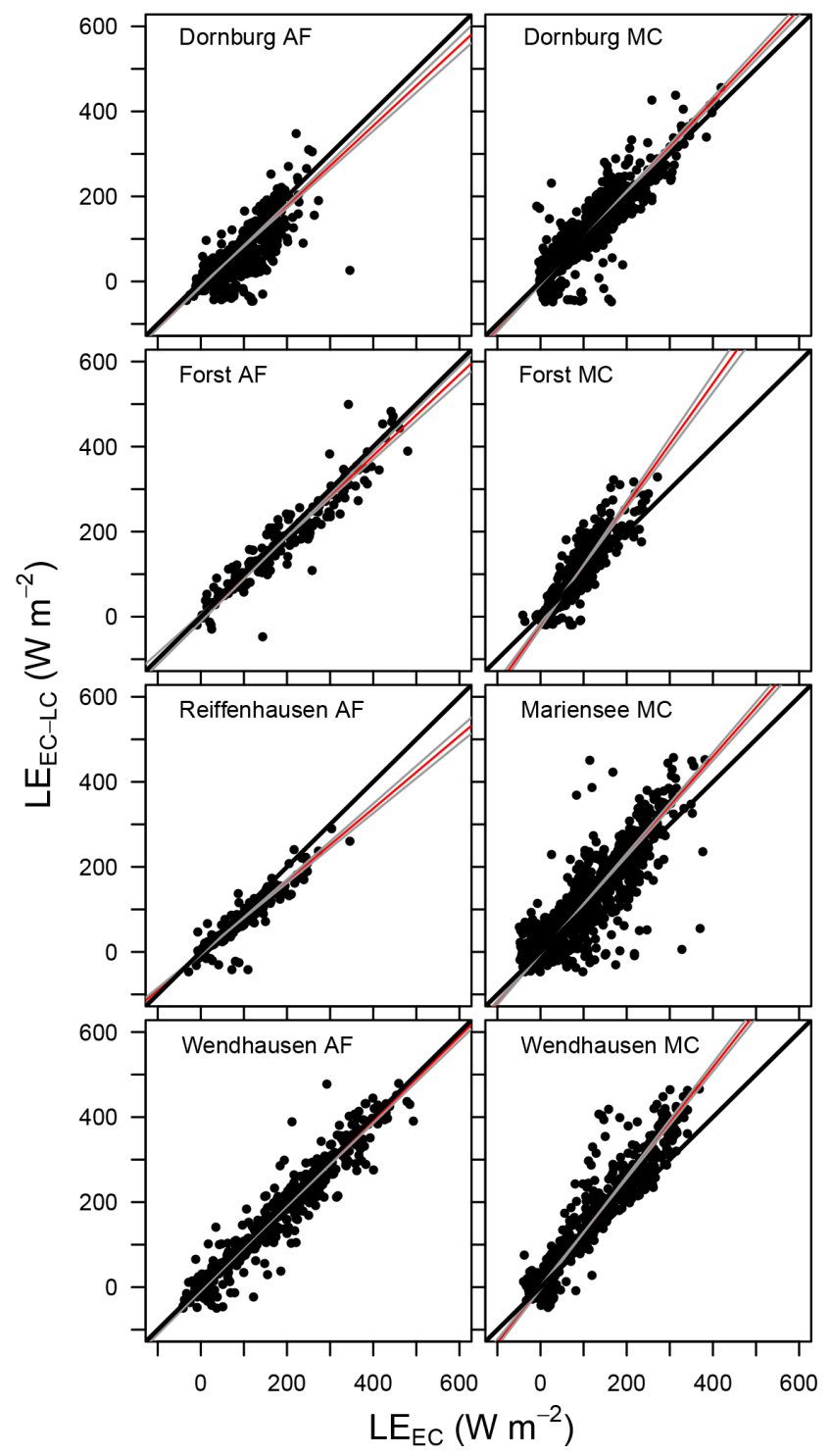

Figure 3.15: Scatter plot of $\mathrm{LE}_{\mathrm{EC}-\mathrm{LC}}$ vs. $\mathrm{LE}_{E C}$ for all sites. The red line denotes the best fit line, with grey lines as the $\pm 2.5 \%$ confidence interval lines, and the solid black lines corresponding to the 1:1 line. Data from Reiffenhausen MC are missing due to the unavailability of a campaign, and $\mathrm{LE}_{\mathrm{EC}-\mathrm{LC}}$ from Mariensee $\mathrm{AF}$ is missing due to sensor malfunctions. 


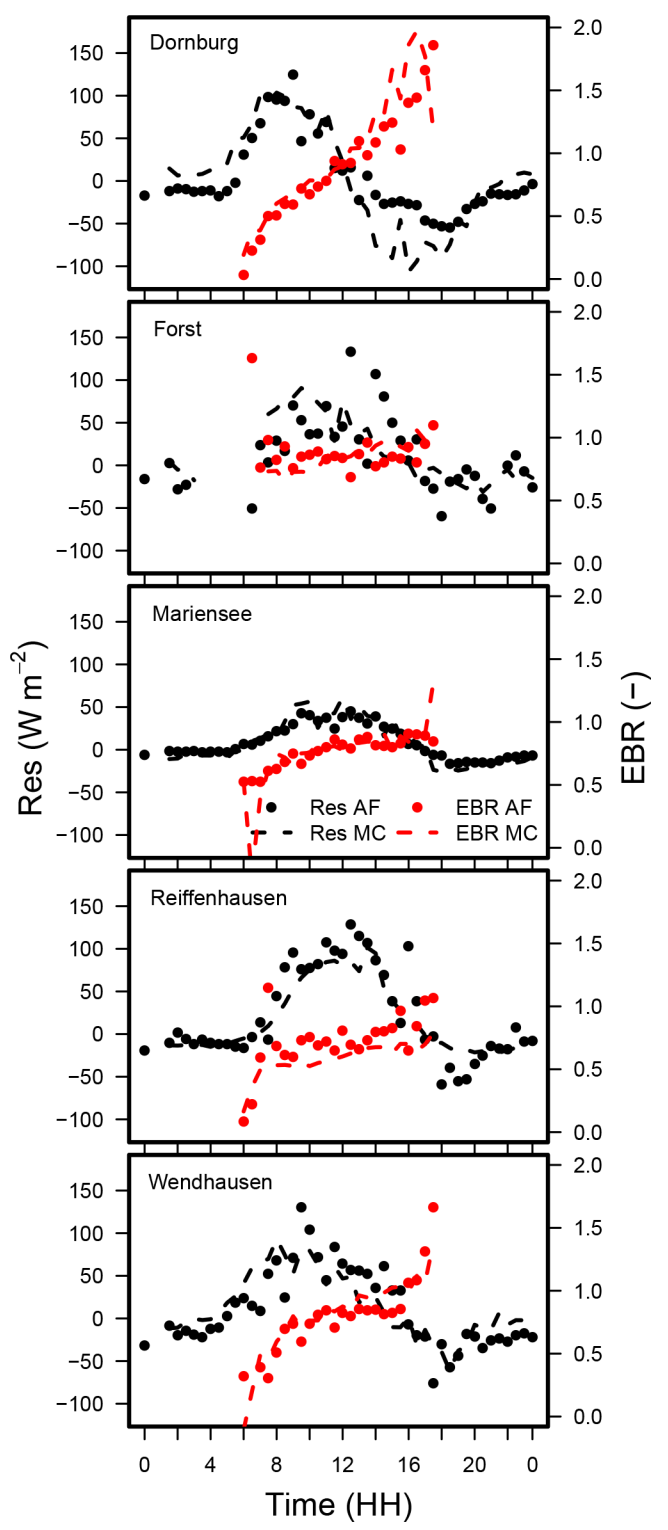

Figure 3.16: Median diel cycle of the energy balance ratio (EBR), and the diurnal cycle of the residual energy for the AF and the MC systems at all sites. LE was obtained by EC-LC. Data from Mariensee AF are from 23 March to 20 November 2016, and at Reiffenhausen MC the analyses are based on data collected from 7 April to 31 December 2016 because no data were available during the campaigns. 


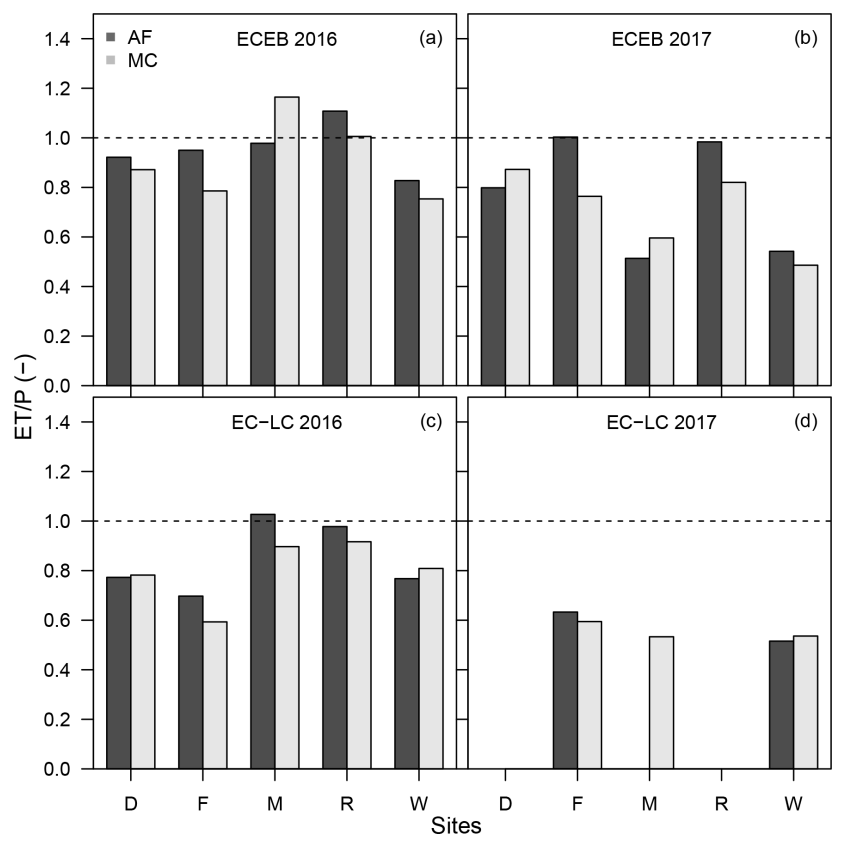

Figure 3.17: Bar plot of the evapotranspiration index for the ECEB method for the years 2016 (a) and 2017 (b) and for the EC-LC method for 2016 (c) and 2017 (d) for the sites, e.g. Dornburg (D), Forst (F), Mariensee (M), Reiffenhausen (R), and Wendhausen (W). The dashed line indicates an evapotranspiration index of one. Evapotranspiration indices for Dornburg AF and MC, Mariensee AF, and Reiffenhausen AF and MC in 2017 are missing due to instrument malfunctions. 


\subsection{Data Availability}

All data used in this study are available at 10.5281/zenodo. 4038399 .

\subsection{Author contribution}

CM designed and performed the field work, analysed the data, and wrote the paper. AK and LS wrote the project's scientific proposal, acquired the funding as part of the BonaRes SIGNAL consortium, and contributed to the field work and analysis. All authors contributed to the discussion and writing of the paper.

\subsection{Competing Interests}

The authors declare that they have no conflict of interest.

\subsection{Acknowledgements}

We wish to acknowledge the contributions by Mathias Herbst to the BonaRes SIGNAL proposal and project design and the technical support through field work received from Frank Tiedemann, Edgar Tunsch, Dietmar Fellert, Martin Lindenberg, Johann Peters (Bioclimatology group), and Dirk Böttger (Soil Science group of Tropical and Subtropical Ecosystems) from the University of Göttingen.

\subsection{Financial support}

This research has been supported by the German Federal Ministry of Education and Research (BMBF; project BonaRes, Modul A: SIGNAL; grant no: 031A562A) and the Deutsche Forschungsgemeinschaft (grant no. INST 186/1118-1 FUGG).

\subsection{Review statement}

This paper was edited by Ivonne Trebs and reviewed by two anonymous referees. 


\section{References}

Amiro, B. (2009): 'Measuring boreal forest evapotranspiration using the energy balance residual'. J. Hydrol., vol. 366(1-4): pp. 112-118 (cit. on p. 62).

Aubinet, M., C. Feigenwinter, B. Heinesch, C. Bernhofer, E. Canepa, A. Lindroth, L. Montagnani, C. Rebmann, P. Sedlak, and E. Van Gorsel (2010): 'Direct advection measurements do not help to solve the night-time $\mathrm{CO} 2$ closure problem: Evidence from three different forests'. Agric. For. Meteorol., vol. 150(5): pp. 655-664 (cit. on p. 87).

Aylott, M. J., E. Casella, I. Tubby, N. R. Street, P. Smith, and G. Taylor (2008): 'Yield and spatial supply of bioenergy poplar and willow short-rotation coppice in the UK'. New Phytol., vol. 178(2): pp. 358-370 (cit. on p. 61).

BALDOCCHI, D. D. (2003): 'Assessing the eddy covariance technique for evaluating carbon dioxide exchange rates of ecosystems: past, present and future'. Glob. Chang. Biol., vol. 9(4): pp. 479-492 (cit. on pp. 62, 85).

BALDOCCHI, D. (2014): 'Measuring fluxes of trace gases and energy between ecosystems and the atmosphere - the state and future of the eddy covariance method'. Glob. Chang. Biol., vol. 20(12): pp. 3600-3609 (cit. on pp. 62, 66).

Beuschel, R., H.-P. Piepho, R. G. Joergensen, and C. Wachendorf (2018): 'Similar spatial patterns of soil quality indicators in three poplar-based silvo-arable alley cropping systems in Germany'. Biol. Fertil. Soils, vol. (cit. on p. 61).

Bloemen, J., R. Fichot, J. A. Horemans, L. S. Broeckx, M. S. Verlinden, T. Zenone, and R. Ceulemans (2016): 'Water use of a multigenotype poplar short-rotation coppice from tree to stand scale'. GCB Bioenergy, vol. (June) (cit. on p. 61).

Boessenkool, B. (2019): Package 'rdwd ': Select and Download Climate Data from 'DWD' (German Weather Service). Tech. rep. Potsdam University, Department of geoecology: pp. 1-24 (cit. on p. 63).

BöHm, C., M. KAnzler, and D. Freese (2014): 'Wind speed reductions as influenced by woody hedgerows grown for biomass in short rotation alley cropping systems in Germany'. Agrofor. Syst., vol. 88(4): pp. 579-591 (cit. on pp. 61, 84).

Bonan, G. (2016): Ecological Climatology - Concepts and applications. 3rd ed. Cambridge University Press: pp. 1-692 (cit. on p. 91).

Budyko, M. I. (1974): Climate and life. New York: Acadamic Press (cit. on p. 81).

Businger, J. A., J. C. Wyngaard, Y Izumi, and E. F. Bradley (1971): 'Flux-Profile Relationships in the Atmospheric Surface Layer'. J. Atmos. Sci., vol. 28: pp. 181-189 (cit. on p. 91).

Chen, T. and C. Guestrin (2016): 'XGBoost: A Scalable Tree Boosting System'. J. Assoc. Physicians India, vol.: pp. 1-10 (cit. on p. 67).

Chen, T., T. He, M. Benesty, V. Khotilovich, Y. Tang, H. Cho, K. Chen, Rory Mitchell, I. Cano, T. Zhou, M. Li, J. Xie, M. Lin, Y. Geng, and Y. Li (2019): Package 'xgboost' - Extreme Gradient Boosting (cit. on p. 67).

Cleugh, H. A. (1998): 'Effects of windbreaks on airflow, microclimates and crop yields'. Agrofor. Syst., vol. 41(1): pp. 55-84 (cit. on p. 61). 
DAKe, J. M. K. (1972): 'Evaporative cooling of a body of water'. Water Resour. Res., vol. 8(4): pp. 1087-1091 (cit. on p. 88).

Davis, J. E. and J. M. Norman (1988): '22. Effects of shelter on plant water use'. Agric. Ecosyst. Environ., vol. 22-23(C): pp. 393-402 (cit. on p. 61).

De Stefano, A. and M. G. Jacobson (2018): 'Soil carbon sequestration in agroforestry systems: a meta-analysis'. Agrofor. Syst., vol. 92(2): pp. 285-299 (cit. on p. 61).

FALGE, E. et al. (2001): 'Gap filling strategies for defensible annual sums of net ecosystem exchange'. Agric. For. Meteorol., vol. 107(1): pp. 43-69 (cit. on p. 67).

Fischer, M., M. Trnka, J. Kučera, G. Deckmyn, M. Orság, P. Sedlák, Z. Žalud, and R. Ceulemans (2013): 'Evapotranspiration of a high-density poplar stand in comparison with a reference grass cover in the Czech-Moravian Highlands'. Agric. For. Meteorol., vol. 181: pp. 43-60 (cit. on pp. 60, 61).

Fischer, M., T. Zenone, M. Trnka, M. Orság, L. Montagnani, E. J. Ward, A. M. Tripathi, P. Hlavinka, G. Seufert, Z. Žalud, J. S. King, and R. Ceulemans (2018): 'Water requirements of short rotation poplar coppice: Experimental and modelling analyses across Europe'. Agric. For. Meteorol., vol. 250-251(April 2018): pp. 343-360 (cit. on pp. 61, 74).

Foken, T. (2008a): Micrometorology. Vol. 1. Bayreuth: Springer-Verlag Berlin Heidelberg (cit. on pp. 86, 87).

Foken, T., F. Wimmer, M. Mauder, C. Thomas, and C. Liebethal (2006): 'Some aspects of the energy balance closure problem'. Atmos. Chem. Phys. Discuss., vol. 6(2): pp. 3381-3402 (cit. on pp. 73, 87).

Foken, T. (2008b): 'The Energy Balance Closure Problem: an Overview'. Ecol. Appl., vol. 18(6): pp. 1351-1367 (cit. on p. 88).

Göbel, L., M. D. Corre, E. Veldkamp, and M. Schmidt (2018): BonaRes SiGNAL, Site: Mariensee and Reiffenhausen, soil characteristics (cit. on pp. 89, 92).

Hill, T., M. Chocholek, and R. Clement (2017): 'The case for increasing the statistical power of eddy covariance ecosystem studies: why, where and how?' Glob. Chang. Biol., vol. 23(6): pp. 2154-2165 (cit. on p. 62).

Hollinger, D. Y. and A. D. Richardson (2005): 'Uncertainty in eddy covariance measurements and its application to physiological models'. Tree Physiol., vol. 25(7): pp. 873-885 (cit. on p. 87).

Imukova, K., J. Ingwersen, M. Hevart, and T. Streck (2016): 'Energy balance closure on a winter wheat stand: Comparing the eddy covariance technique with the soil water balance method'. Biogeosciences, vol. 13(1): pp. 63-75 (cit. on p. 74).

Jacobs, A. F. G., B. G. Heusinkveld, and A. A. M. Holtslag (2008): 'Towards Closing the Surface Energy Budget of a Mid-latitude Grassland'. Bound.-Layer Meteor., vol. 126: pp. 125-136 (cit. on pp. 78, 88).

Kanzler, M., C. Böhm, J. Mirck, D. Schmitt, and M. Veste (2018): 'Microclimate effects on evaporation and winter wheat (Triticum aestivum L.) yield within a temperate agroforestry system'. Agrofor. Syst., vol. 4 (cit. on pp. 61, 85).

Katul, G. G., R. Oren, S. Manzoni, C. Higgins, and M. B. Parlange (2012): 'Evapotranspiration: a process driving mass transport and energy exchnge in the soil- 
plant-atmosphere-climate system'. Rev. Geophys., vol. 50(RG3002): pp. 1-25 (cit. on p. 61).

Kluun, N., P. Calanca, M. W. Rotach, and H. P. Schmid (2015): 'A simple twodimensional parameterisation for Flux Footprint Prediction (FFP)'. Geosci. Model Dev., vol. 8(11): pp. 3695-3713 (cit. on p. 69).

Liebethal, C. and T. Foken (2007): 'Evaluation of six parameterization approaches for the ground heat flux'. Theor. Appl. Climatol., vol. 88(1-2): pp. 43-56 (cit. on p. 88).

Lindroth, A. (1993): 'Aerodynamic and canopy resistance of short-rotation forest in relation to leaf area index and climate'. Boundary-Layer Meteorol., vol. 66(3): pp. 265-279 (cit. on p. 84).

Markwitz, C., A. KnOhL, and L. Siebicke (2020): 'Evapotranspiration over agroforestry sites in Germany'. Biogeosciences, vol. 17: pp. 5183-5208 (cit. on p. 59).

Markwitz, C. and L. Siebicke (2019): 'Low-cost eddy covariance: a case study of evapotranspiration over agroforestry in Germany'. Atmos. Meas. Tech., vol. 12: pp. 46774696 (cit. on pp. $62,63,66,67,87,89$ ).

McNaughton, K. G. (1988): '1. Effects of windbreaks on turbulent transport and microclimate'. Agric. Ecosyst. Environ., vol. 22-23(C): pp. 17-39 (cit. on p. 61).

Moncrieff, J., J. Massheder, H. de Bruin, J. Elbers, T. Friborg, B. Heusinkveld, P. Kabat, S. Scott, H. Soegaard, and A. Verhoef (1997): 'A system to measure surface fluxes of momentum, sensible heat, water vapour and carbon dioxide'. J. Hydrol., vol. 188-189: pp. 589-611 (cit. on p. 66).

Monteith, J. L. (1965): 'Evaporation and environment'. Symp. Soc. Exp. Biol., vol. 19: pp. 205-234 (cit. on p. 90).

Morhart, C. D., G. C. Douglas, C. Dupraz, A. R. Graves, M. Nahm, P. Paris, U. H. Sauter, J. Sheppard, and H. Spiecker (2014): 'Alley coppice-a new system with ancient roots'. Ann. For. Sci., vol. 71(5): pp. 527-542 (cit. on p. 61).

NuberG, I. K. (1998): 'Effect of shelter on temperate crops: A review to define research for Australian conditions'. Agrofor. Syst., vol. 41(1): pp. 3-34 (cit. on p. 85).

OnCLEY, S. P. et al. (2007): 'The energy balance experiment EBEX-2000. Part I: Overview and energy balance'. Boundary-Layer Meteorol., vol. 123(1): pp. 1-28 (cit. on p. 77).

Quinkenstein, A., J. Wöllecke, C. Böhm, H. Grünewald, D. Freese, B. U. SchneiDER, and R. F. HüTTL (2009): 'Ecological benefits of the alley cropping agroforestry system in sensitive regions of Europe'. Environ. Sci. Policy, vol. 12(8): pp. 1112-1121 (cit. on p. 61).

REICHStein, M. et al. (2005): 'On the separation of net ecosystem exchange into assimilation and ecosystem respiration: Review and improved algorithm'. Glob. Chang. Biol., vol. 11(9): pp. 1424-1439 (cit. on p. 67).

SCHMID, H. P. (2002): 'Footprint modeling for vegetation atmosphere exchange studies: A review and perspective'. Agric. For. Meteorol., vol. 113(1-4): pp. 159-183 (cit. on p. 69).

Schmidt-Walter, P., F. Richter, M. Herbst, B. Schuldt, and N. P. Lamersdorf (2014): 'Transpiration and water use strategies of a young and a full-grown short rotation coppice differing in canopy cover and leaf area'. Agric. For. Meteorol., vol. 195-196: pp. $165-178$ (cit. on pp. $61,69,86$ ). 
Smith, J., B. D. Pearce, and M. S. Wolfe (2013): 'Reconciling productivity with protection of the environment: Is temperate agroforestry the answer?' Renew. Agric. Food Syst., vol. 28(1): pp. 80-92 (cit. on p. 61).

Stoy, P. C. et al. (2013): 'A data-driven analysis of energy balance closure across FLUXNET research sites: The role of landscape scale heterogeneity'. Agric. For. Meteorol., vol. 171-172: pp. 137-152 (cit. on pp. 68, 74).

Stull, R. B. (1989): An introduction to boundary layer meteorology. Kluwer Academic Publishers (cit. on pp. 90, 91).

Swieter, A., M. Langhof, J. Lamerre, and J. M. Greef (2018): 'Long-term yields of oilseed rape and winter wheat in a short rotation alley cropping agroforestry system'. Agrofor. Syst., vol. 5(Fao 2014) (cit. on p. 61).

Tsonkova, P., C. Böhm, A. Quinkenstein, and D. Freese (2012): 'Ecological benefits provided by alley cropping systems for production of woody biomass in the temperate region: a review'. Agrofor. Syst., vol. 85(1): pp. 133-152 (cit. on p. 61).

Twine, T. E., W. P. Kustas, J. M. Norman, D. R. Cook, P. R. Houser, T. P. Meyers, J. H. Prueger, P. J. Starks, and M. L. Wesely (2000): 'Correcting eddy-covariance flux underestimates over a grassland'. Agric. For. Meteorol., vol. 103(3): pp. 279-300 (cit. on p. 67).

WARD, P. R., S. F. Micin, and I. R. P. Fillery (2012): 'Application of eddy covariance to determine ecosystem-scale carbon balance and evapotranspiration in an agroforestry system'. Agric. For. Meteorol., vol. 152(1): pp. 178-188 (cit. on p. 74).

Webster, R. (1997): 'Regression and functional relations'. Eur. J. Soil Sci., vol. 48(3): pp. 557-566 (cit. on p. 68).

Williams, C. A., M. Reichstein, N. Buchmann, D. Baldocchi, C. Beer, C. Schwalm, G. Wohlfahrt, N. Hasler, C. Bernhofer, T. Foken, D. Papale, S. Schymanski, and K. Schaefer (2012): 'Climate and vegetation controls on the surface water balance: Synthesis of evapotranspiration measured across a global network of flux towers'. Water Resour. Res., vol. 48(6): pp. 1-13 (cit. on p. 82).

Zenone, T., M. Fischer, N. Arriga, L. S. Broeckx, M. S. Verlinden, S. VanBeveren, D. Zona, and R. Ceulemans (2015): 'Biophysical drivers of the carbon dioxide, water vapor, and energy exchanges of a short-rotation poplar coppice'. Agric. For. Meteorol., vol. 209-210: pp. 22-35 (cit. on pp. 60, 61). 


\section{CHAPTER 4}

Large eddy simulation of the wind field over agroforestry in Germany and wind effects on evapotranspiration

Manuscript to be submitted to 'Atmospheric Chemistry and Physics' 


\section{Abstract}

In past years there has been increased interest in establishing short rotation alley cropping agroforestry $(\mathrm{AF})$ as an alternative land-use practice to monoculture systems. Tree strips in the agricultural landscape are beneficial for reducing wind and water erosion by reducing the wind velocity. In addition, a reduced wind velocity causes a reduced soil evaporation and leaf transpiration (evapotranspiration), which may lead to increased soil water content. The objective of the present study was to investigate the three-dimensional wind field over one model agroforestry system in Germany and the wind effect on evapotranspiration.

We used the All Scale Atmospheric Model (ASAM) to simulate the three-dimensional wind field over agroforestry. The agroforestry system consisted of seven tree strips of $10 \mathrm{~m}$ width, $400 \mathrm{~m}$ length and tree strip distances of 24,48 and $96 \mathrm{~m}$, interleaved by crops. We ran simulations for three tree heights $(2,5,8 \mathrm{~m})$, three wind directions (north, north-west, west) and a reference case without trees. Simulated wind velocities were validated with wind velocity measurements at a $48 \mathrm{~m}$ horizontal transect between two tree strips. We studied the effect of wind velocity on evapotranspiration (ET) as per the FAO potential ET, which we corrected by the crop coefficient. The FAO potential ET was calculated from simulated wind velocities and meteorological data from a flux tower at the site.

Our model simulations indicated the strongest wind velocity reduction for westerly and north-westerly winds in the lee of the tree strips, relative to the reference field. The mean wind velocity reduction increased with increasing tree height, with a reduction of $48.5 \%$ for $2 \mathrm{~m}$ tall trees, $70.4 \%$ for $5 \mathrm{~m}$ tall trees and $79 \%$ for $8 \mathrm{~m}$ tall trees with westerly winds. The whole agroforestry system acted as a roughness element and the change in roughness led to the formation of an internal boundary layer, amplifying with height across the domain. An increase in tree strip distance from $24 \mathrm{~m}$ to $48 \mathrm{~m}$ and to $96 \mathrm{~m}$ led to an increased turbulent kinetic energy at the wind-ward side of the opposite tree strip. Hence, the risk for crop damage by wind increased with distance between tree strips. Therefore, we recommend to use equal sized tree strip distances, when establishing a new agroforestry system to prevent crop damage. In terms of water use the mean evapotranspiration reduction was between $4-7 \%$ for westerly winds, $5-8 \%$ for north-westerly winds and $2-2.6 \%$ for northerly winds. In terms of tree height, evapotranspiration reduction was strongest for the tallest trees.

We conclude that including tree strips into the agricultural landscape is beneficial for the reduction of wind velocity and for preventing erosion. In terms of ET reductions the agroforestry design, such as tree strip alignment, tree strip distance, tree planting density as well as the height should be planned carefully beforehand.

\subsection{Introduction}

In past years there has been increased interest in establishing short rotation alley cropping agroforestry (AF) as an alternative land-use practice relative to monoculture agriculture (MC) systems. Short rotation alley cropping agroforestry combines strips of fast growing trees with annually rotating crops or grasslands (CLEUGH, 1998). The advantages of AF are manifold and include increased carbon sequestration relative to conventional agriculture (QUinkEnstein et al., 2016), improved soil fertility and reduced fertilizer-use, enhanced soil quality (BEuschel et al., 2018), reduced soil erosion (REHÁČEK et al., 2017) and 
increased biodiversity (QUINKEnsTEIN et al., 2009; TsonkOva et al., 2012).

Tree strips shelter adjacent crops against wind (BöHM et al., 2014; KANZLER et al., 2018) and prevent crop damage and soil erosion. The relative wind velocity reduction depends on tree strip properties such as width, height, length, arrangement, as well as tree planting density (ZHOU et al., 2005). The wind pattern behind single tree strips was studied in a number of studies, from both an experimental (e.g. BöHM et al., 2014; KAnzler et al., 2018; Tuzet et al., 2007) and modelling perspective (e.g. PATton et al., 1998). However, it remains unclear how the wind pattern over heterogeneous alley cropping systems with multiple tree strips in a variable arrangement behaves and how the design of the agroforestry system affects turbulent motion.

In addition to a reduction in wind velocity, tree strips also lead to a reduction in incident radiation close to the tree strips (GAMBLE et al., 2019). The area between trees and crops is prone to competition for soil water, light and nutrients and is commonly characterized by yield losses (SwIETER et al., 2018). On the other hand, the trees with deeper roots can provide soil water for adjacent crops from deeper soil layers via the process of hydrolic lift and can lead to reduced water losses via the process of evapotranspiration (ET). In a recent study KANZLER et al., 2018 investigated the effect of tree strips on microclimate and evaporation in a horizontal transect between two tree strips. They found consistently lower evaporation between tree strips at all measurement locations compared to an adjacent field without trees. Nevertheless, the measured evaporation reduction is only affected by a reduction in wind velocity and incident radiation in between the tree strips. But, the response of trees and crops as per the process of transpiration is unaccounted and it is still unknown to which extent system-scale ET scales with wind velocity dynamics over agroforestry systems.

Measurements of turbulence at high spatial and temporal resolution are challenging due to the complexity and dynamics of the turbulent eddies. Here is where numerical solvers come into play, as they provide the opportunity to study three-dimensional flow fields over complex terrain at any point in time and space. The simulation of flows over heterogeneous and complex agroforestry systems requires a model, which resolves turbulent eddies of different scales. Large eddy simulations (LES) do resolve eddies down to the grid resolution, whereas eddies smaller than the grid size (sub-grid scale) need to be parametrized (GERMANo et al., 1991). In this study we present large eddy simulations of the wind field over an agroforestry system as well as derived potential evapotranspiration. The main hypothesis of this study was that a reduction in wind velocity over agroforestry causes a reduction in system-scale evapotranspiration. Our aims were (1) to investigate how the irregular arrangement of tree strips on an agricultural field affect the turbulent flow and (2) to quantify the effect of a wind velocity reduction on system-scale evapotranspiration.

\subsection{Materials and methods}

\subsubsection{Site description and measurements}

\subsubsection{Site description}

In this study we simulated the turbulent motion over an agroforestry system located in Forst, Lower Lusatia, Germany. This agroforestry system is part of the Sustainable 
Intensification of Agriculture through Agroforestry project (SIGNAL, http://www . signal. uni-goettingen. de, last access: 21 August 2019). The site is divided into one agroforestry system and a monoculture system as a reference. The agroforestry system is composed of seven tree strips of $10 \mathrm{~m}$ width, $600 \mathrm{~m}$ length and distances between the tree strips of 24 , 48 and $96 \mathrm{~m}$ (Fig. 4.1). At the site the tree strips consist of poplar (clone Max, Populus nigra L. x P. maximowiczii Henry) and black locust (Robinia pseudoacacia L.) and vary within the tree strips (Fig. 4.1). The mean leaf area index was different with $4.5 \mathrm{~m}^{2} \mathrm{~m}^{-2}$ for poplar and $5.5 \mathrm{~m}^{2} \mathrm{~m}^{-2}$ for black locust (VESTE et al., 2018). From the leaf area index, we calculated a leaf area density of $0.7 \mathrm{~m}^{2} \mathrm{~m}^{-3}$ and $0.93 \mathrm{~m}^{2} \mathrm{~m}^{-3}$ for mean tree heights of $6.4 \mathrm{~m}$ and $5.94 \mathrm{~m}$ for poplar and black locust, respectively. The tree strip density was derived from the product of the leaf area density and the drag coefficient, resulting in values of $0.14 \mathrm{~m}^{2} \mathrm{~m}^{-3}$ for poplar and $0.2 \mathrm{~m}^{2} \mathrm{~m}^{-3}$ for black locust.

Long-term mean air temperature at the site is $9.6^{\circ} \mathrm{C}$ and the mean annual sum of precipitation is $568 \mathrm{~mm}$ (data from Cottbus in $30 \mathrm{~km}$ distance from Forst for 1981-2010, DWD, 2020a; DWD, 2020b). The main wind direction at the agroforestry and monoculture system is west south-west (Fig. 4.2) with mean wind velocities of $2.65 \mathrm{~m} \mathrm{~s}^{-1}$ and 2.31 $\mathrm{m} \mathrm{s}^{-1}$ at the agroforestry and monoculture system, respectively. The mean wind velocity at the agroforestry system was higher than at the monoculture system, due to different measurement heights of $10 \mathrm{~m}$ at the agroforestry and $3.5 \mathrm{~m}$ at the monoculture system.

\subsubsection{Measurements and model validation}

We deploy two flux towers with a height of $10 \mathrm{~m}$ at the agroforestry system and $3.5 \mathrm{~m}$ at the monoculture system. Each tower is equipped with the same set of sensors to measure net radiation, three-dimensional wind components, wind direction, air temperature, relative

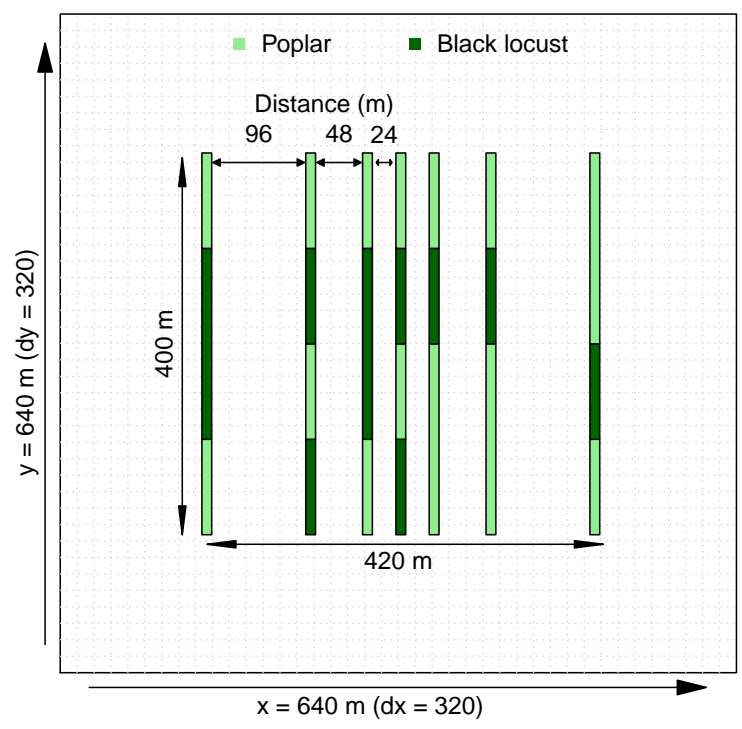

Figure 4.1: Design of the model domain. Light green areas correspond to poplar trees, whereas dark green areas correspond to black locust trees. The horizontal grid spacing is $\Delta \mathrm{x}$ $=\Delta \mathrm{y}=2 \mathrm{~m}$ and the vertical grid spacing $\Delta \mathrm{z}=1 \mathrm{~m}$. 


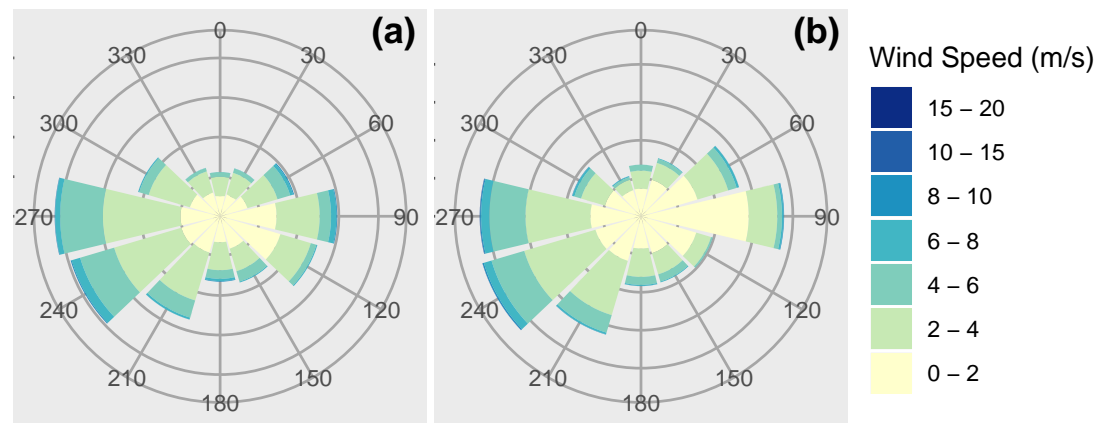

Figure 4.2: Wind roses for wind measurements at the flux tower in Forst at (a) the agroforestry system and (b) the monoculture system from 2016 to 2018.

humidity, precipitation, air pressure, ground heat flux and soil temperature (see MARKWITZ et al., 2020 for detailed information). Actual evapotranspiration $\left(\mathrm{ET}_{a c t}\right)$ representative for the whole agroforestry system was measured with the eddy covariance method following a low-cost eddy covariance set-up (MARKWITz et al., 2020; MARKWITZ et al., 2019). For this study we used data from 2016.

Simulated wind velocities as well as derived evapotranspiration were validated with direct measurements of wind velocity, air temperature and relative humidity at a $48 \mathrm{~m}$ wide crop alley in 2016 (KANZLER et al., 2018). Measurements were performed at 3, 9, and $15 \mathrm{~m}$ west and east of the tree strip, in the centre of the $48 \mathrm{~m}$ wide crop alley at $24 \mathrm{~m}$ and at the monoculture system (Fig. 4.1). The measurement height was $1 \mathrm{~m}$ above ground. Further details on micro-climate measurements can be found in (KANZLER et al., 2018).

\subsubsection{Estimation of evapotranspiration}

We calculated a spatially varying potential evapotranspiration from simulated wind velocity and meteorological parameters measured at the agroforestry system (Fig. 4.3). We used the Penman-Monteith equation to calculate a potential evapotranspiration after the FAO standard (ALLEN et al., 1998) in units of $\mathrm{mm} \mathrm{d}^{-1}$ :

$$
E T_{0}=\frac{0.408 s\left(R_{N}-G\right)+\gamma\left[\frac{900}{\left(\overline{T_{a}}+273\right)}\right] U_{2} \cdot V P D}{s+\gamma\left(1+0.34 U_{2}\right)}
$$

with the mean daily slope of the saturation vapour pressure, $s\left(\mathrm{kPa}^{\circ} \mathrm{C}^{-1}\right)$, net radiation, $\mathrm{R}_{N}\left(\mathrm{MJ} \mathrm{m}^{-2} \mathrm{~d}^{-1}\right)$, ground heat flux, $\mathrm{G}\left(\mathrm{MJ} \mathrm{m}^{-2} \mathrm{~d}^{-1}\right)$, psychrometric constant, $\gamma\left(\mathrm{kPa}^{\circ}\right.$ $\left.\mathrm{C}^{-1}\right)$, mean daily air temperature, $\overline{T_{a}}\left({ }^{\circ} \mathrm{C}\right)$, wind velocity at $2 \mathrm{~m}$ height above ground, $\mathrm{U}_{2}$ $\left(\mathrm{md}^{-1}\right)$ and vapour pressure deficit, $\mathrm{VPD}(\mathrm{kPa})$. 
The wind velocity at $2 \mathrm{~m}$ height above ground was computed as follows

$$
\begin{aligned}
U_{\text {frac }} & =\frac{\bar{U}}{U_{\text {Ref }}} \\
U_{2} & =U_{\text {frac }} \cdot U_{2 m, c o r},
\end{aligned}
$$

with the simulated mean wind velocity over the agroforestry system at $2 \mathrm{~m}$ height, $\bar{U}(\mathrm{~m})$, the simulated reference wind velocity at $2 \mathrm{~m}$ height, $\mathrm{U}_{\text {Ref }}(\mathrm{m})$, and the measured wind velocity at the monoculture system corrected for a measurement height of $2 \mathrm{~m}, \mathrm{U}_{2 m \text {,cor }}$ $(\mathrm{m})$. For this calculation we chose the wind velocity from the monoculture system due to the undisturbed flow at this site. The wind velocity measured over the agroforestry system might be disturbed by the tree strips, especially at westerly wind directions. $\bar{U}$ and $\mathrm{U}_{R e f}$ correspond to the mean over the last 15 minutes of the 30-minute simulation period.

$\mathrm{U}_{2 m, c o r}$ was computed as

$$
U_{2 m, c o r}=U_{z} \cdot \frac{4.87}{67.8 \cdot z_{m}-5.42}
$$

with the wind velocity at height $\mathrm{z}, \mathrm{U}_{z}$, and the measurement height, $\mathrm{z}_{m}$ (Allen et al., 1998).

Finally, we corrected the potential evapotranspiration with the crop coefficient, $\mathrm{C}_{\text {crop }}$

$$
C_{\text {crop }}=\frac{d E T_{a c t}}{d E T_{0}}
$$

which is the slope between hourly actual evapotranspiration, $\mathrm{ET}_{a c t}\left(\mathrm{mmhour}^{-1}\right)$, and hourly potential evapotranspiration (Eq. 4.1), sorted per day. We used the lmodel2 function from the lmodel2 package (LEGENDRE et al., 2018) to calculate the linear regression between $\mathrm{ET}_{\text {act }}$ and $\mathrm{ET}_{0}$. We chose the major axis linear regression method assuming similar errors in $\mathrm{x}$ and $\mathrm{y}$ (WEBSTER, 1997).

We derived then a spatially varying actual evapotranspiration $\mathrm{ET}_{a c t, L E S}$ as follows

$$
E T_{\text {act }, L E S}=C_{\text {crop }} \cdot E T_{0}
$$

\subsubsection{LES set-up}

We simulated the flow-field over the agroforestry system with the All Scale Atmospheric Model (ASAM, JäHN et al., 2015; JÄHN et al., 2016). ASAM is a non-hydrostatic and fully compressible model, which is treated in a Large Eddy Simulation (LES) mode. LESs resolve large eddies as per the governing Euler equations (i.e. the continuity equation, the equation of motion and the energy equation). Small eddies on subgrid-scales, thus smaller than the grid size, need to be parametrized (GERmano et al., 1991). 


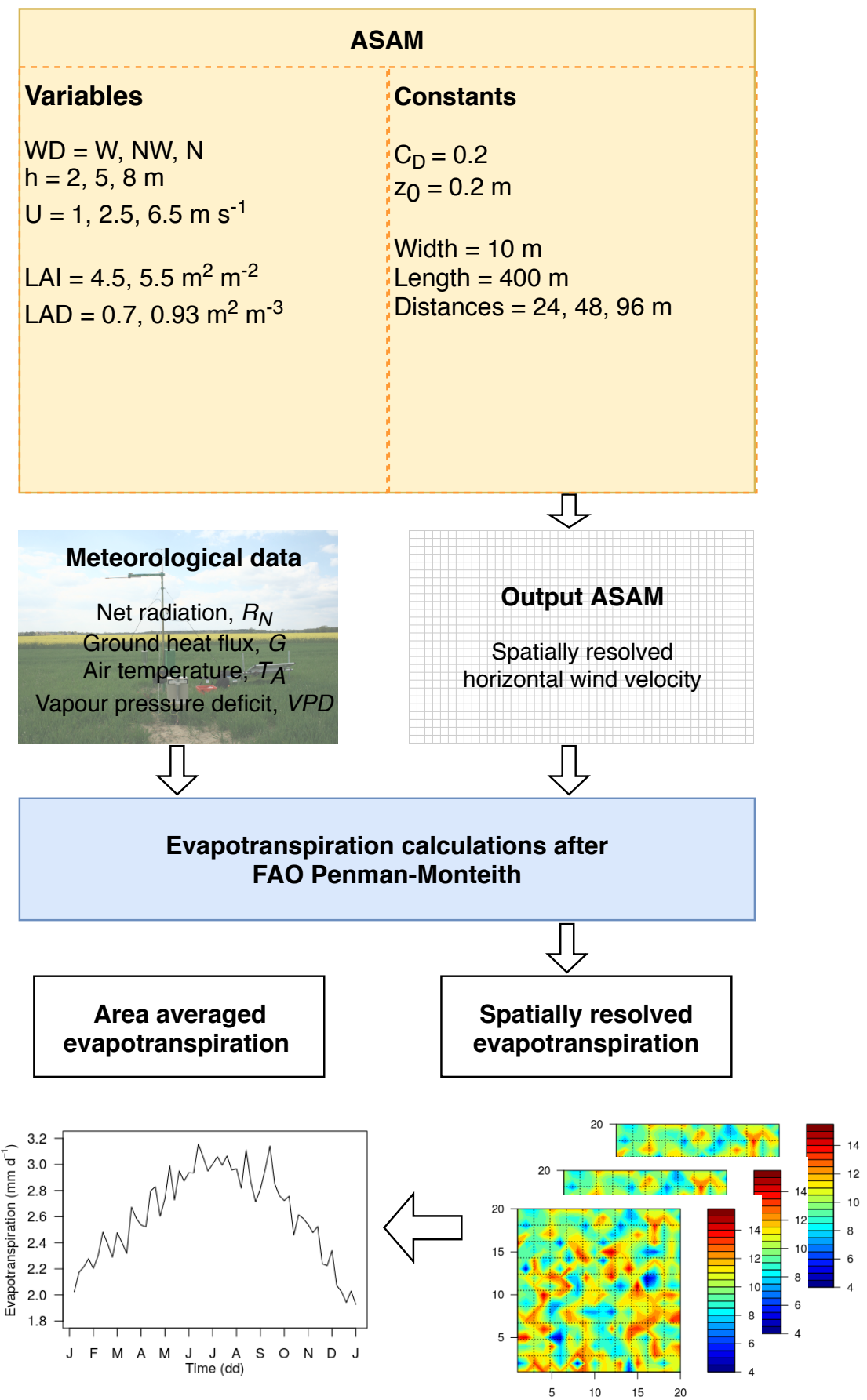

Figure 4.3: Schematic work-flow of the wind velocity simulation and evapotranspiration estimation. 
The governing compressible Euler equations in the flux-form (JÄHN et al., 2015) are

$$
\begin{aligned}
& \frac{\partial \rho}{\partial t}+\nabla \cdot\left(\rho u_{i}\right)=0, \\
& \frac{\partial\left(\rho u_{i}\right)}{\partial t}+\nabla\left(\rho u_{i} u_{i}\right)=-\nabla \cdot \tau-\nabla p-\rho g-2 \Omega \times\left(\rho u_{i}\right), \\
& \frac{\partial(\rho \Phi)}{\partial t}+\nabla\left(\rho u_{i} \Phi\right)=-\nabla \cdot q_{\Phi}+S_{\Phi},
\end{aligned}
$$

with the air density, $\rho\left(\mathrm{kg} \mathrm{m}^{-3}\right)$, the wind velocity in $\mathrm{x}, \mathrm{y}$, and $\mathrm{z}$ direction, $\mathrm{u}_{i}(\mathrm{~m})$, with $\mathrm{i}=1-3$, the gravitational acceleration, $\mathrm{g}=9.81\left(\mathrm{~m}^{2} \mathrm{~s}^{-1}\right)$, the air pressure, $\mathrm{p}(\mathrm{hPa})$, the earth's angular velocity vector, $\Omega\left(\mathrm{s}^{-1}\right)$, a scalar, $\Phi$, the combined scalar source term, $\mathrm{S}_{\Phi}$, and the subgrid-scale term for momentum, $\tau$, and a scalar, $\mathrm{q}_{\Phi}$. In this study the scalar in the energy equation (Eq. (4.9)) is the dry potential temperature, but can be any variable depending on the studied process.

The effect of the canopy drag force on the mean flow is included into the Navier-Stokes equation (Eq. (4.8)) by neglecting the Coriolis force and buoyancy effects, hence, assuming a neutrally stratified atmosphere

$$
\frac{\partial\left(\rho u_{i}\right)}{\partial t}+\nabla\left(\rho u_{i} u_{i}\right)=-\nabla \cdot \tau-\nabla p-c_{d} L A D U u_{i} \rho
$$

The last term on the right hand side of Eq. 4.10 describes the canopy drag force acting on the mean flow following WATANABE, 2004 and SHAW et al., 1992, with the canopy drag coefficient $\mathrm{c}_{d}=0.2$, the leaf area density, $\mathrm{LAD}=\mathrm{LAI} / \mathrm{h}$, and the instantaneous mean wind velocity, $\mathrm{U}=\sqrt{u^{2}+v^{2}+w^{2}}$. For simplicity, we kept the LAD constant inside the tree area. For short crops and shrubs the LAD is constant within the canopy, whereas, for forests the LAD is highest inside the crown area and lowest in the stem area.

Physically, the canopy drag force can not change the sign of the velocity components inside the canopy, it can only reduce the magnitude of the velocity components. Therefore, we limited the impact of the drag force on the wind velocity components, such that the wind velocity can only be reduced to zero. We followed the same strategy as presented in MARONGA et al., 2015 and the implementation in the Parallelized Large-Eddy Simulation Model (PALM).

The effect of the canopy on the turbulence is included into the prognostic equation for the turbulent kinetic energy (TKE), which is TKE/m $=\bar{e}=1 / 2 \overline{u_{i}^{\prime 2}}\left(\mathrm{~m}^{2} \mathrm{~s}^{-2}\right)$. The subgrid-scale model (SGS) for the prognostic TKE equation is given as

$$
\begin{aligned}
\frac{\partial(\rho e)}{\partial t}= & -\nabla\left(\rho u_{i} e\right)+\delta_{i 3} \frac{g}{\theta_{v}}\left(u_{i} \theta_{v}\right)-\nabla \overline{\rho u_{i} u_{i}} \\
& -\nabla\left(u_{i} e\right)-\nabla\left(u_{i} p\right)-\epsilon-2 c_{d} L A D U e \rho
\end{aligned}
$$

with the dissipation rate, $\epsilon$, and the canopy effect on TKE considered in the last term on the right hand side.

For time integration we used a split-explicit Runge-Kutta or multirate infinitesimal step 
(MIS) method (KNOTH et al., 2014), which solves the slow process of advection and the fast process of sound waves separately.

The initial wind field was set to a constant wind velocity over the entire horizontal and vertical domain. We applied a periodic boundary condition in the $\mathrm{x}$ and $\mathrm{y}$ directions. On top of the domain a $10 \mathrm{~m}$ thick damping layer with free slip conditions was defined, such that gravity waves are dissipated and not reflected back to the surface. At the domain surface, we set a constant roughness length of $0.02 \mathrm{~m}$, which represents a homogeneous grass surface.

\subsubsection{Cases for the wind velocity simulation}

The model domain had dimensions of $640 \times 640 \times 50 \mathrm{~m}$, with grid sizes of $2 \mathrm{~m}$ in the horizontal direction and $1 \mathrm{~m}$ in the vertical direction. This yields $320 \times 320 \times 50$ grid points (Fig. 4.1). In this study the agroforestry system consists of seven tree strips of 400 $\mathrm{m}$ length and tree strip distances of 96,48 and $24 \mathrm{~m}$. The tree strips were characterized by tree width, tree base height, tree top height and tree density. The tree density is defined as the product of the leaf area density and the drag coefficient, $\mathrm{c}=\mathrm{c}_{d}$. LAD.

In this study we ran nine model simulations with three wind directions (north, north-west, west), three tree heights $(2,5,8 \mathrm{~m})$ and one reference case, representing a monoculture system without trees. The initial mean wind velocity was $2.5 \mathrm{~m} \mathrm{~s}^{-1}$, which was a representative mean wind velocity at the site (Figure 4.2).

\subsubsection{Statistics}

We studied the impact of tree strips on wind velocity by the relative wind velocity reduction, $\mathrm{U}_{\text {frac }}$ (Eq. 4.2), as the fraction between the wind velocity field for the three tree heights/ wind directions at $2 \mathrm{~m}$ above ground and the wind velocity field for the reference agricultural system without trees. The respective wind velocity represents the mean of the last 15 minutes of the 30 minute simulation time. After 15 minutes the turbulence was well developed and the boundary layer well mixed.

Areal means of the daily sum of evapotranspiration were calculated as

$$
\langle E T\rangle=\frac{\sum_{i=1}^{\Delta x} \sum_{j=1}^{\Delta y} E T_{i j}}{\Delta x \cdot \Delta y},
$$

with the area averaged evapotranspiration, $\langle\mathrm{ET}\rangle$, the evapotranspiration at each grid cell, $\mathrm{ET}_{i j}$, the number of grid cells in x-direction, $\Delta \mathrm{x}$, and the number of grid cells in y-direction, $\Delta \mathrm{y}$.

\subsection{Results and discussion}

\subsubsection{Wind simulations over agroforestry}

\subsubsection{Vertical structure of the wind field}

The mean wind velocity is reduced behind the tree strips (see example for the simulation with westerly winds and tree heights of $8 \mathrm{~m}$, Fig. 4.4 (a)). The area of wind velocity reduction depends on the distance between tree strips. For a tree strip distance of $96 \mathrm{~m}$ the 
wind velocity reduction extends until a distance of eight times the tree height. Thereafter, the mean wind velocity increases, leading to higher wind velocity at the windward site of the tree strip. For shorter distances between tree strips $(\leq 48 \mathrm{~m})$ the leeward wind velocity reduction extends until the windward site of the opposite tree strip.

The vertical wind velocity shows a strong upward motion at the leading edge of the windward tree strips (Fig. 4.4 (b)). Similarly, such upward motion is seen at almost all tree strips, albeit at lower velocity.

The turbulent kinetic energy inside the tree strips and in the lee of the tree strips is close to zero (Fig. 4.4 (c)). After the area of strongest wind velocity reduction TKE is enhanced. The change in distance between tree strips from larger to smaller and smaller to larger distances increases TKE in between the tree strips. This is explicitly critical for crops in the vicinity to the tree strips, as those are endangered by lodging, which is the displacement of shoots from small grained cereals from their vertical stance (BERRY et al., 2004). Lodging is most critical under gusty winds. An increase in tree strip distance leads to higher TKE in between the tree strips, as larger eddies can penetrate the gap. Constant tree strip distances of approximately $48 \mathrm{~m}$ would be more favourable for the prevention of crop damage, rather than variable tree strip distances.

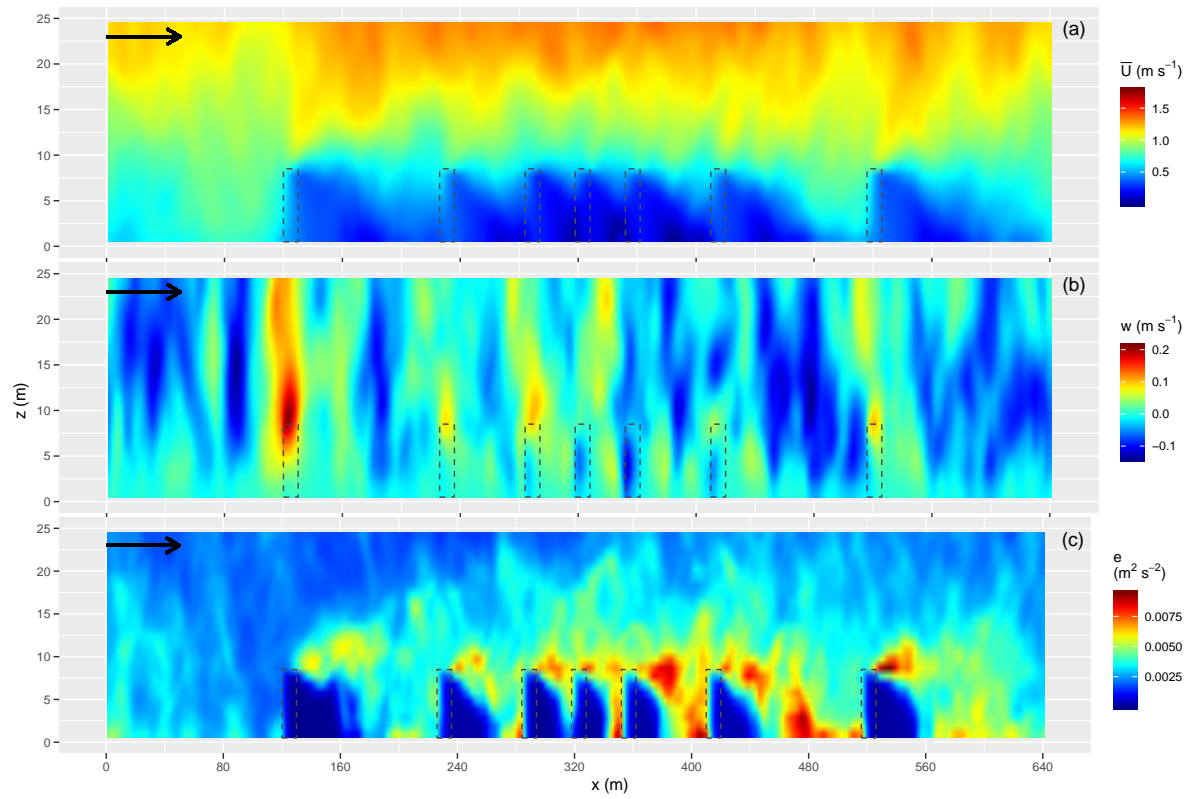

Figure 4.4: Exemplary $x-z$ plane of mean horizontal wind velocity, $\bar{U}$ (a), vertical wind velocity component, $\mathrm{w}$ (b) and turbulent kinetic energy, e (c) at $\mathrm{y}=320 \mathrm{~m}$ for a westerly wind direction and a tree height of $8 \mathrm{~m}$. The locations of the tree strips are indicated by the grey dashed boxes. The scale of the x-axis is approximately 26 times that of the z-axis. 


\subsubsection{Validation of simulated wind velocity}

Simulated and measured wind velocity reductions $\left(\mathrm{U}_{\text {frac }}\right)$ agree in response to the presence of the tree strips (Fig. 4.5). Model simulations and measurements show the strongest wind velocity reduction in the lee of the tree strips and the lowest wind velocity reduction at the windward site of the tree strip for westerly and north-westerly winds (Fig. 4.5 (a) and (b)). For northerly winds model simulations and measurements show the strongest wind velocity reduction close to the tree strips and the lowest wind reduction in the centre between tree strips (Fig. 4.5 (c)).

The magnitude of the median wind velocity increase towards the windward site of the tree strip for westerly and north-westerly winds is lower for the model simulations than for the measurements. We quantified the difference in median wind velocity increase for those wind directions by the slope of $\mathrm{U}_{\text {frac }}$ between the tree strips.

For model simulations the slope was $0.61 \% \mathrm{~m}^{-1}\left(\mathrm{R}^{2}=0.98\right)$ and $0.72 \% \mathrm{~m}^{-1}\left(\mathrm{R}^{2}=0.95\right)$ for westerly and north-westerly winds, respectively, and for measurements the slope was $0.91 \% \mathrm{~m}^{-1}\left(\mathrm{R}^{2}=0.7\right)$ and $0.96 \% \mathrm{~m}^{-1}\left(\mathrm{R}^{2}=0.7\right)$ for westerly and north-westerly winds, respectively. We interpret the different slopes as an effect of the idealised model set-up with uniform trees and the assumption of a constant leaf area density across the vertical domain of the trees. ZHOU et al., 2005 showed that an increase in tree density (reduction in porosity) causes an increased slope of the wind velocity enhancement. Hence, a decrease in tree strip porosity might cause an even better match of model simulations and measurements. 

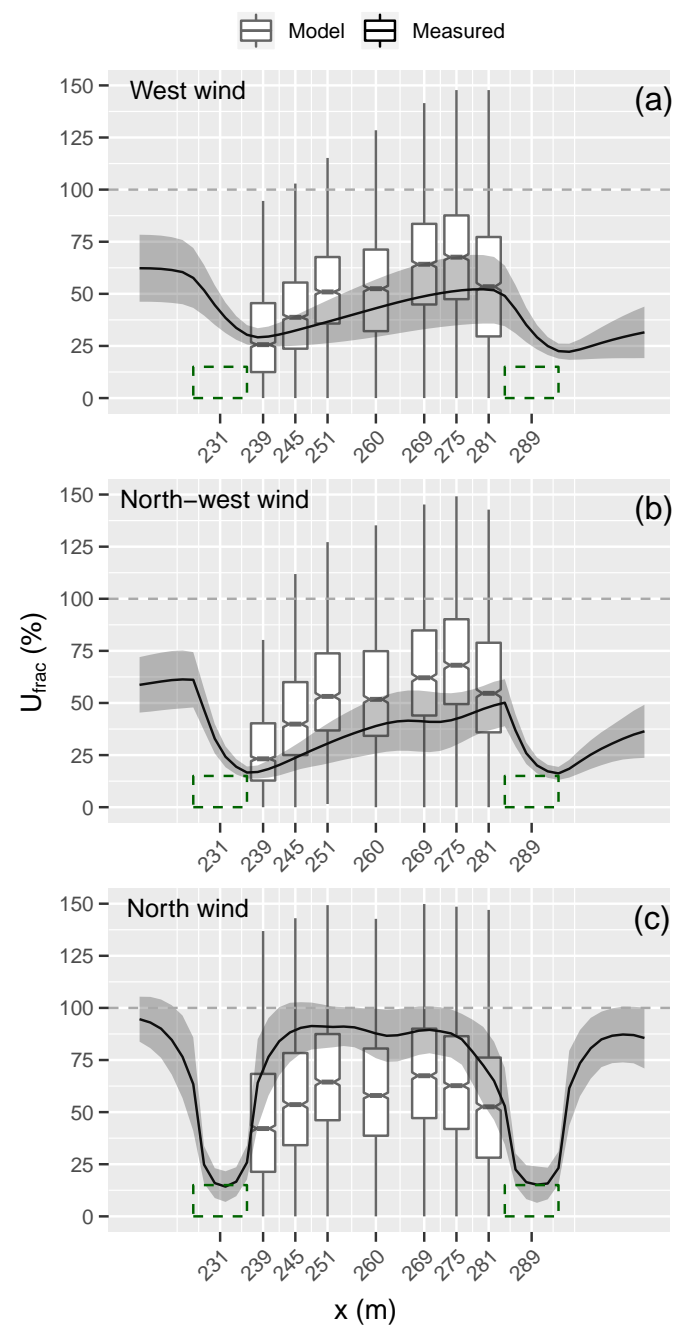

Figure 4.5: Validation of simulated wind velocity reduction against measurements for three different wind directions: (a) west, (b) north-west and (c) north at $2 \mathrm{~m}$ above ground, $\mathrm{y}=320$ $\mathrm{m}$, at the westerly crop field of $48 \mathrm{~m}$ width and a tree height of $2 \mathrm{~m}$. The data from the model simulation represent the mean (bold lines) and the standard deviation (ribbons) over the last 15 minutes of the 30 minute simulation time. Boxplots correspond to measured wind velocities at the site filtered for the wind direction and according to wind velocities $\geq 1 \mathrm{~ms}^{-1}$ at the reference site. In Figure (c) we included also wind velocity measurements for southerly winds. Tree strip locations are indicated by green dashed boxes.

\subsubsection{Effect of tree height, porosity and distance on wind velocity}

In order to investigate the effect of tree height, porosity and the distance between tree strips on the wind velocity, we selected a horizontal cross-section at $\mathrm{y}=320 \mathrm{~m}$ in $2 \mathrm{~m}$ height above ground.

The mean wind velocity decreased with increasing tree height for both west and northwest winds (Table 4.1). With north winds the wind velocity was reduced for all tree heights 
but without any relationship. The linear relationship between tree height and wind velocity reduction is in agreement with direct measurements presented by BöHM et al., 2014. They found the linear relationship independently on the season, but they reported a stronger reduction during summer when trees were leafy.

Tree height had also an effect on the extension of the area of maximum wind velocity reduction (quiet zone). We found an extension of the quiet zone towards the centre of the crop field with increasing tree height for westerly and north-westerly winds (Fig. 4.6). For a tree height of $2 \mathrm{~m}$ the quiet zone extended until $2 \mathrm{~h}$, with $\mathrm{h}$ the tree height, independent of wind direction. For the other tree heights the quiet zone extended the most for westerly winds and trees with a height of $8 \mathrm{~m}$. For north-westerly winds the quiet zone was generally shorter due to the different inflow direction, compared to westerly winds.

The tree porosity increase from $0.14 \mathrm{~m}^{2} \mathrm{~m}^{-3}$ to $0.056 \mathrm{~m}^{2} \mathrm{~m}^{-3}$ for poplar and $0.2 \mathrm{~m}^{2} \mathrm{~m}^{-3}$ to $0.08 \mathrm{~m}^{2} \mathrm{~m}^{-3}$ for black locust led to a lower mean wind velocity reduction compared to a lower tree strip porosity (Table 4.1). The effect was most pronounced for westerly and north-westerly winds, independent of tree height, whereas for northerly winds the effect was negligible.

The lower wind velocity reduction for a more porous tree strip coincides with an extension of the area of maximum wind velocity reduction towards the centre between the tree strips (Fig. 4.7). A tree strip with higher density would lead to a reduction of the quiet zone and an increased wind velocity at the windward site of the tree strip.

A change in tree strip distance from higher to lower distances (from $96 \mathrm{~m}$ to $24 \mathrm{~m}$ ) caused a wind velocity reduction for westerly and north-westerly winds, independent of tree height (Figs. 4.7 and 4.8). For northerly winds the wind velocity reduction depended

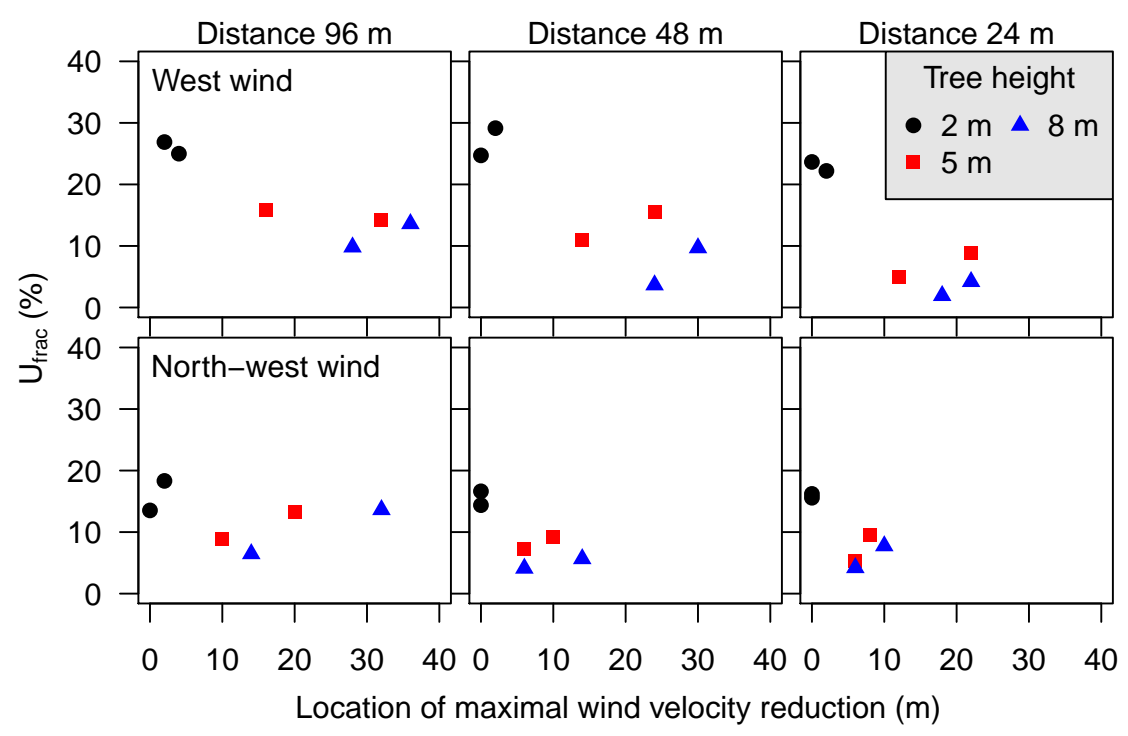

Figure 4.6: Maximum wind velocity reduction relative to the open field versus its location behind the tree strip, for westerly winds (top row) and north-westerly winds (bottom row), tree heights of 2, 5 and $8 \mathrm{~m}$ and tree strip distances of 24,48 and $96 \mathrm{~m}$. 


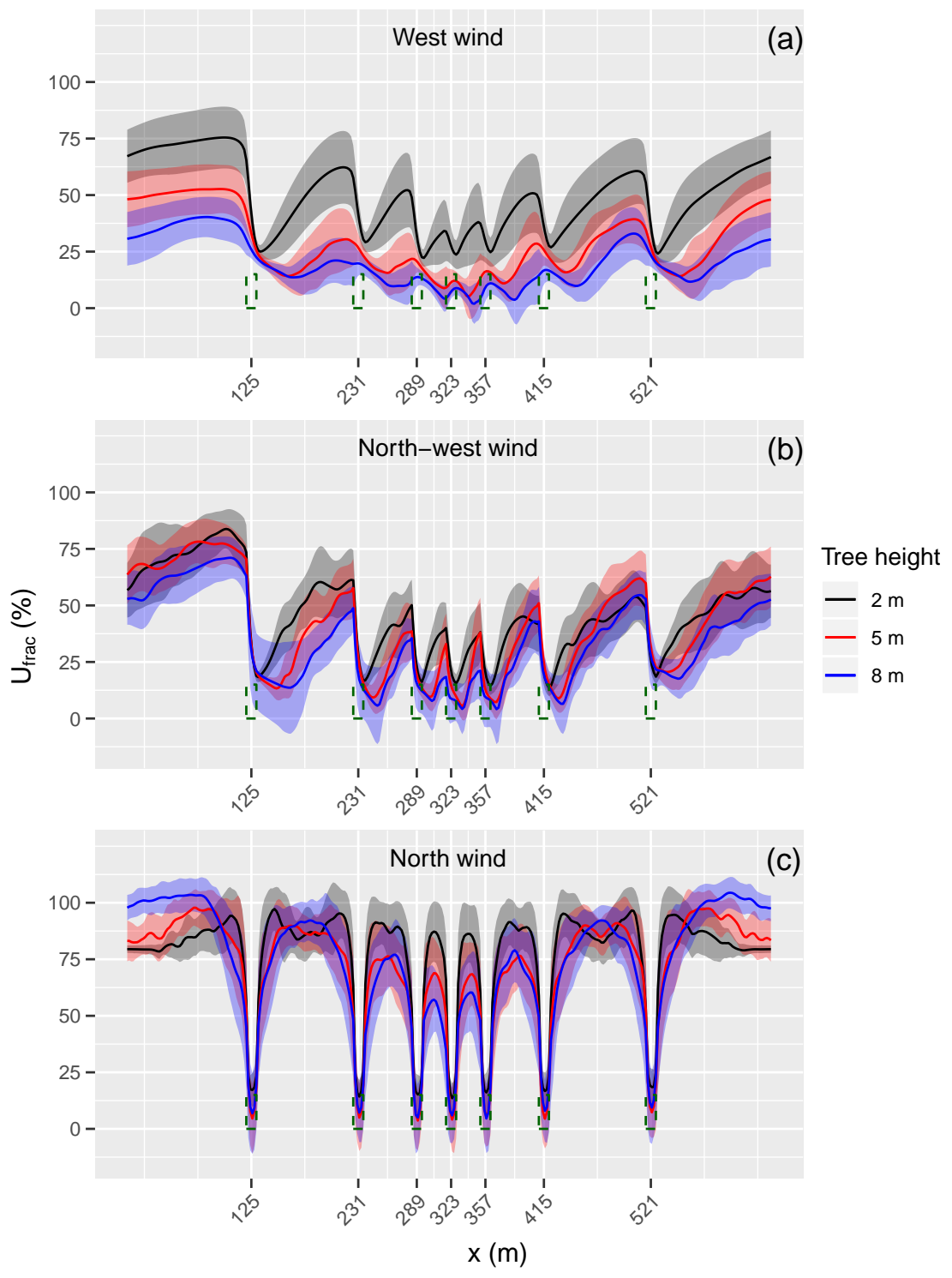

Figure 4.7: Relative wind velocity reduction for (a) west wind, (b) north-west wind and (c) north wind, at a height of $2 \mathrm{~m}$ above and a transect at $\mathrm{y}=320 \mathrm{~m}$. Each sub-plot contains time series for tree heights of 2,5 and $8 \mathrm{~m}$. The data presented are a mean over the last 15 minutes simulation time and the respective standard deviation is included as ribbons around the lines. The locations of the tree strips are indicated by the green dashed boxes. 
Table 4.1: Mean relative wind velocity reduction at $\mathrm{y}=320 \mathrm{~m}$, a height of $2 \mathrm{~m}$ above ground, for tree heights of 2, 5 and $8 \mathrm{~m}$, westerly, north-westerly and northerly wind directions, and two different tree porosities.

\begin{tabular}{l|ccc}
\hline \multirow{2}{*}{ Tree height $(\mathrm{m})$} & \multicolumn{2}{c}{5} & 8 \\
\hline & \multicolumn{4}{|c}{$\mathrm{c}=0.056$} & (poplar) & and $\mathrm{c}=0.08$ & (black locust) \\
\hline $\mathrm{W}$ & $57.3 \pm 13.2$ & $42.6 \pm 11.63$ & $32 \pm 10.62$ \\
$\mathrm{NW}$ & $47.4 \pm 14$ & $48.5 \pm 21.2$ & $39.2 \pm 18.4$ \\
$\mathrm{~N}$ & $82.3 \pm 19.7$ & $77.3 \pm 23.4$ & $77.4 \pm 26.1$ \\
\hline & $\mathrm{c}=0.14$ (poplar) & and $\mathrm{c}=0.2$ & (black locust) \\
\hline $\mathrm{W}$ & $51.5 \pm 16.5$ & $29.63 \pm 14.7$ & $21 \pm 11$ \\
$\mathrm{NW}$ & $47.8 \pm 19$ & $42.4 \pm 22.7$ & $35.1 \pm 20.3$ \\
$\mathrm{~N}$ & $80.72 \pm 22.62$ & $75.45 \pm 25.7$ & $76.6 \pm 28.4$
\end{tabular}

also on tree strip distance (Figure 4.7 (c)), but, the wind velocity reduction was of lower magnitude than for westerly and north-westerly winds.

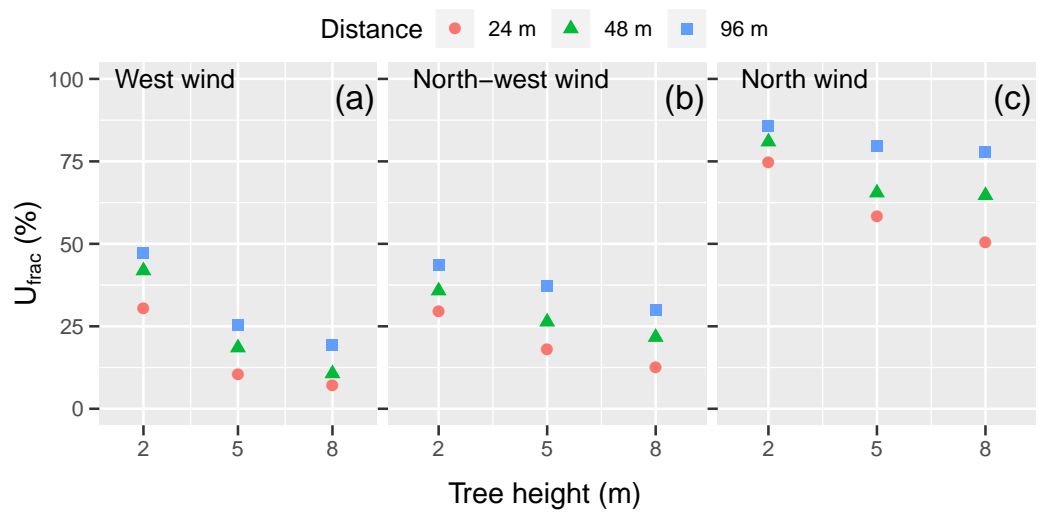

Figure 4.8: Relative wind velocity reduction against tree height for westerly winds, (a), north-westerly winds, (b), and northerly winds, (c), for three tree strip distances of 24, 48 and $96 \mathrm{~m}$.

We interpret the reduction in wind velocity for westerly and north-westerly winds (4.8 (a) and (b); Fig. 4.9) as a breakdown of larger sized eddies into smaller sized eddies. Shorter distances between tree strips inhibit the recovery of the larger sized eddies, whereas for larger distances the eddies recover. This recovery leads to higher wind velocities on the windward site of the tree strip. Independent measurements at the same site confirm a quadratic relation between decreasing relative wind velocity reduction and increasing distance between tree strips (BöHM et al., 2014).

For northerly winds we interpret the dependence of wind velocity reduction from tree strip distance as a combination of deceleration and acceleration of wind velocity at the edges of the tree strips. At locations with shorter distances between tree strips (in the centre of the northerly site) the dynamic pressure is higher than at locations with higher distance (at the outer edges of the northerly site). The pressure gradient of relatively high 
and low dynamic pressure leads to a preferred flow from the centre of the northerly site (high pressure) to the outermost edges (lower pressure). Due to the flow continuity the wind velocity is reduced at shorter tree strip distances $(24 \mathrm{~m})$ and enhanced at wider tree strip distances (48 and $96 \mathrm{~m}$ ).
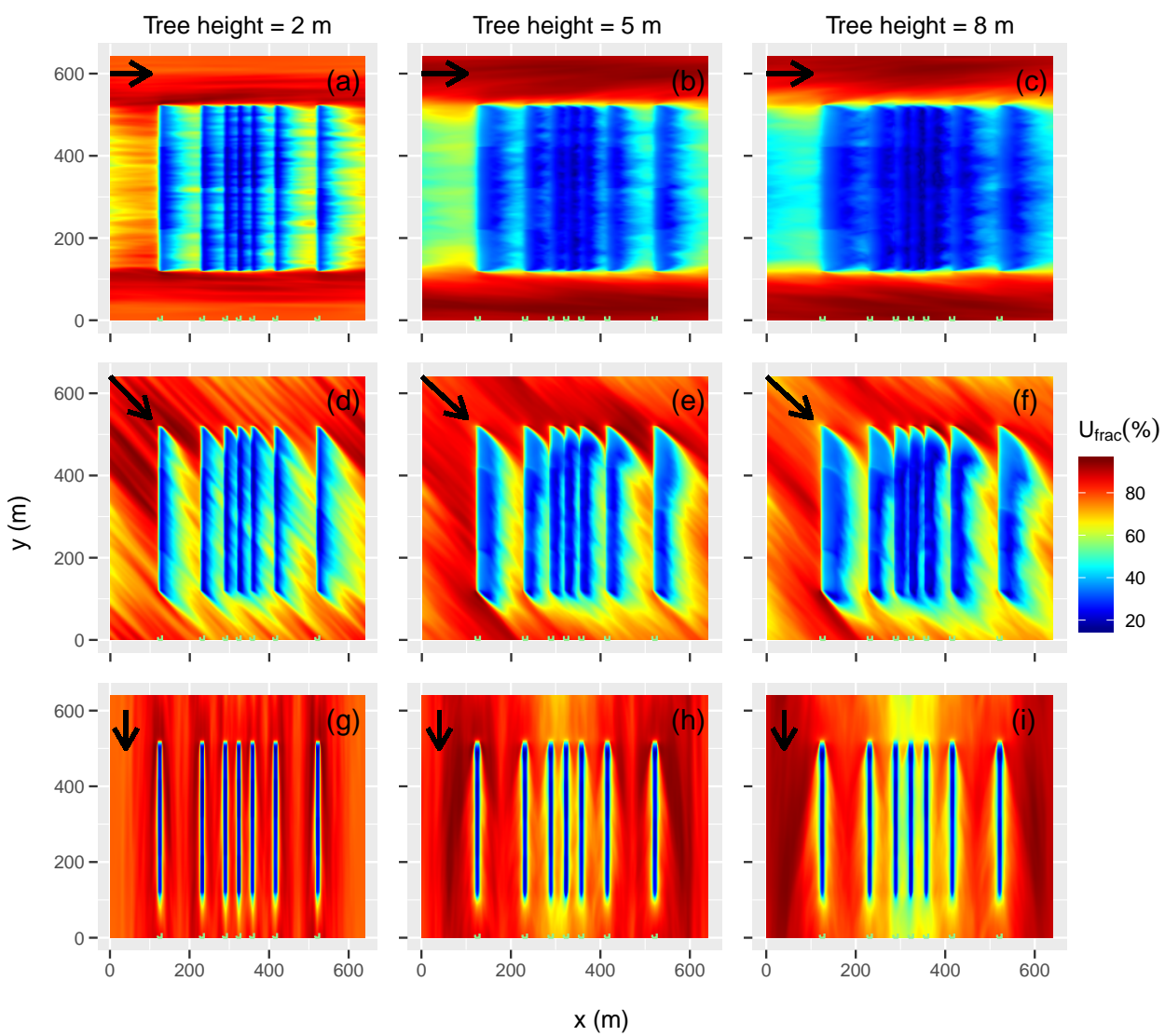

Figure 4.9: Relative wind velocity reduction in a $x-y$ plane for west wind (a)-(c), north-west wind (d)-(f) and north wind (g)-(i) at a domain height of $2 \mathrm{~m}$ for tree heights of 2,5 and $8 \mathrm{~m}$. The wind directions are indicated by the black arrows. The data present a mean over the last 15 minutes of the 30 minute simulation time. 


\subsubsection{Wind effects on evapotranspiration}

\subsubsection{Validation of derived evapotranspiration}

Simulated and measured ET increase with distance from the tree strip for westerly and north-westerly winds (Fig. 4.10). With north winds, ET is reduced only near the tree strips, while in the centre, ET is reduced neither for simulations nor for measurements. The visual agreement between ET from simulations and measurements, contradicts with differences between the magnitude of ET. The median of the relative ET reduction from measurements is lower than from simulations in the lee of the tree strips for west and north-west wind, whereas at the windward site the median of the relative ET reduction from measurements and simulations agree.

We interpret the disagreement between ET from simulations and measurements for west and north-west winds as an effect of the unaccounted spatial variability of air temperature, relative humidity and incident radiation in the simulations. In ET derived from simulations we account only for a spatially varying wind velocity and assume that incident radiation, relative humidity and air temperature are the same across the whole agroforestry system. In contrast to the derivation of ET from simulations, ET derived from the microclimate measurements within the horizontal transect are spatially variable. The assumption of equal meteorological conditions across the whole agroforestry system for simulations hold only for the windward site of the tree strips. There, the air undergoes better mixing due to increased wind velocity. This causes a faster removal of moist air, leading to a higher vapour pressure deficit and subsequently increased ET. Our interpretation agrees with MCNAUGHTON, 1988, who showed that the water vapour pressure during the middle of the day was higher in the sheltered area behind the tree strips (the quiet zone) and lower in the unsheltered area at the windward site of the tree strip (the wake zone). 

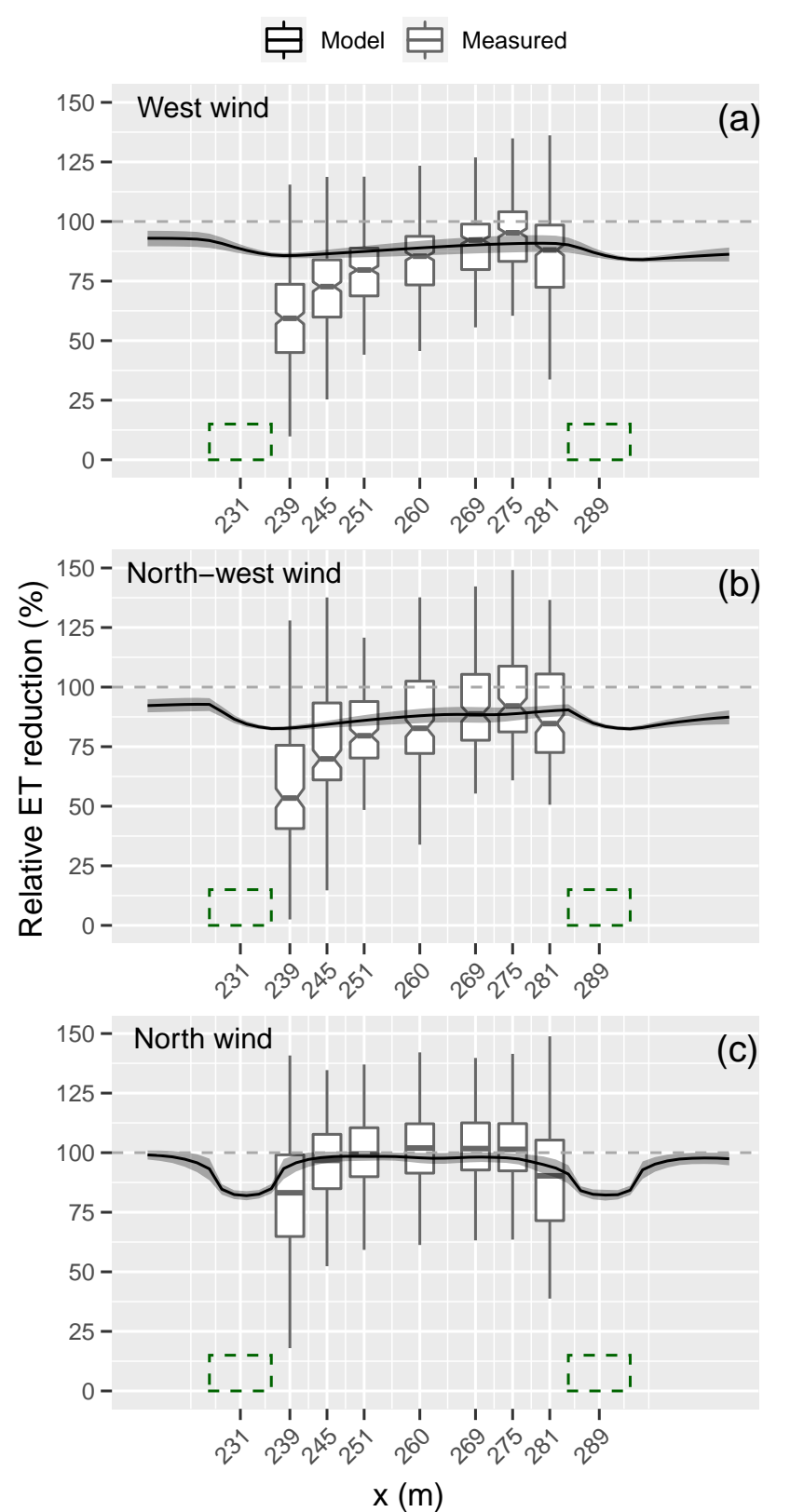

Figure 4.10: Relative reduction of evapotranspiration for west wind (a), north-west wind (b) and north wind (c) at a domain height of $2 \mathrm{~m}$ above ground, at $\mathrm{y}=320 \mathrm{~m}$ and at the westerly $48 \mathrm{~m}$ wide crop field. The time series correspond to the respective model simulation with a tree height of $2 \mathrm{~m}$. The data from the model simulation represent the mean (solid line) and the standard deviation (ribbons) over the last 15 minutes of the 30 minute simulation time. Boxplots correspond to relative reductions of potential evapotranspiration derived from measurements at the site, filtered for wind direction and wind velocities $\geq 1 \mathrm{~m} \mathrm{~s}^{-1}$ at the reference site. For northerly winds (Fig. (c)) we included wind directions from the south as well. The green dashed boxes indicate the tree strip locations. 


\subsubsection{Areal differences between evapotranspiration}

Evapotranspiration is reduced within regions of reduced wind velocity for all different combinations of tree heights and wind directions by maximum $\approx-60 \mathrm{~mm}$, as shown by the difference between simulated potential ET over the agroforestry systems and the monoculture system without trees (Fig. 4.11). This reduction is due to the linear dependency of $\mathrm{ET}_{0}$ on wind velocity (Eq. (4.1)).

However, we found the strongest reduction in ET for west and north-west winds, due to the strongest reduction in wind velocity inside the tree strips and over the crop fields between tree strips (Fig. 4.11 (a)-(c) for west wind and (d)-(f) for north-west wind). For northerly winds the reduction in ET correspond to the region of the tree strips, whereas in between tree strips ET is only slightly reduced (Fig. 4.11 (g)-(i)). Assuming an annual sum of ET of approximately $400 \mathrm{~mm}$ (typical for the site (MARKWITZ et al., 2020)) a difference in ET of maximum $40 \mathrm{~mm}$ in between the $8 \mathrm{~m}$ tall tree strips for northerly winds would account for $10 \%$ of the annual sum at the specific location. Hence, even for northerly winds $10 \%$ more soil water would be available for crop growth, assuming that wind velocity is the only controlling factor of ET. Previous studies found that the presence of tree strips leads to a wetter surface within the protected area and a reduced soil drying rate, compared to an unprotected area (BLACK et al., 1988).

Nevertheless, if the protection of soils for ET losses is of interest winds parallel to the tree strips promote higher ET. To reduce the wind velocity and preventing increased water losses via ET BöHM et al., 2014 suggested to establish tree strips at the edges of the agroforestry system. 

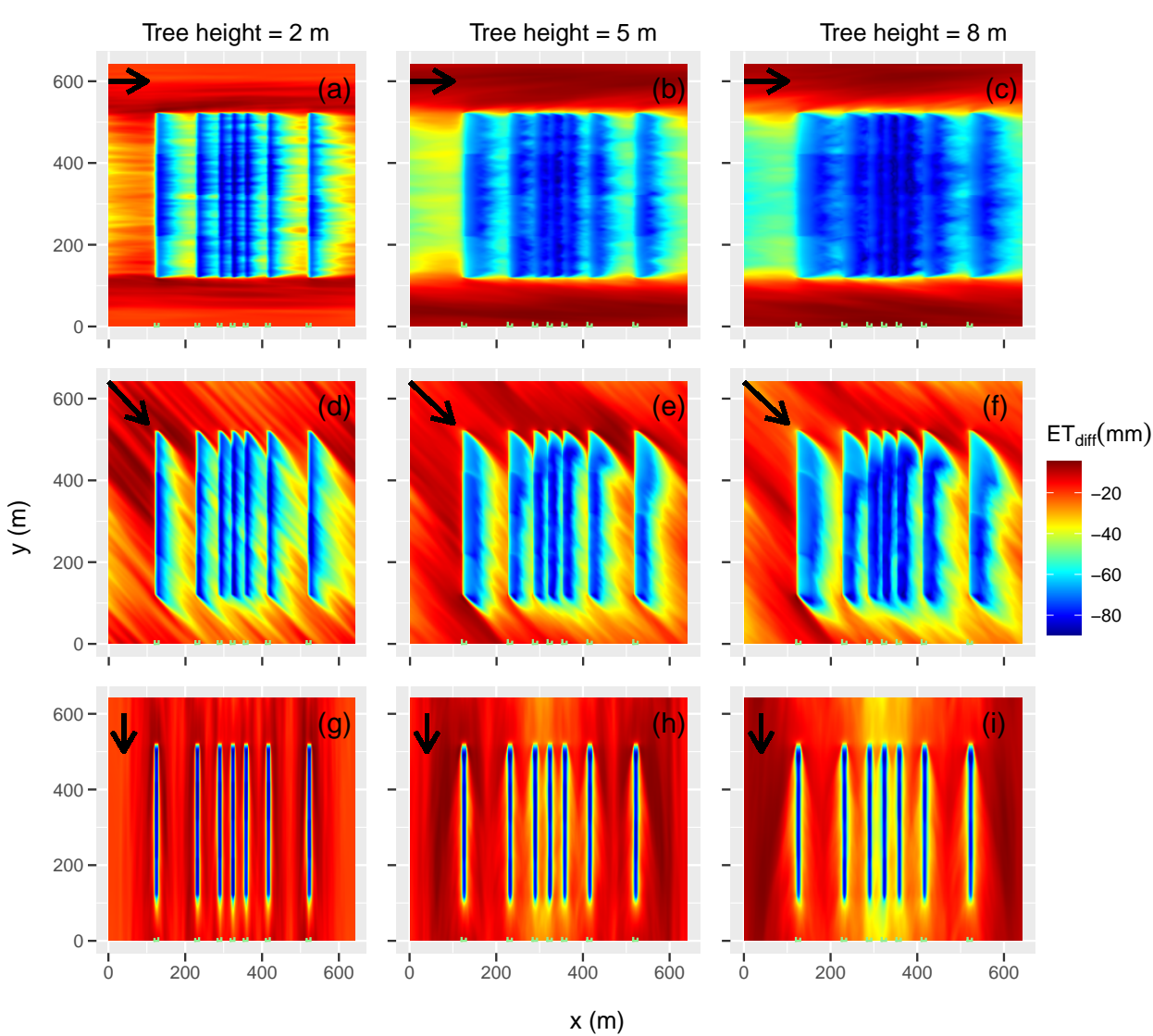

Figure 4.11: Difference between simulated potential ET over the agroforestry systems and the reference case without trees in a $x-y$ plane for west wind (a)-(c), north-west wind (d)-(f) and north wind (g)-(i) at a domain height of $2 \mathrm{~m}$ for tree heights of 2, 5 and $8 \mathrm{~m}$. The wind directions are indicated by the black bold arrows.

\subsubsection{Cumulative evapotranspiration}

The cumulative sum of area averaged potential ET (from now on only ET) for 2016 show a linear increase throughout the vegetation period until October and stays constant until the end of the year for all wind directions and tree heights (Fig. 4.12). ET was reduced for all agroforestry systems relative to the monoculture system without trees (Table 4.2). We observed a decrease in the annual sum of ET with increasing tree height between minimum $5 \%$ and maximum $8 \%$ for westerly and north-westerly winds. The reduction in ET correspond to a stronger wind velocity reduction for westerly and north-westerly winds. With northerly winds we observed a reduction of $3 \%$ independent of tree height.

The potential evapotranspiration adjusted by the crop coefficient follows the same annual cycle, but changes the magnitude of the annual sum (Fig. 4.12). After correction, the annual sum of evapotranspiration amounts to roughly $60 \%$ of the potential evapotranspiration. The ratio $\sum \mathrm{ET}_{a c t} / \sum \mathrm{ET}_{0}$ is low compared to those observed for a short rotation coppice system in the Czech-Moravian highlands between $62 \%$ and $91 \%$ (Fischer et al., 2013). The reduction of ET for the adjusted potential evapotranspiration is slightly lower than 
for the not-adjusted ET, but in the same order of magnitude.

However, the reduction in system-scale ET is relatively small, compared with the change in ET on plot-scale. The mean reduction in ET across a whole agroforestry system relative to a monoculture system was maximum $\approx 8 \%$, whereas ET inside the agroforestry system on plot scale was reduced by maximum $\approx 15 \%$ (Fig. 4.10 and 4.11). In a recent independent study we observed differences between annual sums of actual ET over AF and MC between $1 \%$ and $17 \%$ across five agroforestry and five monoculture systems (MARKWITZ et al., 2020), without a clear trend on how differences are distributed (higher ET over AF or $\mathrm{MC})$.

During the evapotranspiration calculations we considered only the effect of spatially varying wind velocity on evapotranspiration, whereas the effect of air temperature, incident radiation, soil moisture and the plant physiological properties of crops and trees were not. If the parameter would have been considered, differences in evapotranspiration were expected to be higher.

Table 4.2: Reduction of the area averaged annual sum of potential evapotranspiration over agroforestry relative to the monoculture system without trees at a height of $2 \mathrm{~m}$ above ground, for tree heights of 2,5 and $8 \mathrm{~m}$ and westerly, north-westerly and northerly winds. The data are representative for $\mathrm{c}=0.14$ (poplar) and $\mathrm{c}=0.2$ (black locust). The corrected potential evapotranspiration corresponds to the product of the potential ET and the crop coefficient.

\begin{tabular}{|c|c|c|c|}
\hline $\begin{array}{ll}\text { Tree height }(\mathrm{m}) \\
\text { Wind direction }\end{array}$ & 2 & 5 & 8 \\
\hline & \multicolumn{3}{|c|}{$\mathrm{ET}_{0}$ uncorrected } \\
\hline $\mathrm{W}$ & 5.2 & 6.4 & 7.4 \\
\hline NW & 6.0 & 6.6 & 7.9 \\
\hline \multirow[t]{2}{*}{$\mathrm{N}$} & 2.6 & 3.1 & 3.0 \\
\hline & \multicolumn{3}{|c|}{$\mathrm{ET}_{0}$ corrected } \\
\hline $\mathrm{W}$ & 4.8 & 5.9 & 3.8 \\
\hline NW & 5.5 & 6.1 & 7.3 \\
\hline $\mathrm{N}$ & 2.4 & 2.9 & 2.8 \\
\hline
\end{tabular}




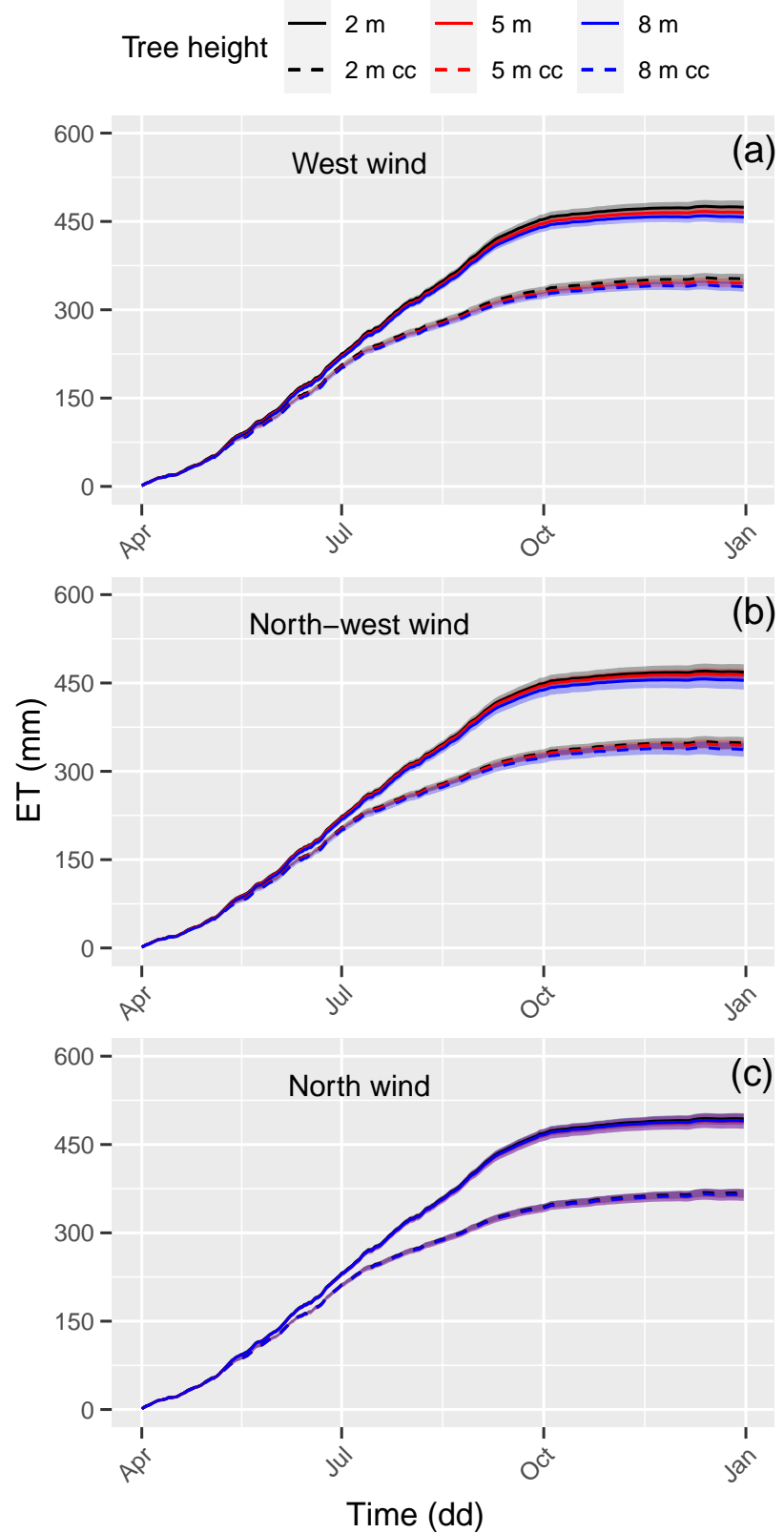

Figure 4.12: Cumulative evapotranspiration for a westerly wind direction, (a), a northwesterly wind direction, (b), and a northerly wind direction, (c). Each sub-plot shows the cumulative sum of evapotranspiration for tree heights of 2,5 and $8 \mathrm{~m}$ for the year 2016 . The change in evapotranspiration according to the standard deviation of wind velocity is included as ribbons around the lines. Solid lines correspond to the potential evapotranspiration and dashed lines correspond to the potential evapotranspiration corrected by the crop coefficient, indicated by a cc in the legend. 


\subsection{Conclusions and future work}

In this study, we performed large eddy simulations of wind velocity over one model agroforestry system and investigated the effect of wind velocity on evapotranspiration. We studied the impact of tree height, tree porosity, distance between tree strips and orientation on wind velocity.

Our results indicate a wind velocity reduction within the agroforestry system for all configurations with strong dependency on the tree strip properties. The wind velocity reduction was strongest for west and north-west winds, associated to a tree strip orientation perpendicular to the main wind direction. With north wind we observed a much lower wind velocity reduction. Increasing tree height led to a stronger wind velocity reduction in the lee and to an extension of the quiet zone towards the centre between tree strips for west and north-west winds. A higher tree strip porosity led to a lower wind velocity reduction and an extension of the quiet zone towards the centre between tree strips. We showed that for distances between tree strips larger than $48 \mathrm{~m}$ the wind velocity at the windward site of the tree strips was enhanced, which could lead to increased wind erosion and crop damage.

The wind velocity reduction led to a reduction in system-scale evapotranspiration over the agroforestry systems relative to the monoculture system. The reduction in ET was small as we considered only the effect of wind velocity on ET and neglected important parameters, such as variations in incident radiation, relative humidity, air temperature, soil moisture and soil temperature.

General recommendations for the best agroforestry design in terms of a reduction in wind velocity and evapotranspiration can not be drawn from the model simulations. The results of the model simulations are representative for one model agroforestry system. For other sites with different agroforestry designs separate simulations need to be performed and under consideration of other processes and parameters, the model can be an ideal tool to understand interactions within an agroforestry system.

\subsection{Author contribution}

CM performed the model implementations and simulations, analysed the data, and wrote the manuscript. LS and AK wrote the project's scientific proposal, acquired the funding as part of the BonaRes SIGNAL consortium, and contributed to analysis, and manuscript writing. MK provided measurements of microclimatic variables, performed data analysis and contributed to manuscript writing. OK supported the model development, model implementations and simulations and contributed to manuscript writing.

\subsection{Competing interests}

The authors declare that they have no conflict of interest.

\subsection{Acknowledgements}

We wish to acknowledge contributions by Mathias Herbst to the BonaRes SIGNAL proposal and project design, the technical support in setting up the model environment by Andre Ringeler and the whole bioclimatology group from the University of Göttingen for fruitful discussions. 


\section{References}

Allen, R. G., L. S. Pereira, D. Raes, K. U. Leuven, and M. Smith (1998): 'Crop evapotranspiration - Guidelines for computing crop water requirements'. FAO Irrig. Drain. Pap. 56, vol. 56: pp. 1-15 (cit. on pp. 107, 108).

Berry, P. M., M. Sterling, J. H. Spink, C. J. Baker, R. Sylvester-Bradley, S. J. Mooney, A. R. TAms, and A. R. Ennos (2004): 'UNDERSTANDING AND REDUCING LODGING IN CEREALS'. Adv. Agron., vol. 84: pp. 217-271 (cit. on p. 112).

Beuschel, R., H.-P. Piepho, R. G. Joergensen, and C. Wachendorf (2018): 'Similar spatial patterns of soil quality indicators in three poplar-based silvo-arable alley cropping systems in Germany'. Biol. Fertil. Soils, vol. (cit. on p. 104).

BlaCK, A. L. and J. K. AASE (1988): '7. The use of perennial herbaceous barriers for water conservation and the protection of soils and crops'. Agric. Ecosyst. Environ., vol. 22-23(C): pp. 135-148 (cit. on p. 121).

Böhm, C., M. KANZLer, and D. Freese (2014): 'Wind speed reductions as influenced by woody hedgerows grown for biomass in short rotation alley cropping systems in Germany'. Agrofor. Syst., vol. 88(4): pp. 579-591 (cit. on pp. 105, 115, 117, 121).

Cleugh, H. A. (1998): 'Effects of windbreaks on airflow, microclimates and crop yields'. Agrofor. Syst., vol. 41(1): pp. 55-84 (cit. on p. 104).

DWD (2020a): Mean air temperature from the German Weather Service (cit. on p. 106).

- (2020b): Mean annual sums of precipitation from the German Weather Service (cit. on p. 106).

Fischer, M., M. Trnka, J. Kučera, G. Deckmyn, M. Orság, P. Sedlák, Z. Žalud, and R. Ceulemans (2013): 'Evapotranspiration of a high-density poplar stand in comparison with a reference grass cover in the Czech-Moravian Highlands'. Agric. For. Meteorol., vol. 181: pp. 43-60 (cit. on p. 122).

Gamble, J. D., G. Johnson, D. A. Current, D. L. Wyse, D. Zamora, and C. C. SHEAFFer (2019): 'Biophysical interactions in perennial biomass alley cropping systems'. Agrofor. Syst., vol. 93(3): pp. 901-914 (cit. on p. 105).

Germano, M., U. Piomelli, P. Moin, and W. H. Cabot (1991): 'A dynamic subgridscale eddy viscosity model'. Phys. Fluids A, vol. 3(7): pp. 1760-1765 (cit. on pp. 105, 108).

JÄHn, M, O Knoth, M KÖNIG, and U Vogelsberg (2015): 'ASAM v2.7: a compressible atmospheric model with a Cartesian cut cell approach'. Geosci. Model Dev., vol. 8: pp. 317-340 (cit. on pp. 108, 110).

Jähn, M., D. Muñoz-Esparza, F. Chouza, and O. Reitebuch (2016): 'Investigations of boundary layer structure, cloud characteristics and vertical mixing of aerosols at Barbados with large eddy simulations'. Atmos. Chem. Phys. Discuss., vol. 15(16): pp. 22637-22699 (cit. on p. 108).

Kanzler, M., C. Böhm, J. Mirck, D. Schmitt, and M. Veste (2018): 'Microclimate effects on evaporation and winter wheat (Triticum aestivum L.) yield within a temperate agroforestry system'. Agrofor. Syst., vol. 4 (cit. on pp. 105, 107). 
Knoth, O. and J. Wensch (2014): 'Generalized split-explicit Runge-Kutta methods for the compressible Euler equations'. Mon. Weather Rev., vol. 142(5): pp. 2067-2081 (cit. on p. 111).

Legendre, P. and J. OKSANEn (2018): lmodel2: Model II Regression. Tech. rep. University of Helsinki: pp. 1-6 (cit. on p. 108).

Markwitz, C., A. Knohl, and L. Siebicke (2020): 'Evapotranspiration over agroforestry sites in Germany'. Biogeosciences, vol. 17: pp. 5183-5208 (cit. on pp. 107, 121, 123).

Markwitz, C. and L. Siebicke (2019): 'Low-cost eddy covariance: a case study of evapotranspiration over agroforestry in Germany'. Atmos. Meas. Tech., vol. 12: pp. 46774696 (cit. on p. 107).

Maronga, B., M. Gryschka, R. Heinze, F. Hoffmann, F. Kanani-Sühring, M. Keck, K. Ketelsen, M. O. Letzel, M. Sühring, and S. RaAsch (2015): 'The Parallelized Large-Eddy Simulation Model (PALM) version 4.0 for atmospheric and oceanic flows: Model formulation, recent developments, and future perspectives'. Geosci. Model Dev., vol. 8(8): pp. 2515-2551 (cit. on p. 110).

McNaughton, K. G. (1988): '1. Effects of windbreaks on turbulent transport and microclimate'. Agric. Ecosyst. Environ., vol. 22-23(C): pp. 17-39 (cit. on p. 119).

PAtTon, E. G., R. H. ShaW, and M. J. JudD (1998): 'LARGE-EDDY SIMULATION OF WINDBREAK FLOW'. Vol.: pp. 275-306 (cit. on p. 105).

Quinkenstein, A. and H. JochHeim (2016): 'Assessing the carbon sequestration potential of poplar and black locust short rotation coppices on mine reclamation sites in Eastern Germany - Model development and application'. J. Environ. Manage., vol. 168: pp. 53-66 (cit. on p. 104).

Quinkenstein, A., J. Wöllecke, C. Böhm, H. Grünewald, D. Freese, B. U. SchneiDER, and R. F. HÜTTL (2009): 'Ecological benefits of the alley cropping agroforestry system in sensitive regions of Europe'. Environ. Sci. Policy, vol. 12(8): pp. 1112-1121 (cit. on p. 105).

Reháček, D., T. Khel, J. Kučera, J. Vopravil, and M. Petera (2017): 'Effect of windbreaks on wind speed reduction and soil protection against wind erosion'. Soil Water Res., vol. 12(2): pp. 128-135 (cit. on p. 104).

Shaw, R. H. and U. Schumann (1992): 'Large-eddy simulation of turbulent flow above and within a forest'. Boundary-Layer Meteorol., vol. 61(1-2): pp. 47-64 (cit. on p. 110).

Swieter, A., M. Langhof, J. Lamerre, and J. M. Greef (2018): 'Long-term yields of oilseed rape and winter wheat in a short rotation alley cropping agroforestry system'. Agrofor. Syst., vol. 5(Fao 2014) (cit. on p. 105).

Tsonkova, P., C. Böhm, A. Quinkenstein, and D. Freese (2012): 'Ecological benefits provided by alley cropping systems for production of woody biomass in the temperate region: a review'. Agrofor. Syst., vol. 85(1): pp. 133-152 (cit. on p. 105).

Tuzet, A. and J. D. Wilson (2007): 'Measured winds about a thick hedge'. Agric. For. Meteorol., vol. 145(3-4): pp. 195-205 (cit. on p. 105).

Veste, M., R. A. Malaga Lineares, D. M. Seserman, D. Freese, D. Schmitt, M. WACHENDORF, and M. KüPPERS (2018): 'Simulation of annual leaf carbon fluxes and analysis of stand structure of poplars and black locusts in an alley-cropping system, Brandenburg, Germany'. Proc. 4th Eur. Agrofor. Conf. - Agrofor. as Sustain. L. Use. Ed. 
by Ferreiro-Domínguez, N. and M. R. Mosquera-Losada. Santiago de Compostela: European Agroforestry Federation and the University of Santiago de Compostela in Lugo (Spain): pp. 488-492 (cit. on p. 106).

WATANABE, T. (2004): 'Large-eddy simulation of coherent turbulence structures associated with scalar ramps over plant canopies'. Boundary-Layer Meteorol., vol. 112(2): pp. 307341 (cit. on p. 110).

Webster, R. (1997): 'Regression and functional relations'. Eur. J. Soil Sci., vol. 48(3): pp. 557-566 (cit. on p. 108).

Zhou, X. H., J. R. Brandle, C. W. Mize, and E. S. Takle (2005): 'Three-dimensional aerodynamic structure of a tree shelterbelt: Definition, characterization and working models'. Agrofor. Syst., vol. 63(2): pp. 133-147 (cit. on pp. 105, 113). 
CHAPTER 5

Synopsis 
Past years were one of the driest and warmest on record in Europe, with shortage of water and reductions in carbon dioxide uptake across ecosystems (BASTOS et al., 2020; GRAF et al., 2020). Agriculture was affected by yield losses due to soil water scarcity and unequally distributed precipitation events. Whilst it is projected that extreme weather events will increase under a future warming climate, modern agriculture have to protect the proper functioning of agricultural soils for sustainable use of water. Including woody components into agricultural fields have been shown to alter the microclimate. In particular, taller trees reduce the wind velocity, causing a reduction in evapotranspiration and leading to an increased soil water content in a region next to the trees. This old, but newly discovered agricultural practice, named agroforestry, might be one future sustainable land-use practice. Past studies have focused on effects of agroforestry on the microclimate (i.e., BöHM et al., 2014; KAnZler et al., 2018; MCNAughton, 1988; Quinkenstein et al., 2009; Tsonkova et al., 2012), whereas studies on effects of agroforestry on system scale turbulent fluxes is scarce. MCNAughton, 1988 presented theoretical discussions on how tree strips affect turbulent fluxes, based on early wind tunnel experiments, whereas direct measurements of turbulent fluxes over agroforestry systems are lacking.

In this thesis, we aimed to understand (1) how agroforestry systems affect system scale evapotranspiration compared to monoculture systems without trees and (2) how the agroforestry design controls wind velocity and evapotranspiration. In order to fulfil our aims, we performed, firstly, continuous measurements of actual evapotranspiration over five agroforestry systems and five monoculture systems without trees with two methods in 2016 and 2017, and secondly model simulations of wind velocity over one model agroforestry system. The basis of this thesis are three scientific publications.

In the first publication (MARKWITZ et al., 2019) we presented the performance of a low-cost eddy covariance set-up for the application of evapotranspiration measurements over agroforestry and monoculture systems for time periods of approximately four weeks duration.

The long-term performance of the low-cost eddy covariance and an eddy covariance energy-balance set-up is presented in a second publication (MARKWITZ et al., 2020a) for two years, 2016 and 2017. This publication further discuss potential effects of agroforestry on weekly and annual sums of evapotranspiration.

Whilst single-point eddy covariance measurements over homogeneous ecosystems with infinite extent provide sound turbulent fluxes, EC measurements over heterogeneous ecosystems like agroforestry might capture the temporal variability of turbulent fluxes, but not spatial differences in turbulent fluxes. Therefore numerical simulations of turbulence are required to firstly, resolve spatial differences in turbulent fluxes, and secondly, assess the influence of landscape elements on turbulent fluxes. Due to the need for a better understanding of the effect of the agroforestry design on wind velocity and evapotranspiration, we performed large eddy simulations of the three-dimensional wind velocity field over one model agroforestry system. We investigated the impact of tree height, density, distance between tree strips and their orientation on wind velocity in the third study (MARKWITZ et al., 2020b). In this study we also discussed the effect of agroforestry on evapotranspiration on different spatial scales (microclimate and system scale) from the derivation of a potential evapotranspiration from model simulations and in-situ measurements. 
In the following sections we give a summary and a discussion of the main results of this thesis and present the results in a broader context.

\subsection{Evapotranspiration measurements over agroforestry - method validation}

The direct comparison of turbulent fluxes between multiple ecosystems requires, firstly, methods of low uncertainty and secondly, that differences between methods are smaller than the flux signal of the ecosystem of interest. In this thesis, we used a newly developed lowcost eddy covariance set-up (EC-LC) and an eddy covariance energy balance set-up (ECEB) for direct evapotranspiration measurements. A first analysis dealt with the evaluation of the performance of the two set-ups relative to direct eddy covariance measurements. Our analyses revealed a superior agreement between $\mathrm{ET}_{E C-L C}$ and $\mathrm{ET}_{E C}$, compared to $\mathrm{ET}_{E C E B}$ and $\mathrm{ET}_{E C}$ on half-hourly time-scale according to linear regression analysis (Table $3.4)$.

Slopes of a linear regression analysis between $\mathrm{ET}_{E C-L C}$ and $\mathrm{ET}_{E C}$ were comparable to differences between conventional EC set-ups observed in PoLONIK et al., 2019. The authors found differences between $4 \%$ and $14 \%$ between water vapour fluxes obtained by EC set-ups consisting of three different sonic anemometers and five conventional infrared gas analysers. Our results agree also with results of the currently only known study of HiLL et al., 2017, who presented a low-cost enclosed-path eddy covariance set-up for carbon dioxide and water fluxes. They observed a $6 \%$ flux magnitude overestimation of the latent heat flux relative to a LI-7500 open-path gas analyser of fast response. Under field conditions, our low-cost thermohygrometer was characterized by mean response times between 1.9 and 3.5 seconds across sites, with an exponential dependency of the response time with relative humidity (Section 2.3.4). This is about one order larger as for conventional gas analyser of fast response and larger than the response time of 1 second reported in the specifications of the thermohygrometer. The low response time of the thermohygrometer caused energy losses in the high-frequency range of the turbulent spectrum, which we corrected during preprocessing. The corrections for high-frequency losses led in average to a $96 \pm 6.4 \%$ increase of the uncorrected $\mathrm{LE}_{E C-L C}$ and to a $14 \pm 0.5 \%$ increase of the uncorrected $\mathrm{LE}_{E C}$ (Figure 2.7), across sites. Hence, a nearly $100 \%$ increase of $\mathrm{LE}_{E C-L C}$ was caused by corrections for signal losses, which is in agreement with HiLl et al., 2017. The authors observed an increase of the latent heat flux magnitude by $144 \%$ after all corrections were applied. The thermohygrometer of our lwo-cost set-up is limited to a maximum response time of one second under ideal ambient conditions. Improving the frequency response of the thermohygrometer would lead to a reduction of the spectral correction factor, hence, a reduction of the flux uncertainty. One improvement of the current set-up would be to place the thermohygrometer inside a tube with a freely and faster moving air stream. This ensures a faster air exchange inside the measurement cell of the thermohygrometer, causing a faster response time.

Another well known method for measurements of LE is the eddy covariance energy balance method, which was successfully applied over multiple ecosystems, e.g. over a boreal forest in Canada (Amiro, 2009), a cotton field at Texas, USA (ANAPAlLI et al., 2018), and a clearcut in British Columbia (ADAMS et al., 1991). In those studies measurements were performed over relatively homogeneous ecosystems, whereas in this thesis the ECEB 
method was applied over heterogeneous agroforestry systems. For our sites, we found an overestimation of $\mathrm{ET}_{E C E B}$ relative to $\mathrm{ET}_{E C}$ on half-hourly time scale independent of the land-use system (AF or MC). This behaviour was somehow expected due to the unaccounted effect of the unclosed surface energy ba lance. Direct EC measurements of latent and sensible heat fluxes are commonly characterised by an energy gap, with the sum of the turbulent fluxes $(\mathrm{H}+\mathrm{LE})$ being lower than the available energy $\left(\mathrm{R}_{N^{-}} \mathrm{G}\right)$ by 10 to $30 \%$ across ecosystems (Foken, 2006; Wilson, 2002). Potential causes for this energy balance gap are given in Section 1.2.3. For latent heat fluxes obtained by ECEB it is assumed that the energy balance on the surface is entirely closed. This has the consequence that the residual energy is added completely to LE and not partitioned to both $\mathrm{H}$ and LE, or even $\mathrm{R}_{N}$ and $\mathrm{G}$. Given the little we know about the partitioning of the residual energy, one first task would be to correctly measure each of the energy balance components to reduce the magnitude of the residual energy. Measurements of evapotranspiration by ECEB over agroforestry systems are challenging due to the heterogeneity of agroforestry systems and the different spatial scales of the energy balance components. For instance, for evapotranspiration measurements by the ECEB set-up over a homogeneous crop-field of infinite extent, we can assume that each of the measured energy balance components $\left(\mathrm{R}_{N}, \mathrm{G}\right.$ and $\left.\mathrm{H}\right)$ represents the mean state of the whole field in space and time. For a typical agroforestry system with alternating tree strips with taller trees and shorter crops in between tree strips (Figure 1.2), the energy balance components might differ in magnitude, depending on the tower location. The sensible heat flux might be valid for the underlying agroforestry system due to the larger footprint, if the sonic anemometer is placed outside the roughness sub-layer of the canopy. But, the ground heat flux might be substantially lower inside the tree canopy due to shading, compared to the transition zone between trees and crops or at an open field. The net radiation might be affected by a mismatch of the reflected shortwave radiation and emitted longwave radiation of crops and trees throughout the vegetation period if measured over one or the other only. Evapotranspiration measurements over agroforestry by the ECEB set-up may be improved by 1) increasing the number of heat flux plates and distributing them equally inside the tree strips, the transition zone between trees and crops, and inside the crop field, 2) increasing the number of net radiometer with one over trees and one over crops, and 3) determining the energy storage terms in the soil, the biomass (trees and crops) and the air.

However, comparing the two set-ups leads to the following conclusions, 1) the low-cost eddy covariance set-up is a viable alternative to conventional eddy covariance set-ups with great potential for direct water-use monitoring over agricultural fields; and 2) the eddy covariance energy balance set-up gives an estimate of evapotranspiration with larger uncertainties compared to the low-cost eddy covariance set-up.

\subsection{Impact of agroforestry on evapotranspiration}

Evapotranspiration over agroforestry systems is affected by site characteristics, such as the local climate, the soil type, the tree and crop types and the agroforestry design. Single point evapotranspiration measurements by EC, EC-LC or ECEB integrate over the whole system and represent a mean turbulent flux of the underlying ecosystem. To reduce the impact of site effects, measurements across multiple sites are required. In this thesis, 
we performed measurements of actual evapotranspiration over five agroforestry and five monoculture systems without trees over the duration of two years. We normalised annual sums of evapotranspiration with annual sums of precipitation (the evapotranspiration index) to account for the effect of different climatic conditions at the sites.

Results suggest that the effect of agroforestry on system-scale evapotranspiration across sites is small, as indicated by the evapotranspiration index as a function of the radiative dryness index $\left(R_{N} / \lambda P\right)$ shown in Figure $5.1 \mathrm{a}$ and $\mathrm{b}$. The scatter of the evapotranspiration index and the radiative dryness index is large among years, methods and land-uses due to annual precipitation lower than normal in 2016 and annual precipitation higher than normal in 2017. In 2016 all sites were water limited $\left(R_{N} / \lambda P>1\right)$, whereas in 2017 the sites Dornburg, Mariensee and Wendhausen were energy limited $\left(R_{N} / \lambda P<1\right)$ with insufficient energy available to transform precipitation into evapotranspiration. Those sites were affected by exceptionally high annual precipitation events, but annual sums of evapotranspiration comparable to 2016. Figure $5.1 \mathrm{~b}$ shows that differences between evapotranspiration indices averaged over two years with contrasting precipitation regimes (2016 and 2017) and averaged over two methods (ECEB and EC-LC) were larger than differences between evapotranspiration indices averaged over the two land-uses (AF and $\mathrm{MC}$ ). Even so the mean evapotranspiration index from the agroforestry systems tends to be slightly larger than those from the monoculture systems, the difference between the evapotranspiration indices are about one order smaller $\left(\overline{E T / P}_{A F}-\overline{E T / P}_{M C}=0.06\right)$ than differences between ET indices averaged over two years with contrasting precipitation regimes $\left(\overline{E T / P}_{2016}-\overline{E T / P}_{2017}=0.2\right)$. Any result on whether agroforestry systems have a higher evapotranspiration than monoculture systems could therefore be obscured by site effects other than the effect of the tree strips.
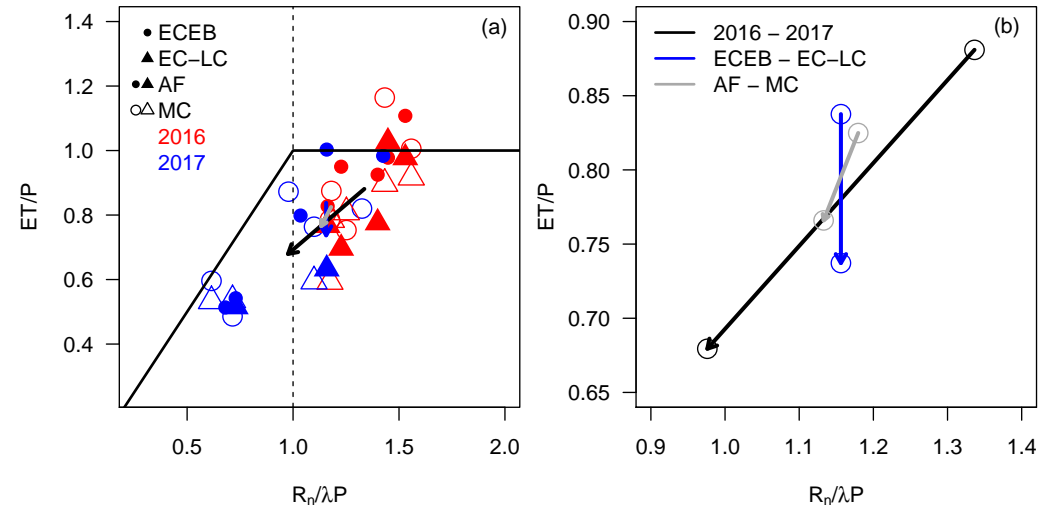

Figure 5.1: (a) Evapotranspiration index $(\mathrm{ET} / \mathrm{P})$ vs. the radiative dryness index $\left(\mathrm{R}_{N} / \lambda \mathrm{P}\right)$ for both land uses (Agroforestry - filled triangles and dots; Monoculture - empty triangles and dots), both set-ups (ECEB - dots; EC-LC - triangles), and both years (2016 - red; 2017 blue). The bold black line describes the regions of an energy limitation $\left(\mathrm{R}_{N} / \lambda \mathrm{P}<1\right)$ and a water limitation $\left(\mathrm{R}_{N} / \lambda \mathrm{P}>1\right)$. The arrows indicate the mean trends of evapotranspiration for the effect of different years (black arrow), different methods (blue arrow), and different land uses (grey arrow). (b) Trends of the mean evapotranspiration index (ET/P) vs. the mean radiative dryness index $\left(\mathrm{R}_{N} / \lambda \mathrm{P}\right)$ for the effect of different years (black), different methods (blue), and different land uses (grey) extracted from (a). 
In the few available studies on water use of agroforestry systems (e.g., UNKOVICH et al., 2003 and Svoma et al., 2016) the authors found either small or not significant differences between agroforestry and a monoculture cropping system. This is in agreement with results presented in this thesis. WARD et al., 2012 found a slightly higher evapotranspiration of 27 $\mathrm{mm}$ over agroforestry relative to a monoculture system, when only trees were present and the soil not covered by crops during a measurement period of five month. The authors interpreted this as a positive result, as increased water use might reduce the risk for dryland salinity in this region.

However, from measurement results presented in this thesis, we reject the main hypothesis and conclude that agroforestry has not resulted in increased water losses to the atmosphere via evapotranspiration compared to a monoculture system without trees. This conclusion lacks any generality and it is speculative whether this is a positive result for each of the individual sites. Whether or not this is the case should be discussed on individual site level.

As part of this thesis we have made great efforts to evaluate the applicability of methods for evapotranspiration measurements over agroforestry systems (Chapter 2 and 3). We limited ourselves to analyses of annual sums of evapotranspiration and compared those to annual sums of precipitation. This analysis neither inform us about the distribution of precipitation and the subsequent availability of soil water throughout the year, nor about the contribution of trees and crops to total evapotranspiration. Further analysis should therefore be performed 1) on a seasonal basis, 2) under consideration of available soil water content and 3) by quantifying the contribution of trees and arable crops to total evapotranspiration.

\subsection{Wind field simulations over agroforestry and effects on evapotranspiration}

Turbulent flux measurements by e.g. the eddy covariance technique represent the mean state of an underlying ecosystem on high temporal resolution of approx. 30 minutes. The measured turbulent flux represents only parts of the underlying ecosystem according to the flux footprint (SCHMID, 2002), which depends on atmospheric stability, wind direction, measurement height and the roughness of the underlying surface. Therefore the source area of the measured flux varies over time and this limits the resolution of differences in turbulent fluxes due to surface heterogeneities. This requires the use of numerical models, which allow the variation of input parameter, boundary conditions and the design of the underlying ecosystem under idealised conditions. However, as part of this thesis we set up a model environment for the simulation of the three-dimensional wind field over agroforestry systems. The model allowed the variation of the geometry of the agroforestry system, such as the tree strip orientation relative to the main wind direction, the tree height, the space between tree strips and the tree strip density.

The model validation of simulated wind velocity with direct wind velocity measurements at the same site (KANZLER et al., 2018) indicated a strong agreement of the pattern and the magnitude of the wind velocity reduction. This is promising as it shows that further analysis and decisions based on the model simulations are reliable.

Overall, our model simulations indicated a strong dependency of the flow field on the geometry of the agroforestry system. We found the strongest wind velocity reduction in 
the lee of the tree strips for westerly and north-westerly winds (perpendicular to the main wind direction). For northerly winds we also observed a wind velocity reduction, which was less pronounced than for westerly or north-westerly winds and mostly at shorter tree strip distances. If soil erosion due to wind is of concern an additional tree strip at the northerly or southerly edge of the agroforestry system could be established to provide a wind shelter effect as suggested by BöHM et al., 2014. Although north or south winds are less frequent in mid-latitudes, their occurrence during droughts with bare and dry soils can lead to considerable soil loss through erosion.

The position and length of the region of maximum wind velocity reduction (quiet zone) was affected by tree strip orientation and tree height. The length of the quiet zone decreased with a change of the tree strip orientation from west to north and increased with increasing tree height for westerly and north-westerly winds (Figure 4.6). Hence, tree strip orientation and height had opposing effects on the length of the quiet zone. With westerly winds tree heights between 2 and $5 \mathrm{~m}$ led to sufficient wind velocity reduction relative to an open field, whereas with north-westerly winds taller trees larger $5 \mathrm{~m}$ were required to reach the same length of the quiet zone as with west winds. As shown in this thesis, tree heights of $2 \mathrm{~m}$ also led to wind velocity reductions at almost all positions within the agroforestry system. This is important in post-harvest periods when the wind protection effect disappears and the risk of wind erosion increases. But the rapid regrowth of the trees up to $2 \mathrm{~m}$ after harvesting guarantees a reduction in wind velocity between the tree strips in the first year.

The location of the quiet zone determines how fast the wind velocity recovers to the initial wind velocity. But the recovery of the wind velocity depends also on the distance between tree strips. If the quiet zone is relatively long compared to the distance between the tree strips, the recovery is less efficient than for a longer distance between tree strips. We found more turbulent conditions at the following tree strip downstream for increasing distances between the tree strips (48 to $96 \mathrm{~m}$ ) (Figure 4.9). This effect was most severe with westerly winds and tree heights of $2 \mathrm{~m}$ and with north-westerly winds and all tree heights. More turbulent and gusty conditions can lead to substantial yield damage (BERRY et al., 2004). Therefore we recommend a maximum distance between tree strips of $48 \mathrm{~m}$.

In this thesis we concentrated only on the simulation of wind velocity over one model agroforestry system. The magnitude of wind velocity and the streamlines of the flow field affect also other biophysical parameter, such as air and soil temperature, relative humidity, and soil water content. All aforementioned biophysical parameter are driver of latent and sensible heat fluxes and determine the variation of turbulent fluxes across the ecosystem. To separate the effect of wind velocity on evapotranspiration from the effect of other biophysical parameter, we derived a potential evapotranspiration from spatially varying wind velocity and tower-based meteorological measurements.

A comparison of simulated evapotranspiration with potential evapotranspiration derived from microclimate measurements indicated a lower reduction of simulated potential evapotranspiration relative to measured potential evapotranspiration in the quiet zone with westerly and north-westerly winds. In the wake zone simulated and measured potential evapotranspiration showed a similar reduction in evapotranspiration. This result indicates that, firstly, the ambient conditions in the wake zone are similar to the tower measurements due to better mixing of air, and secondly, the interactions between air temperature, vapour 
pressure deficit and wind velocity in the quiet zone are more important than in the wake zone.

In general, simulated potential evapotranspiration showed a similar spatial variation and response to the geometry of the agroforestry system due to the linear dependency of evapotranspiration on wind velocity. Hence, the recommendations for the improvement of the agroforestry design with respect to the most efficient wind velocity reduction are also adaptable to evapotranspiration, assuming that wind velocity is the main driver of evapotranspiration. Beside this, we found that differences in evapotranspiration between the quiet zone and the wake zone were much larger than differences between annual sums of evapotranspiration integrated over the whole agroforestry system relative to the monoculture system without trees. Hence, the large-scale effect of agroforestry on evapotranspiration seems to be small, whereas evapotranspiration within the quiet and the wake zone can vary substantially. This confirms our results of small differences in measured evapotranspiration over agroforestry relative to the monoculture systems (Section 5.2).

With regards to the main question of this thesis, whether agroforestry systems have higher evapotranspiration compared to a monoculture system, we conclude from model simulations that evapotranspiration is lower over agroforestry systems than over the monoculture system. This conclusion is limited to the assumption that the spatially varying wind velocity is the only driver of evapotranspiration. This result might change substantially, when considering other site and vegetation specific parameter in the model. Given that model simulations of turbulence are limited in space and time, the following changes could improve the model.

First of all, the parametrisation of the inflow wind field should be adapted to a more natural wind field, potentially derived from direct turbulence measurements. In our model simulations we set wind velocity to a constant value over the vertical and horizontal domain in the beginning, assuming that the heterogeneity of the landscape forms a logarithmic wind profile. We then applied periodic boundary conditions in the horizontal domain, meaning that the turbulent field at the end of the domain is fed into the beginning of the domain. Another option would be to apply the same periodic boundary conditions, but increasing the domain size. This would ensure the generation of a turbulent field which is independent of the agroforestry system. A second model improvement would be the inclusion of other spatially varying parameter, such as incident radiation, air temperature, relative humidity and soil moisture to study the effect of agroforestry on evapotranspiration. For this case one has to consider that many effects of agroforestry on environmental factors vary on small spatial scales $(\mathcal{O}(1 \mathrm{~m}))$, which limits simulation time to maximum one day.

\subsection{The broader context of this thesis}

In this thesis, we studied the effect of agroforestry on the wind field and evapotranspiration by using measurement and modelling techniques. From a measurement techniques perspective, we developed a low-cost eddy covariance set-up (EC-LC) for the application of evapotranspiration measurements over agroforestry and monoculture systems without trees. We showed that this set-up can be a viable alternative to conventional EC set-ups. It can provide a tool for, firstly, evapotranspiration measurements at currently not well represented ecosystems or, secondly, for increasing the representativeness of existing flux measurement 
sites. The set-up is a stand-alone system, which can be powered by solar energy due to low power consumption. Data logging, data processing, real-time flux calculations and the data upload can all be performed with a comparably cheap RaspberryPi. From the user's perspective, this set-up can provide a great tool for irrigation control and could be integrated in smart farming projects for sustainable water management in agriculture.

However, measurements were complemented by modelling work of the three-dimensional wind velocity field. We set up a model environment for the simulation of wind velocity for one model agroforestry system. The model environment is a great tool for the planning of a new agroforestry system if wind reduction is of concern. The major geometrical parameter of an agroforestry system can be changed, such as the tree strip width, the base and top tree height, the density, the distance between tree strips, the wind direction and the wind velocity. Hence, any arrangement of the agroforestry system can be designed. The general results and conclusions can already inform user on a optimal design of an agroforestry system. For a more practical application of this model environment science communication is of significant importance. The German Professional Association for Agroforestry (DeFAF, https://agroforst-info.de/) could provide a valuable platform to interact with practitioner and to learn from experiences from existing agroforestry systems.

\subsection{Future work}

In this thesis we attempted to understand if agroforestry systems affect system-scale evapotranspiration. We presented a unique dataset of evapotranspiration from two different methods across five agroforestry and monoculture systems and two years. We put much effort into the validation of both methods. From discussions in this thesis some important questions and suggestions for further research were made and should be addressed.

$\Rightarrow$ Further development of the low-cost eddy covariance set-up. The lowcost eddy covariance set-up should be further developed towards a stand-alone system, with automatic data logging, flux data processing and data upload. The design of the intake should be changed towards a "flow-through system", with the thermohygrometer placed inside a freely moving air stream to improve the spectral response characteristics.

$\Rightarrow$ Extend the analysis to the individual site level. It would now be preferable to focus on the analysis of evapotranspiration on the individual site level and on shorter time scale, rather than on annual sums of evapotranspiration averaged across all sites. In further analyses, we suggest to consider the effect of different tree heights, the area covered by trees and the soil water availability to characterize critical times in the year, when higher or lower evapotranspiration can be beneficial at the individual site.

$\Rightarrow$ Understand the risk for soil erosion. Our model simulations of wind velocity have highlighted critical regions of increased wind velocities over an agroforestry system relative to an open field and regions of increased turbulent conditions. Those regions are prone to wind erosion, depending on soil properties such as soil texture, soil water content, but also the plants phenology. With an expected increase in mean 
air temperature and the occurrence of droughts, the risk for wind erosion increases. Therefore the wind velocity simulations could be integrated in a soil erosion risk model to characterize critical wind velocities at which erosion takes place and arrive with recommendations of appropriate agroforestry designs.

$\Rightarrow$ Combine measurements and model simulations. Few microclimate measurements in agroforestry exist and the analyses from this thesis showed that differences in evapotranspiration in between the tree strips are potentially larger than differences in system-scale evapotranspiration between agroforestry and a monoculture system. Therefore the vast amount of data measured at a high number of sites and the model simulations should be combined to more precisely give recommendations on the best design of agroforestry systems with respect to water use. From this analyses one would also gain more insights into the nature of turbulence within agroforestry and subsequently inform for the best flux tower locations.

However, the main conclusion of this thesis is that agroforestry has not resulted in higher evapotranspiration compared to a monoculture system, indicating that agroforestry can be a land-use alternative to monoculture agriculture. 


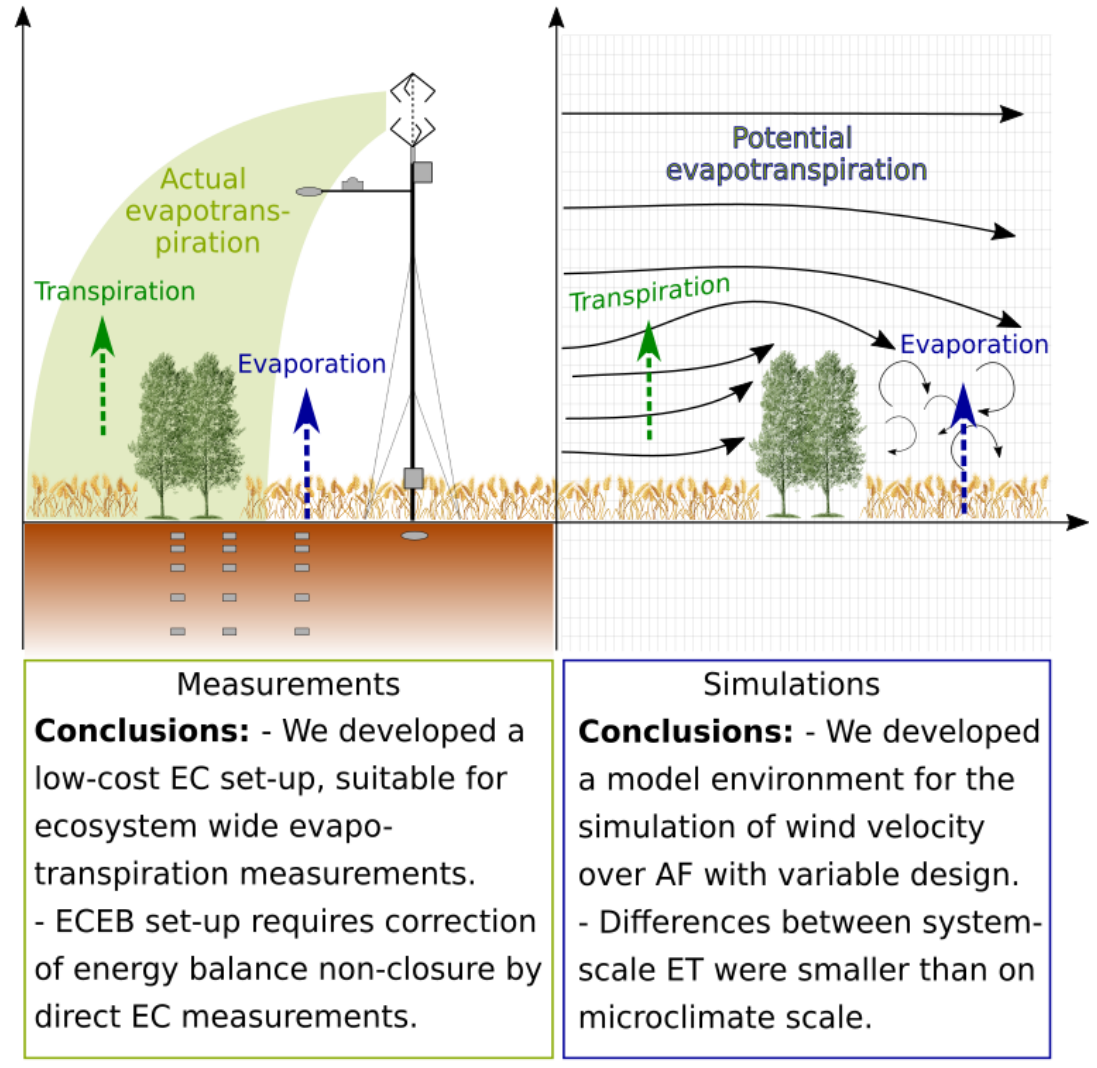

Short-rotation alley cropping agroforestry has not resulted in higher evapotranspiration compared to monoculture systems without trees.

Figure 5.2: The main conclusions of this thesis from measurements and model simulations. 


\section{References}

Adams, R. S., T. A. Black, and R. L. Fleming (1991): 'Evapotranspiration and surface conductance in a high elevation, grass-covered forest clearcut'. Agric. For. Meteorol., vol. 56(3-4): pp. 173-193 (cit. on p. 131).

Amiro, B. (2009): 'Measuring boreal forest evapotranspiration using the energy balance residual'. J. Hydrol., vol. 366(1-4): pp. 112-118 (cit. on p. 131).

Anapalli, S. S., T. R. Green, K. N. Reddy, P. H. Gowda, R. Sui, D. K. Fisher, J. Moorhead, and G. MareK (2018): 'Application of an energy balance method for estimating evapotranspiration in cropping systems'. Agric. Water Manag., vol. 204(September): pp. 107-117 (cit. on p. 131).

BAstos, A. et al. (2020): 'Direct and seasonal legacy effects of the 2018 heat wave and drought on European ecosystem productivity'. Sci. Adv., vol. 6(24): pp. 1-14 (cit. on p. 130).

Berry, P. M., M. Sterling, J. H. Spink, C. J. Baker, R. Sylvester-Bradley, S. J. Mooney, A. R. TAms, and A. R. Ennos (2004): 'UNDERSTANDING AND REDUCING LODGING IN CEREALS'. Adv. Agron., vol. 84: pp. 217-271 (cit. on p. 135).

Böhm, C., M. Kanzler, and D. Freese (2014): 'Wind speed reductions as influenced by woody hedgerows grown for biomass in short rotation alley cropping systems in Germany'. Agrofor. Syst., vol. 88(4): pp. 579-591 (cit. on pp. 130, 135).

Foken, T. (2006): '50 Years of the Monin-Obukhov Similarity Theory'. Boundary-Layer Meteorol., vol. 119(3): pp. 431-447 (cit. on p. 132).

GrAF, A. et al. (2020): 'Altered energy partitioning across terrestrial ecosystems in the European drought year 2018: Energy partitioning in the drought 2018'. Philos. Trans. R. Soc. B Biol. Sci., vol. 375(1810) (cit. on p. 130).

Hill, T., M. Chocholek, and R. Clement (2017): 'The case for increasing the statistical power of eddy covariance ecosystem studies: why, where and how?' Glob. Chang. Biol., vol. 23(6): pp. 2154-2165 (cit. on p. 131).

Kanzler, M., C. Böhm, J. Mirck, D. Schmitt, and M. Veste (2018): 'Microclimate effects on evaporation and winter wheat (Triticum aestivum L.) yield within a temperate agroforestry system'. Agrofor. Syst., vol. 4 (cit. on pp. 130, 134).

Markwitz, C., A. KnOHL, and L. Siebicke (2020a): 'Evapotranspiration over agroforestry sites in Germany'. Biogeosciences, vol. 17: pp. 5183-5208 (cit. on p. 130).

Markwitz, C. and L. Siebicke (2019): 'Low-cost eddy covariance: a case study of evapotranspiration over agroforestry in Germany'. Atmos. Meas. Tech., vol. 12: pp. 46774696 (cit. on p. 130).

Markwitz, C., L. Siebicke, M. Kanzler, A. Knohl, and O. Knoth (2020b): 'Large eddy simulation of the wind field over agroforestry in Germany and wind effects on evapotranspiration'. to be Submitt. to Atmos. Chem. Phys., vol. in prep. (Cit. on p. 130).

McNaughton, K. G. (1988): '1. Effects of windbreaks on turbulent transport and microclimate'. Agric. Ecosyst. Environ., vol. 22-23(C): pp. 17-39 (cit. on p. 130).

Polonik, P., W. Chan, D. Billesbach, G. Burba, J. Li, A. Nottrott, i. Bogoev, B. Conrad, and S. Biraud (2019): 'Comparison of gas analyzers for eddy covariance: 
Effects of analyzer type and spectral corrections on fluxes'. Agric. For. Meteorol., vol. 272-273(December 2018): pp. 128-142 (cit. on p. 131).

Quinkenstein, A., J. Wöllecke, C. Böhm, H. Grünewald, D. Freese, B. U. SchneiDER, and R. F. HÜTTL (2009): 'Ecological benefits of the alley cropping agroforestry system in sensitive regions of Europe'. Environ. Sci. Policy, vol. 12(8): pp. 1112-1121 (cit. on p. 130).

Schmid, H. P. (2002): 'Footprint modeling for vegetation atmosphere exchange studies: A review and perspective'. Agric. For. Meteorol., vol. 113(1-4): pp. 159-183 (cit. on p. 134).

Svoma, B., N. Fox, Q. Pallardy, and R. Udawatta (2016): 'Evapotranspiration differences between agroforestry and grass buffer systems'. Agric. Water Manag., vol. 176: pp. 214-221 (cit. on p. 134).

Tsonkova, P., C. Böhm, A. Quinkenstein, and D. Freese (2012): 'Ecological benefits provided by alley cropping systems for production of woody biomass in the temperate region: a review'. Agrofor. Syst., vol. 85(1): pp. 133-152 (cit. on p. 130).

Unkovich, M., K. Blott, A. Knight, I. Mock, A. RaB, and M. Portelli (2003): 'Water use, competition, and crop production in low rainfall, alley farming systems of south-eastern Australia'. Aust. J. Agric. Res., vol. 54(8): pp. 751-762 (cit. on p. 134).

Ward, P. R., S. F. Micin, and I. R. P. Fillery (2012): 'Application of eddy covariance to determine ecosystem-scale carbon balance and evapotranspiration in an agroforestry system'. Agric. For. Meteorol., vol. 152(1): pp. 178-188 (cit. on p. 134).

WiLSOn, K (2002): 'Energy balance closure at FLUXNET sites'. Agric. For. Meteorol., vol. 113(1-4): pp. 223-243 (cit. on p. 132). 



\section{Acknowledgments}

This $\mathrm{PhD}$ wouldn't have been possible without the valuable support of many people around me. In particular, I would like to thank my supervisors Alexander Knohl, Lukas Siebicke, Oswald Knoth and Eckart Priesack for their support through deep and fruitful scientific discussions, their critical view on my scientific work, and encouraging words. I am also very grateful to Prof. Dirk Hölscher for his willingness to conduct the final examination.

This research was financially supported by the German Federal Ministry of Education and Research (BMBF; project BonaRes, Modul A: SIGNAL; grant no: 031A562A), the Deutsche Forschungsgemeinschaft (grant no. INST 186/1118-1FUGG) and the bioclimatology group at the faculty of forest ecology and forest sciences of the University of Göttingen.

I wish to thank the whole team of the bioclimatology group for the support received through field work from Frank Tiedemann, Edgar Tunsch, Dietmar Fellert, Martin Lindenberg, Johann Peters, and Dirk Böttger (Soil Science group of Tropical and Subtropical Ecosystems, University of Göttingen), but also through scientific discussions and administrative work. I highly appreciate the very good cooperation with all partners of the SIGNAL project, both with the field site operators and the scientific stuff.

For me the $\mathrm{PhD}$ was a project of unbelievable dimensions, covered by many ups and downs, which I finally managed to bring to an end. Making this happen was impossible without the support from many friends, received through excursions into the wilderness, exhausting bike trips, long evenings with good food, helpful and long talks and good words. I would therefore like to thank Nina Tiralla, Eva Schneidewind, Bärbel Fröhlich, Leonie Göbel, Emanuel Blei and Marcus Schmidt.

Schlussendlich möchte ich meiner Familie danken die immer an meiner Seite war, ein offenes Ohr hatte, meine Entscheidungen getragen hat, die Höhen und Tiefen der Doktorarbeit mit durchgestanden und ohne dessen mentale Unterstützung dieses Projekt nicht möglich gewesen wäre. Deshalb an dieser Stelle ein unbeschreibliches Dankeschön an meine Eltern Jutta und Bernd Markwitz, meine Großmutter Henny Kollodzey und meinem Großvater Alfred Markwitz, der in Gedanken immer an meiner Seite ist.

The layout of this thesis is based on a $\mathrm{LT}_{\mathrm{E} X} \mathrm{X}$-Template by Matthias Pospiech http: //www.matthiaspospiech.de/latex/. 
